\title{
Economic Policy in Global Commodity Markets - Methods, EFFiciency AND TRADE-OFFS
}

\author{
By \\ BERNHARD DALHEIMER
}

A thesis submitted to the University of Göttingen

to obtain the degree of Dr.rer.pol.

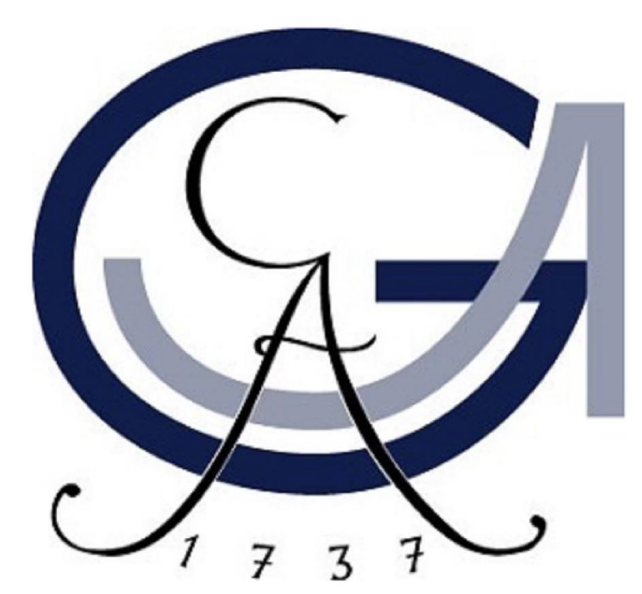

Chair of Agricultural Market Analysis

Department of Agricultural Economics and Rural Development Faculty of Agricultural Sciences University of Göttingen 
D7

$1^{\text {st }}$ Referee: Prof. Dr. Bernhard Brümmer

$2^{n d}$ Referee: Prof. Dr. Meike Wollni

$3^{\text {rd }}$ Referee: Prof. Dr. Stephan von Cramon-Taubadel

Date of Defense: July 13, 2020 


\section{SUMMARY}

Globally, policy-makers increasingly shift value from economic towards social and environmental outcomes of the economy. Successfully achieving economic, social and environmental goals jointly inevitably leads to trade-offs at multiple stages of agricultural value chains. Agricultural commodity markets provide manifold opportunities for policy makers to mitigate such trade-offs by creating environmental and societal values. Both real world applications and advancement of empirical methodology to evaluate those are essential to an exhaustive evidence-base for economic policy that aims at mitigating trade-offs. This dissertation aims at extending two distinct scientific frontiers of research on agri-environmental-social policy trade-offs. The first focus is placed on socio-environmental trade-offs faced at the producer stage. The palm oil boom and related ecological crisis in Indonesia provides a resourceful case to empirically explore the role of smallholder agricultural production within the conflicting aims. The second focus lies on the advancement of data-driven identification techniques in structural time series analysis and its application to commodity market analysis.

The first two essays (chapters two and three) analyse the technical and environmental performance of smallholder oil palm producers in Jambi, Indonesia. We focus on policy implications regarding the production technology, shortcomings in performance compared with best-practice and biodiversity, and deforestation as environmental aspects. The first essay asks whether technical efficiency reduces or accelerates oil palm area expansion. The findings indicate that while the land sparing potential of increased smallholder efficiency is remarkable, higher returns to palm oil production also increase demand for land by a factor of one third. Thus, successful rural development and conservationist policy need to reconcile both effects by connecting smallholder support with more formalized land markets and stringent land policy. The second essay models the trade-off between oil palm output and biodiversity loss and estimates the performance of smallholders. It derives respective shadow prices and simulates several payments for ecosystem services (PES) scenarios. The findings suggest presence of substantial environmental inefficiency in smallholder oil palm production which is in part explained by both chemical and manual weeding practices. Payments for 
ecosystem services schemes could be a viable policy response to conserve meaningful levels of biodiversity while at the same time allowing smallholders to increase palm oil output. Addressing drivers of environmental performance in PES designs could amplify the effect thereof without reducing production levels. The third essay (chapter four) evaluates the policy efficacy of the tripartite rubber council (TRC) to detach the international rubber price from synthetic rubber and crude oil prices. The findings indicate that restricting supply did not impact international markets as expected and increasing domestic consumption might even have backfired and contributed to further decreases in international prices.

The last two essays (chapters five and six) are concerned with data-driven identification methods in multivariate time series models. The fourth essay provides a software implementation of novel structural identification techniques making use of heteroskedasticty-based and independence-based assumptions. The fifth essay applies independent component analysis (ICA) to identify structural crude oil shocks on food markets in Sub-Saharan Africa (SSA). The findings indicate that SSA food markets respond more strongly to oil-supply shocks and less pronounced to oil-specific demand end aggregate-demand shocks than global markets. As transportation costs continue to be very important components of the cost of food production in SSA, inefficient fuel distribution systems and absence of strategic energy reserves lead to vulnerability of food prices to oil-supply shocks. Food prices in Sub-Sahara Africa respond fundamentally different to oil shocks than world market prices or those in developed countries. In addition, SSA food markets are also not alike in their response to global oil shocks but very heterogeneous. This is likely to be also the case for other developing countries' food markets. 


\section{ACKNOWLEDGMENTS}

Completing the $\mathrm{PhD}$ certainly has been a unique and wonderful experience. The last three years would not have been as enjoyable but more difficult if it weren't for great supervisors, inspiring mentors, helpful colleagues, supportive friends and family.

First of all, I would like to thank my supervisor Prof. Bernhard Brümmer. Thank you for your trust in my work and decisions. You always provided me with exceptional academic freedom. At the same time, you always managed to steer me back on track when times got tougher or things did not play out as planned. Further, I'd like to extend my gratitude to Prof. Meike Wollni and Prof. Stephan von Cramon-Taubadel for refereeing my work.

Besides the support I received in academia, I never would have gotten to where I am without the support and inspiration of Dr. Josef Schmidhuber and Dr. Georg Gruber. Josef, thank you for always believing in my capabilities and your immense support during the past years. Georg, working with you has always been inspiring and instructive. Thank you both for setting such great role models.

I am also happy to be part of the market analysis chair. I would like to thank my friends and colleagues of the chair, not only for exchanges of ideas and discussion, for instance during our efficiency-group meetings, but also for the great companionship and good times at the chair-Asados, the swimming \& sliding group, and our weekly chair lunch. Thank you Claudia, Dela, Ella, Elke, Enrique, Gabriel, Insa, Ioannis, Jurij, Mary, Marwan, Nina, OliverKen, Sebastian, Tim, Tinoush, Tom, Yashree, Yuan, and Yueming. Thanks is also due to Nina Enke, Monika Scholz, Bianca Rieck and Ivonne Hein for all their great administrative support provided during these three years.

Furthermore I'm thankful for the friendship and companionship of other colleagues and friends in Göttingen. Particularly I'd like to thank my friend, roommate, gym-buddy and co-author Alex for making these past three years more fun, productive and athletic. I'd also like to extend my gratitude to Caetano, Daniel, Jessie and Selina for their friendship and 
discussions during coffee breaks.

A very special thanks is due to the great C01 Biodiversity crew to whom I owe an extraordinary professional and swift data collection. Particularly, thanks to our counterparts Pak Zulkifli and Ibu Mira, biodiversity advisor Fabian, my student research assistant Jakob, and team members Tito, Yohana, Ismanto, Yossy, Wijil, Nova, Nikita, Tina, and Winda our biodiversity survey turned out very successfully and was a fun and enriching experience. Without your help, the third chapter would not have been possible. Terima kasih!

Although during some times - particularly the last months - of a $\mathrm{PhD}$, there really is no such thing as a "work-life balance". However, for the most part, there is and should be. I am very thankful for friends which I have not mentioned, some of whom are in Göttingen, some abroad. Some I hear from often, some more rarely but still are important parts of my life. Thank you for being there and your support.

All of this would certainly not have been possible without family support in various dimensions. I very much thank my parents Renate and Peter without whom I never would have enjoyed the privilege of living and studying to this extend and in such diverse places. To my brothers - Thomas and Gregor - I am so thankful for your everlasting companionship and support.

Last but certainly not least, I wish to thank my girlfriend Gesa. Thank you for your tremendous and unconditional support during the past years. You have been essential to me for completing this milestone and made it ever more worthwhile. I'm looking forward to our next steps! 


\section{Table of Contents}

1 General Introduction . . . . . . . . . . . . . . . . . . . . . 1

1.1 Oil palm boom: Smallholders between economic success and ecological crises in Indonesia . . . . . . . . . . . . . . . . . . . . . . . . . . . 3

1.2 Identification of structural time series models in commodity policy analysis . . 6

2 Does technical efficiency promote or dampen oil palm area expansion in

Indonesia $\ldots \ldots \ldots \ldots \ldots \ldots \ldots \ldots \ldots$

2.1 Introduction . . . . . . . . . . . . . . . . . . . 12

2.2 Land sparing vs. land expansion . . . . . . . . . . . . . . . . . . . 14

2.2.1 The rebound effect: Definitions . . . . . . . . . . . . . . . . . 14

2.2.2 Land sparing and rebound effects in agriculture: Empirical evidence . . 16

2.2.3 Smallholder palm oil producers in Jambi, Indonesia . . . . . . . . . . . 17

2.3 Methods and Data . . . . . . . . . . . . . . . . . . . 18

2.3.1 Technical efficiency and production frontier . . . . . . . . . . . . 19

2.3.2 Random intercept frontier . . . . . . . . . . . . . . . . . . . . . 19

2.3.3 Land expansion model . . . . . . . . . . . . . . . . . . . . 20

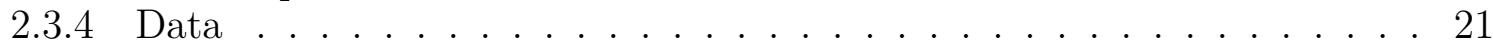

2.3.5 Empirical specification . . . . . . . . . . . . . . . . 22

2.4 Results . . . . . . . . . . . . . . . . . . . . . 23

2.4 Production technology . . . . . . . . . . . . . . . 23

2.4.2 Technical efficiency . . . . . . . . . . . . . . . . . . . 25

2.4.3 Land expansion . . . . . . . . . . . . . . . . . . . 26

2.5 Land sparing vs. land expansion and policy implications . . . . . . . . . . . 27

2.6 Summary and conclusion . . . . . . . . . . . . . . . . . . . . . . 29

3 The palm oil - biodiversity trade-off: Environmental performance of smallholder producers . . . . . . . . . . . . . . . . . . . 31

3.1 Introduction . . . . . . . . . . . . . . . . . . . . . . 32

3.2 Palm oil: Boom and crisis in South East Asia . . . . . . . . . . . . . . . . 34

3.3 Modeling the oil palm-biodiversity trade-off . . . . . . . . . . . . . . 36

3.3.1 Hyperbolic distance functions . . . . . . . . . . . . . . . 36

3.3 .2 Shadow price. . . . . . . . . . . . . . . . . . 39

3.3.3 Measuring biodiversity . . . . . . . . . . . . . . . . . . 40

3.3 .4 Data . . . . . . . . . . . . . . . . . . . . . . 42

3.3.5 Empirical specification . . . . . . . . . . . . . . . . 43

3.4 Results . . . . . . . . . . . . . . . . . . . . . 44

3.4.1 Production technology . . . . . . . . . . . . . . 45

3.4 .2 Inefficiency . . . . . . . . . . . . . . . . . . . . 46

3.4.3 Shadow prices . . . . . . . . . . . . . . . . . 47

3.5 Payments for ecosystem services (PES) simulation . . . . . . . . . . . . . 49

3.5.1 Management-based measures . . . . . . . . . . . . . . . 50

3.5.2 Performance based payments . . . . . . . . . . . . . . . . 51

3.6 Summary and conclusion . . . . . . . . . . . . . . . . . . 53 


\section{Can the Tripartite Rubber Council Manipulate International Rubber}

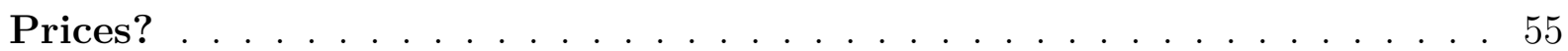

4.1 Introduction . . . . . . . . . . . . . . . . . . . 56

4.2 Background . . . . . . . . . . . . . . . . . . . . . . 57

4.2.1 Agricultural trade policy against global trends . . . . . . . . . . . . 57

4.2 .2 Natural and synthetic rubber value chains . . . . . . . . . . . . . . . 58

4.2.3 Policy measures within the Tripartite Rubber Council . . . . . . . . . . 59

4.3 Model of the interlinked markets . . . . . . . . . . . . . . . . . . . 63

4.3.1 Logic of model extension . . . . . . . . . . . . . . . . . . . 64

4.3.2 Model components . . . . . . . . . . . . . . . . . . . 65

4.3 .3 Policy efficacy . . . . . . . . . . . . . . . . . . . 66

4.4 Econometric analysis . . . . . . . . . . . . . . . . . . . . . . . 68

4.4.1 Vector Error Correction Model . . . . . . . . . . . . . . . . . . 68

4.4 Data . . . . . . . . . . . . . . . . . . . . . 71

4.4 .3 Results . . . . . . . . . . . . . . . . . . . 72

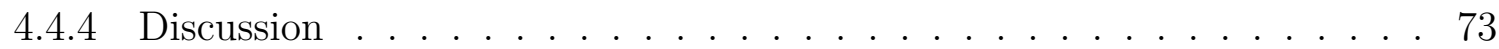

4.5 Conclusions . . . . . . . . . . . . . . . . . . . . . . 75

5 svars: An R Package for Data-Driven Identification in Multivariate Time

Series Analysis . . . . . . . . . . . . . . . . . . . . . . . 77

5.1 Introduction . . . . . . . . . . . . . . . . . . . . 78

5.2 Structural vector autoregressive models . . . . . . . . . . . . . . . . . . 79

5.2 .1 The identification problem . . . . . . . . . . . . . 80

5.2 .2 Identification by means of heteroskedastic innovations . . . . . . . . . . 80

5.2 .3 Identification through independent components . . . . . . . . . . . . . . 84

5.2 .4 Choice of an adequate identification technique . . . . . . . . . . . 86

5.3 SVAR tests, tools and bootstrap methods . . . . . . . . . . . . . . 87

5.3 .1 Tests for structural breaks . . . . . . . . . . . . . . . . . 88

5.3 .2 Testing for identical diagonal elements . . . . . . . . . . . . . . . . 89

5.3 .3 Test for overidentifying restrictions . . . . . . . . . . . . . . . . . 89

5.3 .4 Test on joint parameter significance . . . . . . . . . . . . . . . . 89

5.3.5 Tools for SVAR analysis . . . . . . . . . . . . . . . . . . . . 90

5.3 .6 Bootstrap methods . . . . . . . . . . . . . . . . . . 91

5.4 Package design . . . . . . . . . . . . . . . . . . . . . . . . . 92

5.4 .1 Core functions for SVAR identification . . . . . . . . . . . . 94

5.4.2 Functions and methods for SVAR analysis . . . . . . . . . . . . . 97

5.5 Example . . . . . . . . . . . . . . . . . . . . . . . . . . . . . . . . 99

5.6 Summary . . . . . . . . . . . . . . . . . . . . . . . . . . . . . . . . . .

6 The threat of oil shocks to food security in Sub-Sahara Africa . . . . . . 111

6.1 Introduction . . . . . . . . . . . . . . . . . . . . . . 112

6.2 Food insecurity in Sub-Saharan Africa and the global oil market . . . . . . . 114

6.2.1 Food insecurity in Sub-Saharan Africa . . . . . . . . . . . . . . . . 114

6.2.2 Global oil shocks and local food prices . . . . . . . . . . . . . . . 115

6.3 Empirical framework . . . . . . . . . . . . . . . . . . . . . . 117

6.3.1 Identifying oil shocks via independent components . . . . . . . . . . . 118

6.3.2 Data . . . . . . . . . . . . . . . . . . . . . 119

6.4 Empirical findings . . . . . . . . . . . . . . . . . . . . . . . . . . . . . . . 120

6.4.1 Sub-Sahara African corn markets differ compared with world markets . 122

6.4.2 The role of oil-supply shocks in Sub-Saharan African corn markets . . . 124

6.4.3 The role of aggregated-demand and oil-specific demand shocks in Sub-

Sahara African corn prices . . . . . . . . . . . . . . . . . . . 134

6.4.4 What are the future threats to corn price stability from global oil market

shocks? . . . . . . . . . . . . . . . . . . . . 138 


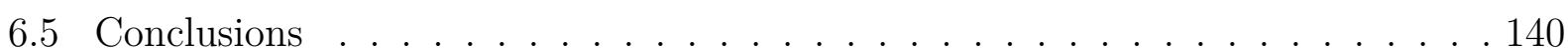

7 General Conclusion . . . . . . . . . . . . . . . . . . . . 143

7.1 Summary of results . . . . . . . . . . . . . . . . . . . . . . . . 143

7.2 Policy implications . . . . . . . . . . . . . . . . . . . . . 145

7.3 Limitations and future research . . . . . . . . . . . . . . . . . . 147

\section{Appendices}

A Appendix of Chapter Two . . . . . . . . . . . . . . . . . . . . 181

A.1 Random intercept model . . . . . . . . . . . . . . . . . . . . . . . . 181

A.2 Derivation of land efficiency measure . . . . . . . . . . . . . . . . 182

B Appendix of Chapter Three . . . . . . . . . . . . . . . . . . . . . 185

B.1 Biodiversity indicators . . . . . . . . . . . . . . . . . . 185

B.2 Hyperbolic and enhanced hyperbolic specifications and estimation results . . . 185

B.3 Hyperbolic, enhanced hyperbolic and restricted hyperbolic with SR loss as undesired output . . . . . . . . . . . . . . . . . . . . . . . . . . 188

C Appendix of Chapter Four . . . . . . . . . . . . . . . . . . . 191

C.1 Derivation of relation between agricultural and industrial input price changes . 191

C.2 Simulation of elasticities based on varying values for sigma . . . . . . . . . . 193

C.3 Robustness checks of $S M S$ measure . . . . . . . . . . . . . . . . . . . 194

C.3.1 Results of short run regression . . . . . . . . . . . . . . . 195

D Appendix of Chapter Six . . . . . . . . . . . . . . . 197

D.1 Alternative transmission channels from crude oil to food markets . . . . . . 197

D.2 Identification by means of independent components . . . . . . . . . . . . . 197

D.3 Further empirical results and data . . . . . . . . . . . . . . . . . . . . . . . 199

D.4 Country case: Chad . . . . . . . . . . . . . . . . . . . . 201

E Declarations . . . . . . . . . . . . . . . . . . . 203 



\section{List of Figures}

2.1 Rebound effect of producers . . . . . . . . . . . . . . . 15

2.2 Distribution of technical efficiency scores of smallholder oil palm producers . . 25

3.1 Hyperbolic efficiency and directional distances . . . . . . . . . . . . . 37

3.2 Histograms of hyperbolic efficiency scores . . . . . . . . . . . . . . . . . . 47

4.1 Global and TRC natural rubber production by year . . . . . . . . . . . . 59

4.2 Importers and exporters of rubber and tires . . . . . . . . . . . . 60

4.3 TRC monthly exports and active AETS periods . . . . . . . . . . . . 62

4.4 Flow chart of causal chain . . . . . . . . . . . . . . . . . . . . 64

4.5 International crude Oil, synthetic and natural rubber prices, 2011-2017 . . . . 71

5.1 US macroeconomic data. . . . . . . . . . . . . . . . . . . 101

5.2 Impulse-response functions with $68 \%$ confidence bands based on 1000 bootstrap replications. Structural shocks identified through unconditional shift in the covariance structure. . . . . . . . . . . . . . . . . . . . . . . 107

5.3 Forecast error variance decomposition for 30 periods. Structural shocks identified by means of the CV model. . . . . . . . . . . . . . . . . . . . . . . 108

5.4 Historical decomposition of the US output gap in percent deviations from the mean. Structural shocks are identified by means of the DC algorithm. . . . . . 110

6.1 Transmission flow from oil shocks to food prices . . . . . . . . . . . 116

6.2 Comparison of cumulative percentage growth in real global corn prices and real African corn prices after the US biofuel mandate in May 2006 and during the international food price crisis in 2007/08. Light blue lines represent the single African countries, and the green line shows the average of SSA countries.123

6.3 Responses of corn prices in Ethiopia, Ghana and Kenya to an oil-supply shortage joint with $68 \%$ and $90 \%$ confidence bands obtained from 2000 bootstrap iterations $($ Hall, 1992). . . . . . . . . . . . . . . . 125 
6.4 Comparison of cumulative percentage growth of real corn prices in Ethiopia, Ghana and Kenya with remaining SSA countries after the Libyan oil production shortfall in 2011 and the oil embargo against Iran in 2012 . . . . . . . . . 127

6.5 Relative contribution to cumulative change in domestic corn prices in Ethiopia, Ghana and Kenya during the Libyan production shortfall and the oil embargo against Iran by structural shocks. The contributions of the four shocks add up to $100 \%$, which represents the total corn price increase. . . . . . . . . . . . 129

6.6 Comparison of cumulative percentage growth of real corn prices in Ethiopia, Ghana and Kenya since January 2014 with and without effects from shale oil boom and expansion of production capacity in the Middle East. . . . . . . . . 131

6.7 Comparison of cumulative percentage growth in transportation costs during the Libyan revolution and during the oil production expansion in several regions.132

6.8 The left panel shows the response of the corn price in Nigeria to a positive aggregated-demand shock and right panel shows the response of the corn price in Chad to a positive oil-specific demand shock joint with $68 \%$ and $90 \%$ confidence bands obtained from 2,000 bootstrap iterations. . . . . . . . . . . . . 135

6.9 Comparison of cumulative percentage growth of real corn prices in Ethiopia, Ghana, Nigeria and Tanzania since June 2007 with and without cumulative demand shocks. . . . . . . . . . . . . . . . . . . . . . 137

6.10 Alternative forecast scenarios for local real corn prices in domestic currencies. The vertical lines represent the beginning of the forecast periods. . . . . . . . 139

B.1 Density of sample plots with different levels of plant species diversity assessed by diversity indices of order $(q=0)(S R),(q=1)(E N S)$, and $(q=2)$ (Simpson diversity). SR is more sensitive to differences between samples but potentially unreliable as diversity measure when undersampling is expected . . 185

C.1 Simulation elasticity based on different values for $\sigma$. The red line indicates the value $(\sigma=10)$ that was used for the calculation in equation $(4.10)$. . . . 193

D.1 Real corn price series in domestic currency. World prices are given in US Dollars.200

D.2 Point estimates of corn price reactions in Africa to different types of oil shocks and a non-oil related shock to corn price. . . . . . . . . . . . . . . . . . 201 


\section{List of Tables}

2.1 Descriptive statistics . . . . . . . . . . . . . . . . . 22

2.2 First and second order terms and group predictors of the random intercept estimator . . . . . . . . . . . . . . . . . . . . 24

2.3 Land expansion models . . . . . . . . . . . . . . . . . 26

3.1 Variable overview and summary statistics . . . . . . . . . . . . . . 42

3.2 First order terms and parameter estimates of the determinants of inefficiency of the restricted hyperbolic distance function . . . . . . . . . . . . . . 46

3.3 Marginal effects of determinants of inefficiency . . . . . . . . . . . . 47

3.4 Shadow prices in constant USD $(2015) \ldots \ldots \ldots$. . . . . . . . . . 48

3.5 Aggregated outcome for different weeding scenarios of practice based PES measures compared with the elimination of inefficiency . . . . . . . . . . . . 50

3.6 Policy scenarios targeting social equality, uniform biodiversity dstribution and cost minimization . . . . . . . . . . . . . . . . . . . . . 51

4.1 Descriptive statistics of the variables entering the analysis . . . . . . . 72

4.2 ECM Results . . . . . . . . . . . . . . . . . . . 73

5.1 Overview of identification models and respective underlying assumptions on

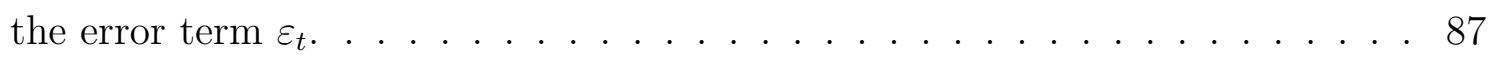

5.2 Package design of svars. . . . . . . . . . . . . . . . . 93

6.1 Theoretical impact directions of global oil shocks on the variables in the empirical model as suggested by Kilian and Murphy (2012). The signs are normalized such that all shocks have a positive impact on the oil price $p_{t} \ldots$. . . . . . 121 
6.2 Significant response directions to oil market shocks of African corn prices relative to global corn prices. An increase of local corn prices relative to global corn prices at the $5 \%(10 \%)$ significance level is indicated by ' ++ ' ('+'). A decrease of local corn prices relative to global corn prices at the $5 \%(10 \%)$ significance level is indicated by '--' ('-'). Significance is obtained from bootstrapped IRFs. . . . . . . . . . . . . . . . . . . . . . . . . . . . . 124

6.3 Contribution of oil-supply shocks to $h$-step ahead FEVD of local corn prices in SSA markets and world markets. . . . . . . . . . . . . . . . . 125

A.1 Random intercept model estimation results . . . . . . . . . . . . . . . . . . 181

A.1 Statistical models . . . . . . . . . . . . . . . . . . . . 182

B.1 Hyperbolic and enhanced hyperbolic distance functions . . . . . . . . . . . 186

B.2 Marginal effects of determinants of inefficiency (from hyperbolic and enhanced

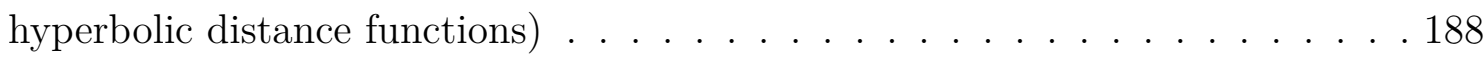

B.3 Shadow pirces in '000 IDR (Derived from hyperbolic and enhanced hyperbolic distance functions . . . . . . . . . . . . . . . . . . . . . . . . 188

B.4 Hyperbolic, restricted and enhanced hyperbolic distance functions with inverse of $S R$ as an undesirable output . . . . . . . . . . . . . . . . 188

C.1 Long run regression models . . . . . . . . . . . . . . . . . . . . . . . 194

C.2 ECM based on LR model 4 . . . . . . . . . . . . . . . . . . . . . 195

C.3 Importers and exporters of rubber and tires . . . . . . . . . . . . . . 196

D.1 Test results on kurtosis and skewness of the estimated structural shocks. Values in parentheses denote $p$-values. . . . . . . . . . . . . . . . 199 


\section{Chapter One}

\section{General Introduction}

Since the beginning of the current century, the world population grew by more than one fourth, and average per capita income doubled ${ }^{1}$ (World Bank, 2020). As a consequence, agriculture attended to an unprecedented surge as well as structural change in demand for food, fiber, and fuel (OECD-FAO, 2011; McMillan and Rodrik, 2011). Concurrently, a remarkable advancement in technology continued to enable farmers to produce more efficiently and provide more output quicker and more targeted than ever before (Fuglie et al., 2012). For the most part, existing incentive structures rewarded merely economic performance as opposed to environmental and social outcomes. Subsequently, numerous clashes of agricultural production with the environment and society at large unfolded around the globe. For instance, the far-reaching implications of climate change as well as persistent poverty, food insecurity, and increasing malnourishment are particularly relevant social and environmental trade-offs that continue to loom over future generations.

In more recent times, global policy has shifted value from economic towards environmental and societal outcomes of the global economy. Perhaps most representatively, the Sustainable Development Goals SDG target global non-economic objectives as a means of overall development. Critically, the SDGs are not only ambitious to reach individually, but most challenging is probably the achievement of the set of goals jointly. For example, SDGs 1 and 2 target the "eradication of poverty" and "ending hunger", respectively, while at the same time SDGs 12 and 15 aim at "ensuring sustainable consumption patterns" and "protecting, restoring and promoting sustainable use of terrestrial ecosystems, sustainably manage forests, combat desertification, and halt and reverse land degradation and halt biodiversity loss", respectively (United Nations, 2015). Achieving these goals jointly inevitably leads to trade-offs at multiple stages of agricultural value chains. A tangible implication for agriculture is that while the provision of food in increasing quantity and quality is still required, concurrently social and environmental outcomes have become imperative by-products.

Agricultural commodity markets provide manifold opportunities for policy makers to create environmental and societal values. Since markets are a hub within value chains where economic goods are traded between producers (sellers) and consumers (buyers), they mir-

\footnotetext{
${ }^{1}$ As measured by the adjusted net national income per capita indicator (World Bank, 2020)
} 
ror the current economic valuation of agricultural produce. Thus, regulation to mitigate trade-offs along various stages of value chains often aims to include other - non-marketed, yet desired - outcomes in the valuation process. The range of policies that address the problem of such externalities are manifold and idiosyncratically adapted to commodity, country, culture and environment specific circumstances. Common examples include carbon taxes, standards and certifications, land titling, and payments for ecosystem services that often are implemented in pursuit of environmental and social outcomes. Also trade policy - albeit regulated profoundly in the WTO - continues to be a popular means for countries to improve welfare of domestic agricultural producers (Disdier and Marette, 2010). All of these are attempts to mitigate particular trade-offs between provision of economic commodities and other services, as valued by society. Nonetheless, most of the times such measures bring about a multitude of consequences, not all of which are desired ubiquitously but instead are unintended by-products (Grant, 2010), adding yet another layer of complexity on the analysis and mitigation of trade-offs at the intersection of the economy, society and the environment.

Thus, there is no one-size-fits all solution for development and agro-environmental policy. Even though the problem of externalities and its typical solutions are well studied in economics, successful policy amid the joint optimization of economic, social and environmental values relies not only on general economic theory, but is also adaptive and flexible enough to adjust situation-specific constraints and challenges (Rodrik, 2007). As much as the trade-offs at the intersection of economic, social and environmental values are highly heterogeneous, so can be the outcomes of policy action along the value chains of agricultural commodities (Grant, 2010; Swinnen, 2010).

At the same time, with more complex trade-offs along agricultural value chains, the detection of meaningful causal relationships and underlying mechanisms becomes an increasingly taller order for researchers. Econometric models that evaluate observational data often rely on key economic assumptions which are increasingly pressured as agriculture faces novel drivers and challenges. Thus, the analysis of trade-offs also imposes stronger requirements on its methodological tools to design effective mitigation strategies. However, the growing availability of observational data over several dimensions enables more data-driven approaches that - in combination with structural models - provide ample avenues for the advancement of causal identification strategies. Hence, both real world applications and progress of empirical methodology to evaluate those are essential to an exhaustive evidence-base for economic policy of agricultural commodities (Waltner-Toews and Lang, 2000; Havlík et al., 2015; Pinstrup-Andersen, 2015; Brümmer et al., 2016; Jack et al., 2017).

This dissertation analyzes agricultural policies at the intersection of economic, environmental and social trade-offs in agricultural commodity markets. In a collection of five essays, the dissertation aims at extending two distinct scientific frontiers of research on agrienvironmental-social policy trade-offs. The first focus is placed on socio-environmental trade- 
offs faced at the producer stage. To that end, the palm oil boom and related ecological crisis in Indonesia provides a resourceful case to empirically explore the role of smallholder agricultural production within the conflicting aims. The second focus lies on the advancement of data-driven identification techniques in structural time series analysis and its application to commodity market analysis. In the remainder of this chapter, I set the stage for the two foci separately.

\subsection{Oil palm boom: Smallholders between economic success and ecological crises in Indonesia}

The first focus of this dissertation is thematic and concerned with developmental and environmental policy analysis of trade-offs amid the palm oil commodity boom and the accompanying ecological crisis in Indonesia ${ }^{2}$. This part of the research analyzes the Indonesian smallholder sector in light of present and hypothetical policy approaches that aim at improving environmental performance and welfare.

With oil palm production continuing to conquest new areas in Indonesia as well as around the world, policymakers and many more stakeholders along the value chain are facing an immense socio-environmental trade-off (Qaim et al., 2020; Grass et al., 2020). The oil palm commodity boom has been shown to both markedly improve rural livelihoods (Krishna et al., 2014; Klasen et al., 2016; Kubitza et al., 2018a; Sibhatu, 2019) while at the same time dramatically deteriorate vital ecosystem functions (Koh and Wilcove, 2008; Savilaakso et al., 2014; Chaplin-Kramer et al., 2015; Fitzherbert et al., 2008; Vijay et al., 2016; Darras et al., 2019a; Bateman et al., 2015).

In Indonesia, smallholder farmers are at the center of this critical trade-off. Even though the lion's share of palm oil output stems from large estates, at present, smallholders manage more than 40\% of oil palm plantation area (Byerlee and Viswanathan, 2018; Qaim et al., 2020). The comparably high participation of smallholders in the commodity boom is likely also a result of continuing government support (Jelsma et al., 2017). The Indonesian government promoted smallholder participation in oil palm starting in the late 1970s, when integrative schemes eased the establishment of large estates and adoption of smallholders jointly. Consequently, an increasing number of smallholders adopted the technology of palm oil and replaced the traditional production of rubber (Kubitza et al., 2018b) as particularly higher harvest frequency renders rubber four times more labour intensive than palm oil (Schwarze et al., 2015). Thus, even though rubber remains an important crop for smallholder farmers in Indonesia and Jambi province, the sector progressively shifts towards oil palm cultivation.

\footnotetext{
${ }^{2}$ This part of the research in this dissertation is integrated in a sub-project of the interdisciplinary Collaborative Research Centre 990: Ecological and Socioeconomic Functions of Tropical Lowland Rainforest Transformation Systems (EFForTS) and is located in Jambi province on the island of Sumatra, Indonesia.
} 
On the one hand, oil palm adoption markedly helped to improve livelihoods, particularly in rural areas, not only in Indonesia but also other tropical regions (Qaim et al., 2020). On the other hand, environmental degradation resulting from the advance of oil palm plantations led to increasing international as well as national pressure on both large estates as well as smallholder producers (IFPRI, 2019; Qaim et al., 2020).

Yet, given the importance of smallholders in palm oil production in terms of their economic contribution and in terms of policy support, the paucity of microeconomic research on their environmental performance is striking. The vast majority of environmental economic research on palm oil production relies on aggregate national level and remote sensing approaches, that - to a large extend - reflect only large estates and corporation practices, while comparably little is known about the environmental performance of smallholders (Sayer et al., 2012; Byerlee and Viswanathan, 2018). As much of the science base stems from such aggregate level studies, policy responses aimed at mitigating environmental degradation often neglected the particularities of smallholder producers. Perhaps the most prominent example thereof is the round table on sustainable palm oil (RSPO) certification scheme, that - albeit certifying a sizable share of national palm oil output - the literature has largely found livelihood impacts ranging from mixed to negative for smallholder producers (e.g. Rist et al., 2010a; Brandi et al., 2013; Krishna et al., 2017a; Glasbergen, 2018; Schleifer and Sun, 2020).

By contrast, the economic role of oil palm production for smallholders and rural development as well as related socio-economic challenges and opportunities and policy efficacy forms another voluminous strand of literature (e.g. Savilaakso et al., 2014; Euler et al., 2017; Krishna et al., 2017b; Woittiez et al., 2017; Jelsma et al., 2017; Kubitza et al., 2018a), which, however, only sporadically addresses the environmental performance of smallholders. Similarly, a substantial body of literature in other scientific fields such as biology and ecology on the environmental effects of oil palm cultivation has formed, however, research linking the two is scarce and the information bases are rarely merged to provide interdisciplinary results. Nonetheless, such integrative studies are probably critical for an exhaustive and comprehensive evidence base that fully encompasses the economics, society and the environmental aspects of oil palm production (Qaim et al., 2020). Notable exceptions are the recent works of Teuscher et al. (2015) and Grass et al. (2020) who find strong trade-offs between production and biodiversity. Some other studies analyze land expansion behaviour of smallholder producers which in turn have consequences on land related environmental degradation (Kubitza et al., 2018b).

Yet another challenge which smallholder producers face are declining real output prices. Since Indonesia is the largest exporter of both palm oil and rubber, and the majority of produce is destined for markets abroad, international market dynamics do not leave Indonesian smallholders unscathed (Amiti and Konings, 2007; Rifin, 2010). Even though real producer prices during the 2010s rose sharply, in the more recent past they have been dwindling 
steadily. Between 2012 and 2018, FAO's producer price index for oil palm fruit bunch and natural rubber in Indonesia declined by 13 and 16\%, respectively (FAOSTAT, 2020). As a response to the decline of palm oil and rubber commodity prices - which, in turn, are likely to be supply-driven - the government has made use of trade policies such as tariffs and quotas as well as domestic demand-stimulating measures in efforts to support producer price levels (Verico, 2013; Anwar, 2017).

The first essay (chapter two) of this dissertation asks whether technical efficiency of oil palm smallholder producers in Indonesia reduces or accelerates land expansion. As smallholders fall short of nearly $40 \%$ of oil palm fruit yields, improving smallholder production efficiency could be a promising avenue for policy to mitigate environmental degradation by means of slowing down area expansion and increasing rural incomes at the same time. However, the net effect of such measures critically depends on the rebound effect that measures the increase of land demand as a response of improved profitability of production. In a two stage approach, we first estimate the technical efficiency of smallholder producers data using a linear mixed model (LMM) that allows for hierarchical panel data structures of farmers who manage multiple plots. Second, we predict current land expansion based on past technical efficiency using a measurement error model where we account for the attenuation bias resulting from the first stage model that has not yet been addressed methodologically in the relevant literature. Both stages rely on a farm survey conducted in a panel of three waves between 2012 and 2018.

Our findings indicate that while the land sparing potential of increased smallholder efficiency is remarkable, higher returns to palm oil production also increase demand for land by a factor of one third. Thus, successful rural development and conservationist policy need to reconcile both effects by connecting smallholder support with more formalized land markets and stringent land policy.

The second essay (chapter three) of this dissertation explores the relationship between smallholder oil palm production and loss of biodiversity. In an interdisciplinary approach, we augment the dataset employed in the first essay by plant diversity data from oil palm plots and derive a measure of biodiversity. We link biodiversity loss to palm oil production using a stochastic hyperbolic distance function. Hereby we extend the model of Cuesta et al. (2009) and provide a restricted form of the function allowing for both fixed and variable input use in the short term. The duality of the approach moreover allows for the calculation of shadow prices of environmental degradation which serve as the basis to develop several payments for ecosystem services schemes.

Our results reveal substantial environmental inefficiency in smallholder oil palm production which is in part explained by both chemical and manual weeding practices. The value for conserving one species on a farmers plantation was 340 USD in 2018, on average. Payments for ecosystem services schemes could be a viable policy response to conserve meaningful levels 
of biodiversity while at the same time allowing smallholders to increase palm oil output. In general, addressing drivers of environmental performance in PES designs amplifies the effect thereof without reducing production levels.

The third essay (chapter four) of this dissertation analyzes the effectiveness of trade policy measures implemented by the Indonesian government jointly with the members of the tripartite rubber council (TRC) to steer international rubber prices. Besides oil palm, rubber remains an important source of income in Indonesia and experienced a considerable decline of real output price. As the availability of synthetic rubber, which is a derivative of crude oil is increasingly dominating natural rubber prices, the TRC aims at detaching natural rubber prices from synthetic ones by shortening supply via export quotas in the short term and promoting domestic consumption in the long term. Relying on international price data series, we employ an error correction model to analyze the price transmission mechanisms between natural and synthetic rubber prices under the assumption of weak exogeneity of crude oil prices.

Our findings indicate that natural and synthetic rubber are co-integrated and strongly driven by crude oil. We find that restricting supply did not impact international markets as expected and increasing domestic consumption might even have backfired and contributed to further decreases in international prices.

\subsection{Identification of structural time series models in commodity policy analysis}

The second focus of this dissertation is concerned with the advancement of methodological innovations to analyze commodity market dynamics. In turn, a profound understanding of the direction, magnitude and cause of market movements are key to respective policy. A substantial body of literature employs time series models to determine the impacts of macroeconomic policy (Sims et al., 1982; Kilian and Lütkepohl, 2017). Prominent examples are the analysis of monetary or fiscal policy (e.g. Blanchard and Perotti, 2002; Mertens and Ravn, 2010; Auerbach and Gorodnichenko, 2012; Lütkepohl and Netsunajev, 2017a; Olivero et al., 2019), trade policy (e.g. Xu, 2000; Glick and Rose, 2002; Stephens et al., 2012; Anderson, 2016) and commodity market policy in general (e.g. Meyer and von CramonTaubadel, 2004; Myers et al., 2010; Brümmer et al., 2016; Lloyd, 2017). In their very essence, multivariate time series models rely on a range of methods and techniques which predict variables based on past values of the same variable or, past and present values of other variables. The seminal work of Granger (1969) introduces a concept of causality among time series variables that conditions that one time series $\left(Y_{t}\right)$ is useful in predicting another $X_{t}$, while vice versa, the latter time series is not useful in predicting the former. Thus, in presence 
of other potentially influential variables $Z_{t}$,

$$
P\left(X_{t+1} \mid X_{t}, X_{t-1}, \ldots, Y_{t}, Y_{t-1}, \ldots Z_{t}, Z_{t-1}\right) \neq P\left(X_{t+1} \mid X_{t}, X_{t-1}, \ldots Z_{t}, Z_{t-1}\right)
$$

The concept of Granger-causality has found numerous applications and inspired a variety of statistical tests and models in causal time series research (Moneta et al., 2011; Kilian and Lütkepohl, 2017). Testing for Granger-noncausality corresponds to testing conditional independence (Florens and Mouchart, 1982; Moneta et al., 2011), and one particularly prominent and widely-used approach are vector autoregression models (VAR) that take the form of

$$
y_{t}=\mu+A_{1} y_{t-1}+\ldots+A_{p} y_{t-p}+u_{t}
$$

as, for instance in (Lütkepohl, 2005). Here $y_{t}$ is a vector of time series variables and $\mu_{t}$ a vector of deterministic terms. The matrix $A_{i}$ captures the autoregressive parameters and $p$ denotes the lag order of the model. The serially - but not contemporaneously - uncorrelated error terms are assumed to have $\mathbb{E}\left(u_{t}\right)=0$ and $\operatorname{Cov}\left(u_{t}\right)=\Sigma_{u}$. By further assumption, the system is stationary ${ }^{3}$. In essence, noncausality between two series of $y_{t}$ thus imply that the respective coefficients in $A_{i}$ are not fading out simultaneously over time (Moneta et al., 2011).

The concept of Granger-causality has been widely relied upon in the applied econometric literature and extended in multiple directions. However, at the same time the Grangertheorem has been challenged by a number of authors. Most notable is Sims (1972) who find that money Granger-causes output and not vice versa, but when accounting for interest rate changes, the effect disappears, as shown by Sims (1980) and Sims et al. (1982) who point out the critical dependence of Granger-causality on the choice of the conditioning set. Another example is Thurman et al. (1988) who show that egg production in the US Granger-causes the chicken population and thereby seemingly solves the problem of which was first: the chicken or the egg. Moreover, there is no causal flow from chicken to the egg. However, well noting that their results are critically conditional on their particular sampling strategy, the authors conclude that causality - in the Granger sense - can be a misleading term and tests for Granger-noncausality not adequately allow meaningful causal inference among correlated time series in cases where the conditioning set is specified or other - usually economic assumptions - are not valid. In such cases, the true structural mechanisms among time series variables remain undetected.

In an effort to go beyond temporal relation ${ }^{4}$, Sims (1980) introduces structural vector autoregression (SVAR) models to reveal the underlying causal directions among time series interdynamics, and thereby enable a more nuanced inference in more general circumstances.

\footnotetext{
${ }^{3}$ Note that in case of non-stationarity and cointegration, resulting VEC models can also be represented as a stationary VAR process (Lütkepohl, 2005; Kilian and Lütkepohl, 2017)

${ }^{4}$ Later, Granger and Newbold (2014) referred the Granger (1969)-concept of causality as "temporally related".
} 
Following Lütkepohl (2005) and Kilian and Lütkepohl (2017) and emerging from equation 1.2 an SVAR model can be expressed as

$$
y_{t}=\mu+A_{1} y_{t-1}+\ldots+A_{p} y_{t-p}+B \varepsilon_{t}, \quad t=1, \ldots, T
$$

where the reduced form error terms $u_{t}$ are a linear transformation of the nonsingular matrix $B$ that collects the instantaneous effects of the structural shocks $\varepsilon_{t}$ on all the variables of the system, and thus $\varepsilon=B^{-1} u_{t}$. The structural shocks are both serially as well as contemporaneously uncorrelated. The covariance matrix of $\varepsilon_{t}$ can be expressed as a function of the reduced-form error term covariance matrix, such that

$$
\operatorname{Cov}\left(u_{t}\right)=\Sigma_{u}=B \Sigma_{\varepsilon} B^{\top}
$$

showing that the reduced-form error terms hide the uncorrelated shocks and merely convey the contemporaneously correlated shocks. Thus, $B$ reflects the response of the variables to the latent drivers of the system. However, even though these economically meaningful shocks can not be observed directly, they can be revealed under certain conditions or restrictions (Kilian and Lütkepohl, 2017). While the estimation of reduced-form error terms is straightforward, e.g. using maximum likelihood (ML) or least squares (LS) estimation, the unique recovery of structural shocks has been subject of an ongoing debate and methodological advancement during the past decades (Kilian and Lütkepohl, 2017).

Sims (1980) and a sizable following strand of literature relies on economically motivated restrictions to identify the structural shocks of multivariate time series systems. An example in the context of commodity markets is found in oil price related analyses. Empiricists often assume exogeneity of oil to other markets which hold minor importance in economic terms, and thereby solve the identification problem by assumption (Serra and Zilberman, 2013). In the oil shocks literature, authors typically assume zero supply elasticity of crude oil (e.g. Kilian, 2009; Wang et al., 2014). In the former case, the restriction assumption has found further evidence in other causal works (Serra and Zilberman, 2013), the latter, by contrast, has been challenged more recently (Baumeister and Hamilton, 2019a). Thus, resulting policy implications are conditioned by the identifying assumptions that often are untestable.

A more recent strand of literature aims to unravelling structural shocks by scrutinizing statistical features of the data. For instance, in presence of heteroskedasticity, the structural shocks can be identified by unconditional shifts in the (co)variance ${ }^{5}$ (Rigobon, 2003), conditional volatility (Normadin and Phaneuf, 2004), and smooth transition in covariance (Lütkepohl and Netsunajev, 2017a). Other authors augment the assumptions of second order independence of contemporaneous non-correlation among the structural shocks to higher order moments and reveal the unique $B$ matrix by non-Gaussian maximum likelihood (Lanne

\footnotetext{
${ }^{5}$ In presence of an exogenous structural break
} 
et al., 2017a), or independent component analysis (ICA) relying, for instance, on the distance covariance statistic (Matteson and Tsay, 2017) or the Cramer-von Mises distance statistic (Herwartz and Plödt, 2016b) ${ }^{6}$. Such data-driven approaches are a convenient means to identify SVARS as they scrutinize the exogeneity of statistical properties of the data and thereby rendering economic assumptions as testable and overidentifying.

In spite of the growing availability of structural identification strategies, the applied literature has been adapting rather slowly. A multitude of authors have expressed the need for structural approaches in context of agricultural time series (e.g. Myers et al., 2010; Nazlioglu and Soytas, 2011; Serra and Zilberman, 2013; Grosche, 2014; Lloyd, 2017). Serra and Zilberman (2013) find that the majority of empirical work on the food-oil price nexus rests on causality in the Granger-sense, which is particularly alarming as the emergence of biofuels could have changed market fundamentals of the food-fuel relationship and consequently could render traditional economic assumptions erroneous. As more layers of complexity are added to commodity and agricultural markets, many other reduced-form models or assumption driven structural identification strategies might become error prone, and thus, misguided evidence-base for policy makers.

As ready-to-use and user friendly software implementations are not available, the fourth essay (chapter five) of this dissertation provides the $\mathrm{R}$ package svars (Lange et al., ming) which implements data-driven techniques to identify SVAR models. As more identification approaches become available, the package moreover provides a platform to host further methods and tools within the framework of SVARS and is continuously updated and extendend. Furthermore, it connects to the other existing time series analysis $\mathrm{R}$ packages such as vars and strucchange.

Finally, the fifth essay (chapter six) of this dissertation applies independent component analysis using distance covariance to reveal the impacts of structural oil shocks on food markets in Sub-Sahara Africa. Even though the crude oil-food market nexus has received great attention in the literature, most works focus on high-income countries and do not consider the existence of different types of oil shocks, i.e. aggregate-demand, oil-supply and oil-specific demand shocks. Yet, food markets have been shown to react differently to different types of oil shocks in the US and world market levels (Baumeister and Kilian, 2014a; Wang et al., 2014).

The findings indicate that food prices in Sub-Sahara Africa respond fundamentally different to oil shocks than world market prices or those in developed countries. We find significant responses of some food markets in SSA to oil-supply shocks as opposed to minimal importance of oil-demand and aggregate-demand. Moreover, SSA food markets are much more heterogeneous in their response to global oil shocks than high-income countries and world markets are. As transportation costs are substantially higher in many SSA countries, and

\footnotetext{
${ }^{6} \mathrm{~A}$ more detailed review of the methods follows in chapter five
} 
also more heterogeneous among different countries, they are a much more powerful transmission channel from oil markets to food markets compared with other parts of the world. Indeed, historical decompositions reveal that the oil-supply shortfalls induced by the Libyan revolution and the oil embargo against Iran in 2011 and 2012 subsequently caused most of the resulting food price increases in SSA. Conversely, the shale oil boom in the US and oil production expansion in the Middle East exerted downward pressures on corn prices in three African countries in 2014/15. Food market policy thus aims to keeping transport costs low and reliant to import shortages, for instance by building up strategic energy reserves. 


\section{Chapter Two}

\section{Does technical efficiency promote or dampen oil palm area expansion in Indonesia? $^{1}$}

Indonesian forest area has dwindled while palm oil output experienced exponential growth during the past decades and continues to improve rural livelihoods. Smallholder farmers are cultivating nearly half of oil palm production area while falling short of $40 \%$ of area yields compared to large estates. Given the substantial opportunities to produce more on less land, eliminating the inefficiency in production could both save and share additional forest land from or to palm oil production. However, in contrast to the adverse effects of technological innovation on land expansion, the link between technical efficiency and demand for land is still unclear. This paper asks whether technical efficiency of oil palm smallholder producers in Indonesia reduces or accelerates land expansion. In a two-stage approach, we estimate technical efficiency by means of a hierarchical random intercept model and determine the expansion effect of efficiency scores by means of an error in variables (EIV) regression. Our key finding is that technical efficiency is an important junction within the land sparing vs. land expansion debate. We show that closing the yield gap provides remarkable land sparing opportunities, which are at serious risk of being offset by more than one third due to increased land demand. Thus, successful conservationist policy flanks the problem and ensures proper land markets in combination with smallholder development measures.

Keywords: Palm oil, deforestation, technical efficiency, rebound effect

\footnotetext{
${ }^{1}$ Acknowledgement: This study was funded by the Deutsche Forschungsgemeinschaft (DFG, German Research Foundation) project number 192626868 in the framework of the collaborative German-Indonesian research project CRC990. I'm very grateful to Christoph Kubitza who provided valuable comments and suggestions as a discussant of the paper at a doctoral seminar in Göttingen. I also thank Bernhard Brümmer, Daniel Chrisendo, Dela Dem Doe Fiankor and Yashree Mehta for useful feedback. Furthermore, I thank members of the early career mentoring post-conference workshop at the AAEA meetings in Atlanta, 2019 for commenting on an early draft of the paper.
} 


\subsection{Introduction}

Global expansion of agriculture has come at the expense of many ecosystem functions (Rasmussen et al., 2018; TEEB, 2012; Hooper et al., 2012). Particularly tropical forests are affected by the advancement of agricultural production (Curtis et al., 2018) and have receded substantially during the past decades. Deforestation has wide ranging and long lasting implications as many ecosystem functions such as biodiversity and carbon uptake but also ecosystem services such as water supply, soil maintenance and flood control (Ellison et al., 2012) are critically conditional on forests. Yet, commodity booms, which remarkably improve rural livelihoods, in conjunction with intangible land use policy set powerful incentives to further convert forests into crop lands, particularly in lower-income tropical regions around the world.

A promising solution to the problem is innovation. Total factor productivity (TFP) increases in agriculture can relieve pressure on land use (Borlaug, 2007), and producing more on less has been shown to lead to land sparing effects in the long term (Balmford et al., 2005, 2018; Feniuk et al., 2019; Phalan et al., 2014; Folberth et al., 2020). Consequently, increasing productivity has become a widely advocated policy goal to combat deforestation and other environmental externalities. In practice, such measures include the promotion of agrochemical and machinery use or the adoption of higher yielding varieties which boost per ha performance of farmers. However, other authors have shown that in turn rising marginal products can exacerbate instead of mitigate the pressure on forests and the reliant ecosystem functions either in the short term (e.g. Foster et al., 2011; Garrett et al., 2013; Desquilbet et al., 2017; Garcia et al., 2020) or depending on the type of technology (Maertens et al., 2006). Such cases are partly explained by market features, particularly relating to the elasticity of demand (Hertel, 2018). Yet, besides technical change, innovation in technical efficiency -or managerial skill- is another important component of TFP change. In contrast to the adverse relationship between technological innovation and land expansion, which has has been studied extensively, the link between technical efficiency and demand for land is still unclear. The gap in the literature is particularly striking as in an effort to boost rural livelihoods, numerous extension service and outreach programs aim at improving managerial skills of farmers. Without respective land use policy, such measures could have ecologically detrimental effects, at least in the short term.

This paper asks whether technical efficiency of oil palm smallholder producers reduces or accelerates land expansion in Indonesia. On the one hand, smallholders in Indonesia benefit from the oil palm boom. With about 34\% (Indonesian Ministry of Agriculture, 2016) smallholders contribute remarkably to national output and exports which is reflected in both poverty as well as food security measures (Sayer et al., 2012; Edwards, 2017). At the same time however, smallholders fall short of nearly $40 \%$ of area yield compared to large 
estates (Indonesian Ministry of Agriculture, 2016) and many authors argue that closing the yield gap could lead to improved livelihoods in conjunction with mitigation of area related environmental externalities, including deforestation.

Our empirical approach is organized in two stages. First, we estimate the technical efficiency of smallholder oil palm producers based on a short panel dataset from Jambi province on the island of Sumatra. We model the production technology relying on a translog functional form and employ a random effects model which accommodates the hierarchical structure of the data. The distance of farmers to the best-practice frontier constitutes the farmers inefficiency scores and determines by how much they fall short of the maximum attainable output considering their input use. Second, we estimate an error in variables (EIV) land use model to link past efficiency levels to land expansion today, revealing how managerial skill links to land demand.

We provide two main innovations to the existing literature. With regards to methodology, our paper is closest to Marchand (2012) who estimate the effect of technical efficiency on land use expansion in the Brazilian amazon using ordinary least squares and potentially neglecting the measurement error stemming from the efficiency score, which has a known distribution. We overcome the attenuation bias by employing an error in variable approach and highlight the advantages thereof. With regards to smallholder oil palm production, our paper is probably closest to Kubitza et al. (2018b), who analyze the effect of agricultural intensification on rubber and oil palm farmers close to the forest frontier. As an extension to their work, our paper focuses exclusively on oil palm producers and particularly assesses effects of technical efficiency as opposed to productivity changes on land expansion.

The key finding of this paper is that technical efficiency is an important junction within the land sparing vs. expansion debate. We show that closing the yield gap provides remarkable land sparing opportunities, which are at risk of being offset by increased land demand by more than one third. Thus, successful conservationist policy flanks the problem and ensures proper land rights as well as the enforcement thereof combined with outreach and extension services which target managerial skill of farmers, simultaneously.

The remainder of this paper is organized as follows: Section 2.2 provides a brief discussion of key findings from the existing literature. We focus on the rebound effect in agriculture and conservation as well as the smallholder oil palm situtation in Indonesia. Section 2.3 derives the two-stage empirical approach and presents the data. In section 2.4 results are presented and section 2.5 calculates the rebound effect and places the result in a policy perspective. Section 2.6 concludes the paper. 


\subsection{Land sparing vs. land expansion}

The role of technical efficiency within the land sparing vs. land expansion debate is not well understood. Before approaching the problem empirically, we briefly discuss some key literature around the discourse and revisit essential empirical and theoretical aspects. Subsequently we set the stage for our case study and provide relevant insights regarding the smallholder oil palm sector in Indonesia.

During the past decades, two distinct views regarding the role of intensification of agriculture in mitigating land use change (LUC) induced deforestation, or other externalities have emerged. First, the Borlaug hypothesis (Borlaug, 2002) states that as a result of intensified cereal production more than one billion ha of land have been spared from agricultural production since the 1950s. Induced by technological innovation -related to the Green Revolutiongrowing demand for food could be met by higher yields as opposed to further area expansion of agriculture. From a policy persepctive, the land sparing view postulates that deforestation - and other environmental externalities - around the world could be dampened by increasing productivity through invention and adoption of new technologies and managing resources more efficiently.

In sharp contrast to the Borlaug hypothesis stands the backfire-type rebound effect, or often referred to as the Jevons paradox ${ }^{2}$, that denotes a contrary situation where intensification in agriculture leads to further expansion of land use. In this view, innovation and more efficient management set further incentives to shift supply outwards as long as demand is elastic. Given such circumstances, any policy aiming at sparing land while relying solely on boosting innovation and performance is bound to backfire.

\subsubsection{The rebound effect: Definitions}

In between both colliding views stands the rebound effect and determines which of the two potential outcomes are likely and to what extent. In figure 2.1 we illustrate the rebound effect using a neo-classical representation and apply the considerations of Berkhout et al. (2000) to the land case.

We consider an agricultural product that has land $(L)$ and other inputs $(O)$. At the initial equilibrium producers face the isoquant $Y$ that represents all feasible combinations of land input $L$ and all other inputs $O$ which yield the same amount of output. A technological innovation which allows producers to produce the same level of output $Y$ using less land input and constant other-input use, shifts the isoquant to the left $\left(Y^{\prime}\right)$. Now point B is feasible for the producer, where $Y$ can be produced at equal level of $O$ of other input, but $L^{-}$as opposed to $L$ of land input and thereby sparing the use of $L-L^{-}$of land input. As a first response,

\footnotetext{
${ }^{2}$ The hypothesis goes back to Jevons (1879) who observed that in response to the invention of more efficient coal ovens, overall coal consumption increased instead of declined.
} 


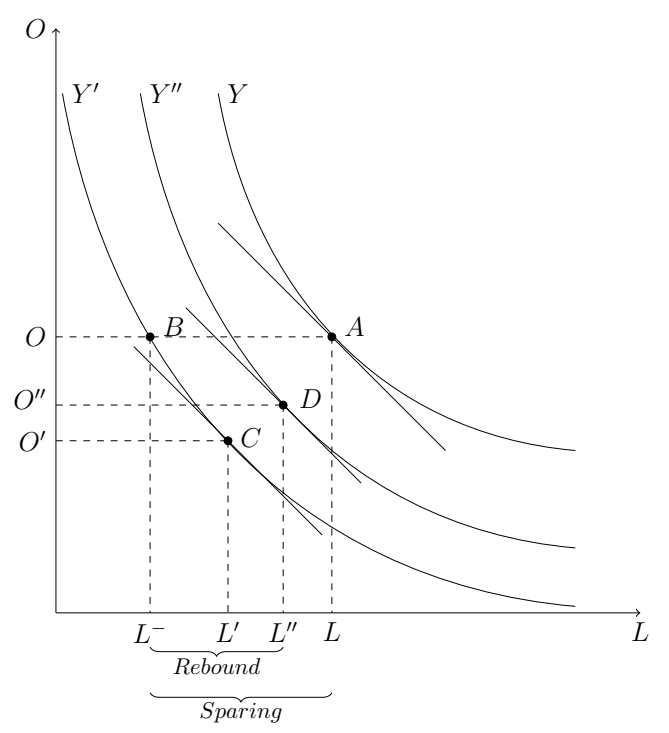

Figure 2.1 Rebound effect of producers

the producer shifts production to $C$ where the isoquant is equal to the relative factor prices and consequently output is maximized. The rebound effect is $L^{\prime}-L^{-}$which reduces the overall sparing potential of the technology shift.

The second part of the rebound effect depends on market features. Under perfect competition, producers compete for market shares and output prices fall until the point where profits are equal to the initial equilibrium. If consumer demand is price elastic, producers respond further and shift supply outward to $Y^{\prime \prime}$ which supports a higher level of output at, in turn, higher level of input use. Thus, the final equilibrium is at point $D$ where the rebound effect is $L^{\prime \prime}-L-$ and net land savings are $L-L^{\prime \prime}$. An exception is the case of perfectly inelastic demand, where producers will not respond with a supply shift and limit the rebound effect to $L-L^{-}$. By contrast, if demand is highly elastic such that $L^{\prime \prime}>L$, net savings are negative and the innovation backfires with regards to land use. Hence, besides the shape of the production function, the extend of the rebound effect critically depends on the elasticity of demand (Berkhout et al., 2000; Hertel, 2018; Villoria et al., 2014; Desquilbet et al., 2017).

The mechanisms described in figure 2.1 are connoted with a technological advancement resulting in an increase of TFP. However, as we may define TFP change as the sum of technical change and technical efficiency change, the shifts of isoquant may also stem from gains in technical efficiency as opposed to technological innovation. In that case, changes of the production process reflect the individual performance of producers given their idiosyncratic production conditions instead of a technology shift which affects to all producers equally. In other words, if we consider $Y$ in figure 2.1 to bound a production possibility set, technical efficiency gains are radial movements of individual producers towards the frontier which, however, entail the equivalent mechanisms concerning land sparing and land expansion. 


\subsubsection{Land sparing and rebound effects in agriculture: Empirical evidence}

Villoria et al. (2014) provide a review of empirical evidence regarding rebound effects in agricultural production. The authors find that intensification of production is overwhelmingly associated with land sparing as opposed to land expansion, particularly in the long run. Furthermore, a number of recent studies confirm the innovation-savings mechanism also regarding other ecosystem services, for instance biodiversity, greenhouse gas emissions (GHG) or deforestation (e.g. Balmford et al., 2005, 2018; Feniuk et al., 2019; Phalan et al., 2014; Folberth et al., 2020). Furthermore, Villoria et al. (2014) find that empirical support for the existence of backfiring rebound effects in agriculture is scarce and, if found, refers to short term horizons or is spatially limited. One example thereof is provided in Gutiérrez-Vélez et al. (2011) who find overall land saving in response of increasing oil palm yields in Peru, however, at the expense of increased deforestation. The authors furthermore highlight the importance of local policy to mitigate local leakage effects.

In a more recent study, Garcia et al. (2020) confirm the long term sparing effect of innovation in agriculture using global aggregate data over a 50 year period, but nonetheless find strong rebound effects in middle income countries for commodities with elastic consumer demand. Another case for presence of rebound effects is found in Desquilbet et al. (2017) who consider global aggregate production and biodiversity conservation.

Strikingly, much of the existing work relies on remote sensing data and aggregates at country, or even continental level while often also spanning over decades, as opposed to short term and micro level perspectives. Notable exceptions who take a more local approach are, for instance, Garrett et al. (2013), Birkenholtz (2017) and Song et al. (2018) who find short term rebound effects for country level soybean yields in Brazil, the introduction of drip irrigation in India and agricultural water use in China, respectively.

An explanation for the lack of local focus in the literature might stem from global balancing effects. Villoria et al. (2014) and Hertel (2018) argue that rebound effects in one region are typically offset by disproportionately higher savings in another one, given that barriers to trade are negligible. For instance, even though total factor productivity (TFP) growth promotes deforestation and LUC resulting in accelerated GHG emissions in South East Asia, global GHG emissions decline as they are saved in other parts of the world, where comparably more resource efficient palm oil replaces other - relatively more resource intensive - vegetable oils. However, such comparisons of local expansion vs. global sparing are conditional on the perfect substitutability between ecosystem functions or services. This assumption is fairly reasonable in the GHG case, but questionable with regards to other ecosystem functions and services. For example, reducing biodiversity in one part of the world can not be compensated with higher levels of biodiversity in another part as many species are endemic to regional 
environments. Thus, for ecosystem functions which are not spatial substitutes, global savings can not offset local rebounds.

At present, technical efficiency has received minimal attention in the land sparing vs. expansion literature as opposed to technological innovation or aggregate TFP growth. To our knowledge, the only exception is Marchand (2012) who find a quadratic relationship between technical efficiency and land expansion among soy producers in Brazil. All other relevant studies consider technical change as part of TFP change and refrain from distinguishing between TE and technology. This should not be problematic in cases where technology is homogeneous and all producers are operating close to the production frontier, or put differently, in absence of inefficiency. Such production systems typically are characterized by advanced technology as well as a relatively sophisticated production sector. However, in developed countries, where technology is still catching up and production subject to inherent idiosyncrasy of producers, gains in technical efficiency translate into large portions of yield increases. Consequently, both considerable sparing as well as rebound potentials are thinkable.

Thus far we synthesize that in spite of a multitude of research on innovation in agriculture amid the land sparing and land expansion debate, the literature lacks (i) local microeconomic evidence on rebound effects in agriculture, and (ii) approaches which assess innovation in farm performance as opposed to technology. As ecosystem services are not spatially substitutable and technical efficiency is a particularly important part of TFP growth, at least in middleincome countries, both shortcomings could manifest in a shaky evidence-base for designing local conservationist policy, particularly at the face of agricultural commodity booms.

\subsubsection{Smallholder palm oil producers in Jambi, Indonesia}

Amid the oil palm boom and the related ecological crisis in South East Asia, smallholder oil palm producers in Jambi constitute an important case to explore how gains in performance affect factor demand for land from a microeconomic perspective. First, even though smallholder farmers in Indonesia significantly contribute to national palm oil output, they do so at comparably low land productivity, compared to large estates. On average, smallholders in Indonesia fall short of nearly $40 \%$ of potential oil palm output (Indonesian Ministry of Agriculture, 2016; Woittiez et al., 2017; Jelsma et al., 2017; Euler et al., 2017) which highlights the sizeable potential of performance improvements from a production perspective. Second, the sector has been subject to heavy government intervention from its very beginning. Since the 1970s, the government launched several development programs - often in conjunction with international organizations - which aimed at promoting smallholder oil palm production. The measures ranged from relocation support and easing of land access (trasmigrasi program) to credit and fertilizer provision as well as extension services (Jelsma et al., 2017).

Considering that smallholders are likely to experience productivity boosts through tech- 
nology and managerial performance, further deforestation could be at stake. Aside from input demand, land markets are a key aspect for rebound effects to translate into accelerated deforestation(Krishna et al., 2017b). With regards to land use policy, the Indonesian government implemented several initiatives aimed at halting deforestation through expedited land regulation. Most prominently, since 2011 a moratorium prohibiting primary forest ground conversion is in place. Studies which evaluate the efficacy of the policy find mixed results. While some authors have found remarkable reduction rates of deforestation associated with the introduction of the moratorium (e.g. Busch et al., 2015; Chen et al., 2019), others find relative inefficacy of the ban (e.g. Suwarno et al., 2018). Additionally, Miyamoto (2006) and Krishna et al. (2014) find that weak property rights favour the direct appropriation of forestland and furthermore the appropriation of larger estates of smallholder cultivation area.

Similarly, in spite of such regulatory efforts, Kubitza et al. (2018b) and Krishna et al. (2017b) find that direct forest appropriation has been common regardless of such institutional developments among smallholder farmers. More precisely - and relevant to our case study Krishna et al. (2017b) find that $18 \%$ of existing oil palm plantations were acquired through direct forest land appropriation among smallholder producers in Jambi Province ${ }^{3}$. Moreover, the authors find that in 2012, $9 \%$ of land expansion occurred at the direct expense of forest grounds. At present, lowland forest land is limited and few opportunities to appropriate forest land exist and direct forest land appropriation rates have plummeted. Nevertheless, the smallholder experience in Jambi province during the past decade could be similar to that of other parts of Indonesia, where oil palm cultivation started only recently (e.g. in Kalimantan) or other regions in the world where agricultural commodity booms are closely linked to ecological crises (Kubitza et al., 2018b).

\subsection{Methods and Data}

The methodology to measure the rebound effect of performance innovation of smallholder oil palm producers is organized in two main stages. In the first stage, we estimate technical efficiency scores of oil palm smallholders and employ a translog production function in a hierarchical random intercepts model. In the second stage, we predict land expansion of farmers based on past technical efficiency scores by means of an EIV model which accounts for the measurement error in the estimated efficiency score introduced in stage one. Moreover, in this section we present the data at hand and both empirical specifications.

\footnotetext{
${ }^{3}$ The sample of Krishna et al. (2017b) and Kubitza et al. (2018b) is also the basis for the analysis in this study.
} 


\subsubsection{Technical efficiency and production frontier}

Since the seminal works of Aigner et al. (1977) and Meeusen and van Den Broeck (1977), empirical production frontiers are widely used to model production processes of firms and determine their technical efficiency. In essence, production functions aim at evaluating the provision of outputs against the usage of inputs and determine how well individual units perform compared to each other. Critically, they allow to distinguish the production technology from technical efficiency, which ultimately is a measure of managerial skill. We define the latter as the ratio between an individually realized outcome and a best practice outcome. From an output perspective technical technical efficiency designates the difference between maximum attainable output and individually achieved, i.e.,

$$
T E_{i}=\frac{y_{i}}{y_{i}^{*}}
$$

where $y_{i}$ and $y_{i}^{*}$ designate output of firm $i$ and the best practice scenario respectively. ${ }^{4}$.

However, aside from technical efficiency, output is conditional on a set of inputs and the transformation process which, in contrast to technical efficiency, is not adjustable and in the short term exogenous to the manager. The stochastic version of production function is generally expressed as

$$
\ln \left(y_{i}\right)=\ln F\left(x_{i}, \beta\right)-u_{i}+v_{i}
$$

where $x_{i}$ are inputs used in the production process and $\beta$ is a vector of technological parameters (Parmeter et al., 2014; O'Donnell, 2018). The error components $u_{i}$ and $v_{i}$ capture inefficiency and statistical noise respectively. Estimating the production frontier parameterically requires, (i) choosing an appropriate functional form for the production process $F(x)$ and suitable distributions for, (ii) the efficiency term and (iii) the random error term.

\subsubsection{Random intercept frontier}

The productivity and efficiency literature provides a variety of parametric and non-parametric frontier models to determine both the production functions as well as efficiency scores of decision making units (DMUs) fitting a vast set of data types. The problem of heterogeneous technology, for instance, has been addressed using random coefficient models (Tsionas, 2002; Skevas, 2019) and latent class models (Emvalomatis, 2012). By the same rationale, we can express the production frontier as a random intercept model and allow for group specific effects to vary in between groups as well as across (e.g. Gelman and Hill, 2006; Mehta and Brümmer, 2020).

\footnotetext{
${ }^{4}$ One could also define efficiency from an an input perspective. In this case efficiency refers to the difference between individually used inputs and minimum level of input use.
} 


$$
\begin{array}{r}
y_{i c}=\alpha_{0}+x_{i c} / \beta-u_{c}+v_{i c} \\
y_{i c}=\alpha_{c}+x_{i c} \beta+v_{i c} \\
v_{i c} \sim \mathcal{N}\left(0, \sigma_{v}^{2}\right) .
\end{array}
$$

Where $x$ and $y$ are now logarithmized and the group intercept $\alpha_{c}=\alpha_{0}-u_{c}$ and $u_{c} \geq 0$ is the one-sided inefficiency term. The technical efficiency can be retrieved following the transformation proposed in Schmidt and Sickles (1984) where $u_{c}=\max \left\{\alpha_{c}\right\}-\alpha_{c}$ and subsequently $T E_{c}=\exp \left(-u_{c}\right)$. Equation 2.3 describes a convenient model for hierarchical data structures where a production unit operates several production sites. Particularly, the specification accommodates small and heterogeneous group sizes, where the aggregation of which would introduce severe bias, for instance resulting from rotating sampling schemes or missing observations.

One of the drawbacks of the model is that in case of correlation between inputs and the group level predictor, the estimator is biased as the Gauss-Markov assumption of independence is violated. To overcome the problem, we make use of the modification proposed in Bafumi and Gelman (2006) and allow for correlation between inputs and group effects by introducing group level predictors ${ }^{5}$, such that

$$
\alpha_{c}=\gamma_{0}+z_{c}^{\prime \prime \gamma}+\epsilon_{c}
$$

Here $z_{i}$ are predictors at the group level. If no additional group characteristics are available, simple group means of the next level predictors $\left(x_{i c}\right)$ could be employed to resolve the correlation problem. Besides addressing the potential correlation between individual level predictors and group effects, the group level predictors can also be interpreted as determinants of (in)efficiency.

\subsubsection{Land expansion model}

After estimating the efficiency of smallholders in the first stage, we predict land expansion using the efficiency estimates from stage one in the second stage. Particularly, we need to overcome two challenges.

First, it is likely that both inputs and the intercepts reversely cause each other. In other words, farmers which are efficient could expand their business and conversely, expanded farmers could become more efficient. The literature has numerous approaches in store to address endogeneity, including reverse causality, in frontier models. Notably Amsler et al. (2016), Tran and Tsionas (2015) and Kutlu et al. (2019) propose instrumental variables, copula

\footnotetext{
${ }^{5}$ Note that this is similar to the Mundlak (1978) correction in panel models
} 
function and time-varying true individual effects combined with an additional decomposition of the irregular error term respectively. However, such approaches impose questionable assumptions of the distribution of potential endogeneity, the presence of proper instruments or availability of a sufficient amount cross-sections.

A simpler yet straightforward to implement solution is to use time lags. Even though time lags have been shown to avoid identification problems under certain circumstances, they are still valid under two explicit assumptions (Bellemare et al., 2017; Reed, 2015). The first assumption relates to no contemporaneous causality from efficiency and land expansion but merely from efficiency at $t-1$ to land expansion at $t$ (Bellemare et al., 2017), which we can confidently make given the time it takes to either establish new oil palm area or purchase existing plantations. The second assumption is the absence of unobserved confounding (Bellemare et al., 2017), which is a much harder one to make and - while to some extend addressed by the addition of controls - needs to be taken into account when interpreting the estimation results.

Thus, in line with these considerations, we specify the land expansion model

$$
\Delta A_{c t}=w_{c, t-1} / \delta+\tau T E_{c, t-1}+e_{i}
$$

where $\delta A_{i}$ is land expansion in period $t$, or in other words the first difference of $x_{1 t}$. We predict present land expansion using TE scores in $t-1$ and other covariates gathered in $w$. The error term $e_{i}$ is assumed to be normally distributed with mean zero and variance $\sigma_{e}$.

Second, while estimating Equation 2.5 by means of ordinary least squares (OLS) addresses the reverse causality issue, the attenuation bias arising from the stochastically estimated variable $u_{i}$ is not accounted for. However, we obtain $T E_{c}$ from $\alpha_{c}$ which is modelled depending on group specific covariates as well as a measurement error. Thus, Equation 2.5 can be interpreted as an error in variance model (EIV) (e.g. Fuller, 2009) where land use expansion is the observed dependent variable and $u_{i}$ the measured variable with known measurement error $\epsilon_{c}$ and variance $\sigma_{\epsilon}$. Consequently, we can estimate Equation 2.5 as an EIV model, for instance by means of total least squares (TLS) or M-Estimation relying on an updated design matrix which is adjusted by $\epsilon_{c}$ (Stefanski and Boos, 2002; Fuller, 2009).

\subsubsection{Data}

Our case study relies on a farm survey conducted in Jambi province on Sumatra island, Indonesia. More precisely, a multi-stage random sampling approach, stratifying on the regency, district, and village levels which reflects geographical and regional differences. The survey was conducted in 2012 for the first time and repeated in 2015 and 2018, resulting in a short panel data set ${ }^{6}$. The data is hierarchical in that farmers own one or more plots. All plots

\footnotetext{
${ }^{6} \mathrm{~A}$ more detailed description of the data is available in Krishna et al. (2014) and Kubitza et al. (2018a)
} 
of a farmer have been sampled during the first round in 2012. In the subsequent waves only one randomly selected plot per farmer has been recorded due to time and budget constraints. Moreover, in addition to the unbalanced plot dimension, the panel structure is also unbalanced. We combine the first two waves for the first stage of the analysis which is depicted in Table 2.1. In total, the dataset comprises 340 observations (plots) which belong to 211 groups (farmers). 205 of the observations were collected in 2012 and 125 in 2015 . Hence, the resulting data is an unbalanced multilevel data set with small groups. Additionally, we use total land expansion from the 2018 wave in the second stage model.

Table 2.1 Descriptive statistics

\begin{tabular}{lccccccc}
\hline \hline Statistic & Unit & Mean & St. Dev. & Min & Pctl $(25)$ & Pctl $(75)$ & Max \\
\hline Production & $\mathrm{kg}$ & 27,789 & 33,571 & 38 & 8,825 & 36,000 & 240,000 \\
Size & ha & 1.9 & 1.6 & 0.3 & 1.0 & 2.0 & 12.0 \\
Labour & man hours & $3,101.5$ & $6,650.2$ & 9 & 1,224 & $2,953.8$ & 100,500 \\
Agrochemicals & $\mathrm{kg}$ & 709 & 1,073 & 0 & 13 & $1,041.2$ & 12,050 \\
Palm age & years & 12 & 7 & 2 & 7 & 18 & 30 \\
Palm density & No. trees & 119 & 30 & 30 & 100 & 130 & 283 \\
Yield & $\mathrm{kg} \mathrm{ha}^{-1}$ & 13,998 & 8,631 & 125 & 7,000 & 20,000 & 39,000 \\
Age (manager) & years & 47 & 11 & 24 & 38 & 55 & 80 \\
Education & years & 7 & 3 & 0 & 6 & 9 & 17 \\
Houshold size & No. people & 5 & 2 & 1 & 4 & 6 & 11 \\
Transmigrant & binary & 0.3 & 0.5 & 0 & 0 & 1 & 1 \\
\hline
\end{tabular}

\subsubsection{Empirical specification}

We propose to estimate the first stage production frontier as a mixed linear estimator in a multilevel model. We express the production of fresh fruit bunches of oil palm in $\mathrm{kg}\left(y_{i c t}\right)$ as a function of plot size in ha $\left(x_{1 i c t}\right)$, labour in man hours $\left(x_{2 i c t}\right)$, agrochemical application in $\mathrm{kg}\left(x_{3 i c t}\right)$, the age of the palms $\left(x_{4 i c t}\right)$ as well as the density of the palms $\left(x_{5 i c t}\right)$. Based on conventional tests for nested models we choose the translog functional form which offers more flexibility as opposed to Cobb-Douglas or quadratic production functions and thereby estimate output as

$$
\mathbf{y}_{i c t}=\alpha_{c}+\sum_{j}^{5} \beta_{j} \mathbf{x}_{j i c t}+\frac{1}{2} \sum_{j} \sum_{k} \beta_{j k} \mathbf{x}_{j i c t} \mathbf{x}_{k i c t}+\rho \mathbf{t}+\mathbf{v}_{i c t} .
$$

The group intercept is additionally modelled as in Equation 2.4 where the specific independent variables $\left(z_{1}, \ldots, z_{4}\right)^{\prime}$ are age of the farm manager in years, education of the farm manager in years, gender, household size and transmigratory status. Moreover, we include a time trend $t$ to capture technical change between the two periods. All variables enter the equation in mean scaled form such that we can interpret the coefficients as elasticities 
at the sample mean. We estimate model 2.6 by means of restricted maximum likelihood (REML) and subsequently retrieve technical efficiency using the Schmidt and Sickles (1984) transformation, namely

$$
T E_{c}=\exp \left(-\max \left\{\alpha_{c}\right\}-\alpha_{c}\right)
$$

Finally, we estimate the land expansion model in Equation 2.5 by means of total least squares (TLS) (Fuller, 2009) accounting for the error in the technical efficiency variable and retrieve the OLS estimator as a means of comparison.

\subsection{Results}

Our two-stage empirical empirical approach delivers several layers of results ${ }^{7}$. First, we examine the parameter of the production frontier and assess the technology of smallholder oil palm producers. Second, we evaluate the technical efficiency scores of the farmers and their determinants. Third, we gauge the land expansion effect resulting from the land expansion model of the second stage and calculate the rebound effect.

\subsubsection{Production technology}

Table 3.2 details the REML estimates of the first and second order terms as well as the group predictors, which we can interpret as drivers of inefficiency within the random intercept model. The second column lists the corresponding standard errors of the coefficients ${ }^{8}$. The coefficients capture the effect of the individual variables on oil palm output. The parameters associated with the first-order terms are significant in both models and have the expected sign. Considering the plant-specific variables palm age and density, both exhibit first-order positive and second order-negative coefficients and thereby empirically confirm the quadratic relationships for both variables with output, which is often found in the plant-growth literature (e.g. Corley and Tinker, 2008). Although the time trend coefficient is negative, the comparably large standard error leads to the presumption of no meaningful technical change over the three year period, which is also reasonable in light of long lasting life cycles of oil palm plantations. Notably, the model reveals a considerable effect of land size, while the elasticity of agrochemical use is quite low, confirming the experimental findings of Darras et al. (2019b). The effect of labour is not statistically significant while the direction as well as magnitude are reasonable and finds support in the relevant literature on the low labour intensity of oil palm production (Kubitza et al., 2018a).

\footnotetext{
${ }^{7}$ The econometric analysis is carried out in $\mathrm{R}$ ( $\mathrm{R}$ Core Team, 2017). We estimate the random intercept model using the lme4 package (Bates et al., 2015) and the EIV model using the eivtools package (Lockwood, 2018).

${ }^{8} \mathrm{~A}$ full list of parameter estimates is available Table A.1 in appendix A.1
} 
Another notable finding of the production function are increasing returns to scale of the smallholder oil palm production sector. The sum of the size, labour and agrochemical use coefficients amounts to a scale elasticity of 1.15. In other words, average farm size is smaller than the equilibrium size where marginal returns to scale are constant. Increasing returns to scale could manifest in strong incentives for managers to grow their business.

With regards to robustness and model choice, the intra-class correlation (ICC) is 0.85 , suggesting that random intercepts are useful in explaining overall variation. Also a likelihood ratio (LR) test further supports the use of the LMM.

Table 2.2 First and second order terms and group predictors of the random intercept estimator

\begin{tabular}{|c|c|}
\hline & LMM \\
\hline \multicolumn{2}{|l|}{ Technology } \\
\hline$\beta_{0}($ Intercept $)$ & $0.16(0.56)$ \\
\hline$\beta_{1}($ Size $)$ & $0.90(0.09)^{* * *}$ \\
\hline$\beta_{2}$ (Labour) & $0.09(0.05)$ \\
\hline$\beta_{3}$ (Agrochemicals) & $0.16(0.05)^{* * *}$ \\
\hline$\beta_{4}$ (Palm age $)$ & $0.21(0.10)^{* *}$ \\
\hline$\beta_{5}($ Palm density $)$ & $0.21(0.10)^{* *}$ \\
\hline$\beta_{11}\left(\mathrm{Size}^{2}\right)$ & $0.12(0.12)$ \\
\hline$\beta_{33}\left(\right.$ Agrochemicals $\left.^{2}\right)$ & $0.05(0.02)^{* *}$ \\
\hline$\beta_{22}\left(\right.$ Labour $\left.^{2}\right)$ & $-0.09(0.05)^{*}$ \\
\hline$\beta_{44}\left(\right.$ Palm age $\left.{ }^{2}\right)$ & $-0.95(0.21)^{* * *}$ \\
\hline$\beta_{55}\left(\right.$ Palm density $\left.^{2}\right)$ & $-0.89(0.47)^{*}$ \\
\hline$\rho($ time $)$ & $-0.09(0.14)$ \\
\hline \multicolumn{2}{|l|}{ Group predictors } \\
\hline$\gamma_{1}$ (Age) & $0.01(0.02)$ \\
\hline$\gamma_{11}\left(\operatorname{Age}^{2}\right)$ & $-0.00(0.00)$ \\
\hline$\gamma_{2}$ (Education) & $0.01(0.01)$ \\
\hline$\gamma_{3}($ Household size $)$ & $-0.08(0.03)^{* * *}$ \\
\hline$\gamma_{4}$ (Transmigrant) & $0.05(0.13)$ \\
\hline$\gamma_{5}$ (Transmigrant village) & $-0.03(0.12)$ \\
\hline$\gamma_{6}($ Land title $)$ & $-0.01(0.17)$ \\
\hline$\sigma_{\alpha_{c}}$ & 0.12 \\
\hline$\sigma_{\text {epsilon }}$ & 0.27 \\
\hline$I C C$ & 0.85 \\
\hline Mean TE & 0.66 \\
\hline
\end{tabular}




\subsubsection{Technical efficiency}

The distribution of technical efficiency scores is illustrated in Figure 2.2. The estimated technical efficiency have a mean of 0.66 , implying that palm oil output falls short of $44 \%$, on average. While generally technical efficiency is rather low, in combination with the production function parameter estimates, which suggest relatively strong importance of land size as a productive input, we additionally note further evidence for the apparent low land productivity of smallholder farmers.

With regards to the potential drivers of inefficiency, we merely find household size to significantly contribute to inefficiency in oil palm production (Table 3.2). All other coefficients of the intercept model exhibit relatively large standard errors, including age, education transmigratory status as well as presence of a land title, failing to result in statistical significance. Nevertheless, the signs are as expected. For instance farmers become more efficient with increasing age until at some point, the slope is negative and additional age is associated in increased inefficiency.

Figure 2.2 Distribution of technical efficiency scores of smallholder oil palm producers

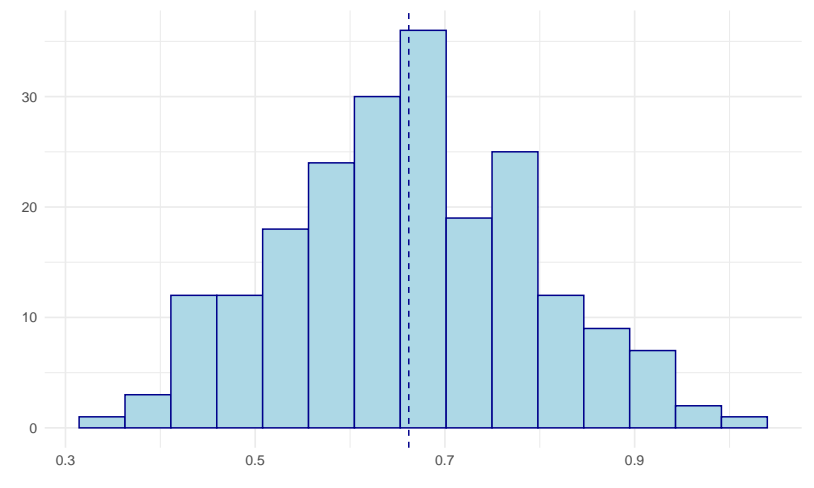




\subsubsection{Land expansion}

The efficiency scores obtained from the first-stage estimation serve as an explanatory variable in the land expansion model. We estimate the effect of lagged efficiency jointly with other variables on the farm manager level on land expansion in percent by means of OLS and TLS in an EIV model.

Table 2.3 lists the OLS estimates and associated standard errors es well as the EIV parameter estimates, where we additionally account for measurement error in the TE variable. Before interpreting the coefficients, we note that with the exception of the error-prone variable, the coefficients of the other covariates are of comparable dimension in both models. Nevertheless, the OLS model exhibits substantially more uncertainty in the parameter estimates as well as a considerably smaller estimate of $\tau$ due to the attenuation bias. Both the lower precision of estimates as well as the bias of error-prone variable is in line with the relevant theory Nelson (1995) and highlights the importance of EIV estimation in case variables are measured with error, as the OLS results can lead to fundamentally different outcomes and hence, misguided coefficient interpretation.

Aside from these methodological considerations, both models suggest a considerable effect of past technical efficiency on farm area expansion and the measurement error model additionally provides statistical confidence of that effect. A unit change in efficiency leads to an area expansion of 65 percent, on average. Needless to mention, as $0 \leq T E_{c} \leq 1$ real unit changes hardly occur and efficiency changes are of the order of decimal changes. Additionally, we find transmigrant households to be less likely to expand their production which confirms Kubitza et al. (2018b), who find that transmigrants often intensify their production and refrain from seeking ways to expand their plantation and is also in line with the finding that autochthonous farm households are much more involved in deforestation than migrants of Krishna et al. (2017b).

Table 2.3 Land expansion models

\begin{tabular}{lcc}
\hline & OLS & $E I V$ \\
\hline$\delta_{0}$ (Intercept) & $-1.41(0.75)^{*}$ & $-1.48(0.87)^{*}$ \\
$\delta_{1}$ (Age) & $0.02(0.01)^{* *}$ & $0.02(0.01)$ \\
$\delta_{2}$ (Gender) & $0.63(0.53)$ & $0.63(0.45)$ \\
$\delta_{3}$ (Education) & $0.01(0.03)$ & $0.01(0.02)$ \\
$\delta_{4}$ (HHSize) & $0.00(0.06)$ & $-0.00(0.03)$ \\
$\delta_{5}$ (Transmigrant) & $-0.42(0.21)^{* *}$ & $-0.42(0.21)^{*}$ \\
$\delta_{6}$ (Zero-expansion dummy) & $1.28(0.19)^{* * *}$ & $1.28(0.27)^{* * *}$ \\
$\tau$ (Technical efficiency) & $0.55(0.66)$ & $0.65(0.39)^{*}$ \\
\hline
\end{tabular}

${ }^{* * *} p<0.01,{ }^{* *} p<0.05,{ }^{*} p<0.1$ 
Altogether, the main findings of the two-stage approach are that (i) the output of smallholder oil palm producers is overwhelmingly area driven. Other inputs such as labour and agrochemical application play minor roles for the provision of palm oil. (ii) Smallholders generally operate farms which are too small. Increasing returns to scale suggests presence of strong expansion incentives regarding profitability. (iii) The sector exhibits, on average, relatively low mean, and furthermore heterogeneous levels of technical efficiency. This implies ample room to increase output without additional use of inputs. (iv) Past technical efficiency is a good predictor of land expansion in the current period and improvements thereof are likely to result in increasing demand for land expansion.

\subsection{Land sparing vs. land expansion and policy impli- cations}

As returns to scale are increasing, technical efficiency levels low and at the same time act as drivers of land expansion, the effects of policy aiming at improvements in farm management could have sizable (detrimental) impacts on deforestation in the Jambi case. In this section we simulate the potential aggregate outcome of increasing smallholder technical efficiency and compare it to potential land savings the sector could provide in an effort to better understand the adverse effects of agricultural development policy.

First, we determine the overall potential of land saving resulting from improvements in technical efficiency only. In other words, we ask how much less land would farmers require to produce the given level of output? One way of disentangling the technologically feasible minimum land input from our production frontier is to follow Reinhard et al. (1999) and derive a single-input efficiency measure by equating the a hypothetical minimum input use frontier with the output oriented production frontier. Reinhard et al. (1999) define input (environmental) efficiency as the ratio of minimum level of input use and observed input output, which is a convenient measure of land efficiency for our case at hand. Hence, we apply their $\sqrt{ }$ formula to our production function ${ }^{9}$

$$
L E_{i c t}=\frac{\left[-\left(\beta_{1}+\sum_{j}^{4} \beta_{1 j} x_{i c t j}+\beta_{11} x_{1 i c t}\right) \pm\left\{\left(\beta_{1}+\sum_{j}^{4} \beta_{1 j} x_{i c t j}+\beta_{11} x_{1 i c t}\right)^{2}-2 \beta_{11} u_{i c t}\right\}^{.5}\right]}{\beta_{11}} .
$$

The resulting measure can be interpreted as the minimum amount of land required to provide the given level of output, holding all other parts of the technology constant. Applied to our data at hand, a hypothetical elimination of land inefficiency results in the sparing of 360 ha. Put in perspective, this is more than half of the area under cultivation of the whole

\footnotetext{
${ }^{9} \mathrm{~A}$ detailed derivation of this measure is provided in appendix A.2
} 
sample. Yet, the large land inefficiency of smallholder oil palm farmers is not surprising in light of the inherent yield gap compared to larger estates. The finding merely confirms the ubiquitously recognized circumstance that smallholder oil palm farmers fall remarkably short of potential production on ecologically valuable land.

Second, we turn to quantifying the land expansion potential as the aggregated effect from increased technical efficiency on land expansion. Just as in the land sparing case, we conversely simulate a hypothetical elimination of technical inefficiency and calculate the resulting additional area demand of the smallholders. Relying on the estimated coefficient form the second-stage expansion model, we calculate an expansion demand of 139 ha. In perspective, this represents $22 \%$ of the currently cultivated palm oil area of the sampled farmers.

Comparing both land sparing and land expansion potentials, we calculate a rebound effect of 0.39 , implying that more than one third of potentially spared land input could be offset by increased land demand. In other words, each ha of land which is saved from efficiency gains actually translates into 0.61 ha only. In sum, we find a substantial drag of efficiency induced land sparing.

However, the hitherto found effects should be interpreted cautiously. First, the land saving potential derives from a scenario in which other production factors are disregarded and, hence, constitutes a maximum solution which is likely to be different under consideration of inevitable by-effects from other inputs. Second, so far, we do not account for non-linear expansion effects. The reason here is that we cannot adequately correct, for instance, a squared effect of a error-prone variable having at disposal only errors of the linear variable. In contrast, Marchand (2012) find concave effects of technical efficiency in soy bean on land expansion in the Brazilian amazon, however, without correcting for measurement errors. Third, our results should be seen in view of area demand. Between increased land input demand and deforestation, or other means of land appropriation, stands the land market and its institutions.

Hence, with regards to policy our results have two main implications. (i) The yield gap between smallholder producers and large estates is characterized by substantial inefficiency, also with regards to land use. Therefore, outreach and extension programs which target managerial skill could be promising avenues to increase smallholder productivity which, in turn, is likely to show positive impacts on livelihoods. (ii) We join Kubitza et al. (2018b) and Gawith and Hodge (2019) in advocating that such policies must be accompanied by measures to control resulting increased input demand in order to mitigate short-term deforestation, which has ecologically long lasting impacts. Particularly, regulation of land markets and their proper enforcement are inevitable means of halting LUCs. 


\subsection{Summary and conclusion}

While deforestation remains a major local and global concern, commodity booms continue to provide powerful opportunities for rural development and livelihoods. Oil palm production on Sumatra, Indonesia, is a point in case where nearly half of ecologically invaluable forest land has made way for more than 7 million ha of oil palm plantation. One solution to the problem is shifting the oil palm advancement from area expansion to intensification of existing cultivation by means of technological innovation and improvements of production management. However, in light of the elastic demand for palm oil, such measures could in turn accelerate land demand and further fuel deforestation, at least in the short term.

As smallholders cultivate nearly half of Indonesia's oil palm area and provide nearly $34 \%$ of aggregate output, and in addition often subject to informal land regulation, they are key for both halting deforestation as well as continued rural development. While the adverse effects of technological innovation within the land sparing vs. land expansion debate are well researched, the equivalent mechanism for technical efficiency remains empirically opaque. This paper aimed at at placing smallholder oil palm technical efficiency in context of the land sparing vs. land expansion controversy. Our empirical approach contains two stages. First, relying on a random intercept model, we estimate the production frontier of smallholder oil palm producers in Indonesia in a translog specification and determine their technical efficiency. Based on the estimated technology parameters, land specific efficiency can be calculated and we determine the land an overall savings potential. Second, we regress area expansion on past efficiency scores by means of an EIV model to reveal by how much farmers are driven to expand with regards to their own efficiency of production.

Our main results are threefold. First, we find that smallholders are considerably technical and land inefficient. Additionally, land is by far the most decisive factor of production. Therefore, remarkable opportunities for optimizing the sector persist, including sizable savings potentials. Second, we find that past efficiency is correlated with future land expansion. Improvements of managerial skill are likely to into rising demand for land expansion -and in absence of proper land markets and enforcement- to further deforestation. The problem is amplified by overall increasing returns to scale. Third, consolidating the first two results, we find that productivity gains achieved through gains in technical efficiency -for instance by means of extension and outreach- are are partially offset by one third due to rebound effects.

Consequently, scrutinizing the opportunities of closing the smallholder yield gap are convenient means to promote rural development. However, policy-makers should be aware of partial rebound effects that increasing efficiency is only a partially effective measure to combat deforestation. Successful rural development policy, which is also conservationist, flanks the problem through both capacity building in conjunction with implementation of thorough land use policy. 
In general, we suspect that managerial skill in agriculture is a critical junction within the land sparing-land expansion debate. Yet, the policy importance of managerial skill, being the focus of many extension and outreach programs in both developing and developed countries, is not matched by empirical evidence regarding their potential rebound effects particularly in settings in which environmental outcomes are envisaged. Particularly in case demand elasticity conditions are different, much more (less) pronounced rebound effects are likely. 


\section{Chapter Three}

\section{On the palm oil - biodiversity trade-off: Environmental performance of smallholder producers ${ }^{1}$}

Oil palm remains an important source of rural income in South East Asia. At the same time, Indonesia has become a hotspot for large-scale species extinction and a loss of biodiversity in favour of agricultural production. The present study sets out to assess the environmental performance of smallholder oil palm production with respect to biodiversity. Using a panel dataset that combines conventional farm data together with an account of plant diversity, we estimate a restricted hyperbolic environmental distance function. We integrate loss of biodiversity as an undesirable output into the production model which allows explaining shortfalls in environmental performance and the derivation of shadow prices of biodiversity conservation. We find a substantial environmental inefficiency, which is partly explained by both chemical and manual weeding practices, highlighting the potential for improvements in both the environmental and the economic dimension. Moreover, the value for conserving one species of the average biodiversity on a farmers plantation was 340 USD in 2018. Payments for ecosystem services schemes could be a viable policy response to conserve meaningful levels of biodiversity while simultaneously allowing smallholders to increase palm oil output. In general, addressing drivers of environmental performance in PES designs amplifies its effect without reducing production levels.

Keywords: Palm oil, Biodiversity, Environmental performance, Shadow price, Hyperbolic distance function

\footnotetext{
${ }^{1}$ This chapter is under review at Journal of Environmental Economics and Management and co-authored by Fabian Brambach (FB), Mirawati Yanita (MY), Holger Kreft (HK) and Bernhard Brümmer (BB). Bernhard Dalheimer $(\mathrm{BD})$ and $\mathrm{BB}$ conceptualized the research idea. $\mathrm{BD}$ and $\mathrm{BB}$ developed the theoretical framework. BD managed and collected the data with support from FB and MY. BD compiled the biodiversity indicators under guidance of $\mathrm{FB}$ and $\mathrm{HK}$. BD developed the empirical strategy and implemented the econometric modelling. BD and BB interpreted the results. BD wrote the paper with contributions from FB (biodiversity sections). All authors edited the manuscript.

Acknowledgement: This study was funded by the Deutsche Forschungsgemeinschaft (DFG, German Research Foundation) - project number 192626868 - in the framework of the collaborative German-Indonesian research project CRC990. The authors are grateful for valuable comments from Sebastian Lakner who discussed an earlier version of the paper at a doctoral seminar presentation in Göttingen. The authors also thank Oliver-Ken Haase for feedback on an earlier draft.
} 


\subsection{Introduction}

Agriculture is strongly intertwined with the environment and therefore key to the provision and decay of ecosystem services. Biodiversity is a critical link between the two as numerous ecosystem functions rely on the diversity of organisms. For instance, the provision of food, water, medicine, fuels and fiber and air quality are vital ecosystem services that are heavily dependent on intact biodiversity (TEEB, 2012; Hooper et al., 2012). On the other hand, many forms of agricultural production and the related land use change (LUC) have been shown to critically reduce local species diversity (Grass et al., 2020; Clough et al., 2016). Both expansion and intensification of agricultural production are increasingly threatening biodiversity and species existence, which have been declining dramatically around the world (IPBES, 2019; Chaplin-Kramer et al., 2015).

Indonesia has become a hotspot for large-scale species extinction and a loss of biodiversity in favor of agricultural production. At the expense of several ecological crises, the palm oil boom contributes to rising exports and poverty reduction. Increases in income and consumption have been linked to palm oil production (Kubitza et al., 2018a; Qaim et al., 2020), and have been shown to contribute to the remarkably declining rates of poverty and undernourishment in the country (FAOSTAT, 2020). Nonetheless, remedying the trade-offs between economic and environmental objectives is becoming an increasingly important item on both national and intergovernmental policy agendas. More precisely, policy-makers are interested in steering production towards maximized oil palm output over minimized biodiversity loss (IFPRI, 2019; IPBES, 2019). However, only a few policy programs have been implemented in the region to date and even fewer have been successful (Hein, 2019). One obstacle to policy action on a meaningful scale could be the lack of valuation of biodiversity within the palm oil production system and vice versa.

This paper aims to assess the environmental performance of smallholder oil palm producers in Indonesia during the past decade. Smallholder producers are particularly interesting as they contribute to $34 \%$ of national palm oil production (Indonesian Ministry of Agriculture, 2016). In addition, given the relatively low yields of smallholders compared with large estates, the share of the area that they manage is even larger (Euler et al., 2017; Byerlee and Viswanathan, 2018). On the biodiversity side, smallholders provide exceptional opportunities for conservation as their mosaic-type spatial arrangements allow for a highly diverse landscape matrix. (Sayer et al., 2012). Consequently, the negative impacts on biodiversity related to production area are considerable (Grass et al., 2020). If possibilities for mitigating such negative, area-related effects exist, they would hold particular relevance for the smallholder sector. A critical prerequisite for identifying such an option is to gain a better understanding of the trade-off between the environmental effects and economic benefits of palm oil production. In other words, is there potential to improve environmental outcomes without having to 
give up economic benefits for at least some smallholders, or is there an inevitable trade-off in terms of the economic benefit forgone for one additional unit of environmental benefit? Thus, the joint analysis of desirable and undesirable outcomes of the production process enables not only conservation potentials but also detecting win-win scenarios in which production could be increased without an additional loss of biodiversity, or vice versa.

Our work offers several contributions to the existing literature. First, instead of limiting the analysis exclusively to either ecological aspects of the decay of ecosystem services (e.g. Koh and Wilcove, 2008; Savilaakso et al., 2014; Fitzherbert et al., 2008; Vijay et al., 2016; Darras et al., 2019a) or its socioeconomics (e.g. Klasen et al., 2016; Lanz et al., 2018; Sibhatu, 2019; Cacho et al., 2014), we choose an interdisciplinary approach to empirically identify the underlying mechanisms of the trade-off between the two. Second, in contrast to previous work focusing on macro-relationships between biodiversity and palm oil production (e.g. ChaplinKramer et al., 2015; Bateman et al., 2015), we base our analysis on microeconomic data to assess the impacts of managerial skill on the trade-off. Third, we analyze the behavior of smallholder producers of palm oil. The environmental costs of palm oil production are comparably well documented for large estates, whereas little is known about the environmental performance of smallholder oil palm producers (Savilaakso et al., 2014; Robbins et al., 2015). Fourth, we contribute to the debate on the payments for ecosystem services (PES) policy debate and highlight the advantages and challenges related to differently-designed incentive schemes.

We develop a hybrid between hyperbolic and enhanced hyperbolic distance functions (Cuesta et al., 2009) to model the production process of smallholder oil palm farmers in Sumatra, Indonesia, including biodiversity loss as an undesirable environmental output. We use a comprehensive data set on oil palm output, plant biodiversity, conventional production inputs, management practices as well as socioeconomic variables of smallholder oil palm producers to describe the trade-off between oil palm output and biodiversity loss and its underlying mechanisms. Furthermore, the duality of the approach allows us to derive shadow prices and gain insights into the opportunity cost of biodiversity conservation in this production system.

Our results indicate that smallholder oil palm production suffers from environmentally inefficient production. This implies that either substantially higher output could be achieved or - conversely - a higher local plant diversity could be maintained at the present level of input use by eliminating the environmental inefficiency of production. Similarly, overuse in input results in inefficient outcomes in terms of both desirable and undesirable outputs. Furthermore, environmental performance is linked to both manual and chemical weeding practices, as well as the migratory status of the farmer. We calculate the average abatement cost for farmers of raising average biodiversity on their plantation by one more species at 340 USD per year. Finally, simulating several PES scenarios highlights promising policy options 
to reduce the loss of biodiversity while simultaneously increasing smallholder output levels.

The remainder of this paper proceeds as follows. Section 3.2 sets the stage by providing some background on the palm oil boom and problems as well as the study site. Section 3.3 introduces the theory and application of environmental performance measurement based on distance functions and the intuition of biodiversity measurement as well as presenting the data. Section 3.4 details the results from the analysis and places them in context of the relevant literature. In section 3.5, we simulate several incentive-based policy schemes. Finally section 3.6 summarizes and concludes the paper.

\subsection{Palm oil: Boom and crisis in South East Asia}

In 2018, global palm oil production exceeded 70 million ton per year, making it the most important vegetable oil in terms of quantity as well as the tenth largest agricultural crop worldwide. Remarkably, back in 1980 global production levels were only at about 5 million ton and palm oil held only minor relevance in international oil and commodity markets (FAOSTAT, 2020). Being relatively more productive in terms of area and labor, it has emerged as a particularly competitive crop in some agricultural systems around the world. Although the oil palm originates in Africa, the massive expansion of palm oil mainly occurred in tropical Asia and more precisely in Indonesia and Malaysia, which together supply more than $87 \%$ of global palm oil. During the times of exponential growth in oil palm output, a variety of development indicators also sharply improved in the respective areas. For instance, the prevalence of undernourishment in Indonesia more than halved from $18.5 \%$ in 2000 to $8.3 \%$ in 2017 . The poverty headcount ratio of people living off less than $1.90 \$$ per day declined from more than $70 \%$ in the early-1980s to 6\% in 2017 (World Bank, 2020). While the economic development in Indonesia is certainly tied to a multivariate set of drivers, agricultural advancement and oil palm production are a significant part of this equation. Indeed, a number of studies relate increased national palm oil income to improved rural livelihoods, rural poverty and economic development in general (e.g., Sayer et al., 2012; McCarthy et al., 2012; Kubitza et al., 2018a).

Smallholder producers are also part of the economic success of palm oil, and as of 2016 they provide $34 \%$ of palm oil output in Indonesia (Indonesian Ministry of Agriculture, 2016). Besides establishing large governmental plantations, the government proactively promoted smallholder participation in the value chain launching several programs starting in the 1980s. One prominent example is the trasmigrasi program which supported the relocation of some 1.7 million family farmers from the densely populated islands of Java and Bali to less-populated parts of Indonesia, including Sumatra, to cultivate - among other crops - oil palm. The extraordinary large contribution of smallholders is also part of the reason why the economic benefits of oil palm production became manifested in improvements in rural livelihoods. 
However, in the more recent past, smallholder participation has been declining and smallholders are increasingly marginalized within the palm oil supply chain in Indonesia. From an environmental perspective, smallholder producers are still associated with direct forest land appropriation (Krishna et al., 2017b; Kubitza et al., 2018b), and notoriously low yields, which imply less efficient environmental performance, at least regarding land input. Additionally, questionable land rights policy places further pressure on smallholder producers in Indonesia (McCarthy et al., 2012; Kubitza et al., 2018b; Rist et al., 2010b).

Against the background of massive growth of oil palm output and area expansion, the accelerated rates of LUC have led to several ecological crises. Koh and Wilcove (2008) suggest that in Malaysia and Indonesia more than $50 \%$ of the palm oil area was formerly forested land, including rain forests with exceptionally high levels of species diversity and endemism. Oil palm plantations harbour much lower levels of biodiversity than forests and dramatically alter species composition across taxonomic groups (Fitzherbert et al., 2008; Grass et al., 2020). At current rates of deforestation, Sodhi et al. (2004) predicts that $42 \%$ of biodiversity in tropical Southeast Asia could be lost by the end of the century. Similarly, tropical forests play a role in serving as the terrestrial carbon sink, storing $428 \mathrm{Gt}$ of carbon. LUC has led to fundamental changes in the balance and according to the IPCC (2000), LUC in the tropics is the world's second largest green house gas (GHG) emitter, with estimates ranging from $12-20 \%$ of global GHG emissions. Finally, other environmental problems such as wildfire hazes bearing substantial human health threats, severe soil degradation and pressured water imbalances as well as quality have been associated with the expansion of oil palm in South East Asia.

Jambi province on Sumatra Island is a point in case for both the economic palm oil boom as much as the ecological crises development. Oil palm plantations were first introduced by large governmental estates and subsequently also adopted by smallholders during 1980s and 1990s. Smallholder adoption was particularly promoted by the government by means of contract schemes (Gatto et al., 2017) and the trasmigrasi program in the past, although today it usually occurs independently. Between 1990 and 2018, oil palm production and plantation area increased more than tenfold from 45,000 ha to 506,000 ha and 107,000 ton to $1,142,000$ ton of oil palm fruit, respectively. As of 2018, more than 200,000 households are dependent on palm oil production in Jambi province (Kubitza et al., 2018a).

On the environmental side, Jambi has been experiencing severe degradation during the recent decades. For instance, over $80 \%$ of GHG emissions in Jambi result from LUC, deforestation as well as forest and peat land degradation. At the peak of the palm oil boom, an average annual forest loss of 76,522 ha was measured between 2006 and 2009 (Hein, 2019), leading to a severe reduction of biodiversity (Rembold et al., 2017) and threatening the survival of plant and animal species (Linkie et al., 2003; IUCN, 2015).

Besides being exemplary for the oil palm boom in the face of several ecological crises, 
Jambi province is also a meaningful region to study the trade-off between desired and undesired outputs in the light of a long-standing tradition of incentive-based policy programs, in particular regarding biodiversity loss mitigation. Already in 2002 the Rewarding Upland Poor for Environmental Services (RUPES) by the World Agroforestry Centre (ICRAF) aimed to pinpoint key monetary benchmarks to develop incentive-based pro-poor PES in Jambi (Villamor and van Noordwijk, 2011). Since 2010, Jambi is one of Indonesia's National Council on Climate Change (DNPI) model provinces for REDD and green growth. However, environmental policy programs and particularly PES in Jambi have been short lived thus far (Hein, 2019). One crucial reason is certainly the cumbersome economic valuation of the complex dovetail of palm oil production systems - composed of smallholders and large estates - and the manifold ecosystem services in Jambi province. Policy suffers from a lack of value assessment of local ecosystem services to design fruitful incentive schemes. One particularly relevant case is the trade-off between palm oil production and biodiversity.

\subsection{Modeling the oil palm-biodiversity trade-off}

In order to quantify the trade-off between the production of fresh fruit bunches for palm oil and the associated loss of biodiversity, we need (i) an adequate measure of biodiversity, and (ii) a suitable economic model that can subsequently be parameterized with the data at hand. Regarding the latter, we propose a directional distance function in a duality framework considering one desirable output, one undesirable output as well as regular inputs of production. However, the former warrants some more attention as biodiversity is a relatively broad term. Accordingly, in order to quantify a particular environmental-economic relationship, we need to establish comprehensible concepts for both. In this section, we focus on the derivation of the hyperbolic distance function approach to investigate the interdependence between environmental degradation and economic output, while our measure of choice for biodiversity is described in a dedicated part of the data section. Finally, we outline our data at hand and the empirical specification.

\subsubsection{Hyperbolic distance functions}

Microeconomic production theory provides various ways of measuring firm performance, starting by evaluating the production of output from usage of inputs building up on the seminal works of Aigner et al. (1977) and Meeusen and van Den Broeck (1977). Production functions help to assess the overall performance and efficiency of firms relying on either stochastic or deterministic techniques. Expanding the framework to settings in which firms produce multiple outputs, output distance and input distance functions have been introduced by Shephard (1970). Subsequently, output distance functions have become the workhorse for 


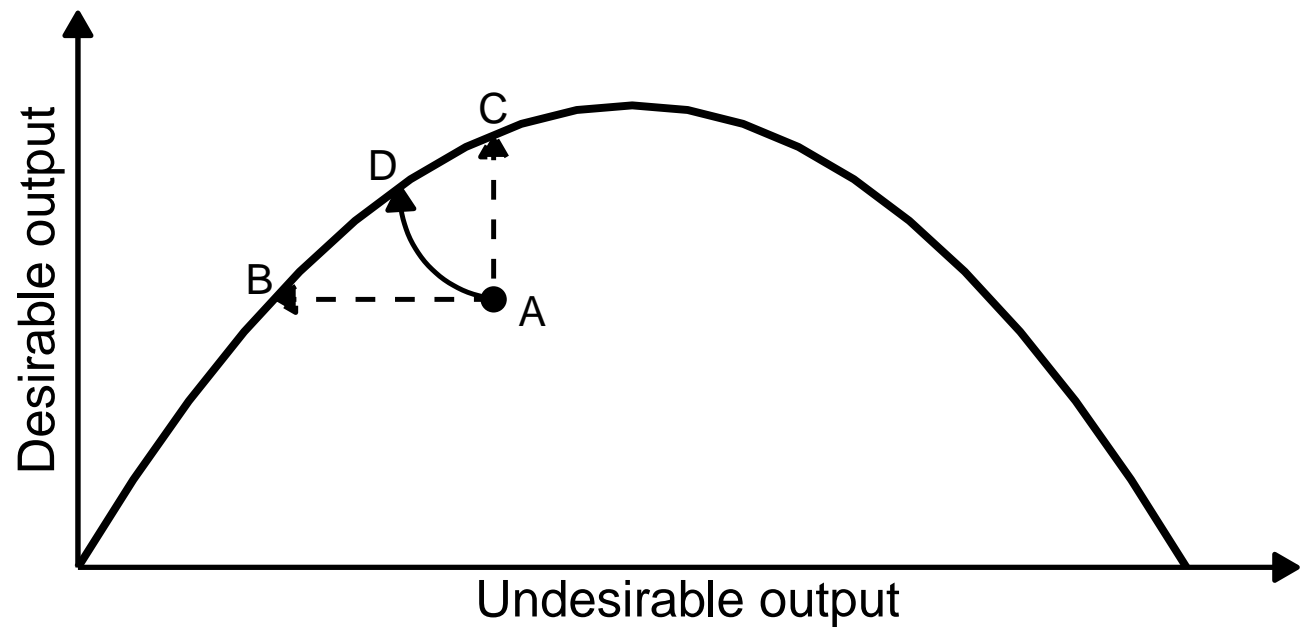

Figure 3.1 Hyperbolic efficiency and directional distances

evaluating multiple desirable output scenarios (Chambers et al., 1998; Brümmer et al., 2002, 2006), as well as the trade-off between desirable and undesirable outputs (e.g. Coggins and Swinton, 1996; Chung et al., 1997; Färe et al., 2007; Hoang and Coelli, 2011; Huang et al., 2016; Dakpo et al., 2016; Tothmihaly et al., 2019).

More recently, Cuesta and Zofío (2005) have developed parametric and non-parametric estimation approaches for the hyperbolic distance model in a multiple output setting. Cuesta et al. (2009) extend the model to accommodate desirable and undesirable outputs and consequently the expansion of one output and contemporaneous contraction of another. This method has been used to address various environmental performance problems of production processes (Skevas et al., 2018; Mamardashvili et al., 2016; Adenuga et al., 2019). One of the advantages of the hyperbolic distance function - as opposed to directional distance functions - is that the movement of inefficient units towards the frontier is not driven by an arbitrarily-chosen directional vector; instead, it follows a hyperbolic trajectory based on equiproportionate increases in desirable outputs and decreases in undesirable outputs as well as inputs. Therefore, no preference towards either increases in desirable output or decreases in undesirable output or any distinct weights is required to estimate the efficiency of the unit. Figure 3.1 presents an illustrative example of the hyperbolic efficiency adapted from Skevas et al. (2018). Let us assume that a unit produces at point $A$ and therefore is inefficient since it falls short of the frontier. A directional distance measure directs the farmer on either $A C$, $A B$ or any linear vector in between the two. The hyperbolic measure eliminates inefficiency taking the unit to point $D$.

In essence, hyperbolic distance functions model the entire production process, including potential trade-offs among inputs, between inputs and outputs as well as among outputs. Extending this framework to the presence of environmental outputs also enables modeling negative externalities of production, which have been labeled as environmental distance functions. Assuming that a firm produces a set of desirable outputs $\mathbf{y}=\left(y_{1}, y_{2}, \ldots, y_{n}\right)$ and 
$\mathbf{b}=\left(b_{1}, b_{2}, \ldots, b_{n}\right)$ undesirable outputs using inputs $\mathbf{x}=\left(x_{1}, x_{2}, \ldots, x_{n}\right)$, the value of the distance function is equal to the maximum possible proportional expansion in desirable outputs $\mathbf{y}$ and the proportional reduction of the undesirable outputs $\mathbf{b}$ that is simultaneously feasible, at the given input level. The frontier spanned by the observations for which no further expansion (reduction) is feasible constitutes an implicit function of the trade-off between economic output and the undesirable environmental output. Following Cuesta et al. (2009) we define the hyperbolic distance function as

$$
D_{H}(\mathbf{x}, \mathbf{y}, \mathbf{b})=\min \left\{\theta:\left(\mathbf{x}, \frac{\mathbf{y}}{\theta}, \mathbf{b} \theta\right) \in P(\mathbf{x})\right\}
$$

where $P(\mathbf{x})$ represents the production possibility set, i.e., the feasible quantities of $\mathbf{y}$ and $\mathbf{b}$ that can be produced from the available input vector $\mathbf{x}$.

For $D_{H}(\mathbf{x}, \mathbf{y}, \mathbf{b})=1$, the farmer is fully efficient in the sense that no reduction of undesirable output or an increase of desirable output is possible at the given level of inputs, which also renders the distance value as a measure of environmentally-adjusted technical efficiency. In contrast to conventional measures of technical efficiency, the hyperbolic efficiency measure takes into account the negative environmental outputs of the production process and consequently it may be considered as a measure of environmental performance of the producing unit.

Further, in order to also allow for adjustments in input use, the enhanced hyperbolic distance function additionally accommodates potential reductions of inputs, and therefore it provides an even more flexible framework:

$$
D_{E}(\mathbf{x}, \mathbf{y}, \mathbf{b})=\min \left\{\theta:\left(\mathbf{x} \theta, \frac{\mathbf{y}}{\theta}, \mathbf{b} \theta\right) \in T\right\}
$$

where $T$ represents the technology set of all combinations of $\mathbf{y}, \mathbf{b}$, and $\mathbf{x}$ that are technologically feasible.

The hyperbolic distance function has properties of (i) almost homogeneity ${ }^{2}$, and (ii) monotonicity, in particular non-decreasing in desirable outputs ${ }^{3}$, and non-increasing in undesirable outputs $^{4}$, and non-increasing in inputs ${ }^{5}$ (Cuesta et al., 2009). The enhanced hyperbolic distance function also allows a simultaneous contraction of inputs in addition to the asymmetric behavior of desirable and undesirable outputs, such that the almost homogeneous property is also extended to the inputs ${ }^{6}$. Additionally, both functions exhibit (iii) concavity: more precisely they are quasi-concave in desirable outputs for all undesirable outputs and inputs. In the enhanced hyperbolic case, this also applies for inputs, while the hyperbolic distance

\footnotetext{
${ }^{2} D_{H}\left(\mathbf{x}, \mu \mathbf{y}, \mu^{-1} \mathbf{b}\right)=\mu D_{H}(\mathbf{x}, \mathbf{y}, \mathbf{b})$, for $\mu>0$

${ }^{3} D_{H}(x, \lambda \mathbf{y}, \mathbf{x}) \leq D_{H}(\mathbf{x}, \mathbf{y}, \mathbf{b}), \lambda \in[0,1]$

${ }^{4} D_{H}(\mathbf{x}, \mathbf{y}, \lambda \mathbf{b}) \leq D_{H}(\mathbf{x}, \mathbf{y}, \mathbf{b}), \lambda \geq 1$

${ }^{5} D_{H}(\lambda \mathbf{x}, \mathbf{y}, \mathbf{b}) \leq D_{H}(\mathbf{x}, \mathbf{y}, \mathbf{b}), \lambda \geq 1$

${ }^{6} D_{H}\left(\mu^{-1} \mathbf{x}, \mu \mathbf{y}, \mu^{-1} \mathbf{b}\right)=\mu D_{H}(\mathbf{x}, \mathbf{y}, \mathbf{b})$ for $\mu>0$
} 
function is concave in inputs for all desired and undesired outputs.

However, the framework of the hyperbolic - and its more flexible version, the enhanced hyperbolic distance - function either do not allow for input contraction or they do so for all inputs. In smallholder production systems, only some of the inputs are flexible while others are not adjusted swiftly such that both hyperbolic and enhanced hyperbolic distance are too restrictive. To overcome this problem, we propose a hybrid of both functions in which fixed inputs are distinguished from flexible inputs. Practically, this implies multiplying only flexible inputs by $\theta$ and not others. Thus, our restricted enhanced hyperbolic distance function becomes

$$
D_{R}(\overline{\mathbf{x}}, \mathbf{x}, \mathbf{y}, \mathbf{b})=\min \left\{\theta:\left(\overline{\mathbf{x}}, \mathbf{x} \theta, \frac{\mathbf{y}}{\theta}, \mathbf{b} \theta\right) \in T\right\},
$$

where $\overline{\mathbf{x}}$ now designates inputs that are fixed in the short term and $\mathbf{x}$ inputs that are variable. Based on the almost homogeneity property, we obtain an estimable form of the function by setting $\theta=\frac{1}{y_{m}}$, which is the inverse of the $\mathrm{m}^{\text {th }}$ output. $y_{m}$ is the normalizing output of the distance function ${ }^{7}$, which subsequently can be expressed as

$$
D_{R}\left(\bar{x}_{i}, b_{i} x_{i}, \frac{y_{i}}{y_{m}}, b_{i} y_{m}\right)=\frac{1}{y_{m}} D_{R}\left(\bar{x}_{i}, x_{i}, y_{i}, b_{i}\right)
$$

and in logarithmized form

$$
\ln D_{R}\left(\bar{x}_{i}, x_{i}, y_{i}, b_{i}\right)=\ln D_{R}\left(\bar{x}_{i}, b_{i} x_{i}, \frac{y_{i}}{y_{m}}, b_{i} y_{m}\right)+\ln y_{m}
$$

Assigning that $u_{i}$ is the the logarithmized distance function value, we can take equation 3.5 into the form of a stochastic production frontier by isolating $\mathbf{y}_{m}$ and adding the error term $v_{i}$ to capture statistical noise:

$$
-\ln y_{m}=\ln D_{R}\left(\bar{x}_{i}, x_{i}, \frac{y_{i}}{y_{m}}, b_{i} y_{m}\right)-u_{i}+v_{i},
$$

which we can estimate by means of maximum likelihood (ML). The procedure is equivalent to obtaining estimable forms of the regular hyperbolic and the enhanced hyperbolic distance function (equations 3.1 and 3.2).

\subsubsection{Shadow price}

The duality of the distance function allows deriving shadow prices, i.e., expressing one output, either desirable or undesirable, in units of another output. If price data for the base output are available, shadow prices are widely used to assign a price to unit changes in outputs, which are difficult to quantify endogenously. Shadow prices are a means to understand the

\footnotetext{
${ }^{7}$ Note that $\theta$ can also be set equal to any of the undesirable outputs, see e.g. Huang et al. (2016)
} 
cost at which a producer can contract a unit of undesirable output (Färe et al., 2002; Cuesta et al., 2009; Mamardashvili et al., 2016; Adenuga et al., 2019) and thereby they represent a measure of abatement costs. Assuming that a smallholder farmer aims to maximize profits, she faces the following problem:

$$
\Pi\left(x, p_{y}, p_{b}\right)=\max _{y, b}\left\{\frac{p_{g}}{p_{b}}: D_{R}(\overline{\mathbf{x}}, \mathbf{x}, \mathbf{y}, \mathbf{b}) \leq 1\right\} .
$$

The corresponding first order conditions for the desirable and the undesirable output are:

$$
\frac{p_{g}}{p_{b}}=\lambda\left(\frac{\partial D_{R}}{\partial y}\right) y=\lambda\left(\frac{\partial \ln D_{R}}{\partial \ln y}\right) D_{H}
$$

and

$$
\frac{p_{g}}{p_{b}}=\lambda\left(\frac{\partial D_{R}}{\partial y}\right) b=-\lambda\left(\frac{\partial \ln D_{R}}{\partial \ln b}\right) D_{R}
$$

respectively. Hence, the price ratio is:

$$
-\frac{\frac{\partial D_{H}}{\partial b}}{\frac{\partial D_{H}}{\partial y_{m}}} p_{m}=p_{m} \frac{d y_{m}}{d b},
$$

which we can solve for the unknown price of the undesirable output. Note that the shadow price formulation always refers to performance at the frontier, which implies no inefficiency in production $\left(D_{R}=1\right)$.

\subsubsection{Measuring biodiversity}

Having established a suitable economic model to quantify the trade-off between conventional outputs under consideration of conventional inputs, we require an equally suitable measure of biodiversity. In the context of this study, biodiversity refers to species diversity. While there are often taxon-specific responses to LUC, plants have been shown to be reliable proxies of overall species diversity in our study region (Clough et al., 2016). Therefore, we focus on plants exclusively because they are ecologically highly relevant as well as relatively easy to record. Plants provide both habitat and energy (e.g. in the form of food) for other organisms like animals and fungi, and they can thus be considered as the foundation of terrestrial biological communities. Consequently, plant diversity is closely coupled with that of various animal groups, thus making it a proper proxy for overall diversity (e.g. Barnes et al., 2017; Potapov et al., 2019).

In addition, diversity is highly scale-dependent (Chase et al., 2018) and distinguished into (i), $\alpha$-diversity, the diversity at a given site with presumed homogeneous environmental conditions; (ii) $\gamma$-diversity, the diversity of a region; and (iii) $\beta$-diversity, which describes the differences in species composition between sites in a region (Jost, 2007). To relate biodiver- 
sity to farmers' management practices, focusing on the $\alpha$-diversity at the plantation level is the most adequate spatial scale, since management practices presumably vary between farmers. As recording all plant species and individuals of a plantation is eminently timeconsuming, sampling plots of appropriate sizes is preferable under the assumption that they are representative of the whole plantation (Newbold et al., 2015).

Besides the matters of organism groups and scale considerations, choosing an appropriate measure is a further critical pillar of reliably quantifying biodiversity. One widely-used measure of $\alpha$ diversity is species richness $(S R)$ which constitutes the mere count of species. A notorious problem of $S R$ is that it assigns equal weight to all species regardless of their abundance in the community. By ignoring relative abundance, the measure weighs rare species disproportionately heavier. In order to correct for the bias towards presence and against abundance, the measure of the effective number of species (ENS) is commonly employed. The ENS states the number of species in a hypothetical community with all species being equally abundant and the same Shannon entropy ${ }^{8}$ as a given sample and thus it favours neither rare nor common species (Jost, 2007; Chao et al., 2014). More precisely, the ENS is the exponential of Shannon entropy, i.e. $E N S=\exp \left(-\sum\left(\ln p_{i} \times p_{i}\right)\right)$, with $\ln p_{i} \times p_{i}=0$ for $p_{i}=0$, given the relative abundance $p$ of a species $i$. Both $S R$ and $E N S$ can be considered versions of Hill-numbers (Hill, 1973) or measures of diversity of different orders $q$. Such diversity of order zero $(q=0, S R)$ is insensitive to species frequencies, that of order one $(q=1, E N S)$ weighs rare and common species equally and higher-order measures of diversity ( $q>1$, e.g. Simpson diversity) are biased towards common species (Jost, 2007).

Generally, the lower the order of diversity, the more sensitive to undersampling are measures such that the real $S R$ is difficult to assess with a reasonable amount of time and resources. Especially in diverse ecosystems like tropical forests, many species are extremely rare (Magurran and Henderson, 2003) and therefore they are likely to be missed in a given sampling plot. Consequently, the observed number of species in a plot will be a biased underestimate and highly sensitive to the number of individuals surveyed. Higher-order diversity measures, like Simpson diversity $(q=2)$ are more robust to undersampling because they mostly rely on common species. Their downside is the lower sensitivity to differences in diversity between samples (Figure B.1 in appendix B.1). ENS provides a good compromise between susceptibility to undersampling and sensitivity to differences between samples. Techniques of rarefaction and extrapolation that produce species accumulation curves serve to standardize measures of diversity by estimating them for a given number of individuals, which is a prerequisite for comparing the diversity of two or more communities (Chao et al., 2014).

${ }^{8}$ The Shannon entropy is a widely used diversity index that considers the relative abundances of all species. 


\subsubsection{Data}

Just as much as the methods employed in this study, the data also cover two main components. The first part emerges from a representative extensive socioeconomic farm survey conducted in 2012 for the first time and repeated in 2015 and 2018. The panel covers all conventional input and output data required to accurately model palm oil production as well as socioeconomic variables that may help to explain managerial performance. The dataset has been applied in other empirical works (e.g. Kubitza et al., 2018b; Euler et al., 2017; Kubitza et al., 2018a; Krishna et al., 2017b; Clough et al., 2016)

Table 3.1 lists the variables used in the analysis and the respective units of measurement, variable designations in the empirical part of the paper as well as key summary statistics. Production of fresh fruit bunches serves as the desirable output $(y)$ while the inverse of the effective number of species ENS is the measure of the undesirable output (b). The inputs for production are selected to represent conventional agricultural production functions, i.e. area of production, labor and use of agrochemicals which constitutes the sum of herbicides, pesticides and fertilizer. Additionally, the age of the plantation is crucial to oil palm production since the yield of the perennial crop has a nonlinear relationship with time. Oil palms start only producing fruit bunches 3 years after plantation. Peak yields vary across regions and can start as early as seven or as late as sixteen years. Usually, at the age of 24 oil palms exhibit declining yields and after 30 years they reach zero production levels Corley and Tinker (2008). In addition to the economic production variables, a range of socioeconomic variables such as age, education and household size are available for specifying the restricted hyperbolic distance function.

Table 3.1 Variable overview and summary statistics

\begin{tabular}{|c|c|c|c|c|c|c|c|c|}
\hline Variable & Unit & Variable & Mean & St. Dev. & Min & $\operatorname{Pctl}(25)$ & $\operatorname{Pctl}(75)$ & Max \\
\hline \multicolumn{9}{|l|}{ Desirable output } \\
\hline Production & $\mathrm{kg}$ & $y$ & 33,744 & 30,896 & 38 & 15,800 & 42,200 & 204,000 \\
\hline \multicolumn{9}{|l|}{ Undesirable output } \\
\hline Biodiversity loss & $E N S_{e s t}$ & $b$ & 5.009 & 2.327 & 1.331 & 3.244 & 6.498 & 15.132 \\
\hline \multicolumn{9}{|l|}{ Technology } \\
\hline Size & ha & $x_{1}$ & 2.17 & 1.78 & 0 & 1.5 & 2 & 12 \\
\hline Labour & man hours & $x_{2}$ & 2,629 & 3,068 & 9 & 1,369 & 2,893 & 31,008 \\
\hline Palm age & years & $x_{3}$ & 16.02 & 7.46 & 3 & 10 & 22 & 30 \\
\hline Agrochemicals & $\mathrm{kg}$ & $x_{4}$ & 7689 & 988 & 0 & 10 & $1,222.5$ & 6,000 \\
\hline Yield & $\mathrm{kg} \mathrm{ha} \mathrm{a}^{-1}$ & - & 15,738 & 7,626 & 152 & 10,658 & 20,000 & 37,860 \\
\hline \multicolumn{9}{|l|}{ Inefficiency } \\
\hline Age & years & $z_{1}$ & 48.07 & 11.33 & 25 & 40 & 55 & 79 \\
\hline Education & years & $z_{2}$ & 7.82 & 4.09 & 0 & 6 & 12 & 17 \\
\hline HHSize & people & $z_{3}$ & 4.789 & 1.564 & 2 & 4 & 6 & 11 \\
\hline Transmigrant & binary & $z_{4}$ & 0.42 & 0.50 & 0 & 0 & 1 & 1 \\
\hline Chemical weeding & binary & $z_{5}$ & 0.73 & 0.44 & 0 & 0 & 1 & 1 \\
\hline Manual weeding & binary & $z_{6}$ & 0.31 & 0.46 & 0 & 0 & 1 & 1 \\
\hline Land title & binary & $z_{7}$ & 0.69 & 0.46 & 0 & 0 & 1 & 1 \\
\hline
\end{tabular}


Variables on the migratory status of farmers have also been collected. They are particularly interesting as the government of Indonesia has been operating the trasmigrasi program which promoted and assisted in the reallocation of people from Java to Sumatra to cultivate oil palm. The program also offered training related to oil palm production which makes the migration variables particularly interesting to model the determinants of (in)efficiency of production. In our dataset, a dummy variable captures whether the family of the farmer itself migrated to cultivate oil palm in the past.

Regarding management practices variables on whether a farmer used chemical weeding or manual weeding are available. Weeding practices on the plot have crucial impacts on both the growth of the palms and their respective output as well as the plant biodiversity on the plot. The variable on land titles captures whether the farmer is in possession of any kind of governmental ownership certificate for his plot $^{9}$.

To record the $\alpha$-diversity of vascular plants in the understorey (including ferns, lycophytes, and seed plants), we established a square vegetation plot of $25 \mathrm{~m}^{2}$ in each plantation. Within each plot, we assigned all plant individuals to morphospecies and counted the number of individuals per morphospecies. Each morphospecies was photographed for later species identification. Using the iNEXT-package in R (Hsieh et al., 2016), we calculated the observed per-plot species richness $\left(S R_{o b s}\right)$ and effective number of species $\left(E N S_{o b s}\right)$ (Jost, 2006). Since the number of individuals widely varied between plots with a minimum of 3 , a median of 364 and a maximum of 6616 , we standardized the diversity measures using the rarefaction/extrapolation procedure of Chao et al. (2014) which is implemented in Hsieh et al. (2016) with the median number of individuals $(n=364)$ as the base sample size. The plot-wise rarefaction/extrapolation curves indicated that some individual-poor plots did not adequately represent local $S R$ while sampling coverage was sufficient for $E N S$. We therefore used the estimated effective number of species per 364 individuals $\left(E N S_{\text {est }}\right)$ as our primary measure of biodiversity, although we also ran our model separately with the estimated species richness per 364 individuals $\left(S R_{e s t}\right)$ for comparison and robustness checks (Appendix B.3).

\subsubsection{Empirical specification}

In our distance function framework, we propose combining features of the hyperbolic as well as the enhanced hyperbolic distance function to model fresh fruit bunches of a plot in $\mathrm{kg}$ as the desirable output $\left(y_{i}\right)$ and biodiversity loss on the same plot, measured as the inverse of the $E N S$, as the undesirable output $\left(b_{i}\right)$. The input variables are the size of the plot $x_{1}$, $x_{2}$ is labor, $x_{3}$ agrochemicals as well as $x_{4}$ the age of the plantation. While the size and age of palms are indubitably fixed inputs, we further argue that labor is also fixed as farms

\footnotetext{
${ }^{9}$ Please refer to Kubitza et al. (2018b) for a detailed overview of land ownership structure and certification in Jambi.
} 
almost exclusively employ family labor and agrochemicals remain as the variable input ${ }^{10}$. We make use of the translog functional form which offers more flexibility as opposed to CobbDouglas or quadratic production functions ${ }^{11}$. We employ stochastic frontier analysis (SFA) to estimate the restricted hyperbolic distance function $\left(D_{R}\right)$ by means of ML. The final translog restricted hyperbolic distance function specification is:

$$
\begin{array}{r}
-\ln y_{i}=\alpha_{0}+\sum_{k=1}^{3} \alpha_{k} \ln \left(x_{k i}\right)+\alpha_{4} \ln \left(x_{4 i}^{*}\right)+\beta_{1} \ln \left(b_{i}^{*}\right)+\sum_{k=1}^{3} \beta_{1 k} \ln \left(b_{i}^{*}\right) \ln \left(x_{i}\right) \\
+\beta_{14} \ln \left(b_{i}^{*}\right) \ln \left(x_{4 i}^{*}\right)+\frac{1}{2} \sum_{k=1}^{3} \sum_{l=1}^{3} \alpha_{k l} \ln \left(x_{k i}\right) \ln \left(x_{l i}\right)+\frac{1}{2} \sum_{k=1}^{3} \alpha_{k 4} \ln \left(x_{k}^{*}\right) \ln \left(x_{4}\right)+ \\
+\frac{1}{2} \alpha_{44} \ln \left(x_{i}\right)^{2}+\frac{1}{2} \beta_{11} \ln \left(b_{i}^{*}\right)^{2}+\rho_{0} t_{i}+u_{i}+v_{i}
\end{array}
$$

where $b_{i}^{*}=y_{i} * b_{i}$ and $x_{i}^{*}=\frac{x_{i}}{y_{i}}$. In order to circumvent potential convergence problems we scale all variables by dividing them by their mean so that we evaluate elasticities at sample means. To additionally account for technical change over time, we also include the time trend $t_{i}$. Other panel data specifications are unfeasible to implement parametrically due to the limited number of observations. $v_{i}$ is a normally-distributed component of the twocomponent error term and captures statistical noise. The other component represents the distance function value, or in other words, the inefficiency of production, also accounting for loss of plant biodiversity. We assume heteroskedasticity of $u_{i}$ and consequently model it using the farmer, migratory and management practices characteristics captured in $z_{i}$. Therefore:

$$
\sigma_{u, i}^{2}=\exp \left(\tau^{\prime} \mathbf{z}_{i}\right)
$$

We estimate the entire stochastic frontier with heteroskedastic inefficiency by means of ML techniques. The parameters to be estimated are $\alpha, \beta, \rho$ and $\tau$.

\subsection{Results}

Our empirical model delivers several layers of results ${ }^{12}$. First we evaluate the production function part of the estimated equation and discuss its insights. Second, we turn to the coefficients of the inefficiency component model of the error and derive marginal effects as well their implications regarding smallholder environmental performance. Third, we calculate

\footnotetext{
${ }^{10}$ As robust checks, we also derive the empirical specification and estimate the corresponding enhanced hyperbolic and hyperbolic distance functions where all inputs are treated equally. We also calculate further resulting measures thereof in appendix B.2.

${ }^{11}$ The translog specification is tested to be superior to the Cobb-Douglas specification using conventional tests for nested models.

${ }^{12}$ The distance functions are estimated in $\mathbf{R}$ ( $\mathrm{R}$ Core Team, 2017) using the npsf package (Badunenko et al., 2019)
} 
the cost of abatement by means of shadow price calculation from our dual framework.

\subsubsection{Production technology}

Table 3.2 exhibits the ML estimates of the first order terms and the determinants of inefficiency as well as the associated standard errors of the restricted hyperbolic distance function $^{13}$. The coefficients capture the effect of the individual variables on the distance function value. Loss of biodiversity as well as increases in inputs augment the distance value which is reflected in the negative signs of the respective coefficients and compare well with results of other works on smallholder oil palm production concerning both biodiversity trade-off (Grass et al., 2020) and input use (Soliman et al., 2016). The effect of labor is not statistically significant, while the direction as well as magnitude are reasonable in light of the notoriously low labor intensity of oil palm production (Kubitza et al., 2018a).

Unsurprisingly the first-order coefficient of the age of trees is significant and explains a large chunk of desired output. Additionally the coefficient of the time trend $\rho$ suggests that environmental technology progressed by $8 \%$ between periods, i.e. over three years. The negative and significant $\beta_{1}$ and - in the case of the hyperbolic distance function - positive and significant $\beta_{11}$ reflect an inverse- $U$ relationship between palm output and biodiversity loss. Accordingly, we observe both farmers with low as well as farmers with high levels of biodiversity loss at equivalent levels of output of oil palm fruits. In between farmers with such output structures, we also observe a wide range of farmers exhibiting either higher levels of output, lower levels of biodiversity loss or both. Regarding the environmental production function this implies the existence of a maximum. As oil palm production increases, biodiversity is lost until a point where in turn, high levels of biodiversity loss are likely to negatively influence production.

\footnotetext{
${ }^{13} \mathrm{~A}$ table detailing the full list of parameters is listed in Table B.1 of appendix B.2
} 
Table 3.2 First order terms and parameter estimates of the determinants of inefficiency of the restricted hyperbolic distance function

\begin{tabular}{lc}
\hline & $D_{R}(x, y, b)$ \\
\hline Technology & \\
$\alpha_{0}$ (Intercept) & $-0.48(0.08)^{* * *}$ \\
$\alpha_{1}$ (Size) & $-0.37(0.08)^{* * *}$ \\
$\alpha_{2}$ (Labor) & $-0.06(0.06)$ \\
$\alpha_{3}$ (Age of Palms) & $-0.26(0.08)^{* * *}$ \\
$\alpha_{4}$ (Agrochemicals) & $-0.06(0.02)^{* * *}$ \\
$\beta_{1}$ (Biodiversity loss) & $-0.42(0.04)^{* * *}$ \\
Inefficiency & \\
$\tau_{0}$ (Intercept) & $1.24(2.36)$ \\
$\tau_{1}$ (Age) & $-0.29(0.12)^{* *}$ \\
$\tau_{2}$ (Age $\left.{ }^{2}\right)$ & $0.00(0.00)^{* *}$ \\
$\tau_{3}$ (Education) & $-0.03(0.43)$ \\
$\tau_{4}$ (Education $\left.{ }^{2}\right)$ & $0.03(0.08)$ \\
$\tau_{5}$ (HH size) & $0.31(0.15)^{* *}$ \\
$\tau_{6}$ (Transmigrant) & $1.17(0.48)^{* *}$ \\
$\tau_{7}$ (Chemical weeding) & $0.50(0.46)$ \\
$\tau_{8}$ (Manual weeding) & $1.09(0.39)^{* * *}$ \\
$\tau_{10}$ (Land title) & $0.98(0.55)^{*}$ \\
\hline
\end{tabular}

${ }^{* * *} p<0.01,{ }^{* *} p<0.05,{ }^{*} p<0.1$

\subsubsection{Inefficiency}

Figure 3.2 depicts the distribution of hyperbolic efficiency scores across the sample. The mean efficiency of production under consideration of loss of biodiversity - or alternatively, the environmental performance regarding loss of biodiversity - is 0.78 , implying that farm managers could expand output by $28.22 \%$ (1/0.78) or contract biodiversity loss by $22.01 \%$ $(1-0.28)$ at the same (or lower) level of (agrochemical) input use, on average, respectively.

While the bottom end of table 3.2 lists the parameter estimates $(\rho)$ of the drivers of inefficiency, table 3.3 exhibits the corresponding marginal effects. We find that the age of the household head of the farm is positively associated with environmental performance. The switched sign of the squared term additionally indicates that decreasing returns also exist in this relationship, although, the magnitude of this effect is rather small. Regarding 


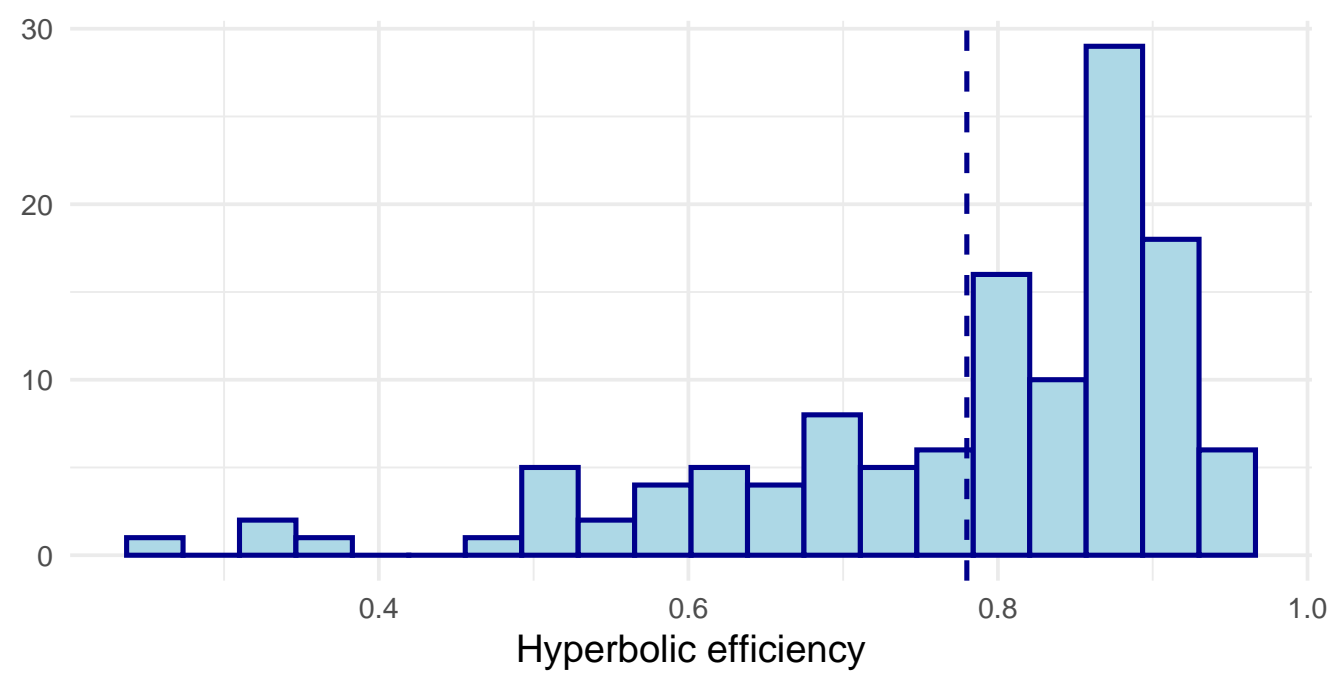

Figure 3.2 Histograms of hyperbolic efficiency scores

Table 3.3 Marginal effects of determinants of inefficiency

\begin{tabular}{lrrrr}
\hline & Mean & St. Dev. & Min & Max \\
\hline Age & -0.041 & 0.018 & -0.099 & -0.011 \\
Education & -0.004 & 0.002 & -0.009 & -0.001 \\
Household Size & 0.043 & 0.019 & 0.012 & 0.105 \\
Transmigrant & 0.164 & 0.072 & 0.045 & 0.399 \\
Chemical weeding & 0.070 & 0.031 & 0.019 & 0.171 \\
Manual weeding & 0.153 & 0.068 & 0.042 & 0.373 \\
Land title & 0.138 & 0.061 & 0.038 & 0.335 \\
\hline
\end{tabular}

management practices, we find large inefficiency increasing effects from chemical and manual weeding practices as well as whether the family of the farm has participated in the trasmigrasi program at some point in the past. The latter two are also statistically significant at the $5 \%$ levels in both models. Weeding - whether manual or chemical - targets the elimination of species on the plot and therefore reduces the performance of the production with respect to biodiversity. While other authors find that producers who had been associated with the trasmigrasi program are more productive and economically better off (Gatto et al., 2017), evidence from our model suggests that their environmental performance is worse than that of autochthonous producers. A likely explanation is found in the higher agrochemical input use of transmigrant farmers, as well as the intensified production of farmers with land titles (Kubitza et al., 2018b). Both practices disproportionally inflict stronger effects on biodiversity, albeit increasing oil palm fruit output on average.

\subsubsection{Shadow prices}

In order to derive shadow prices expressing the abatement cost of the unmarketed output, we require real market prices to solve the equation. The survey data reveals the average prices 
Table 3.4 Shadow prices in constant USD (2015)

\begin{tabular}{rrrrrrrr}
\hline & \multicolumn{3}{c}{ per farm } & & \multicolumn{3}{c}{ per ha } \\
\cline { 2 - 3 } \cline { 7 - 8 } & Mean & Median & St. Dev. & & Mean & Median & St. Dev. \\
\hline 2018 & 340 & 341 & 227 & & 173 & 173 & 71 \\
2015 & 372 & 373 & 248 & & 189 & 190 & 78 \\
2012 & 395 & 396 & 264 & & 201 & 201 & 83 \\
\hline
\end{tabular}

per $\mathrm{kg}$ of oil palm fresh fruit bunch obtained by the sampled farmers are 890, 1, 010 and 1, 023 Indonesian Rupiah (IDR) for 2012, 2015 and 2018, respectively. We deflate the Indonesian consumer price index retrieved from the Federal Reserve Bank of St. Louis (2020) and apply a constant exchange rate ${ }^{14}$. Making use of the duality of the distance function, we calculate shadow prices for biodiversity loss which are presented on the left-hand side of table 3.4. The values indicate how much revenue would be forgone if one more species was conserved on the plot. Shadow prices reflect the dynamics on the frontier, namely in the absence of inefficiency. The shadow price of an inefficient producer would be zero since biodiversity can be increased without reducing outputs or - at least for agrochemicals - input use. The right hand side illustrates individual shadow prices divided by the respective plot size and thus it provides a measure on both a per species and per ha basis.

The interpretation of shadow prices is subject to some limitations. First of all, variation of the shadow prices is quite substantial, confirming the results of Bateman et al. (2015) who find susbtantial idiosyncrasy in oil palm smallholders' capacities to conserve biodiversity. In our sample, the value for conserving one species on a farmers plantation is 340 USD in 2018 on average. However, at the high end of the distribution, farmers exceed shadow values of 1,400 USD, although it is important to note that the price level refers to the plantation that the farmer is operating. Therefore, the stark variability of shadow prices may also be partly attributed to scale effects. Larger farmers naturally suffer more output when conserving the same average number of species compared with smaller farmers. In other words, the abatement costs per unit of detrimental output become more expensive as producers expand and become larger. This is particularly important when designing potential financial incentive schemes to increase environmental conservation in smallholder palm oil production systems. Second, since we measure biodiversity on agricultural production sites our trade-off measure entails only the lower part of biodiversity. The potential relationship between oil palm production and biodiversity beyond sample values is unknown and most likely non-linear. Third, our sample also contains cases of negative shadow prices, which imply that farmers operate under a technology regime where they produce little oil palm fruit at high biodiversity loss. In these cases, reducing biodiversity loss comes at no cost but instead increased oil palm output and higher income.

\footnotetext{
$14 \frac{U S D}{I D R}=0.00007$
} 
To put the average shadow price in perspective, in 2018 the average farm income of smallholders in Jambi province was 2,179 USD per year. Thus, for an average farmer, the abatement cost for raising average biodiversity by one species on the whole plantation area amounts to almost $16 \%$ of the average annual farm palm oil income. In turn, the cost of eliminating biodiversity shortfalls - namely augmenting the biodiversity of all farmers to the level of the best practitioner (15.1 ENS) - would inflict costs of 443,437 USD.

\subsection{Payments for ecosystem services (PES) simulation}

As shadow prices reveal the opportunity cost of producing less marketable output and instead diminish unmarketable output, shadow prices are key to designing respective conservationist policy. Although shadow prices only reflect the private marginal benefit while the social marginal benefit from conserving biodiversity remains unknown - albeit larger than the private one - they still allow us to derive supply functions for the biodiversity provision of smallholder producers.

PES are a popular policy instrument and they are frequently implemented to preserve ecosystem services (Bulte et al., 2008; Jack et al., 2008; Salzman et al., 2018; Schomers and Matzdorf, 2013). In essence, PES schemes take the form of a Pigouvian subsidy in which the government subsidizes the provision of an environmental good that is otherwise not marketed. Practically, PESs are implemented in different ways depending on the specific goods as well as the desired outcomes. Among a variety of PES schemes, two prominent designs are management- and performance-based PES. The former reward producers for engaging in or refraining from specific agricultural practices that are harmful to the ecosystem service. In the latter scheme producers are compensated for providing certain levels of the ecosystem service which are set a priori (FAO, 2007; Schomers and Matzdorf, 2013). In this section we examine potential applications of both designs in the smallholder oil palm production sector of Jambi province.

In the following, we calculate the outcomes of the two alternative incentive settings to achieve higher levels biodiversity. First, we predict a management-based payment, in which participants are rewarded for engaging in or refraining from certain practices associated with environmentally detrimental outcomes. Second, we compare the management-based measure with a scenario of performance based payments that reward the participant for achieving a certain level of outcome in the environmental indicator. For the sake of simplicity, we pool the panel and confine this section to highlighting the incentive mechanisms as well as the premium and cost magnitudes of environmental policy action in Jambi. 
Table 3.5 Aggregated outcome for different weeding scenarios of practice based PES measures compared with the elimination of inefficiency

\begin{tabular}{l|rr|rr}
\hline Eliminating & $\Delta E N S$ & $\Delta E N S(\%)$ & $\Delta y$ & $\Delta y(\%)$ \\
\hline Manual weeding & 10 & 1.7 & 53,013 & 1.3 \\
Chemical weeding & 9 & 1.4 & 42,562 & 1.0 \\
All weeding & 19 & 3.1 & 99,527 & 2.4 \\
\hline Inefficiency & 118 & 19.1 & $1,026,078$ & 24.7 \\
\hline
\end{tabular}

\subsubsection{Management-based measures}

We argue that manual weeding could be a reward-worthy agricultural practice due to two particular reasons, one of which is empirical and the other theoretical. First, since weeding increases the hyperbolic distance to the production frontier and therefore lowers the environmental performance of farmers, moderating the management practice could lead to less loss of biodiversity without losing output. Second, selectively removing plant species from the plots by definition lowers biodiversity. Hence, a policy targeting manual weeding could kill two birds with one stone, namely eliminating a source of inefficiency - without a loss of productivity - as well as technologically lowering the loss of biodiversity - potentially with a loss of productivity.

Table 3.5 details the aggregated outcome of farmers refraining from weeding practices. Even though the marginal effects of manual weeding are substantially higher than those of chemical weeding the omission of either leads to comparable increases of both biodiversity and oil palm output at around $1.4-1.7 \%$ and $1.0-1.3 \%$ respectively. If farmers dispense of both weeding practices biodiversity could be increased by $3 \%$ and oil palm output by $2.4 \%$, lifting the aggregate ENS by 19 species, on average, and the production level by almost $100,000 \mathrm{~kg}$.

Increasing biodiversity by means of encouraging refraining from weeding practices inflicts no costs and premiums could even be zero as farmers simultaneously benefit from increased production. Nevertheless, the result that introducing a PES scheme based on rewarding refraining from weeding will yield win-win situations requires some caution in its interpretation. Although including both dummy variables in the technology function of the production function does not reveal a significant dependence of output on the respective weeding practices, both practices could be more important due to two reasons. First, the insignificant importance of weeding practices for the production technology and the importance for the environmental performance could be due to the overall low productivity. In case of non-linearity of this relationship, with further technological change farmers could reach production levels where weeding practices make a more profound difference. Second, the significance levels of the coefficients are conditional on the sample size, which is rather small. Nonetheless, the 
fact that the weeding practices can be associated with negative environmental performance of smallholders could feed into policy measures to mitigate biodiversity at minimal output cost.

\subsubsection{Performance based payments}

Within performance-based PES schemes, policymakers target specific outcomes of an environmental variable, either int erms of increases or specific target levels (FAO, 2007; Bulte et al., 2008; Sattler and Matzdorf, 2013). Additionally, they set a premium - usually based per cultivation area unit - which the farmer receives if he participates in the program. The farmer's willingness to participate is equal to the shadow price. If premium payments are equal or exceed his potential loss of oil palm output, she is likely to participate, and otherwise she will not. An obvious starting point for our PES simulation is to target a similar level of biodiversity increase that could be achieved by eliminating inefficiency in the production process. In a second scenario, we aim at targeting biodiversity growth levels comparable with the management based programs from the previous section.

Table 3.6 Policy scenarios targeting social equality, uniform biodiversity dstribution and cost minimization

\begin{tabular}{lrrr}
\hline & Social inclusivity & Uniform Biodiversity & Cost minimizing \\
\hline Inefficiency-oriented & & & \\
Aggregated ENS increase & $19.1 \%$ & $16.7 \%$ & $20 \%$ \\
$p x_{1}^{-1}$ & $448 \$$ & $667 \$$ & $306 \$$ \\
$\Delta Y$ & $-36,090 \$$ & $-40,696 \$$ & $-55,3566 \$$ \\
$\Delta E N S$ & 118 & 103 & 122 \\
Participation & $100 \%$ & $98 \%$ & $73 \%$ \\
Cost & $119,489 \$$ & 177,922 & 65,484 \\
\hline Weeding-inefficiency oriented & & & \\
Aggregated ENS increase & $3.1 \%$ & $2.3 \%$ & $3.8 \%$ \\
px $x_{1}^{-1}$ & $74 \$$ & $337 \$$ & $51 \$$ \\
$\Delta Y$ & $-48,715 \$$ & $-6,124 \$$ & $-104,840 \$$ \\
$\Delta E N S$ & 19 & 14 & 23 \\
Participation & $100 \%$ & $99 \%$ & $72 \%$ \\
Cost & $19,697 \$$ & $89,895 \$$ & $10,697 \$$ \\
\hline
\end{tabular}

$p x_{1}^{-1}$ designates the premium per land unit (ha), $\Delta Y$ the change in oil palm fruit output $(\mathrm{kg})$ and $\triangle E N S$ the change in the effective number of species.

Table 3.6 illustrates the results of playing out different performance based PES. The first one considers an additional target that ensures that all farmers are willing to participate in the program, i.e. that the premium is equal to the maximum value of the farmer's willingness to pay. While such an approach might not be the most cost-efficient or cheapest one, it 
favors social inclusivity alongside some level of equality of biodiversity. The second column lists the outcomes of a policy program that targets raising biodiversity to an equal standard throughout the region. In other words, the policy targets a set minimum level of species to be present at every plantation. From a biodiversity perspective this makes sense as a uniform distribution of species across space determine higher gamma-diversity levels. To achieve similar biodiversity increases as in the previous scenario, the policy rewards farmers with at least three and five ENS respectively and sets the premium such that all farmers are willing to participate. The third column eventually exhibits the cost minimizing results while ensuring participation rates of more than $50 \%$.

From the three sets of results we conclude that, (i) while aiming at equal levels of biodiversity throughout the sector is ecologically highly desirable, it is by far the most expensive endeavor among the three options at hand. The policy sets in on farmers with high levels of biodiversity loss and high shadow values and targets minimum levels accordingly. On the downside, many farmers are rewarded without adjustments as their production already byproduces sufficiently little loss of biodiversity. However, individual losses in forgone production revenue are very limited. moreover, (ii) unequal but substantial increases of biodiversity are comparably cheap to obtain.

However, although PES schemes are frequently applied to address externality problems in many different - including developing country - settings (Wunder et al., 2008; Sims and Alix-Garcia, 2017) around the world, their practicality and success are driven by transaction costs (Banerjee et al., 2017). Monitoring and measuring the provision of environmental goods is often not feasible at all and if possible associated with very high transaction costs which in turn often outpaces provision expenses, thus rendering policies as highly cost ineffective. However, remote-sensing based biodiversity monitoring opportunities are arising and could soon be available at a granularity that allows cheaply determining site-specific measurements of biodiversity and other environmental indicators (Gullstrand et al., 2014).

Generally, detecting agricultural practices that are detrimental to the provision of not only desired outputs but also undesired ones is perhaps a promising start to design PES schemes. PESs often solely rely on the mere minimization of practices that are harmful to the ecosystem service and thereby neglect potential win-win scenarios which naturally should be exploited before policy targets improving environmental outcomes, which inevitably come at the cost of agricultural production. Therefore, incentive-based environmental policies are likely to be beneficial not only as they achieve the desired conservation of biodiversity but also because they might lead farmers to increase their environmental performance, i.e. producing more at a lower burden of biodiversity loss. 


\subsection{Summary and conclusion}

Indonesia has become a hotspot for environmental degradation, while providing the world's largest supplies of palm oil. Smallholder farmers are substantially contributing to both palm oil production as well as the decay of ecosystem services. Concurrently, the trade-offs between oil palm production and several ecosystem services in large-scale operations are well understood, while the environmental performance of smallholders has not been addressed in the relevant literature.

In this paper we address the literature gap and derive a full environmental production function accounting for the economic desirable output, undesirable environmental degradation - measured as plant biodiversity - conventional farm inputs and socioeconomic factors as well as management practices to explain shortfalls in managerial outcomes. Additionally, the duality of the outputs enables calculating the cost of abatement in the smallholder production system, which we use to simulate several PES policy scenarios.

Our main results are fourfold. First, we find that the production of fresh fruit bunches leaves ample room to improve efficiency under consideration of environmental degradation. Oil palm output can be expanded by $28 \%$ while loss of biodiversity at given input levels could be contracted by $22 \%$. Second, both chemical as well as manual weeding result in worsened environmental performance of oil palm production. Third, aside from potentially eliminating inefficiency, the abatement cost for increasing average biodiversity by one species on a farmers plantation amounts to 340 USD, on average, or about $16 \%$ of average annual palm oil income for smallholder oil palm producers. Fourth, PESs are promising policy options to conserve ecologically meaningful levels of biodiversity while simultaneously allowing smallholders to increase output levels. In general, identifying drivers of environmental inefficiency is key to successfully designing respective PES schemes.

Given that smallholders are important contributors to global palm oil supply, our results regarding their environmental performance suggest that improved management practices can play an important role in counteracting large-scale species extinction. Smallholders manage nearly half of Indonesia's oil palm area at comparably low yields, and effectively-designed policy aims to eliminate inefficiencies in production and reward conservation of biodiversity at average levels of opportunity costs and thereby provides promising avenues for more sustainable smallholder palm production. 


\section{Chapter Four}

\section{Can the Tripartite Rubber Council Manipulate International Rubber Prices? ${ }^{1}$}

The three largest natural rubber producers in the world have collectively introduced a set of policy measures to detach rubber prices from interlinked markets and to increase world rubber prices. However, policies intended to manipulate prices in one sector can have unintended consequences on the prices of goods in other sectors, such as substitute goods or final composite products. But can such effects be predicted? This paper applies an extended version of the Gardner Model to the natural and synthetic rubber markets in Southeast Asia, as well as crude oil, to predict the effects of exogenous policy shocks on the price of goods in related markets. Using an error correction analysis, we find that prices of natural rubber, synthetic rubber, and crude oil are co-integrated. Results further indicate that export taxes and supply-restricting policies, jointly enacted by Thailand, Indonesia, and Malaysia, both serve to detach the price of natural rubber from that of synthetic rubber in international markets. However, one of the policy measures to restrict exports, the increased domestic use of natural rubber, might have caused a decrease in international rubber prices, a consequence detrimental to the intended targets.

Keywords: VECM, Gardner-Model, Policy Interventions, Rubber, Indonesia

\footnotetext{
${ }^{1}$ This chapter is under review at Agricultural Economics and co-authored by Thomas Kopp (TK), who is the lead author, Mirawati Yanita (MY), Zulkifli Alamsyah (ZA) and Bernhard Brümmer (BB). TK, Bernhard Dalheimer (BD) and BB conceptualized the research idea. TK developed the theoretical framework. BD managed and collected the data. TK, BD and BB developed the empirical strategy and BD implemented the econometric modelling. TK, BD and BB interpreted the results. TK and BD wrote the paper with support from MY and ZA. All authors edited and revised the final manuscript.

Acknowledgement: This study was funded in part by the Deutsche Forschungsgemeinschaft (DFG, German Research Foundation), project number 192626868, in the framework of the collaborative German - Indonesian research project CRC990. Thomas Kopp thanks DFG for support within project KO 5269/1-1. Valuable assistance in data collection was provided by Angga Eko Emzar, Immanuel Manurung, and Sodiq Adeoye.
} 


\subsection{Introduction}

Natural rubber is one of the most regulated agricultural products in Southeast Asia. Starting with the first International Rubber Agreement in 1980 (Gilbert, 1996), there has been a long tradition of hefty government interventions at the multinational level. Currently the three biggest exporters of natural rubber - Thailand, Indonesia, and Malaysia - are at the fore front of market intervention. In terms of both production and export quantities these countries are the most important suppliers of natural rubber globally with a combined share of $63 \%$ of global production. Within the framework of the "Tripartite Rubber Council" (TRC), launched in November 2001, these countries have set out to alter rubber prices on the world market (International Rubber Consortium Limited, 2001).

However, despite the TRC's large market share and the implementing organisations' claims of these measures to be a great success, anecdotal evidence suggests that the apparent possibility to exert market power has not translated into international price dynamics as desired by the member countries (Verico, 2013). To date, no quantitative study has investigated whether policies introduced by the TRC have indeed had any measurable effects, and if they did, whether such effects were as desired or detrimental.

The markets most closely related to natural rubber are determined by the primary use of natural rubber, tire manufacturing. The other key components in tire making are, apart from natural rubber, synthetic rubber and other petrochemical products. While specialised tires, such as the ones for air planes, racing cars, or heavy machinery, require a specific ratio between natural rubber and its synthetic counterpart, for regular car and motorcycle tires this ratio can vary within certain boundaries. Therefore synthetic and natural rubber are effectively perfect substitutes at the margin, closely interlinking price developments in the two markets. Both are further influenced by developments in the notoriously volatile crude oil market, given that synthetic rubber is made from crude oil and that crude oils is the raw material for most other, non-rubber inputs in tire manufacturing.

The first question that this study seeks to answer is whether the members of the TRC have indeed managed to detach the price finding process of natural rubber from the ones of synthetic rubber and crude oil. The second question is in how far the policies have contributed to the political target of increasing the international price for natural rubber. Understanding the consequences of these interventions is crucial not only for economic welfare in rural areas, but also for generating insights on these dynamics' effects on ecological sustainability. For example, Feintrenie et al. (2010) highlight the role of price levels and price volatility in natural rubber for land-use change decisions.

These questions are addressed by modelling policy effects through an extension of the well-established Gardner Model (Gardner, 1975) by two kinds of policy interventions, followed by its empirical application. The first intervention is a long-term reduction of output 
quantities and the second one is an export quota. Our extended Gardner model allows us to understand the possible effects of policy interventions that try to detach prices on agricultural commodity markets from price trends in other sectors. Employing a standard Error Correction Model (ECM), we then first analyse the level of integration and cointegration of natural and synthetic rubber markets in order to establish the presence and extent of spillovers between these markets. Second, we analyse the spatial and temporal dynamics of price formation processes in these markets.

In line with economic theory, the econometric results indicate that the prices of natural and synthetic rubber are cointegrated with a factor of 0.97 , indicating close substitutability. Regarding short run effects, the policies under consideration - an export tax and several measures to restrict supply - did not affect cointegration, possibly due to a lack of implementation of the export tax for reasons of free riding. However, both policies were partly successful in detaching the natural from the synthetic rubber price in international markets on the long run, possibly due to the signals that the intended policies sent to market stakeholders. The different measures of output reduction varied in their effects, up to the point of having consequences opposite to their intended objectives. While the slower expansion of land dedicated to rubber production has indeed increased world prices, the increased domestic use through subsidised tire manufacturing affected natural rubber prices negatively, possibly by causing lower world price for tires.

The paper is structured as follows: the following Section 4.2 provides the background of the policies of the Tripartite Rubber Council. Subsequent Section 4.3 is devoted to model development. The empirical application is undertaken in Section 4.4, before Section 4.5 concludes.

\subsection{Background}

\subsubsection{Agricultural trade policy against global trends}

International trade in intermediate products has increased largely in the past decades and has become equally important to the trade of final products (Jones, 2000). Besides priceand technology driven reductions in transport and transaction costs, this development has largely been fostered by political changes, such as multi-lateral or regional trade liberalisation, including liberalisation of input markets. Evidence on the trade effects of the role of trade liberalisation in input markets has been analysed in the existing literature for some emerging economies, e.g., Chile (Pavcnik, 2002), China (Khandelwal et al., 2013), India (Topalova and Khandelwal, 2011), and Indonesia (Amiti and Konings, 2007). Bas and Strauss-Kahn (2015) show that manufacturers of final manufactured goods gain from input trade liberalisation, especially when specialising in high-quality products. On the firm level, Chevassus-Lozza 
et al. (2013) find that tariffs on agricultural inputs disadvantage lower productive firms while Olper et al. (2017) find correspondingly that higher levels of trade-integration advantages the most productive firms stronger.

In contrast to these overall trends in trade liberalisation along supply chains for manufactured goods, the situation for agricultural products in general, and non-food agricultural products that are used in non-agricultural supply chains in particular, remains fundamentally different. Governments continue to intervene heavily in agricultural markets. Mitra and Josling (2009) observe that especially in times of market turmoil and crises, exporting countries for example often impose export restrictions on agricultural goods, including non-food agricultural commodities, before other sectors.

These interventions, targeting one specific sector, can result in undesired by-effects when spilling over to other sectors - including ones in other regions - due to globally integrated production networks. Interventions that target prices for agricultural commodities like natural rubber might not only induce price effects on the targeted market itself but likely induce effects on markets for close substitutes, such as synthetic rubber. At the same time, the effectiveness of interventions in agricultural price formation can be affected by price shocks in related, non-agricultural markets, such as crude oil in this case. The nature of the interplay between targeted and closely connected markets will hence be decisive for both the effectiveness of government interventions, and the resulting by-effects.

\subsubsection{Natural and synthetic rubber value chains}

One of the reasons for governments especially in developing and emerging economies to intervene in agricultural markets is the substantial income effects that the prices of these goods have for smallholder producers. Throughout Southeast Asia, natural rubber is produced predominantly by small scale farmers and has been subject to policy interventions for decades (Verico, 2013; Kopp and Brümmer, 2017). Especially for farmers with little land, rubber is an important income source (Krishna et al., 2017a). Although the TRC member countries' share of global output has been declining steadily over the past 15 years and is substantially lower than during the 1960s and 1970s, in 2016 the three producers were still responsible for about $63 \%$ of the world's production (FAOSTAT, 2017) (Figure 4.1).

The natural rubber supply chain starts with smallholders, who tap rubber trees, grown in monoculture agroforests, for their sap, the liquid latex. This sap is solidified with chemical substances, so-called coagulants. The resulting slabs of raw rubber are obtained by crumb rubber factories, located throughout the rubber producing regions. These factories process the rubber mechanically to produce technically specified rubber (TSR), a standardised commodity which is sold on the international market, mainly to tire factories all over the world (Kopp and Sexton, 2019). The importers of natural rubber are displayed in figure 4.2. 
Figure 4.1 Global and TRC natural rubber production by year

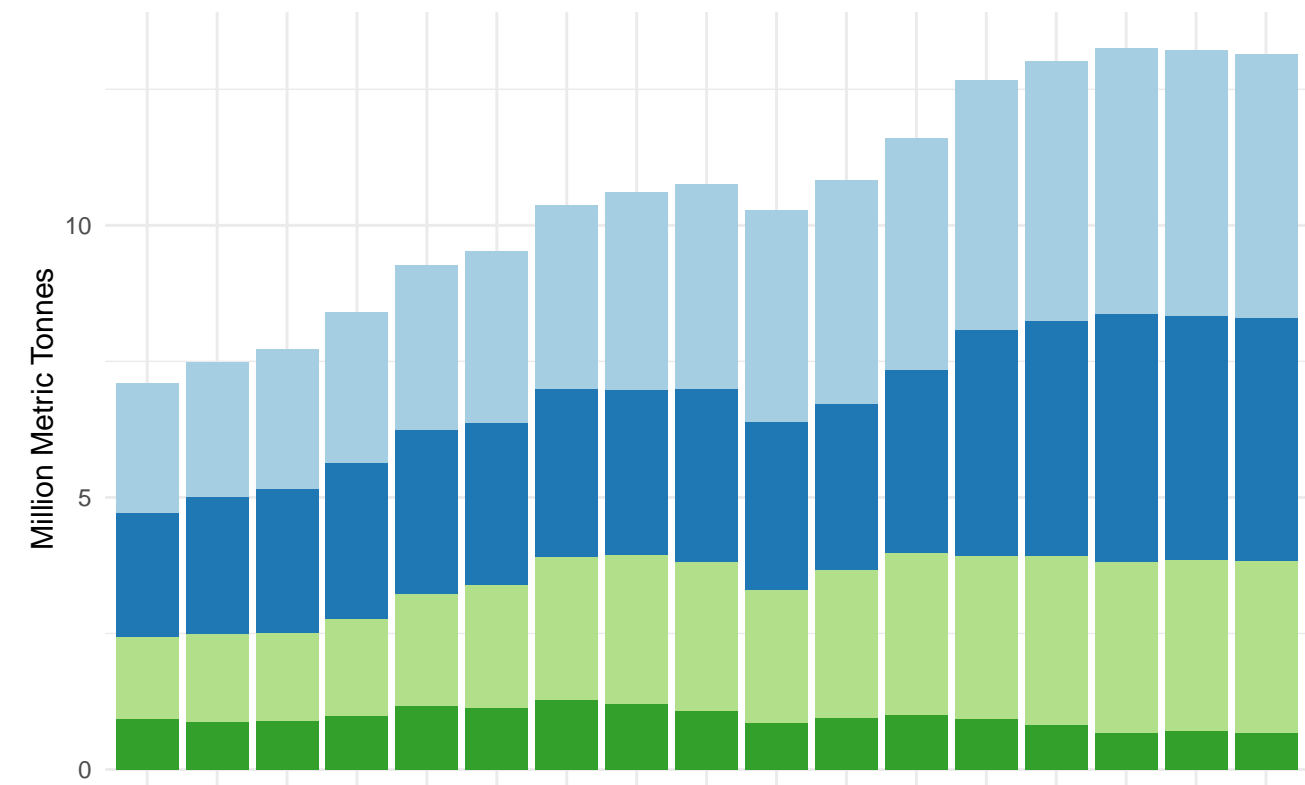

20002001200220032004200520062007200820092010201120122013201420152016

\section{Rest of the World $\square$ Thailand Indonesia Malaysia}

Source: Own production, based on data from FAOSTAT (2017).

Annual global production quantities compared to those of the members of the TRC agreement.

The markets for synthetic rubber and tires are characterised by greater competition both in exports and imports than the one for natural rubber exports, with C3 ratios being substantially below the one for natural rubber exporting (table C.3). The main importers of both types of rubber are China and the US. The main tire producers and exporters are located in China, Germany, Japan, the US, and Thailand. Apart from the tire industry, synthetic rubber is also used in the manufacturing of rubber flooring, shoe soles, and wire insulation, amongst others (Horowitz, 1963). Synthetic rubber is produced from crude oil, primarily in Korea, Germany, China, Japan, and the US.

\subsubsection{Policy measures within the Tripartite Rubber Council}

In an effort to insulate price developments in natural rubber from price shocks in related markets and to pressure international rubber prices upwards in both long and short term horizons, the member states of the TRC have established a set of three distinct policy measures (Ministry of Industry and Trade Indonesia, 2002). All of these policies are implemented under the supervision of the International Tripartite Rubber Consortium Ltd. (ITRC), which has been founded jointly by the three governments (Verico, 2013). Policy interventions are agreed in member state meetings, and then coordinated and implemented by the ITRC. Within each member country, a National Tripartite Rubber Corporation (NTRC) is respon- 
Figure 4.2 Importers and exporters of rubber and tires

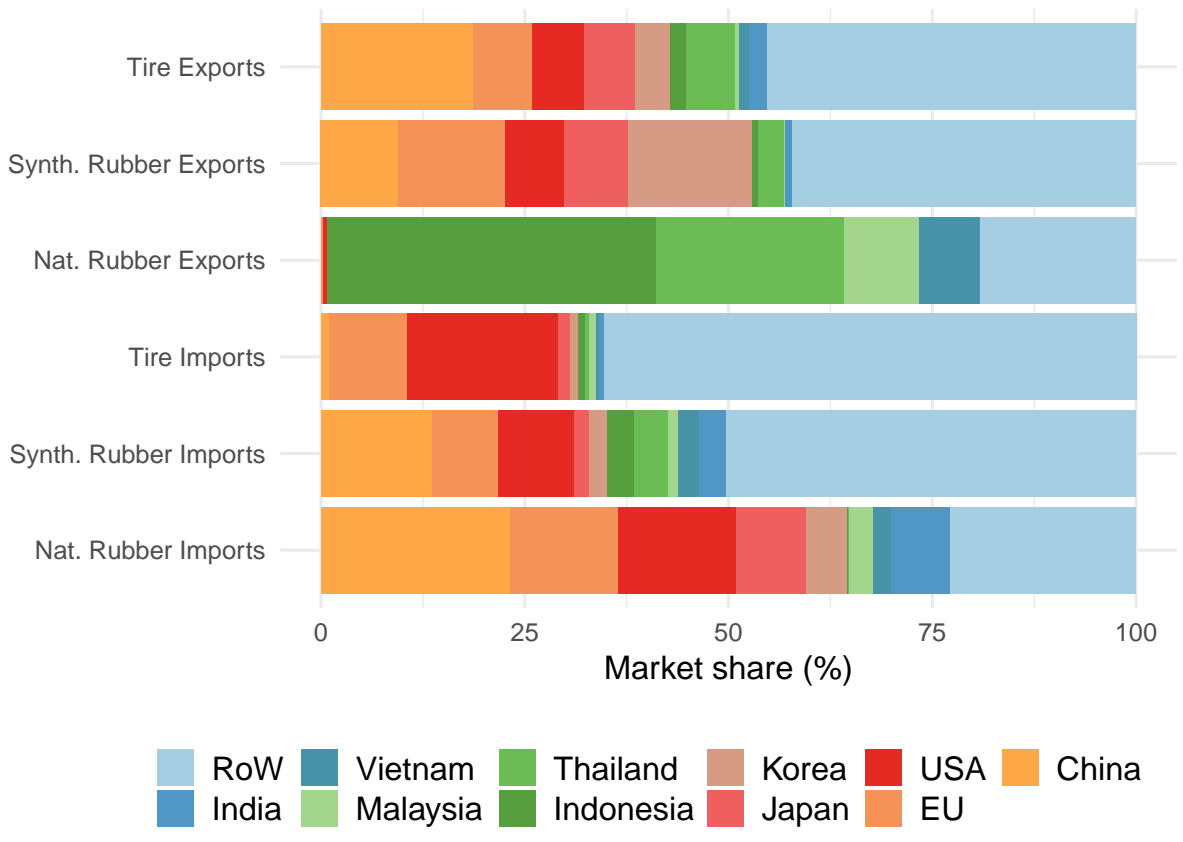

Source: Own production, based on data from TradeMap (2020) and Market Access Database (2020) for data on extra-EU trade.

The following data enter the graph: HS400122 (technically specified rubber, i.e., natural rubber), HS400211 + HS400219 (styrene butadine rubber, i.e., synthetic rubber), HS4011 (new tires made of rubber, including all kinds of tires, including cars, motorcycles, bicycles, aircrafts, buses, lorries, heavy machinery).

All numbers are for 2018 and indicate shares of export and import values, respectively. The figure includes the four largest countries in each category. Detailed numbers provided in appendix table C.3.

The $\mathrm{C} 3$ ratios are, in the order of the bars, $32.4 \%, 38.5 \%, 72.6 \%, 32.1 \%, 28.3 \%$, and $46.2 \%$, respectively. 
sible for the implementation of the agreed policy measures. In Indonesia, this function has been transferred to the Association of Rubber Businesses Indonesia, GAPKINDO (Ministry of Industry and Trade Indonesia, 2002). In Thailand and Malaysia, the Thai Rubber Association and the Malaysian Rubber Board, respectively, are in charge of implementing the policy measures in collaboration with the ITRC.

The first policy, the Supply Management Scheme (SMS), is intended as a long term strategy to influence prices via restraining supply. Measures under the SMS include reducing the planted area through crop diversification (International Tripartite Rubber Council, 2014), limiting the establishment of new plantations (ibid.), and an increased frequency of rejuvenation of rubber plantations in times of low prices (Ministry of Agriculture Indonesia, 2008), ${ }^{2}$ as well as promoting domestic consumption (Anwar, 2017) by an "increase in locally manufactured rubber based products" (International Tripartite Rubber Council, 2015). In its first phase from 2002 onwards, the SMS was set to aim at a reduction of aggregate output by $4 \%$ per annum (Verico, 2013). The program goals where redefined following the global financial crisis to reduce production quantities by 215,000 tonnes per annum from 2009 onwards (Ministry of Agriculture Indonesia, 2008).

Second, short term export quotas are applied under the framework of the Agreed Export Tonnage Scheme (AETS). This scheme provides the potential to limit export supplies to international markets for a limited time span of less than one year (Anwar, 2017). In practice, the institutions at the national levels are supposed to implement the AETS by allocating export quotas to each company producing and exporting rubber (Malaysian Rubber Board, 2012). The governing bodies agree upon targeted reductions in export quantities. However, the reference period has not clearly been identified which prevents the derivation of de facto quotas. The AETS was applied in 2002, in 2009, over 2012/2013 (October to March), and in 2016 (March to August) (Anwar, 2017). During 2002 the goal of an export reduction of $10 \%$ has been set for each country in combination with the aforementioned production reduction of $4 \%$ under SMS (Verico, 2013). From 2009 on, the AETS has been defined as export reduction in tonnes. The countries decided to collectively reduce rubber exports by 700,000 tonnes in this year as a response to low prices. In 2012/2013 the reduction quantity was set to 300,000 tonnes which was shared among the three countries in proportion to production quantities in 2011 (Malaysian Rubber Board, 2012). In 2016 the member countries agreed to a reduction of exports by 615, 000 tonnes (Thailand: 324, 005 tonnes, Indonesia: 238, 736 tonnes, Malaysia: 52, 259 tonnes, Ministry of Industry and Trade Indonesia, 2016).

Third, the Strategic Market Operation (SMO) program envisages mostly market information systems to support and evaluate other international agreements and policies, in particular

\footnotetext{
${ }^{2}$ While rejuvenation is likely to increase output per plot in the first years of the next tree generation, it reduces the share of area that is productive at an aggregate level, which might outbalance the productivity gains. The SMS measure is based upon the premise that the aggregate output of a given area of rubber plantation over a period of time greater than the life span of one tree generation is reduced.
} 
both SMS and AETS. Furthermore, governments agree to purchase excess supplies for public storage, aiming to reach certain price levels through this stock management. However, until 2018, only Thailand has actively intervened in its rubber market by building up domestic stocks. Hence, the SMO is primarily a long term policy with regards to improved information systems and monitoring, and serves in rare case as a short term policy when stocks are bought in times of low prices (International Tripartite Rubber Council, 2016).

However, despite the efforts being undertaken to form the ITRC and to agree upon policy measures, the success of the intergovernmental union and their policy framework is unclear, as the body of literature is marginal. Only few scientific studies analysing the efficacy of international rubber policy are available. While the implementing organs of all member states have attributed short term upward price developments towards AETS and SMS implementations (e.g. Malaysian Rubber Board, 2012; Thai Rubber Association, 2016), some literature points out that the policies have been largely ineffective due to lack of compliance as well as coordination. Verico (2013) argues that TRC member states are actually competing instead of collaborating and exploiting their hypothetical oligopolistic power, despite the decreasing importance of agricultural exports in all three countries (Yeah et al., 1994). Figure 4.3 reveals a point in case. The two periods of active AETS from October 2012 to March 2013 and from March 2016 to August 2016 are represented by the dark shaded area. In the first period, accumulated exports of the partners have increased, although a drop is observable after the policy had expired. The second period featured larger fluctuations of exports and a rather increasing trend in the post implementation period. In both cases no strategic export reduction can be observed.

Figure 4.3 TRC monthly exports and active AETS periods

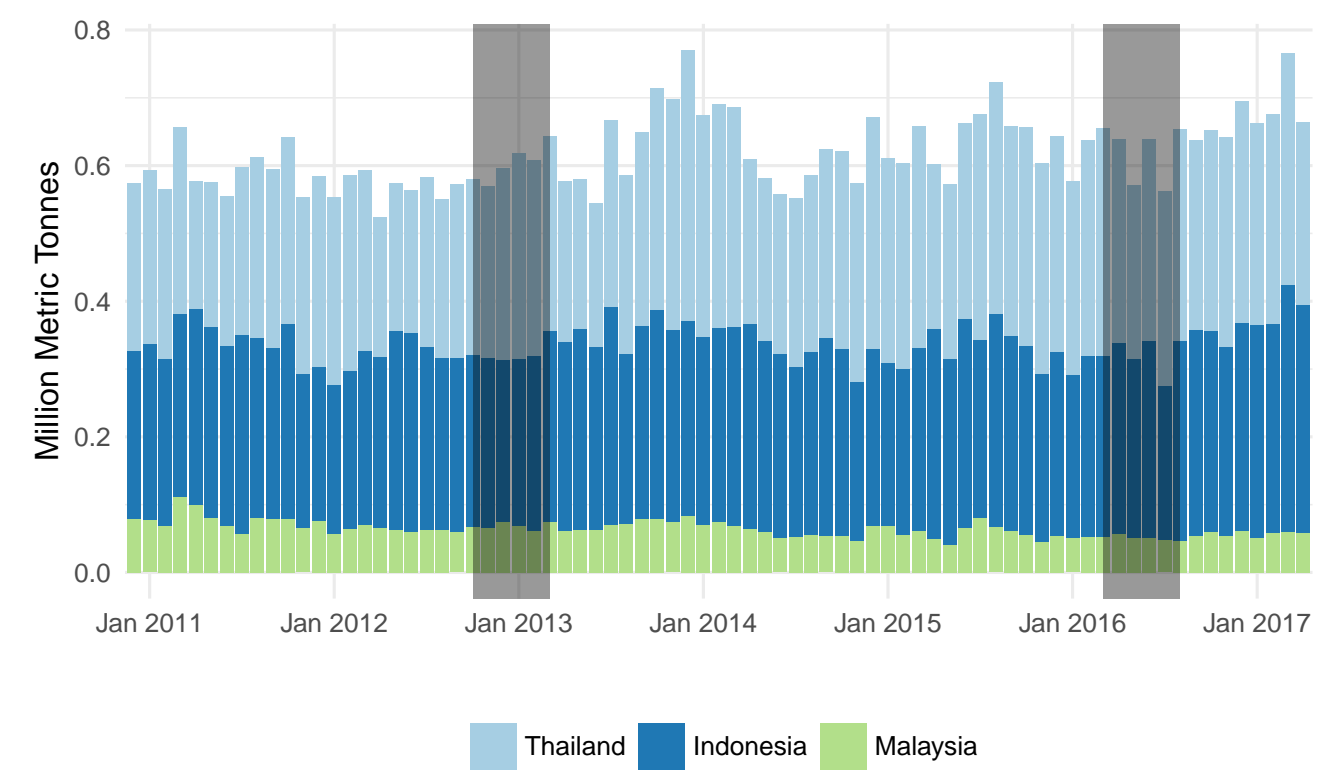

Source: Own production, based on data from UNCTAD/WTO (2017).

Natural rubber exports from 2011 to 2017. 
Nevertheless, commodity markets follow complex mechanisms and available quantities may not solely be responsible for price formation. For instance, the mere announcement of restrictive policy may already have impacts on international price development. Therefore, the assessment of the efficacy of TRC policy calls for a more profound analysis.

\subsection{Model of the interlinked markets}

To evaluate the consequences of the policy measures that try to detach the natural rubber price from price dynamics in synthetic and crude oil markets it is essential to develop an understanding of which factors affect these consequences and what outcome is within the realm of possibility for policy makers. The policies' success is determined by a) the level of market power that the implementing stakeholders can exercise, b) the level of the cross price elasticity between the markets and c) the rigorousness with which the measures are implemented. The same factors are equivalently decisive for the dynamics in the other sector as a result of the policy measures.

We base our analysis on the market model introduced by Bruce Gardner (1975), which has served as a workhorse model for decades (Kinnucan and Zhang, 2015). It includes three markets, one for the agricultural input, $a$ (natural rubber), one for the non-agricultural/industrial input, $b$ (synthetic rubber), and one for the composite output, $Q$ (tires). The model accounts for external effects on production such as factors influencing production like weather, as well as factors influencing demand, such as the global macroeconomic environment.

The objective of our extensions to the basic Gardner model is to allow for an assessment of the cross price elasticity between natural and synthetic rubber, and how it can be affected by measures implemented by stakeholders who have the potential to exercise market power. The solution of the model allows for a prediction of the highest effect that the policy can plausibly achieve.

This general intuition stands in the tradition of authors who have applied the Gardner model and its subsequent extensions to numerous market power related problems. E.g., Brümmer et al. (2009) base their price-transmission analysis of Ukrainian wheat and flour markets on the basic model. Assumptions on the key variables entering the model, i.e., the elasticities, enabled those authors to derive plausible magnitudes for the long-run relation between prices, which indeed confirmed their empirical results. Along similar lines, Hosseini and Shahbazi (2010) and Kinnucan and Tadjion (2014) exploit the basic model's zero-restrictions to test for perfect price transmission and to draw conclusions regarding the competitivenesses of the markets under consideration. Modifications of the model to allow for a non-competitive market environment include Holloway (1991) who assumes a conjectural-variations oligopoly with endogenous entry and Azzam (1998)'s extension towards a partially integrated oligopsonistic industry. Yu and Bouamra-Mechemache (2016) develop a model similar to Gardner 
to predict the effects of the implementation of production standards which reduce total output quantity.

\subsubsection{Logic of model extension}

This paper suggests an approach of explicitly modelling policies that interfere with the market of the agricultural input in situations of globally distributed production networks. The producers of natural rubber and synthetic rubber are exporters located in different countries while the manufacturers of tires import all inputs.

As Figure 4.4 shows, the market of the agricultural input, natural rubber, is subject to policy interventions in the TRC member countries: policy A refers to the short run policy of export quotas while policy B refers to the SMS policy, i.e., legislature to reduce farm output on the long run. Natural rubber is further affected by the demand from tire manufacturers and synthetic rubber by crude oil and the global economy, which, in turn, also affects demand for tires. The global economy also affects the tire price because more cars are sold in times of high macroeconomic growth rates and new cars being marketed requires more tires than replacement of worn-out tires when cars are used for longer. We do not assume a direct effect of crude oil price on agricultural supply because energy costs are minor both in production of natural rubber and its processing.

Figure 4.4 Flow chart of causal chain

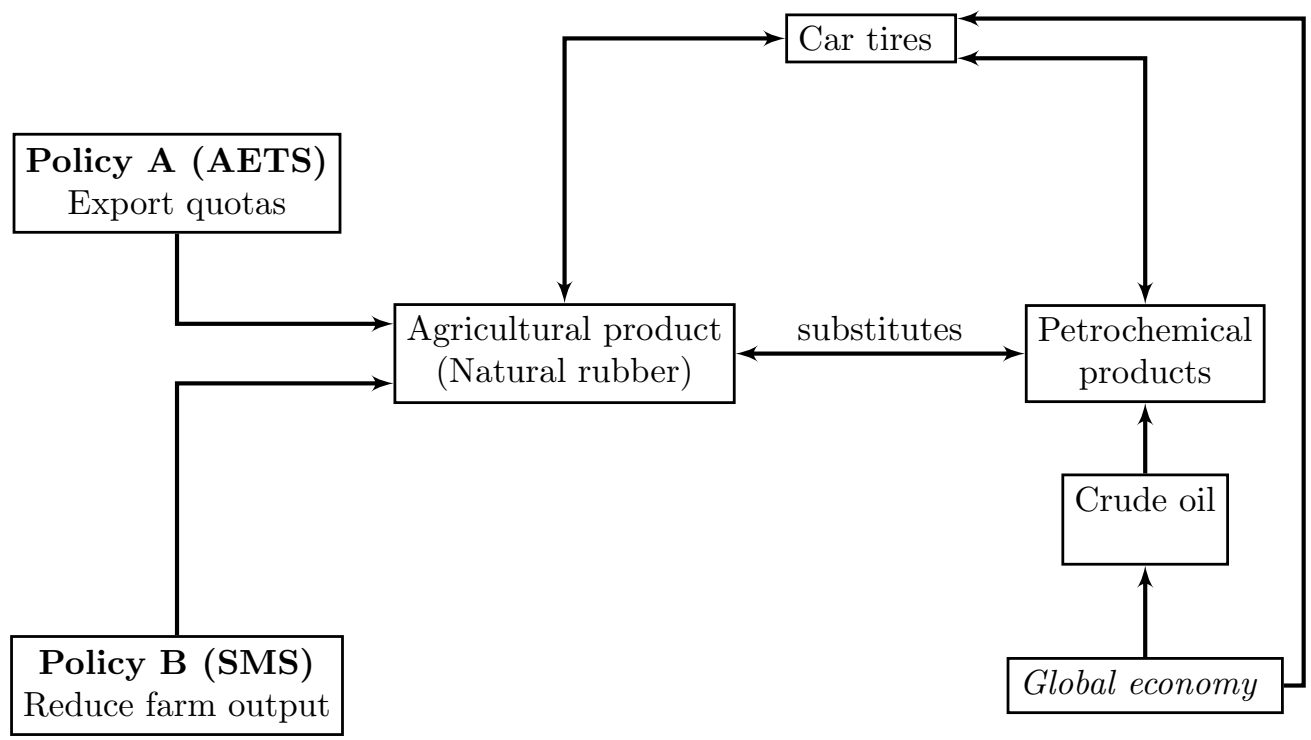

Source: own design

Bold refers to policy instruments, italics refer to external factors, and normal font to production quantities. 


\subsubsection{Model components}

First we set up demand and supply relations for the markets for natural rubber (input $a$ ), synthetic rubber (input b), and tires (composite output $Q$ ) and subsequently derive the market equilibria. We start with the supplies of the two inputs. Natural rubber supply on the domestic market, indicated by superscript $D$, is provided by the inverse supply function,

$$
p_{a}^{D}=h(a, U)
$$

in which $U$ is an exogenous shifter including natural shocks, as well as the SMS policy to reduce supply and therefore increases the reactivity of supply to price changes. Equivalently, inverse supply of synthetic rubber is given by

$$
p_{b}=g(b, V)
$$

where $V$ is an exogenous shifter, such as a tax or the global macroeconomic environment. Note that no superscript is included because no trade policy is assumed to exist on the market for $b$. The demand for $a$ and $b$ stems from manufacturers who use inputs $a$ and $b$ to produce the composite output $Q$. Demand for the agricultural input $a$ in the world, indicated by superscript $W$, is given by the assumption of perfect competition on the output market, i.e. manufacturers of $Q$ equate the input price for the agricultural input, $p_{a}^{W}$, to the value of its marginal product:

$$
p_{a}^{W}=p_{Q} \frac{\partial Q}{\partial a}
$$

and equivalently, demand for the industrial input $b$ is given by

$$
p_{b}=p_{Q} \frac{\partial Q}{\partial b}
$$

Demand for the final product $Q$ is given by

$$
Q=D\left(p_{Q}, N\right)
$$

in which $Q$ represents the demand for output product quantity, $p_{Q}$ is product price, $N$ is an exogenous demand shifter, for instance income or macroeconomic variables. The production of $Q$ is given by the production function $f$ :

$$
Q=f(a, b)
$$

The elasticity of substitution between $a$ and $b$ in production of $Q$ is given by $\sigma=$ $\left(\frac{\partial Q}{\partial a} \frac{\partial Q}{\partial b}\right) / Q\left(\frac{\partial^{2} Q}{\partial a \partial b}\right)$ (Allen, 1938, p. 343).

The equilibrium on the market for natural rubber, $a$, is affected by the export quota 
collectively introduced by the members of the TRC. The gross price $p_{a}^{W}$ that manufacturers of tires, $Q$, have to pay for the natural rubber input is the domestic price, $p_{a}^{D}$, inflated by the big exporter's export quota, represented by the ad valorem equivalent (AVE) of the quota. Based on Holloway (1991, p. 980), it is equal to the net price, multiplied by the AVE, and weighted by a proxy for the exporters' combined market power:

$$
p_{a}^{W}=p_{a}^{D}(1+t)
$$

where $(1+t)$ stands for the effect of a big exporter's policy instrument. In other words, $t$ does not represent the mere tax but is furthermore weighted by the exporter's ability to exert market power, which can be understood as the conjectural variation anticipated by the exporter (Huang and Sexton, 1996). Conjectural variations express seller power by a single parameter and measure how strongly competitors react to changes in price or quantity supplied by the market participant under consideration. It varies between 0 (perfect competition) and 1 (monopoly).

\subsubsection{Policy efficacy}

To predict how policies detach the natural from the synthetic and crude oil price dynamics, the model is solved to express the cross price elasticity between natural and synthetic rubber, $\varepsilon_{a, b}$, as a function of policy-induced alterations in the farm supply: ${ }^{3}$

$$
\varepsilon_{a, b}=\frac{\varepsilon_{U}}{(1+t)} \frac{\left(\varepsilon_{b}+S_{a} \sigma-S_{b} \eta_{Q}\right)}{S_{a}\left(\eta_{Q}+\sigma\right)}
$$

where $\varepsilon_{b}$ is the partial supply elasticity of quantity $b, S_{a}$ and $S_{b}$ are output shares, $\eta_{Q}$ is the elasticity of demand for car tires, and $\varepsilon_{U}$ stands for the quantity-reducing effect of the SMS policy. It is not possible to make an ad hoc assumption on the magnitude of the effects of the output reduction caused by the SMS policy $\left(\varepsilon_{U}\right)$. The export tax $t$ enters in the denominator on the right hand side of equation (4.8), which means that increasing $t$ will continuously detach the agricultural input price from the industrial input price. The free-market situation, i.e. when neither the AETS policy (effect of export tax) nor the SMS Policy (long-term reduction of farm output) are active is accounted for by setting $t=0$ and $\varepsilon_{U}=1$. The combined market power of the rubber exporting countries that are organised within the TRC might allow them to affect global prices of natural rubber. The AETS policy of the TRC is the introduction of an export quota, represented by its AVE, which is only employed by policy-makers if the price is low. ${ }^{4}$ This gives two cases:

Case 1: If the world price is low, the TRC introduces export tax $t$, the situation that is

\footnotetext{
${ }^{3}$ The derivation is provided in Appendix 7.1.

${ }^{4}$ There is no clear definition of what 'high' and 'low' prices are, as the decision on when to implement measures is made rather spontaneously between the TRC's member countries.
} 
described by equation (4.8).

Case 2: If the world price is high, no export quota is issued.Equation (4.8) simplifies to

$$
\varepsilon_{a, b}=\varepsilon_{U} \frac{\left(\varepsilon_{b}+S_{a} \sigma-S_{b} \eta_{Q}\right)}{S_{a}\left(\eta_{Q}+\sigma\right)}
$$

\section{Implications of equation (4.8) for the relation between input prices}

Brümmer et al. (2009) state some observations regarding the values of a number of variables in this model of which some can also be applied to this case. $S_{a}$ and $S_{b}$ can be generated from our data. ${ }^{5}$ The synthetic rubber price has been approximately 2505 US $\$$ per ton and the natural rubber 2437 US $\$$ per ton on average during 2011-2017. They enter the production in roughly the same amounts, so $S_{a} \approx 0.49$ and $S_{b} \approx 0.51$. Given that tires are complements to cars and represent a minor share of the car price, the own price elasticity of demand for tires, $\eta_{Q}$, can be assumed to be close to zero, so the respective terms is omitted from the formula. Regarding the elasticity of substitution in production, however, we can - unlike Brümmer et al. (2009) - not assume $\sigma$ to be very small because synthetic and natural rubber are indeed close substitutes at the margins, as indicated by results from qualitative key stakeholder interviews with tire manufacturers: the quantity-ratio between the two can be varied easily between 45:55 and 55:45. Harder (2018) reports that 8\% of all natural rubber demand in China could switch to synthetic rubber. This means that the elasticity of substitution in production $\sigma \gg 1$. For the prediction we assume $\sigma=10 .{ }^{6}$ The supply elasticity of synthetic rubber, $\varepsilon_{b}$, is derived from the literature: Horowitz (1963) estimates a supply elasticity for synthetic rubber of 1.49. Since we cannot make an ad hoc assumption on the magnitude of $\varepsilon_{U}$, this parameter is to be estimated in the subsequent empirical analysis. Inserting all numbers into equation (4.8) yields

$$
\varepsilon_{a, b}=\frac{\varepsilon_{U}}{(1+t)} 1.29
$$

This means that in the absence of policies $\left(\varepsilon_{U}=1\right.$ and $\left.t=0\right)$ the long-run elasticity of the natural rubber price relative to the price of synthetic rubber is about 1.3, providing "an indication of the expected magnitude of the long-run elasticity" of industrial input prices with respect to agricultural input prices (Brümmer et al., 2009, p. 215). In other words, price changes in the industrial good - synthetic rubber - are amplified by the factor 1.3 during transmission to the price for the agricultural good - natural rubber if no policies are active. The econometric estimation of $\frac{E_{p_{a}, U}, U}{E^{p_{b}, U}}$ will therefore allow an assessment of the success of the TRC in insulating the prices.

The theoretical model shows that the policy measures under consideration do indeed have

\footnotetext{
${ }^{5}$ Calculated as $S_{a}=p_{a} q_{a} /\left(p_{a} q_{a}+p_{b} q_{b}\right)$ and equivalently for $S_{b}$.

${ }^{6}$ Appendix 7.2 provides a simulation for $\frac{E_{p_{a} W}, U}{E_{p_{b}, U}}$ when inserting values for $\sigma \in[1 ; 25]$.
} 
the potential to decouple the reaction in prices. The next section provides empirical evidence on whether this potential was exploited.

\subsection{Econometric analysis}

\subsubsection{Vector Error Correction Model}

The substitutability between natural and synthetic rubber suggests that the prices of these are correlated over time. The theoretical model from section 4.3 implies that policies targeting the supplies of natural rubber either via export reduction or farm output reduction impact its international price if the implementing countries are large enough. These impacts could be transmitted into the industrial input, i.e. prices of petrochemical products, including synthetic rubber. Both of which obviously are subject to the dynamics of the global economy and determine the framework for the tire market (figure 4.4).

In order to assess policy efficacy in a time series context, a number of methods have been implemented in the relevant literature (Ihle et al., 2012, provide a review of this literature). Two prominent options are regime dependent estimation and dummy variable approaches. The former entails estimation of different regimes in which policies have been operational or not, whereby the transition from a policy to a non-policy (or different policy) regime may be predefined (e.g. Thompson et al., 2000), or estimated (e.g. Brümmer et al., 2009). In the latter method, policies are simply controlled for using dummy variables. In this application one long term policy, SMS, and one short term policy, AETS, ought to be evaluated. Since SMS stretches over the entire time horizon and the AETS has been active for two periods of six months each, the dummy approach is preferred in this particular setting.

Given the long and short term policy structure of the TRC as well the usual suspicion that price data are non-stationary and $I(1)$, an Error Correction Model (ECM) is estimated. In that, both prices are exposed to exogenous shocks from the oil price $p^{C O}$. Hence, in this context the oil price is not considered as a cointegrated variable, yet it must be allowed to impact the relationship exogenously. This approach has been adopted also by Ihle et al. (2012) who augmented the cointegration relation with exogenous policy variables. The same idea applies to the long term SMS policy. In accordance with Dickey et al. (1991), we include $p^{C O}$ and the SMS policy variable in the long run equation and the residuals of which form the Error Correction Term (ECT) in the ECM representation. Given that the price series are cointegrated ${ }^{7}$, the long run equation is formulated as

$$
p_{t}^{N R}=\beta_{0}+\beta_{1} p_{t}^{S R}+\beta_{2} p_{t}^{C O}+\beta_{3} S M S_{t}+\epsilon_{t}
$$

where $p_{t}^{N R}$ is the price of natural rubber and corresponds to the price of the agricultural

\footnotetext{
${ }^{7}$ This is shown to be the case in section 4.4.3.
} 
input, $p_{a}^{W}$, in equation (4.8). $p^{S R}$ is the price of the industrial input, namely synthetic rubber and $p_{t}^{C O}$ stands for the crude oil price. Additionally, the long term policy set of the SMS, $S M S_{t}$, is included. ${ }^{8} \epsilon_{t}$ is an $I(0)$ variable.

Establishing an indicator for or modelling the SMS policies poses a challenge since it is impossible to account for specific measures taken in given time periods. The SMS defines a target and the executive companies then contribute to the target by implementing a variety of measures. The dynamics of area cultivation over time certainly reflect these measures, however, they are highly endogenous to the prices. Since no measure for the actually implemented policies exists, we proxy the propensity of the governments and agencies to implement the measures. To test for robustness proxies are generated for the different measures and compared to each other. As a further robustness check we also capture the propensity to implement via a modelling approach as described below.

The SMS policy targets the reduction of rubber that is traded on the world market to increase the price in the long run. This is achieved through two sub-goals: reducing the productive area and promoting domestic consumption. Three instruments contribute to the former: limiting the establishment of new plantations, more frequent rejuvenation of trees, and crop diversification at farm level.

The first measure of SMS implementation is the promotion of domestic consumption by motivating local business and public sourcing to use more rubber. The private sector is incentivised to develop and produce more natural rubber based goods and the public sector procures goods that contain rubber, such as rubberised roads or dams (Anwar, 2017; International Tripartite Rubber Council, 2015). Since no panel data are available for the public procurement of all three countries, this application focuses on the private sector to proxy these policies. Since the main industry to use rubber are tire manufacturers, the measurement of choice is the output of the domestic tire industry: the possibly increased domestic demand for natural rubber due to SMS is proxied by the deviation of the output of the downstream industry (i.e. tire manufacturing) from its long-run trend, denoted by $S M S_{T O}$.

As a second measure the acceleration / slowing down of expansion of area under cultivation is proxied by a dummy variable, $S M S_{e x}$, which takes the value of 1 in case the change of area harvested $a$ in $t$ is larger than the change in $t-1$ and 0 otherwise. In other words, it distinguishes between slowing down or acceleration of area expansion. While this is also caused by an array of other factors, it will reflect the efforts of the implementing agencies.

$$
S M S_{e x, t}= \begin{cases}1 & \text { if } \Delta a_{t}-\Delta a_{t-1}>0 \\ 0 & \text { otherwise }\end{cases}
$$

${ }^{8}$ The short term policy AETS enters in the estimation of the short-run dynamics. 
The third measure to proxy the effects of this policy instrument was generated via a modelling approach: the rate of plantation encroachment is the result of small scale farmers land use decisions which are a function of three key determinants: the SMS policy, the expected price development of natural rubber and the expected price development of oil palm, the alternative cash crop growing in these geographical regions and climatic zones. We therefore isolate the policy effect by stripping the dynamics in the land area used for rubber production from the other two effects in terms of proportional changes:

$$
\begin{aligned}
\frac{A_{t}-A_{t-1}}{A_{t}}= & S M S_{h a, t}+\frac{p_{t}^{N R, \text { expected }}-p_{t-1}^{N R, \text { expected }}}{p_{t}^{N R, \text { expected }}}+\frac{p_{t}^{\text {PO,expected }}-p_{t-1}^{P O, \text { expected }}}{p_{t}^{\text {PO,expected }}} \\
& \Leftrightarrow \\
S M S_{h a, t}= & \frac{A_{t}-A_{t-1}}{A_{t}}-\frac{p_{t}^{N R, \text { expected }}-p_{t-1}^{N R, \text { expected }}}{p_{t}^{N R, \text { expected }}}-\frac{p_{t}^{\text {PO,expected }}-p_{t-1}^{\text {PO,expected }}}{p_{t}^{\text {PO,expected }}}
\end{aligned}
$$

where the expected price for natural rubber, $p^{N R \text {,expected }}$, and for palm oil, $p^{P O \text {,expected }}$, is proxied by yearly price indices of the two commodities.

It was considered to include lags of the SMS policy variable since the results of reducing/not expanding land area may take some time to take effect. We decided against, however, since a change of land area under cultivation in one year does indeed have already impacts in the same year since changes in land use policies influence traders' decisions which drive the price.

We have therefore three proxies for the SMS policy that targets the long-run reduction of the international natural rubber supply: first is the deviation from the long-run trend of tire output, second is a dummy that captures acceleration or slowing down of rubber plantation expansion and third is a continuous variable that measures rubber plantation expansion, controlling for price effects. To test for the robustness of these measures we estimate the long run relation with each of them individually and also combine the first measure (tire exports) with each of the measures for area expansion.

Having estimated the cointegration relationship, the ECM specification becomes

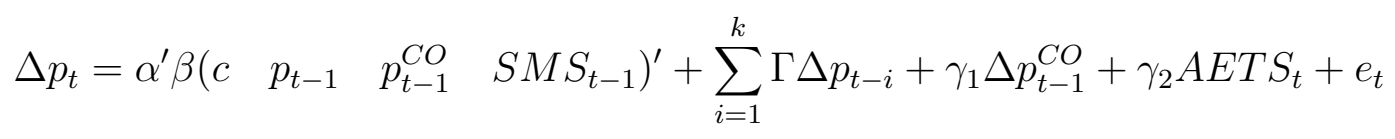

The endogenous prices of natural and synthetic rubber are gathered in the $2 \times 1$ vector $p_{t}$. The vector in brackets is the cointegrating vector. The short term policy instrument enters the equation as a component of the short-run adjustments in form of the dummy variable $A E T S_{t}$ and as $k$ lags of the endogenous variable. $e_{t}$ are independent Gaussian errors with mean zero. In the case of the short term relation, the short term policies are be formulated 
as a dummy variable which indicates periods in which the policy is operational and periods in which it is not.

\subsubsection{Data}

Translating the theoretical model into an empirical application requires proxies for petrochemical tire inputs, the agricultural input as well as the crude oil price. First, styrene butadine rubber prices have been obtained from Shanghai Shengiyshe Data Consulting Ltd. and are expressed in CNY per tonne. Second, the Standard Malaysian Rubber (SMR) price time series at the Malaysian rubber exchange in Kuala Lumpur in Ringgit per tonne and the West Texas Intermediate crude oil price in US $\$$ per barrel have been retrieved from Thompson Reuters Datastream. The panel hence consists of three time series covering roughly six and a half years or 1549 observations. The rubber prices have been converted in US \$ using daily exchange rates. The three series are displayed in figure 4.5. Descriptive statistics are provided in table 4.1. For the policy data, government bills and documents have been reviewed to determine periods of active AETS, and data on area harvested have been drawn from FAOSTAT (2017).

Figure 4.5 International crude Oil, synthetic and natural rubber prices, 2011-2017

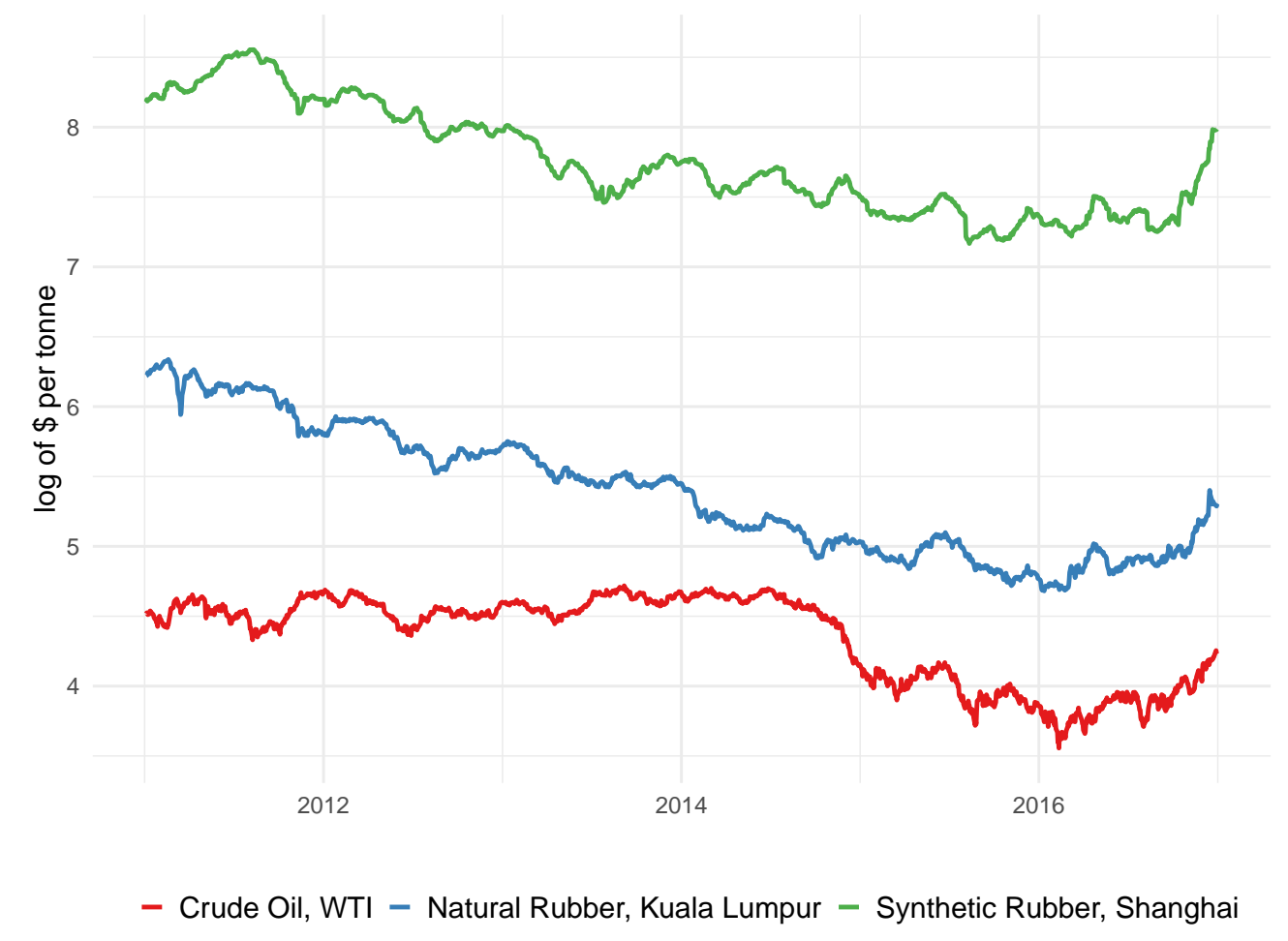


Table 4.1 Descriptive statistics of the variables entering the analysis

\begin{tabular}{lccccc}
\hline \hline Statistic & N & Mean & St. Dev. & Min & Max \\
\hline Crude oil & 1484 & 78.6 & 24.7 & 26.2 & 112.4 \\
Natural rubber & 1484 & 800 & 318 & 436 & 1743 \\
Synthetic rubber & 1484 & 158907 & 6621 & 8821 & 34367 \\
\hline
\end{tabular}

Source: Own production.

Styrene butadine rubber prices are expressed in CNY per tonne, the Standard Malaysian Rubber price time series in Ringgit per tonne, and the West Texas Intermediate crude oil price in US\$ per barrel. The estimation was carried out with the logarithmised variables.

\subsubsection{Results}

\section{Stationarity and order of integration}

In order to analyse univariate stationarity and determine the order of integration, all series are tested for unit roots using the ADF (Dickey and Fuller, 1979) and KPSS (Kwiatkowski et al., 1992) test routines. All tests bring about substantial evidence for non-stationarity of the data and for the variables to be $I(1)$ at significance levels of at least $5 \%$. With respect to the analysis of interdependence of the time series this implies testing for cointegration, that is testing for the existence of a long term equilibrium relationship.

\section{Seasonality and structural breaks}

The standard decomposition revealed no seasonality. Neither did seasonal dummies make a significant difference. It is conceivable that the standard tests (ADF, KPSS, etc.) are biased by the structural breaks that we assume to be in the data (i.e. policy regimes). These structural breaks are captured by the variables capturing the policies. Apart from these, there are no a priori reasons to expect other structural breaks.

\section{Cointegration}

The focus of the cointegration analysis lies on the prices of synthetic and natural rubber, as well as crude oil. Considering the substantial degree of substitutability between natural and synthetic rubber and that synthetic rubber is produced directly from crude oil, we would assume the three series to be cointegrated, with the two types of rubber following to some extend the Law of One Price (LOP). Both Johansen trace (Johansen, 1991) and eigenvalue, as well as the residual based Engle-Granger (Engle and Granger, 1987) testing procedures reveal the presence of a cointegrating relationship at a $5 \%$ significance level. The estimated long-run equation is depicted in table 4.2. 
Table 4.2 ECM Results

\begin{tabular}{ccccccccc}
\hline & \multicolumn{4}{c}{ Long run equation } & \multicolumn{3}{c}{ Short run coefficients } \\
\cline { 2 - 9 } & const. & $p_{t}^{S R}$ & $p_{t}^{C O}$ & $S M S_{T O, t}$ & $S M S_{h a, t}$ & $E C T_{t-1}$ & $\Delta p_{t}^{C O}$ & $A E T S_{t}$ \\
$(\Delta) p_{t}^{N R}$ & -3.19 & 0.97 & 0.28 & -0.18 & -0.31 & 0.01 & 0.09 & 0.00 \\
& $(0.06)$ & $(0.01)$ & $(0.01)$ & $(0.01)$ & $(0.01)$ & $(0.00)$ & $(0.02)$ & $(0.01)$ \\
$(\Delta) p_{t}^{S R}$ & & & & & & 0.01 & 0.16 & 0.02 \\
& & & & & & $(0.01)$ & $(0.04)$ & $(0.01)$ \\
\hline
\end{tabular}

Standard errors in parentheses. Results reported here are based on the long-run model 4 (Appendix 7.3), the estimation in which the effect of the $S M S$ policy is proxied by the development of the area harvested and the tire exports. The robustness checks for alternative proxies for the $S M S$ variable can be found in appendix 7.3. The full results of the short-run dynamics are available in appendix 7.4.

\section{Error Correction Model}

The coefficients of the error correction term are significant for natural rubber as well as in the synthetic rubber equation. That is, both rubber prices are cointegrated with adjustment speeds to deviations from the long run equilibrium of $1 \%$ daily in both natural and synthetic rubber prices. With regards to the AETS policies, we find a small and statistically insignificant coefficient in both equations. The prices of both natural and synthetic rubber react to short-run price dynamics of crude oil. These results are also displayed in table 4.2.

\subsubsection{Discussion}

\section{Validation of conceptual framework}

The price for synthetic rubber and the price for natural rubber are correlated positively in the long run, showing that these two products are gross substitutes at the margin. This is in line with insights from interviews with tire manufacturers. Based on the considerations in the theory section (equation 4.10), the expected long run relationship between natural and synthetic rubber prices was computed as $\ln p_{a}^{W}=1.29$ in the absence of policies and estimated to be 0.97 . The similarity in the order of magnitude validates the theoretical model.

\section{Policy effectiveness}

The significant coefficients of the short run parameters for the error correction term and the crude oil price indicate that even though policies have been operational, they did not fully insulate the natural rubber price from price developments in related markets. Prices are still transmitted between the natural and synthetic rubber markets. Additionally, the short run price dynamics of both natural and synthetic rubber are affected by changes in the crude oil price.

The AETS policy of export quotas was only partially successful in reducing mutual dependence between natural and synthetic rubber prices on the long run: since the policy to reduce farm supply is accounted for in the econometric model, the effect of the export quota 
can be derived from the difference between computation and estimation, subject to errors in the estimation and assumptions in the computation. $\frac{1}{1+t} \approx \frac{0.97}{1.29}=0.75$, so $(1+t) \approx 1.33$. This is an indicator for the export quota having led to a minor detachment of the natural rubber price from the synthetic one's in the long run.

The part of the $S M S$ policy that leads to an increase of domestic use of natural rubber in tire production over the long run, proxied by $S M S_{T O}$, is negatively correlated with $p^{N R}$. Two transmission channels between the export of car tires from Indonesia, Thailand and Malaysia and the world price for natural rubber are thinkable: first is that the reduction of the natural rubber supply base in the rest of the world increases global prices, as intended by the TRC. However, adverse effects are also conceivable: an increase of tire exports can lead to an oversupply on the world market, leading to a reduction in the tire price which in turn results in a reduction of the world prices for the inputs. Since the TRC countries contribute a combined share of $8.4 \%$ to this 74 billion US $\$$ market, which makes them collectively the second largest tire exporter in the world, this is indeed plausible. ${ }^{9}$ The negative sign of the corresponding coefficient indicates that this is indeed happening. This means that - if the TRC's SMS policy indeed increased tire exports - the policy backfired, being associated with an actual reduction in the price for natural rubber.

The coefficient capturing the policy's effect on land expansion, $S M S_{h a}$, has the politically desired negative coefficient, indicating that the targeted reduction of land area did indeed lead to an increase in prices.

The domestic rubber sectors have been subject to a dramatic price decrease between 2012 and 2015. While the determinants of the price fall are empirically not yet understood to a full extent, it is likely that increased production of non-TRC member countries, most notably India and Vietnam, in conjunction with a demand shift from Europe and the United States towards China and India, where tire legislation is laxer regarding minimum natural rubber contents, have contributed to the phenomenon. From a trade economics perspective, the comparative advantage of TRC member countries in supplying rubber to world markets appears to be decreasing giving not only rise to rubber sectors of other countries but also to other domestic sectors. The inefficacy of policy support underscores the strength of the shift of land use in the region. It is likely that already observable decreases in rubber production area in favour of oil palm production systems will continue to prevail.

\section{Oil price}

The price of crude oil is a proxy for global business cycles and its positive correlation with the natural rubber price on the long run and the positive short run dynamics indicate that increased demand for all goods also increases the natural rubber prices on the long run.

\footnotetext{
${ }^{9}$ Numbers

from

http://www.worldstopexports.com/rubber-tires-exports-country

(accessed on 06.01.2019).
} 


\subsection{Conclusions}

While the effect of policies on the targeted market are often subject to analysis, their effects on a secondary market are seldom discussed. A prominent example for this at work is the world market for natural rubber, dominated by three large exporters which are organised in the Tripartite Rubber Council. The TRC unites Indonesia, Thailand and Malaysia who jointly restrict raw rubber production and tax exports with the target to increase the natural rubber price and to insulate it from the interlinked markets of synthetic rubber and crude oil.

This paper extends the well-established Gardner Model by the TRC's policy measures to predict the maximum feasible outcome of the policy. The findings of the theoretical model suggest that an export tax on intermediate input $a$ introduced by a big exporter decouples the price of the industrial input $p_{b}$ from the one of the agricultural input, $p_{a}$. The same holds for the other policy under review: implementing policies that reduce the total output of $a$ weakens the reaction of $p_{a}$ to a change in $p_{b}$. Empirical results are generated using cointegration and ECM techniques where policies are modelled as potential exogenous drivers of price transmission and levels.

Results indicate that the prices of natural and synthetic rubber, as well as of crude oil, are well cointegrated. The markets for both types of rubber are subject to crude oil price dynamics. The AETS policy of export restriction seems to have partially detached the dynamics in synthetic rubber and crude oil from the natural rubber price. The $S M S$ policy of supply restrictions did have two effects: while the slowing down of plantation expansion increased price levels as intended, the increased domestic consumption seems to have back fired and led to a decrease of international natural rubber prices. While the implementing TRC institutions claim that the policies have unambiguously contributed to price increments in the past, our results indicate that the export reductions did not cause a measurable effect and the domestic demand stimulus even caused detrimental effects. However, the reduction of land expansion slightly contributed to the intended target. 


\section{Chapter Five}

\section{svars: An R Package for Data-Driven Identification in Multivariate Time Series Analysis ${ }^{1}$}

Structural vector autoregressive (SVAR) models are frequently applied to trace the contemporaneous linkages among (macroeconomic) variables back to an interplay of orthogonal structural shocks. Under Gaussianity the structural parameters are unidentified without additional (often external and not data-based) information. In contrast, the often reasonable assumption of heteroskedastic and/or non-Gaussian model disturbances offers the possibility to identify unique structural shocks. We describe the R package svars which implements statistical identification techniques that can be both heteroskedasticity based or independence based. Moreover, it includes a rich variety of analysis tools that are well known in the SVAR literature. Next to a comprehensive review of the theoretical background, we provide a detailed description of the associated $R$ functions. Furthermore, a macroeconomic application serves as a step-by-step guide on how to apply these functions to the identification and interpretation of structural VAR models.

Keywords: SVAR models, identification, independent components, non-Gaussian maximum likelihood, changes in volatility, smooth transition covariance, $R$

${ }^{1}$ This chapter is forthcoming in the Journal of Statistical Software and co-authored by Alexander Lange (AL), who is the lead author, Simone Maxand (SM) and Helmut Herwartz (HH). AL conceptualized the $\mathrm{R}$ package. $\mathrm{AL}$ and Bernhard Dalheimer (BD) coded the $\mathrm{R}$ package with support from SM. AL, BD and SM wrote help files and the user manual. HH and SM provided advisory support throughout the package development. The essay was written by AL, with support from BD and SM. All authors edited and revised the final manuscript.

Acknowledgement: We thank the editors and two anonymous reviewers for helpful comments and suggestions. Furthermore, we thank Bernhard Pfaff for his kind help. Financial support of the DFG through project HE 2188/12-1 and 192626868 as well as the Academy of Finland (308628) are gratefully acknowledged. 


\subsection{Introduction}

Particularly in macroeconometrics, structural vector autoregressive (SVAR) models have become a prominent tool to determine the impacts of different (economic) shocks in a system of variables. Within these models, the unobserved structural shocks represent information that is hidden in the reduced form vector autoregressive (VAR) model. Nevertheless, analysts might be interested in the system's reaction to exactly this type of isolated shocks, which is commonly visualized by means of impulse-response functions. For instance, policy makers could be interested in revealing the effects of an unexpected interest rate cut. Estimating the reduced form VAR by means of least squares (LS) or maximum likelihood methods (ML) is straightforward (see, e.g., Lütkepohl, 2005), however, identifying the non-unique structural form is a controversial topic in the SVAR literature.

Beginning with the pioneering work of Sims (1980), two main types of identification strategies have been developed. On the one hand, following Sims (1980) original ideas such strategies refer to economic theory. Theory based methods implement economic restrictions (e.g., short-run restrictions (Sims, 1980), long-run restrictions (Blanchard and Quah, 1989) or specific sign patterns (Uhlig, 2005)) a-priori. On the other hand, statistical identification methods which have been developed more recently exploit the informational content of specific data features (heteroskedasticitiy of structural shocks, uniqueness of non-Gaussian independent components). The R package svars, which we describe in this paper, focuses on these statistical methods to identify the structural shocks.

The R (R Core Team, 2017) archive network comprises several widely applied packages for multivariate time series models and, in particular, for analyzing VAR models. The vars package (Pfaff, 2008) contains estimation techniques for reduced form VAR models, and functions to determine the lag order and to perform several diagnostic tests. Moreover, the vars package allows for the estimation of a basic structural form by means of theory-based short- and long-run restrictions. Further $\mathrm{R}$ packages for multivariate time series analysis and VAR estimation are tsDyn (Stigler, 2010) and MTS (Tsay, 2015). To the authors' knowledge, currently only the VARsignR package (Danne, 2015) contains functions for SVAR identification by means of theory-based sign restrictions.

Given the lack of implementations of statistical identification techniques in R, the package svars has been explicitly developed to fill this gap by providing various recent statistical methods to estimate SVAR models. These methods build upon distinct but not mutually exclusive statistical properties of the data (i.e., covariance changes and the uniqueness of independent non-Gaussian distributed structural shocks). The svars package supports six identification techniques. Three identification methods make use of the assumption of heteroskedastic shocks, i.e., the identification (i) via changes in volatility (Rigobon, 2003), (ii) via smooth transitions of covariances (Lütkepohl and Netsunajev, 2017b) and (iii) via gen- 
eralized autoregressive conditional heteroskedasticity (GARCH) (Normadin and Phaneuf, 2004; Bouakez and Normandin, 2010). Three further identification methods connect to the uniqueness of non-Gaussian independent components, namely the detection of least dependent innovations based on (iv) Cramér-von Mises (CVM) statistics (Herwartz, 2018), (v) the distance covariances (Matteson and Tsay, 2017) and (vi) a parametric non-Gaussian ML approach (Lanne et al., 2017b).

By offering a variety of identification methods, the svars package can be applied in diverse data settings. Additionally, it extends the existing pool of SVAR techniques in $\mathrm{R}$ with more recent bootstrap procedures, further statistics and hypothesis tests directly related to inference in SVAR models. In this sense, the svars package is designed as a complete toolbox for the structural analysis of multivariate time series. Based on objects from reduced form estimations, svars is compatible with other packages such as vars, tsDyn and MTS. Moreover, computationally demanding modules are fully implemented in $\mathrm{C}++$ and linked to R using the Rcpp (Eddelbuettel and François, 2011) and RcppArmadillo (Eddelbuettel and Sanderson, 2014) libraries. The package is available on CRAN at https://cran.rproject.org $/$ package $=$ svars.

The article is organized as follows: Section 5.2 outlines the SVAR model and the alternative identification methods. In Section 5.3, we describe bootstrap methods and further diagnostic tools for SVAR analysis. Section 5.4 details the package design, and Section 5.5 provides an illustrative application of two identification schemes to a real world dataset. Lastly, a summary and an outlook on future extensions of the svars package complete this article.

\subsection{Structural vector autoregressive models}

Consider a $K$-dimensional VAR model of order $p$

$$
\begin{aligned}
y_{t} & =\mu+A_{1} y_{t-1}+\ldots+A_{p} y_{t-p}+u_{t}, \\
& =\mu+A_{1} y_{t-1}+\ldots+A_{p} y_{t-p}+B \varepsilon_{t}, \quad t=1, \ldots, T,
\end{aligned}
$$

where $y_{t}=\left[y_{1 t}, \ldots, y_{K t}\right]^{\top}$ is a vector of observable variables, $A_{i}, i=1, \ldots, p$, are $(K \times K)$ coefficient matrices, and intercept parameters are collected in $\mu$. We focus on the case of time invariant deterministic terms for notational clarity. Model augmentation with time-varying deterministic terms (e.g., breaks, linear trends), however, is straightforward. Furthermore, the VAR model is stationary (invertible) by assumption. The vector $u_{t}$ consists of reducedform residuals, which are serially uncorrelated with $\mathbb{E}\left(u_{t}\right)=0$ and $\operatorname{Cov}\left(u_{t}\right)=\Sigma_{u}$. The nonsingular matrix $B$ captures the instantaneous effects of the structural shocks $\varepsilon_{t}=B^{-1} u_{t}$ 
on the variables of the system.

In the following, we briefly discuss the identification problem in SVAR analysis. Subsequently, we present six alternative statistical approaches to uniquely determine the structural shocks. Finally, we provide a short guidance on how to choose between these alternative identification approaches.

\subsubsection{The identification problem}

Cross-equation relations between the reduced-form residuals in Equation 5.1 are characterized by the covariance matrix

$$
\operatorname{Cov}\left(u_{t}\right)=\Sigma_{u}=B \Sigma_{\varepsilon} B^{\top}
$$

where the covariance of the structural shocks $\operatorname{Cov}\left(\varepsilon_{t}\right)=\Sigma_{\varepsilon}$ is a diagonal matrix. Thus, structural shocks are uncorrelated, which enables a meaningful impulse-response analysis (Lütkepohl, 2005). Without any further model specification, Equation 5.3 holds for every matrix $B$ which decomposes the covariance matrix $\Sigma_{u}$. Hence, additional restrictions are necessary to identify a (unique) matrix $B .^{2}$ In this paper, we focus on identification techniques which use the underlying data structure to determine the structural matrix. After estimating the model in Equation 5.1 by means of LS or ML methods, the resulting reduced form residual estimates $\hat{u}_{t}$ and the corresponding covariance estimate $\widehat{\Sigma}_{u}$ provide the starting point for the subsequent identification techniques. The following two Sections introduce the statistical identification methods which constitute the core functions of the svars package.

\subsubsection{Identification by means of heteroskedastic innovations}

Time series are often characterized by time-varying covariance structures. Therefore, it is tempting to unravel the structural relationships by means of such changes in the second order moments (see, e.g., Sentana and Fiorentini, 2001; Rigobon, 2003). The svars package includes three alternative heteroskedasticity based SVAR identification schemes. The first approach is built upon unconditional shifts in the covariance (Rigobon, 2003), while the second procedure allows for a smooth transition between the covariance regimes (Lütkepohl and Netsunajev, 2017b). The third scheme implements the identification of the structural shocks via conditional heteroskedasticity (Normadin and Phaneuf, 2004).

\footnotetext{
${ }^{2}$ The identification problem is described in more detail, for instance, in Chapter 1 of Lütkepohl (2005). Kilian and Lütkepohl (2017) resume a variety of traditional and more recent methods to identify the structural shocks.
} 


\subsubsection{Changes in volatility $(\mathrm{CV})$}

Rigobon (2003) uses the presence of shifts in the time series' variance at known time points for the identification of structural shocks. He considers a model of exogenous covariance changes. More precisely, the changes of the covariance matrix occur at prespecified break dates implying

$$
\mathbb{E}\left(u_{t} u_{t}^{\top}\right)=\Sigma_{t}=\Sigma_{u}(m) \text { for } m=1, \ldots, M, t=1, \ldots, T
$$

Here, the index $m=1, \ldots, M$ indicates the respective variance regime. In the most simple framework of two volatility states (i.e., $M=2$ ) with a structural break at time point $T_{s b} \in$ $\{1, \ldots, T\}$, the reduced form covariance matrix is

$$
\mathbb{E}\left(u_{t} u_{t}^{\top}\right)=\left\{\begin{array}{l}
\Sigma_{1} \text { for } t=1, \ldots, T_{s b}-1 \\
\Sigma_{2} \text { for } t=T_{s b}, \ldots, T
\end{array}\right.
$$

where $\Sigma_{1} \neq \Sigma_{2}$. The two covariance matrices can be decomposed as $\Sigma_{1}=B B^{\top}$ and $\Sigma_{2}=$ $B \Lambda B^{\top}$, where $\Lambda$ is a diagonal matrix with diagonal elements $\lambda_{i i}>0, i=1, \ldots, K$. The matrix $\Lambda$ formalizes the change of the variance of structural shocks $\varepsilon_{t}$ in the second regime. In other words, the structural shocks have unit variance in the first regime, and variances $\lambda_{i i}, i=1, \ldots, K$, in the second regime. The structural shocks are uniquely identified if all diagonal elements in $\Lambda$ are distinct. Under the assumption of Gaussian residuals $u_{t}$, the log-likelihood function for the estimation of $B$ and $\Lambda$ is

$$
\begin{aligned}
\log \mathcal{L}= & T \frac{K}{2} \log 2 \pi-\frac{T_{s b}-1}{2}\left[\log \operatorname{det}\left(B B^{\top}\right)+\operatorname{tr}\left(\widehat{\Sigma}_{1}\left(B B^{\top}\right)^{-1}\right)\right] \\
& -\frac{T-T_{s b}+1}{2}\left[\log \operatorname{det}\left(B \Lambda B^{\top}\right)+\operatorname{tr}\left(\widehat{\Sigma}_{2}\left(B \Lambda B^{\top}\right)^{-1}\right)\right]
\end{aligned}
$$

where $\widehat{\Sigma}_{1}$ and $\widehat{\Sigma}_{2}$ are retrieved from estimated residuals $\widehat{u}_{t}$, respectively, as

$$
\widehat{\Sigma}_{1}=\frac{1}{T_{s b}-1} \sum_{t=1}^{T_{s b}-1} \widehat{u}_{t} \widehat{u}_{t}^{\top} \quad \text { and } \quad \widehat{\Sigma}_{2}=\frac{1}{T-T_{s b}+1} \sum_{t=T_{s b}}^{T} \widehat{u}_{t} \widehat{u}_{t}^{\top} .
$$

For the numerical log-likelihood optimization of (5.4), the initial matrix $B$ is the lower triangular decomposition of $T^{-1} \sum_{t=1}^{T} \widehat{u}_{t} \widehat{u}_{t}^{\top}$, and the initial matrix $\Lambda$ is set to the identity matrix. Lanne and Lütkepohl (2008) introduce an iterative procedure to improve the estimation precision of this routine. The matrices $\widetilde{B}$ and $\widetilde{\Lambda}$, which are obtained from maximizing the log-likelihood function, are used for iterative generalized least squares (GLS) estimation of 
the deterministic and autoregressive parameters

$$
\begin{aligned}
\widehat{\beta}= & \operatorname{vec}\left[\widehat{\mu}, \widehat{A}_{1}, \ldots, \widehat{A}_{p}\right] \\
= & {\left[\sum_{t=1}^{T_{s b}-1}\left(Z_{t} Z_{t}^{\top} \otimes\left(\widetilde{B} \widetilde{B}^{\top}\right)^{-1}\right)+\sum_{t=T_{s b}}^{T}\left(Z_{t} Z_{t}^{\top} \otimes\left(\widetilde{B} \widetilde{\Lambda} \widetilde{B}^{\top}\right)^{-1}\right)\right]^{-1} } \\
& \times\left[\sum_{t=1}^{T_{s b}-1}\left(Z_{t} \otimes\left(\widetilde{B} \widetilde{B}^{\top}\right)^{-1}\right) y_{t}+\sum_{t=T_{s b}}^{T}\left(Z_{t} \otimes\left(\widetilde{B} \widetilde{\Lambda} \widetilde{B}^{\top}\right)^{-1}\right) y_{t}\right]
\end{aligned}
$$

where $Z_{t}^{\top}=\left[1, y_{t-1}^{\top}, \ldots, y_{t-p}^{\top}\right]$. Then, the GLS estimator $\widehat{\beta}$ is used to update the covariance estimates by means of $\widehat{u}_{t}=y_{t}-\left(Z_{t}^{\top} \otimes I_{K}\right) \widehat{\beta}$. This algorithm iterates until the log-likelihood converges. Furthermore, standard errors for the structural parameters can be obtained from the square root of the inverted information matrix (Hamilton, 1994).

Identification through changes in volatility is conditional on the determination of the variance regimes. If available, the analyst might use external information for the selection of suitable break points $\left(T_{s b}\right)$. Typically these are extraordinary events in history which can be associated with a change in data variation (see, e.g., Rigobon and Sack, 2004). Alternatively, the model might be evaluated conditional on a range of alternative break point candidates from which the analyst selects the model with the highest log-likelihood as described in Lütkepohl and Schlaak (2018).

\subsubsection{Smooth transition (co)variances (ST)}

The implementation of identification via smooth transition covariances follows the descriptions in Lütkepohl and Netsunajev (2017b) and generalizes the identification via changes in volatility. The covariance matrix of the error terms $u_{t}$ consists of several volatility states, and the transition from one state to another is formalized by means of a non-linear function. For two volatility regimes with distinct covariance matrices $\Sigma_{1}$ and $\Sigma_{2}$, the covariance structure at time $t$ is

$$
\mathbb{E}\left(u_{t} u_{t}^{\top}\right)=\Omega_{t}=\left(1-G\left(s_{t}\right)\right) \Sigma_{1}+G\left(s_{t}\right) \Sigma_{2}, \quad t=1, \ldots, T
$$

In (5.5), $G(\cdot)$ is the transition function determined by the transition variable $s_{t}$. While the transition variable is usually deterministic (e.g., $s_{t}=t$ ), the model also allows for stochastic transition variables, for instance, lagged dependent variables (see Lütkepohl and Netsunajev, $2017 \mathrm{~b}$, for more details). The most frequently employed transition function is the logistic function proposed by Maddala (1977), which is of the form

$$
G\left(\gamma, c, s_{t}\right)=\left[1+\exp \left(-\exp (\gamma)\left(s_{t}-c\right)\right)\right]^{-1}
$$

The coefficient $\gamma$ determines the slope of the function and $c$ is the time point of transition. Based on the covariance structure in Equation 5.5 and Equation 5.6, and the assumption of 
normally distributed residuals $u_{t}$, the log-likelihood function reads as

$$
\log \mathcal{L}=T \frac{K}{2} \log 2 \pi-\frac{1}{2} \sum_{t=1}^{T} \log \operatorname{det}\left(\Omega_{t}\right)-\frac{1}{2} \sum_{t=1}^{T} u_{t}^{\top} \Omega_{t}^{-1} u_{t}
$$

Grid optimization enables the determination of the transition parameters $\gamma$ and $c$. Lütkepohl and Netsunajev (2017b) suggest an iterative procedure for every pair of parameters $(\gamma, c)$. The first step is the maximization of the log-likelihood in (5.7) with respect to the structural parameters $B$ and $\Lambda$. In the second step, the estimated matrices $\widetilde{B}$ and $\widetilde{\Lambda}$ are used to re-estimate the reduced form VAR parameters by means of GLS estimation

$$
\widehat{\beta}=\left(\left(Z_{t}^{\top} \otimes I_{K}\right) W_{T}\left(Z_{t} \otimes I_{K}\right)\right)^{-1}\left(Z_{t}^{\top} \otimes I_{K}\right) W_{T} y
$$

where $W_{T}$ is a blockdiagonal $(K T \times K T)$ weighting matrix

$$
W_{T}=\left[\begin{array}{ccc}
\Omega_{1}^{-1} & \cdots & 0 \\
\vdots & \ddots & \vdots \\
0 & \cdots & \Omega_{T}^{-1}
\end{array}\right]
$$

The GLS step obtains $\widehat{\beta}$ to update the covariance estimates by means of $\widehat{u}_{t}=y_{t}-\left(Z_{t}^{\top} \otimes I_{K}\right) \widehat{\beta}$. The two steps are performed until the log-likelihood converges. The iterative procedure is evaluated at every parameter pair $(\gamma, c)$ within a prespecified range. The parameter pair which maximizes the log-likelihood in Equation 5.7 is considered to provide the best estimate for the true transition. For a more detailed discussion of the parameter choice see Lütkepohl and Netsunajev (2017b).

\subsubsection{Conditional heteroskedasticity (GARCH)}

As proposed by Normadin and Phaneuf (2004), Lanne and Saikkonen (2007) and Bouakez and Normandin (2010) structural shocks are unique if their conditional variances are of the GARCH type. For the formal exposition let $\mathcal{F}_{t}$ denote a filtration that summarizes systemic information which is available until time $t$. Accordingly, the time-varying covariance can be represented as

$$
\mathbb{E}\left(u_{t} u_{t}^{\top} \mid \mathcal{F}_{t-1}\right)=\Sigma_{t \mid t-1}=B \Lambda_{t \mid t-1} B^{\top}
$$

where

$$
\Lambda_{t \mid t-1}=\operatorname{diag}\left(\sigma_{1, t \mid t-1}^{2}, \ldots, \sigma_{K, t \mid t-1}^{2}\right)
$$

is a $(K \times K)$ matrix with GARCH implied variances on the main diagonal. In the context of SVAR identification typically low order $\operatorname{GARCH}(1,1)$ specifications are assumed, such that 
the individual variances exhibit a dynamic structure as

$$
\sigma_{k, t \mid t-1}^{2}=\left(1-\gamma_{k}-g_{k}\right)+\gamma_{k} \varepsilon_{k, t-1}^{2}+g_{k} \sigma_{k, t-1 \mid t-2}^{2}, \quad k=1, . ., K
$$

Higher-order GARCH structures are rarely employed in practice, even though this can be done in principle. Under suitable distributional and parametric restrictions, $\gamma_{k}>0, g_{k} \geq 0$ and $\gamma_{k}+g_{k}<1$, the marginal GARCH processes $\varepsilon_{k, t}$ are covariance stationary (Milunovich and Yang, 2013). Sentana and Fiorentini (2001) have shown that the structural parameters in $B$ are uniquely identified, if there are at least $K-1 \mathrm{GARCH}$-type variances present in $\Lambda_{t \mid t-1}$. The parameters $\gamma_{k}$ and $g_{k}$ can be estimated by means of standard univariate ML approaches. The multivariate Gaussian log-likelihood to obtain the structural parameters in $B$ is

$$
\log \mathcal{L}=T \frac{K}{2} \log 2 \pi-\frac{1}{2} \sum_{t=1}^{T} \log \operatorname{det}\left(\Sigma_{t \mid t-1}\right)-\frac{1}{2} \sum_{t=1}^{T} u_{t}^{\top} \Sigma_{t \mid t-1} u_{t} .
$$

For the practical implementation of identification through patterns of conditional heteroskedasticity, we follow the approach suggested by Lütkepohl and Milunovich (2016), and estimate the parameters in (5.10) and (5.11) iteratively until the log-likelihood in (5.11) converges.

\subsubsection{Identification through independent components}

As implied by a result of Comon (1994), independence of the components of $\varepsilon_{t}$ could serve to identify the matrix $B$ if at most one component $\varepsilon_{i t}$ exhibits a Gaussian distribution. Furthermore, partial identification of the non-Gaussian components is possible if the system contains multiple Gaussian components (cf. Maxand, 2019). The svars package implements three distinct approaches for identification by means of independent components. Referring to principles of Hodges-Lehman estimation (HL estimation, Hodges and Lehmann, 2006), the first two identification strategies allow for the detection of least dependent structural shocks by the minimization of nonparametric dependence criteria. More specifically, the first technique reveals the structural shocks by minimizing the CVM distance of Genest et al. (2007). Following a suggestion of Matteson and Tsay (2017), the distance covariance statistic of Székely et al. (2007a) is employed as a nonparametric independence diagnostic for the second estimator. The third identification scheme is a fully parametric ML approach for detecting independent Student- $t$ distributed shocks (Lanne et al., 2017b).

\subsubsection{Least dependent innovations build on Cramér-von Mises statistics (CVM)}

Under Gaussianity, the decomposition factor $B$ of the covariance matrix $\Sigma_{u}$ is not unique as Gaussian random vectors do not change their joint distribution under rotation. In contrast, assuming not more than one Gaussian distributed component $\varepsilon_{i t}$ in $\varepsilon_{t}$, the structural matrix $B$ can be uniquely determined. Introducing the nonparametric identification scheme, let $D$ 
denote a lower triangular Choleski factor of the covariance matrix of the reduced-form errors, $\Sigma_{u}=D D^{\top}$, which links the structural and reduced form errors by $\varepsilon_{t}=D^{-1} u_{t}$. Further candidate structural shocks can be generated as

$$
\tilde{\varepsilon}_{t}=Q \varepsilon_{t}=Q D^{-1} u_{t}
$$

where $Q$ is a rotation matrix such that $Q \neq I_{K}, Q Q^{\top}=I_{K}$. The rotation matrix could be parameterized as the product of $K(K-1) / 2$ distinct forms of orthogonal Givens rotation matrices. In the case of $K=3$, for instance, $Q(\theta)$ is defined as

$$
Q(\theta)=\left[\begin{array}{ccc}
1 & 0 & 0 \\
0 & \cos \left(\theta_{1}\right) & -\sin \left(\theta_{1}\right) \\
0 & \sin \left(\theta_{1}\right) & \cos \left(\theta_{1}\right)
\end{array}\right] \times\left[\begin{array}{ccc}
\cos \left(\theta_{2}\right) & 0 & -\sin \left(\theta_{2}\right) \\
0 & 1 & 0 \\
\sin \left(\theta_{2}\right) & 0 & \cos \left(\theta_{2}\right)
\end{array}\right] \times\left[\begin{array}{ccc}
\cos \left(\theta_{3}\right) & -\sin \left(\theta_{3}\right) & 0 \\
\sin \left(\theta_{3}\right) & \cos \left(\theta_{3}\right) & 0 \\
0 & 0 & 1
\end{array}\right]
$$

with rotation angles $0 \leq \theta_{i} \leq \pi, i=1,2,3$. By definition, the random vector $\tilde{\varepsilon}_{t}$ in Equation 5.12 is a rotation of $\varepsilon_{t}$. The set of possible structural matrices $B(\theta)=D Q(\theta)$ is defined in terms of the Choleski factor $D$ and the vector of rotation angles $\theta$ of the Givens matrices $Q(\theta)$.

To avoid any restrictive assumption on the distribution of $\varepsilon_{t}$, nonparametric independence tests are applied to measure the degree of dependence. For instance, the copula-based CVM distance of Genest et al. (2007) has been successfully applied in the SVAR literature (Herwartz and Plödt, 2016a; Herwartz, 2018) to assess mutual dependence. The CVM distance is

$$
\mathcal{B}_{\theta}=\int_{(0,1)^{K}}\left[\sqrt{T}\left(C(\tilde{\varepsilon})-\prod_{i=1}^{K} U\left(\tilde{\varepsilon}_{i}\right)\right)\right]^{2} d \tilde{\varepsilon}
$$

where $C$ is the empirical copula and $U$ is the distribution function of a uniformly distributed variable on $\{1 / T, \ldots, T / T\}$. The CVM algorithm provides a matrix estimate $\widehat{B}$ such that the rotated structural shocks $\tilde{\varepsilon}_{t}$ minimize the CVM dependence criterion. Hence, the obtained structural shocks are least dependent according to the statistic in (5.13) and the corresponding structural matrix $\widehat{B}$ is the HL estimator. Standard errors for $\widehat{B}$ are obtained by means of bootstrap procedures as presented in Section 5.3.6.

\subsubsection{Least dependent innovations build on distance covariance (DC)}

There is a variety of nonparametric criteria available to measure the degree of dependence between random variables, one of which, namely the CVM distance, has been described before. The ICA algorithm by Matteson and Tsay (2017) provides a matrix estimate $\widehat{B}$ such that the respective structural shocks $\tilde{\varepsilon}_{t}=\widehat{B}^{-1} \widehat{u}_{t}$ minimize the distance covariance of Székely et al. (2007a), which we denote as $\mathcal{U}_{T}\left(\tilde{\varepsilon}_{t}\right)$, i.e., the elements in $\tilde{\varepsilon}_{t}$ are least dependent according 
to $\mathcal{U}_{T}($.$) . Similar to the procedure building on the CVM statistic, the set of possible structural$ matrices $B(\theta)$ is defined in terms of the Choleski factor $D$ and the vector of rotation angles $\theta$ of $Q(\theta)$. The rotation angles $\tilde{\theta}=\operatorname{argmin}_{\theta} \mathcal{U}_{T}\left(\tilde{\varepsilon}_{t}(\theta)\right)$ determine the estimated structural matrix $\widehat{B}=B(\tilde{\theta}){ }^{3}$ In the svars package, we take advantage of the function steadyICA from the R package steadyICA (Risk et al., 2015) to estimate $\widehat{B}$. The minimum is determined by means of a gradient algorithm.

\subsubsection{Non-Gaussian maximum likelihood (NGML)}

The identification technique described by Lanne et al. (2017b) is also based on the assumption of non-Gaussian structural error terms. They propose ML estimation to determine the set of independent structural innovations, which are assumed to exhibit a Student $t$-distribution. Moreover, Lanne et al. (2017b) suggest a three-step estimation method for computationally demanding situations. The first step consists of LS estimation of the VAR parameters $\beta=$ $\operatorname{vec}\left[\mu, A_{1}, \ldots, A_{p}\right]$ and of the reduced form residuals $u_{t}(\widehat{\beta})=y_{t}-\widehat{\mu}-\widehat{A}_{1} y_{t-1}, \ldots,-\widehat{A}_{p} y_{t-p}$. In the second step the log-likelihood function is maximized conditional on the first step estimates $\widehat{\beta}$. The log-likelihood function is

$$
\log \mathcal{L}(\delta)=\log \mathcal{L}(\widehat{\beta}, \delta)=T^{-1} \sum_{t=1}^{T} l_{t}(\widehat{\beta}, \delta)
$$

where

$$
l_{t}(\widehat{\beta}, \delta)=\sum_{i=1}^{K} \log f_{i}\left(\sigma_{i}^{-1} \iota_{i} B(b)^{-1} u_{t}(\widehat{\beta}) ; d f_{i}\right)-\log \operatorname{det}(B(b))-\sum_{i=1}^{K} \log \sigma_{i},
$$

and $I_{i}$ is the $i$-th unit vector. The parameter vector of the log-likelihood function is composed of $\widehat{\beta}$ and $\delta=(b, \sigma, d f)$. Regarding the latter, $b$ is a $K(K-1) \times 1$ vector which contains the off-diagonal elements of the covariance decomposition matrix $B$. The parameters $\sigma_{i}$ and $d f_{i}$ are the scale and the degrees of freedom parameters of the density function $f_{i}$ of a Student $t$-distribution, respectively. In the third step, the parameter vector $\delta$ is replaced by the estimate $\tilde{\delta}$ and the log-likelihood

$$
\log \mathcal{L}(\beta)=\log \mathcal{L}(\beta, \widetilde{\delta})=T^{-1} \sum_{t=1}^{T} l_{t}(\beta, \widetilde{\delta})
$$

is maximized.

\subsubsection{Choice of an adequate identification technique}

In the face of a variety of statistical approaches available to model latent structural relationships, method selection becomes an important step of statistical identification. To facilitate

\footnotetext{
${ }^{3}$ For details on the exact minimization procedure and the empirical definition of the dependence measure we refer to Matteson and Tsay (2017).
} 
this selection step Table 5.1 provides an overview of the assumptions on the error terms $\varepsilon_{t}$ within the alternative identification models. Estimating the structural parameters by means of heteroskedasticity based approaches necessitates the corresponding type of covariance structure. Contrarily, identification through independent components is only possible in non-Gaussian distributional frameworks. Note that we distinguish between nonparametric models (i.e., CVM and DC) where no further specification of the distribution of the innovations is required and fully parametric ML approaches.

\begin{tabular}{|c|c|c|c|c|c|c|}
\hline \multirow{4}{*}{ Model } & \multicolumn{6}{|c|}{ Assumptions on } \\
\hline & \multirow{3}{*}{$\begin{array}{r}\text { the } \\
\text { Homoskedasticity }\end{array}$} & \multicolumn{2}{|l|}{ variance of $\varepsilon_{t}$} & \multicolumn{3}{|c|}{ the distribution of $\varepsilon_{t}$} \\
\hline & & Heteroske & lasticity & Gaussian & Non- & Gaussian \\
\hline & & Unconditional & Conditional & & Arbitrary & $t$-distribution \\
\hline \multicolumn{7}{|c|}{ Heteroskedasticity } \\
\hline $\mathrm{CV}$ & & $\checkmark$ & & $\checkmark$ & & \\
\hline $\mathrm{ST}^{4}$ & & $\checkmark$ & $\checkmark$ & $\checkmark$ & & \\
\hline GARCH & & & $\checkmark$ & $\checkmark$ & & \\
\hline \multicolumn{7}{|c|}{ Independence } \\
\hline CVM & $\checkmark$ & & & & $\checkmark$ & \\
\hline $\mathrm{DC}$ & $\checkmark$ & & & & $\checkmark$ & \\
\hline NGML & $\checkmark$ & & & & & $\checkmark$ \\
\hline
\end{tabular}

Table 5.1 Overview of identification models and respective underlying assumptions on the error term $\varepsilon_{t}$.

A more detailed discussion on method selection in the context of identification via heteroskedasticity can be found in Lütkepohl and Netsunajev (2017a) and Lütkepohl and Schlaak (2018). Moreover, Herwartz et al. (2019) compare heteroskedasticity and independence based models in a large scale simulation study. They show that identification by means of covariance changes provides precise estimation results if the log-likelihood is correctly specified, whereas under (co)variance misspecification such identification schemes lack efficiency or might suffer from estimation bias. In contrast, simulation based evidence suggests that identification via independent components is more robust with respect to alternative distributional frameworks and heteroskedasticity as long as the innovations are non-Gaussian.

\subsection{SVAR tests, tools and bootstrap methods}

As a basis for the six identification techniques, the statistical analysis of SVAR models requires a diagnostic analysis of the underlying data structure. The presented package comprises two types of data-driven procedures where the first group assumes heteroskedasticity and the second one non-Gaussianity of the error terms. To decide on Gaussianity of the data a number of normality tests are available in respective $\mathrm{R}$ packages (see e.g., normtest and

\footnotetext{
${ }^{4}$ Depending on the choice of the transition variable, the ST model can capture unconditional as well as conditional heteroskedasticity (Lütkepohl and Netsunajev, 2017b).
} 
ICtest, Gavrilov and Pusev, 2015; Nordhausen et al., 2018). Furthermore, the svars package contains several useful tests for SVAR analysis which have not yet been implemented in R. Next we describe the diagnostics and discuss several tools which support the economic interpretations of SVAR estimation results.

\subsubsection{Tests for structural breaks}

As described in Section 5.2, identification based on changes in volatility presumes at least one break point to occur in the covariance structure. To detect different types of breaks in the data, several tests that have been implemented in the strucchange package (Zeileis et al., 2002) are accessible for VAR analysis via the method stability() of the vars package. In the following, we consider two additional types of multivariate Chow tests, the sample split and the break point test. The sample split test addresses the null hypothesis of constant VAR parameters $\mu$ and $A_{i}, i=1,2, \ldots, p$. The break point test works similarly, but also tests if the covariance matrix of the residuals $u_{t}$ is constant over time (Lütkepohl and Kraetzig, 2004, Chapter 3). To implement suitable likelihood ratio statistics, the VAR is estimated conditional on the full sample of $T$ observations and conditional on the first $T_{1}=T_{s b}-p-1$ and the last $T_{2}=T-p-T_{s b}$ observations with $T_{s b}$ indicating the break point. The resulting residuals are denoted by $\widehat{u}_{t}, \widehat{u}_{t}^{(1)}$ and $\widehat{u}_{t}^{(2)}$. Then, the sample split and break point test statistic are defined, respectively, as

$$
\lambda_{S P}=\left(T_{1}+T_{2}\right)\left\{\log \operatorname{det}\left(\widehat{\Sigma}_{1,2}\right)-\log \operatorname{det}\left[\left(\frac{1}{T_{1}+T_{2}}\left(T_{1} \widehat{\Sigma}_{1}+T_{2} \widehat{\Sigma}_{2}\right)\right)\right]\right\}
$$

and

$$
\lambda_{B P}=\left(T_{1}+T_{2}\right) \log \operatorname{det}\left(\widehat{\Sigma}_{(1,2)}\right)-T_{1} \log \operatorname{det}\left(\widehat{\Sigma}_{1}\right)-T_{2} \log \operatorname{det}\left(\widehat{\Sigma}_{2}\right),
$$

where the covariance estimators are

$$
\begin{gathered}
\widehat{\Sigma}_{(1,2)}=\frac{1}{T_{1}} \sum_{t=1}^{T_{1}} \widehat{u}_{t} \widehat{u}_{t}^{\top}+\frac{1}{T_{2}} \sum_{t=T-T_{2}+1}^{T_{2}} \widehat{u}_{t} \widehat{u}_{t}^{\top}, \\
\widehat{\Sigma}_{1,2}=\frac{1}{T_{1}+T_{2}}\left(\sum_{t=1}^{T_{1}} \widehat{u}_{t} \widehat{u}_{t}^{\top}+\sum_{t=T-T_{2}+1}^{T_{2}} \widehat{u}_{t} \widehat{u}_{t}^{\top}\right), \\
\widehat{\Sigma}_{1}=\frac{1}{T_{1}} \sum_{t=1}^{T_{1}} \widehat{u}_{t}^{(1)} \widehat{u}_{t}^{(1)^{\top}}, \text { and } \widehat{\Sigma}_{2}=\frac{1}{T_{2}} \sum_{t=T_{1}+1}^{T} \widehat{u}_{t}^{(2)} \widehat{u}_{t}^{(2)^{\top}} .
\end{gathered}
$$

Candelon and Lütkepohl (2001) show that both test statistics $\lambda_{B P}$ and $\lambda_{S P}$ converge to a non-pivotal asymptotic limit distribution. Hence, bootstrap procedures are a natural device to obtain critical values for the statistic at hand. 


\subsubsection{Testing for identical diagonal elements}

Since the structural shocks are estimated by the volatility models under the assumption that the variance of the structural shocks change differently, respective diagnostic tests are frequently employed in the SVAR literature (see, e.g., Herwartz and Plödt, 2016b; Lütkepohl and Velinov, 2016; Lütkepohl and Netsunajev, 2017a). A suitable Wald statistic to test the null hypothesis of proportional variance shifts, $H_{0}: \lambda_{i i}=\lambda_{j j}$ is defined as

$$
\lambda_{W, i j}=\frac{\left(\lambda_{i i}-\lambda_{j j}\right)^{2}}{\operatorname{Var}\left(\lambda_{i i}\right)+\operatorname{Var}\left(\lambda_{j j}\right)-2 \operatorname{Cov}\left(\lambda_{i i}, \lambda_{j j}\right)} \sim \chi_{(2)}^{2},
$$

where parameter estimates and (co)variances obtain from the ML estimation. The null hypothesis is rejected for large values of $\lambda_{W, i j}$.

\subsubsection{Test for overidentifying restrictions}

The non-Gaussian ML and heteroskedasticity based models rest on a stylized log-likelihood optimization, which also allows for restricting the structural parameter space. Subsequently, the implied restrictions can be tested by means of likelihood ratio statistics

$$
\lambda_{L R}=2\left[\log \mathcal{L}(\operatorname{vec}(\widetilde{B}))-\log \mathcal{L}\left(\operatorname{vec}\left(\widetilde{B}_{r}\right)\right)\right] \sim \chi_{(N)}^{2},
$$

where $\widetilde{B}$ is the unrestricted ML estimator as defined in Equation 5.4, Equation 5.7 or Equa-

tion 5.14. Moreover, $\widetilde{B}_{r}$ denotes the restricted ML estimator, and $N$ is the number of restrictions. The null hypothesis that the restricted model holds is rejected for large values of $\lambda_{L R}$ (Lütkepohl, 2005).

\subsubsection{Test on joint parameter significance}

To test joint hypotheses of parameter significance for non likelihood based models as in Herwartz (2018) the package provides a $\chi^{2}$-test. The statistic for testing a number of $J$ linearly independent hypotheses is defined as

$$
\lambda_{J S}=(R \operatorname{vec}(\widehat{B})-r)^{\top}\left[\widehat{\operatorname{Cov}}\left(\operatorname{vec}\left(\widehat{B}^{* *}\right)\right)\right]^{-1}(R \operatorname{vec}(\widehat{B})-r) \approx \chi_{(J)}^{2}
$$

where $R$ is a known $J \times K^{2}$ dimensional selection matrix of rank $J$, and $r$ is a known $J \times 1$ vector, which represents the considered restrictions, such that the composite null hypothesis is $H_{0}: R \operatorname{vec}(B)=r$. The matrix $\widehat{B}^{* *}$ is the bootstrap version of the covariance decomposition matrix, and can be obtained from one of the bootstrap procedures described in Section 5.3.6 below. 


\subsubsection{Tools for SVAR analysis}

The identified structural matrix $B$ can help capturing the dynamic and instantaneous impacts of the structural shocks within the set of variables under consideration. Several tools to analyze these relations are described, for instance, in Kilian and Lütkepohl (2017) and Lütkepohl (2011). The svars package provides impulse-response functions, forecast error variance decompositions as well as historical decompositions.

\section{Impulse-response functions}

Impulse-response functions describe the impact of isolated unit shocks on the variables of the system with respect to a certain response delay (e.g., the zero delay gives the instantaneous impact). For the model formulation in Equation 5.1 the response matrices can be derived as follows (see, e.g., Lütkepohl, 2005)

$$
\begin{aligned}
A(L) y_{t} & =\mu+B \varepsilon_{t} \\
y_{t} & =A(L)^{-1} \mu+A(L)^{-1} B \varepsilon_{t} \\
& =\nu+\Phi(L) B \varepsilon_{t}=\nu+\sum_{i=0}^{\infty} \Phi_{i} B \varepsilon_{t-i}=\nu+\sum_{i=0}^{\infty} \Theta_{i} \varepsilon_{t-i}
\end{aligned}
$$

where $\nu$ is the unconditional mean of the series and $A(L)=I-A_{1} L-A_{2} L^{2}-\ldots-A_{p} L^{p}$. The elements of $\Theta_{i}:=\Phi_{i} B$ can be interpreted as the responses of the system to shocks $\varepsilon_{t}$ which summarize the informational content of dynamic parameters in $\Phi_{i}, i=1,2,3, \ldots$ and of the structural matrix $B$. In particular, $\Theta_{0}=B$.

\section{Forecast error variance decompositions}

Forecast error variance decompositions (FEVD) highlight the relative contribution of each shock to the variation a variable under scrutiny. For the multivariate series $y_{t}$, the corresponding $h$-step ahead forecast error is $y_{t+h}-y_{t \mid t}(h)=\Theta_{0} \varepsilon_{t+h}+\ldots+\Theta_{h} \varepsilon_{t+1}$, and the forecast error variance of the $k$-th variable is $\sigma_{k}^{2}(h)=\sum_{j=0}^{h-1}\left(\Theta_{k 1, j}^{2}+\ldots+\Theta_{k K, j}^{2}\right)$ (Lütkepohl, 2005). Since $\Sigma_{\varepsilon}=I_{K}$ holds by assumption, the relative contribution of shock $\varepsilon_{i t}$ to the $h$-step forecast error variance of variable $y_{k t}$ is

$$
F E V D_{k i}(h)=\left(\Theta_{k i, 0}^{2}+\ldots+\Theta_{k i, h-1}^{2}\right) / \sigma_{k}^{2}(h)
$$

\section{Historical decompositions}

Further information on the contribution of structural shocks to a variable of interest can be drawn from historical decompositions. The contribution of shock $\varepsilon_{j t}$ to a variable $y_{k t}$ in time 
period $t$ is

$$
y_{k t}^{(j)}=\sum_{i=0}^{t-1} \Theta_{k j, i} \varepsilon_{j, t-i}+\alpha_{j 1}^{(t)} y_{0}+\ldots+\alpha_{j p}^{(t)} y_{-p+1},
$$

where $\alpha_{j i}^{(t)}$ is the $j$-th row of $A_{i}^{(t)}$, and $\left[A_{1}^{(t)}, \ldots, A_{p}^{(t)}\right]$ consists of the first $K$ rows of the companion form matrix with exponent $t, \mathbf{A}^{t}$ (see Lütkepohl, 2005, for more details).

\subsubsection{Bootstrap methods}

\section{Wild bootstrap}

Inferential issues (e.g., estimating standard errors of point estimates or confidence intervals of impulse-responses) might rely on the so-called wild bootstrap approach, which is robust in case of various forms of heteroskedasticity (Goncalves and Kilian, 2004; Hafner and Herwartz, 2009). For instance, under a fixed-design, bootstrap samples can be constructed as

$$
y_{t}^{*}=\widehat{\mu}+\widehat{A}_{1} y_{t-1}+\widehat{A}_{2} y_{t-2}+\cdots+\widehat{A}_{p} y_{t-p}+u_{t}^{*}, \quad t=1, \ldots, T,
$$

where $\widehat{A}_{j}, j=1, \ldots, p$, and $\widehat{\mu}$ are LS parameter estimates retrieved from the data. To determine bootstrap error terms $u_{t}^{*}=\omega_{t} \widehat{u}_{t}$, the scalar random variable $\omega_{t}$ is drawn from a distribution with zero mean and unit variance $\left(\omega_{t} \sim(0,1)\right)$ which is independent of the observed data. A prominent distribution choice for sampling $\omega_{t}$ is the Gaussian distribution. Two other frequently considered approaches are drawing $\omega_{t}$ (i) from the so-called Rademacher distribution with $\omega_{t}$ being either unity or minus unity with probability 0.5 (Liu, 1988), and (ii) from the distribution suggested by Mammen (1993), where $\omega_{t}=-(\sqrt{5}-1) / 2$ with probability $(\sqrt{5}+1) /(2 \sqrt{5})$ or $\omega_{t}=(\sqrt{5}-1) / 2$ with probability $(\sqrt{5}-1) /(2 \sqrt{5})$.

For the error terms $\widehat{u}_{t}^{*}$, estimated from (5.20), we determine the bootstrap structural parameter matrix as $\widehat{B}^{* *}=\widehat{\Sigma}_{u}^{1 / 2} \widehat{\Sigma}_{\widehat{u}^{*}}^{-1 / 2} \widehat{B}^{*}$. Here, $\widehat{B}^{*}$ is a decomposition of $\widehat{\Sigma}_{\hat{u}^{*}}$ derived by the described identification procedures. The matrices $\widehat{\Sigma}_{u}^{1 / 2}$ and $\widehat{\Sigma}_{\widehat{u}^{*}}^{1 / 2}$ are symmetric eigenvalue decompositions of $\widehat{\Sigma}_{u}$ and $\widehat{\Sigma}_{\widehat{u}^{*}}$, respectively. Thus, $\widehat{B}^{* *}$ provides a factorization of the sample covariance matrix $\widehat{\Sigma}_{u}$ such that it can be used for inference on the structural parameters as depicted, for instance, in (5.19).

\section{Moving-block bootstrap}

Brüggemann et al. (2016) suggest the moving-block bootstrap for inference in VAR models characterized by conditional heteroskedasticity. The moving-block bootstrap depends on a chosen block length $\ell<T$, which determines the number of blocks $n=T / \ell$ needed for data generation. The $(K \times \ell)$-dimensional blocks $M_{i, \ell}=\left(\widehat{u}_{i+1}, \ldots, \widehat{u}_{i+\ell}\right), i=0, \ldots, T-\ell$, are laid randomly end-to-end together to obtain the bootstrap residuals $u_{1}^{*}, \ldots, u_{T}^{*}$. After centering 
the residuals, the bootstrap time series may be constructed recursively as

$$
y_{t}^{*}=\widehat{\mu}+\widehat{A}_{1} y_{t-1}^{*}+\widehat{A}_{2} y_{t-2}^{*}+\cdots+\widehat{A}_{p} y_{t-p}^{*}+u_{t}^{*}, \quad t=1, \ldots, T .
$$

It is important to note that asymptotic theory for block bootstrap schemes is typically derived under the assumption that $\ell \rightarrow \infty$ as $T \rightarrow \infty$. Yet, there is no consensus in the literature on the choice of $\ell$ in finite samples and, hence, choosing a block length in practice is not straightforward. In general, the chosen block length should ensure that residuals being more than $\ell$ time points apart from each other are uncorrelated. A more thorough discussion on the choice of the block length can be found in Lahiri (2003). The bootstrap covariance decomposition $\widehat{B}^{* *}$ is determined analogously to the case of wild bootstrap sampling described before. Note that both the wild bootstrap and the moving-block bootstrap can be implemented either under a fixed-design as in (5.20) or a recursive-design as in (5.21).

\section{Bootstrap-after-bootstrap}

Kilian (1998) proposes a bias-corrected bootstrap procedure to account for small sample biases. By means of the so-called bootstrap-after-bootstrap method, the true underlying data generating process (DGP) is not approximated by the bootstrap DGP as in Equation 5.20 and Equation 5.21 , but rather by means of a bootstrap DGP with bias-corrected VAR parameters $\widehat{\beta}^{B C}=\left[\widehat{\mu}^{B C}, \widehat{A}_{1}^{B C}, \ldots, \widehat{A}_{p}^{B C}\right]$.

The approach consists of two stages. In the first stage, bootstrap replications for $\widehat{\beta}^{*}=$ $\left[\widehat{\mu}^{*}, \widehat{A}_{1}^{*}, \ldots, \widehat{A}_{p}^{*}\right]$ are generated according to Equation 5.20 or Equation 5.21 , and bias terms are approximated as $\widehat{\Psi}=\overline{\widehat{\beta}}^{*}-\widehat{\beta}$. Subsequently, the modulus of the largest root of the companion matrix associated with $\widehat{\beta}$ can be calculated, which is denoted by $m(\widehat{\beta})$. If $m(\widehat{\beta}) \geq 1, \widehat{\beta}^{B C}=\widehat{\beta}$ is set without any adjustment. However, if $m(\widehat{\beta})<1$, then the VAR parameters are corrected such that $\widehat{\beta}^{B C}=\widehat{\beta}-\widehat{\Psi} \cdot{ }^{5}$

In the second stage, the actual bootstrap samples can be obtained from substituting $\widehat{\beta}^{B C}$ for $\widehat{\beta}$ in Equation 5.20 or Equation 5.21. Kilian (1998) shows by means of a simulation study that in small samples the bootstrap-after-bootstrap method tends to be more accurate than standard bootstrap approaches. Kilian and Lütkepohl (2017) provide more insights into the merits of bias adjustments in resampling, as well as a detailed overview of further bootstrap approaches in the context of SVAR models.

\subsection{Package design}

Table 5.2 summarizes the design of the svars package. The package is built around the six core functions for identification of the structural VAR form (id.cv, id.cvm, id.dc, id.garch,

\footnotetext{
${ }^{5}$ The exact bias correction is an iterative procedure and described in Kilian (1998)
} 
id.ngml, id.st). Moreover, various methods and further diagnostic tools are available for the resulting objects of class svars which have been described in Section 5.3. In the following, we describe the mandatory and optional input arguments of the implemented functions in a detailed manner.

Function or method Class Methods for class Functions for class Description

- Core functions for SVAR identification

$\diamond$ SVAR models refered to (co)variance changes

$\begin{array}{llll}\text { id.cv } & \text { svars } & \begin{array}{l}\text { fevd, irf, } \\ \text { print, summary }\end{array} & \begin{array}{l}\text { hd, mb.boot, } \\ \text { wild.boot }\end{array} \\ \text { id.garch } & \text { svars } & \begin{array}{l}\text { fevd, irf, } \\ \text { print, summary }\end{array} & \begin{array}{l}\text { hd, mb.boot, } \\ \text { wild.boot }\end{array} \\ & & \text { fevd, irf, } & \text { hd, mb.boot, } \\ \text { id.st } & \text { svars } & \text { print, summary } & \text { wild.boot }\end{array}$

$\diamond$ SVAR models based on independent components

$\begin{array}{llll}\text { id.cvm } & \text { svars } & \begin{array}{l}\text { fevd, irf, } \\ \text { print, summary }\end{array} & \begin{array}{l}\text { hd, mb.boot, } \\ \text { wild.boot }\end{array} \\ & \text { svars } & \begin{array}{l}\text { fevd, irf, } \\ \text { print, summary }\end{array} & \text { hd, mb.boot, } \\ & & \text { wild.boot } \\ & \text { svars } & \text { fevd, irf, } & \text { hd, mb.boot, } \\ \text { id.ngml } & & & \end{array}$

- Functions and methods for SVAR analysis

$\diamond$ Pre-tests and joint significance tests

$\begin{array}{llll}\text { chow.test } & \text { chow } & \text { print, summary } & \\ \text { stability } & \text { chowpretest } & \text { plot, print } & \text { chow.test } \\ & \text { jstest } & \text { print, summary } & \\ \text { js.test } & & \end{array}$

$\diamond$ Further SVAR statistics

$\begin{array}{lll}\text { irf } & \text { svarirf } & \text { plot, print } \\ \text { fevd } & \text { svarfevd } & \text { plot, print } \\ \text { hd } & \text { hd } & \text { plot, print }\end{array}$

$\diamond$ Bootstrap procedures

$\begin{array}{lll}\text { mb.boot } & \text { sboot } & \text { plot, } \\ & & \text { print, summary } \\ \text { wild.boot } & \text { sboot } & \text { plot, } \\ & \text { print, summary } \\ \text { ba.boot } & \text { sboot } & \text { plot, } \\ & & \text { print, summary }\end{array}$

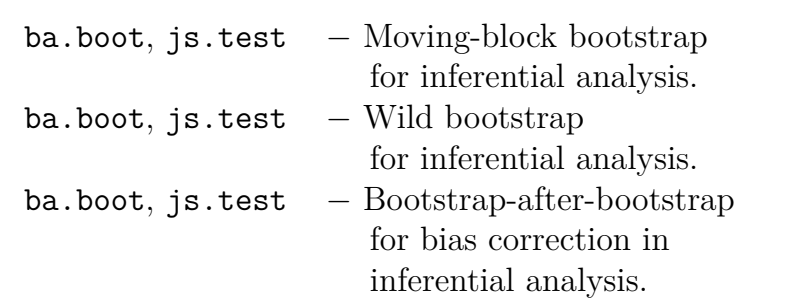

Moving-block bootstrap inferential analysis. for inferential analysis.

for bias correction in inferential analysis.

- Estimates the structural shocks via unconditional (co)variance shifts.

- Estimates the structural shocks through conditional heteroskedasticity.

- Estimates the structural shocks via smooth (co)variance transitions.

- Estimates the structural shocks via nonparametric CVM statistic.

- Estimates the structural shocks via nonparametric distance covariance statistic.

- Estimates the structural shocks via parametric non-Gaussian ML.

- Computes Chow test types on structural breaks.

- Performs multiple Chow tests in prespecified range.

- Performs chi-square test on joint parameter significance.

- Calculates impulseresponse functions.

- Calculates forecast error variance decomposition.

- Computes historical decomposition.

Table 5.2 Package design of svars. 


\subsubsection{Core functions for SVAR identification}

To apply the implemented identification techniques the user needs to provide an estimated reduced form VAR or vector error correction model (VECM) object of class varest or vec2var from the vars package. Alternatively, an object of class nlVar or VECM from the tsDyn package or the list delivered by the function VAR of the MTS package can serve as an input argument for id.cv, id.cvm, id.dc, id.garch, id.ngml or id.st. Besides the estimated VAR objects, the identification procedures allow for further input arguments which differ across the techniques. In the following, we describe these options separately.

\subsubsection{SVAR models built on (co)variance changes}

For identification by means of changes in volatility the following command can be used

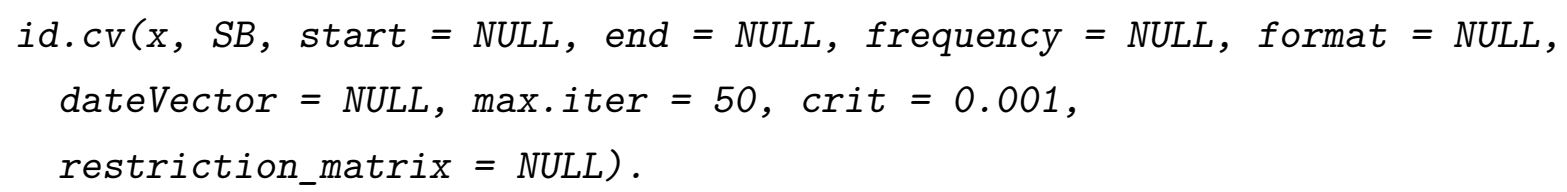

The function id.cv() requires the specification of a structural break point. Conditional on the data structure, the user may provide the breakpoint SB in various formats. Firstly, the sample can be separated into two parts by specifying the breakpoint in either integer or date formats. Secondly, single time instances can be assigned to a variance regime by passing a vector consisting of zeros and ones to the function. If the estimation of the reduced form VAR is based on a non-time series class object (e.g., ts), the user can add the information on the date and frequency by making use of the parameter dateVector or by specifying start/end and format/frequency. However, providing time series class objects or specifying dates is optional and the function also handles conventional observation numbers.

The log-likelihood and VAR coefficients are re-estimated in the algorithm until the loglikelihood changes by less than the value of crit or the maximum number of iterations (max.iter) is reached. Additionally, the function id.cv() allows for restricted ML estimation via the input argument restriction_matrix. There are two formats of specifying the restriction matrix, either pass (i) a $K \times K$ matrix, in which NA indicates unrestricted elements and 0 a restricted element, or (ii) a $K^{2} \times K^{2}$ matrix of rank $M$, where $M$ is the number of unrestricted coefficients (Lütkepohl, 2005). In this case, unit (zero) values on the main diagonal refer to the unrestricted (restricted) coefficients. In case of over-identifying restrictions, id.cv() estimates the unrestricted and the restricted SVAR to perform the likelihood ratio test outlined in Section 5.3.3.

The function

$i d \cdot \operatorname{garch}(x, \max . i t e r=5$, crit $=0.001$, restriction_matrix $=$ NULL) 
provides model identification if structural shocks exhibit conditional heteroskedasticity. Identification proceeds in two steps. In the first step $K$ univariate $\operatorname{GARCH}(1,1)$ models (see Equation 5.10) are estimated. In the second step a full, joint ML estimation of the parameters in $B$ is performed. These two steps are executed until the multivariate log-likelihood changes by less than the value of crit or the maximum number of iterations (max.iter) is reached. Analogously to the id.cv() function, passing a restriction_matrix enables the user to estimate and test restricted models.

Identification by means of smooth covariance transitions is implemented as

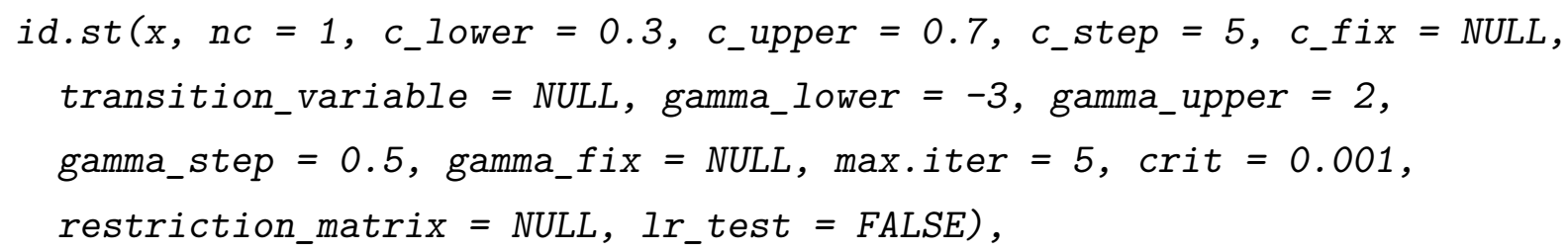

which entails several input arguments for adjustments. However, the user may run the function without any further specifications of input arguments only by passing the reduced form estimated VAR object. Since finding the optimal parameters $\gamma$ and $c$ as described in Section 5.2.2.2 is computationally demanding, the id.st function supports parallelization with nc determining the number of cores used. Grid optimization is optional. By default, the function searches for the transition point $c$ to be located between $0.3 T$ (c_lower) and $0.7 T$ (c_upper) with a step width of 5 time points (c_step). If the user wants to specify the transition point in advance, she can pass an observation number to c_fix. Analogously, for the slope parameter $\gamma$ the user can either specify a fixed slope parameter gamma_fix, or let the function optimize the transition coefficient between gamma_lower and gamma_upper.

Conditional on the location $(c)$ and slope $(\gamma)$ parameter the algorithm consists of an iterative procedure of log-likelihood optimization and GLS estimation until the improvement of the log-likelihood is smaller than crit or the maximum number of iterations (max.iter) is reached. By default, the transition variable corresponds to time, however, the user may choose another transition variable by passing a numeric vector to transition_variable. Note that the input argument for the location parameter has to be adjusted to the scale of the transition variable. Analogously to the previous functions, passing a restriction_matrix enables the estimation of restricted models. Due to the fact that the smooth transition covariance model is computationally demanding, it is possible to decide if the function performs a likelihood ratio test or not by specifying $1 r_{-}$test as either TRUE or FALSE.

\subsubsection{SVAR models built on independent components}

For identifying independent components by means of the CVM distance the function

id. $\operatorname{cvm}(\mathrm{x}, \mathrm{dd}=$ NULL, itermax $=500$, steptol $=100$, iter2 $=75)$ 
can be employed. In Section 5.2 we have elaborated on how this approach evaluates a CVM test for rotated versions of the shocks. We use the implementation of the CVM test in the package copula (Hofert et al., 2017). The function indepTestSim from the copula package generates an independent sample to calculate the $p$-value for the test statistic. The sample is passed to the svars function id.cvm as argument dd. If $\mathrm{dd}=$ NULL the sample is simulated within the id.cvm function. Simulating the independent sample in advance and passing the object to the id.cvm function may save computation time if the estimation is repeatedly applied to the same data set. The estimation of independent components through CVM statistics proceeds in two steps. The first stage is a global optimization using the differential evolution algorithm from the DEoptim package (Ardia et al., 2016). In the second stage, the test statistic is optimized locally around the estimated parameters from the first stage. The precision of the algorithm can be determined by the input arguments itermax and steptol at the first stage (for more details see the help file of DEoptim) and iter2 at the second stage.

The function

$i d \cdot d c(x, P I T=F A L S E)$

identifies the structural shocks by means of distance covariance statistics. The implementation is built on the ICA algorithm from the package steadyICA (Risk et al., 2015). The function steadyICA therein applies a gradient algorithm to determine the minimum of the dependence criterion. The option PIT determines if probability integral transformation (PIT) is applied to transform the marginal densities of the structural shocks prior to the evaluation of the dependence criterion.

Estimating the structural shocks via non-Gaussian ML estimation is implemented with the function

id.ngml (x, stage3 = FALSE, restriction_matrix $=$ NULL).

The input argument stage3 indicates if the autoregressive parameters of the VAR model are estimated by maximizing the log-likelihood function which Lanne et al. (2017b) describe as the third step of their model. Since this step does not change the result of the estimated covariance decomposition, and the estimation of the autoregressive parameter is computationally rather demanding, the default is set to FALSE. Analogously to the functions id.cv, id.garch and id.st, the user may run a restricted estimation by passing an appropriate restriction_matrix argument to id.ngml.

All identification functions (id.cv, id.garch, id.st, id.cvm, id.dc, id.ngml) return an object of class svars. The summary method for this class returns the estimated impact relation matrix with standard errors and various further information depending on the chosen identification method, while print only returns the covariance decomposition. The plot method 
is only applicable to objects from the function id.st and shows the optimized transition function of the variance from the first to the second volatility regime.

\subsubsection{Functions and methods for SVAR analysis}

The following functions and methods are built around the cornerstone functions which have been introduced in the last section. To obtain a user-friendly environment within the svars package, most of the implementations are feasible only by passing an object of class svars or sboot and leaving further specifications optional. Moreover, to facilitate compatibility with other R packages, we refer to the vars package (Pfaff, 2008), and adapt methods for parameter tests, impulse-response analysis and forecast error variance decompositions.

\subsubsection{Pre-tests and joint significance tests}

For prior analysis of parameter stability, the function

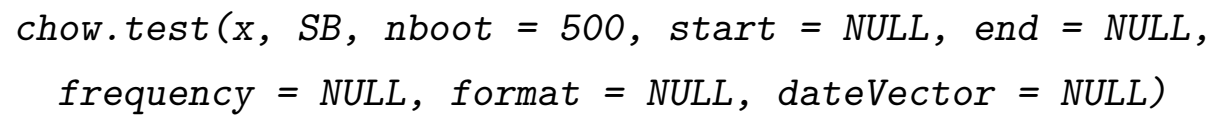

includes two versions of structural break tests. The input argument $\mathrm{x}$ needs to be a reduced form estimation result of class varest, vec2var or nlVar. The time point of the assumed structural break has to be passed in SB. The user can work with date formats, in the same way as described for the id.cv() function above. To calculate the $p$-values and critical values, the function employs a fixed-design wild bootstrap. The number of bootstrap replications needs to be provided by nboot. The summary() method returns the results from the sample split and break point tests. Additionally, the package includes an augmentation of the stability() method of the vars package (Pfaff, 2008), which provides access to a variety of parameter stability analysis tools of strucchange (Zeileis et al., 2002). The method has been extended to contain multivariate Chow tests

stability $(x$, type $=$ "mv-chow-test", $h=0.15)$.

By specifying type $=$ "mv-chow-test" and $\mathrm{h}=0.15$ the test statistics for all possible structural break points between $(\mathrm{h} / 2) T$ and $(1-\mathrm{h} / 2) T$ are calculated. The resulting object of class chowpretest from stability() can be used as an input argument for $\mathrm{x}$ in chow.test() afterwards without any further input specifications. Subsequently, the function provides the test results for the structural break at the observation with the corresponding highest break point test statistic resulting from stability().

After obtaining point- and bootstrap estimates, the user can test joint hypotheses on the estimated elements in the structural matrix $B$ by means of the function

js.test $(x, R, r=N U L L)$, 
where $\mathrm{x}$ is an object of class sboot. If $\mathrm{r}=$ NULL, the function performs a test of the hypothesis $H_{0}: R \operatorname{vec}(B)=0$.

\subsubsection{Further SVAR statistics}

Following the descriptions in Section 5.3, impulse-response functions can be calculated by means of

$\operatorname{irf}(x, n \cdot$ ahead $=20)$

where $\mathrm{x}$ is an object of class svars. The user can specify the time horizon of the impulseresponse functions, which is 20 periods by default. The same input arguments are passed to calculate forecast error variance decompositions using

fevd $(x, n$. ahead $=10)$.

Historical decompositions are calculated by the function

$h d(x$, series $=1)$.

By default, the first series, i.e., the series in the first column of the original data set is decomposed. For all three analysis tools plot methods are available to visualize the resulting objects.

\subsubsection{Bootstrap procedures}

The bootstrap procedures described in Section 5.3 are implemented in the functions mb . boot, wild.boot and ba.boot. The required input object $\mathrm{x}$ is of class svars. Furthermore, it is possible to record how often one or multiple bootstrap shocks hold a specific sign pattern. This helps to evaluate the plausibility of the signs of instantaneous effects as described in Herwartz (2018). The appearance of specific sign patterns is documented by passing a list of vectors containing 1 and -1 to the input argument signrest. Every list entry represents the impact effects of a shock to the variables in the system. Thus, each list entry is of the same size as the VAR model, i.e., contains $K$ elements. The list can consist of 1 up to $K$ entries, one for each structural shock. By default, the bootstrap functions evaluate the occurrence of the sign pattern of the point estimate. The $\mathrm{R}$ function for the moving-block bootstrap is

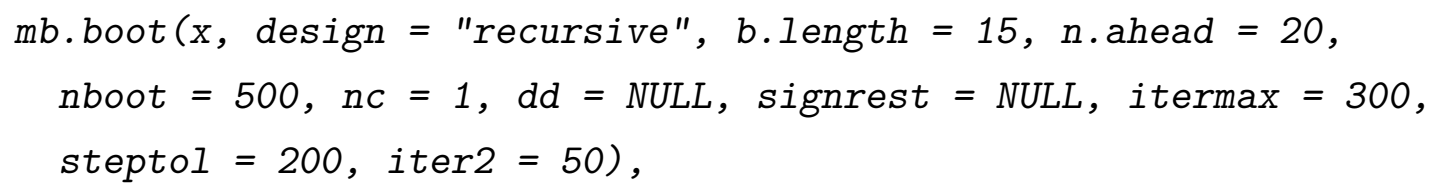


where the user needs to specify the block length with input argument $\mathrm{b}$. length. As described in Section 5.3.6 there is no consensus in the literature about the optimal block length in finite samples. In applied work, however, a typical block length is about $10 \%$ of the sample size (see, e.g., Brüggemann et al., 2016; Lütkepohl and Schlaak, 2019). The wild bootstrap method is implemented as

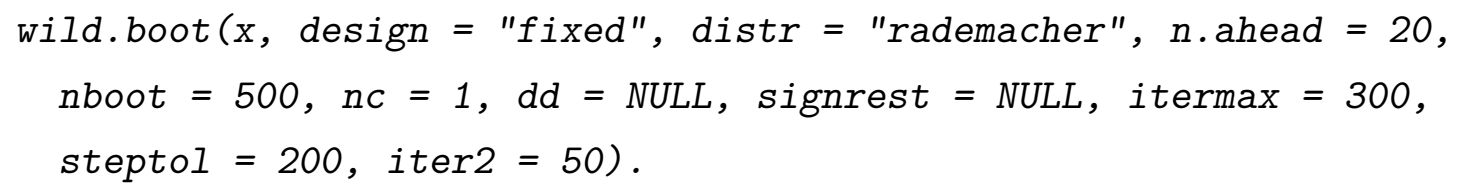

The user can choose to draw $\omega_{t}$ from a Rademacher distribution with distr = "rademacher", from a Gaussian distribution with distr = "gaussian" or from the distribution suggested in Mammen (1993) with distr = "mammen". The remaining input arguments for the two bootstrap functions are identical, e.g., both can be called as fixed-design (design = "fixed") or as recursive-design (design = "recursive"). Bootstrap impulse-responses are calculated in the functions for which the horizon needs to be determined via n.ahead. An integer for the number of bootstrap replications is supplied by the nboot argument. Parallelization is possible with a suitable choice of nc. The arguments dd, itermax, steptol and iter 2 correspond to the input arguments of the id.cvm model and are only applied if the point estimates have been derived by this method. Both bootstrap functions return an object of class sboot for which summary and plot methods can be applied.

Furthermore, the bootstrap-after-bootstrap procedure is implemented as

ba. $\operatorname{boot}(x, n c=1)$.

In contrast to the other bootstrap functions of svars, $\mathrm{x}$ is of class sboot, since the function only performs the bias correction and the second step of the procedure described above in Section 5.3.6. The necessary results from the first step of the algorithm are determined from the bootstrap object, which is passed to the function to obtain the most efficient implementation of this hierarchical bootstrap procedure. The second step bootstrap (after the bias correction) is executed with exactly the same specifications as in the first stage. Hence, no further input arguments are needed.

\subsection{Example}

To illustrate the functions and methods of the svars package, we replicate the empirical results of Herwartz and Plödt (2016b) obtained through the identification by means of unconditional covariance shifts (id.cv()). We augment their analysis by further statistics and complement the analysis with results from identification through independent components using the DC 
approach (id.dc()). ${ }^{6}$ The main objective of the application in this Section is to present the usage of the functions rather than discussing the results in depth.

Herwartz and Plödt (2016b) apply identification by means of the CV approach to investigate the effects of a monetary policy shock on the economy of the United States (US). They consider three series: the output gap " $\mathrm{x}$ ", which is defined as the log-deviation of real gross domestic product (GDP) from the potential output, the inflation "pi" as quarter-on-quarter growth rates of the GDP deflator and the federal funds rate " $i$ ". The data comes from the Federal Reserve Economic Data (FRED) database of the Federal Reserve Bank of St. Louis. The time series are sampled at the quarterly frequency and cover the time period from 1965Q1 until 2008Q3. The svars package contains this example data set labeled "USA".

The first step of the analysis is to load the svars package into the workspace. Furthermore, the ggplot2 (Wickham, 2009) package enables to display the data in a convenient way.

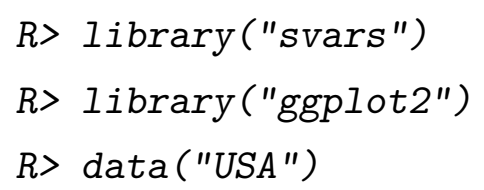

In order to estimate the structural shocks via the id.cv() function, the user has to specify the time point of the variance shift in advance. An appropriate time point might be found by visual inspection of the series, historical information or previous analyses. Figure 5.1 depicts the three time series. Inflation data ("pi") show less fluctuation during the second half of the data set.

$R>$ autoplot (USA, facets $=T)+$ theme_bw ()$+y l a b\left({ }^{\prime}{ }^{\prime}\right)$

Herwartz and Plödt (2016b) determine the break point at 1979Q3 due to a policy shift of the Federal Reserve Bank which caused a reduction of the volatility in US macroeconomic data (Stock and Watson, 2003).

The next step of the analysis is the estimation of the reduced form VAR, for instance, by means of the function VAR() from the vars package. We specify a VAR model with intercept of order $p=6$. After model estimation, we can use the resulting varest object to estimate the structural form with the function id.cv(). We provide the structural break point with the function argument SB in ts date format.

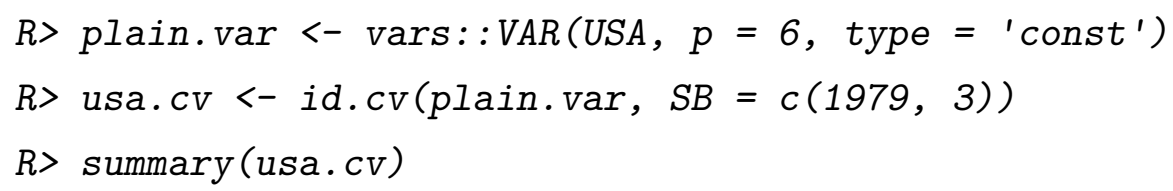

\footnotetext{
${ }^{6}$ Estimation via the CVM criterion and DC deliver qualitatively the same results. Identifying independent components by means of NGML and ST models provide results that are comparable to those obtained from assuming covariance shifts. Identification via the assumption of GARCH-type variances obtains results which are qualitatively different from those of all other approaches.
} 


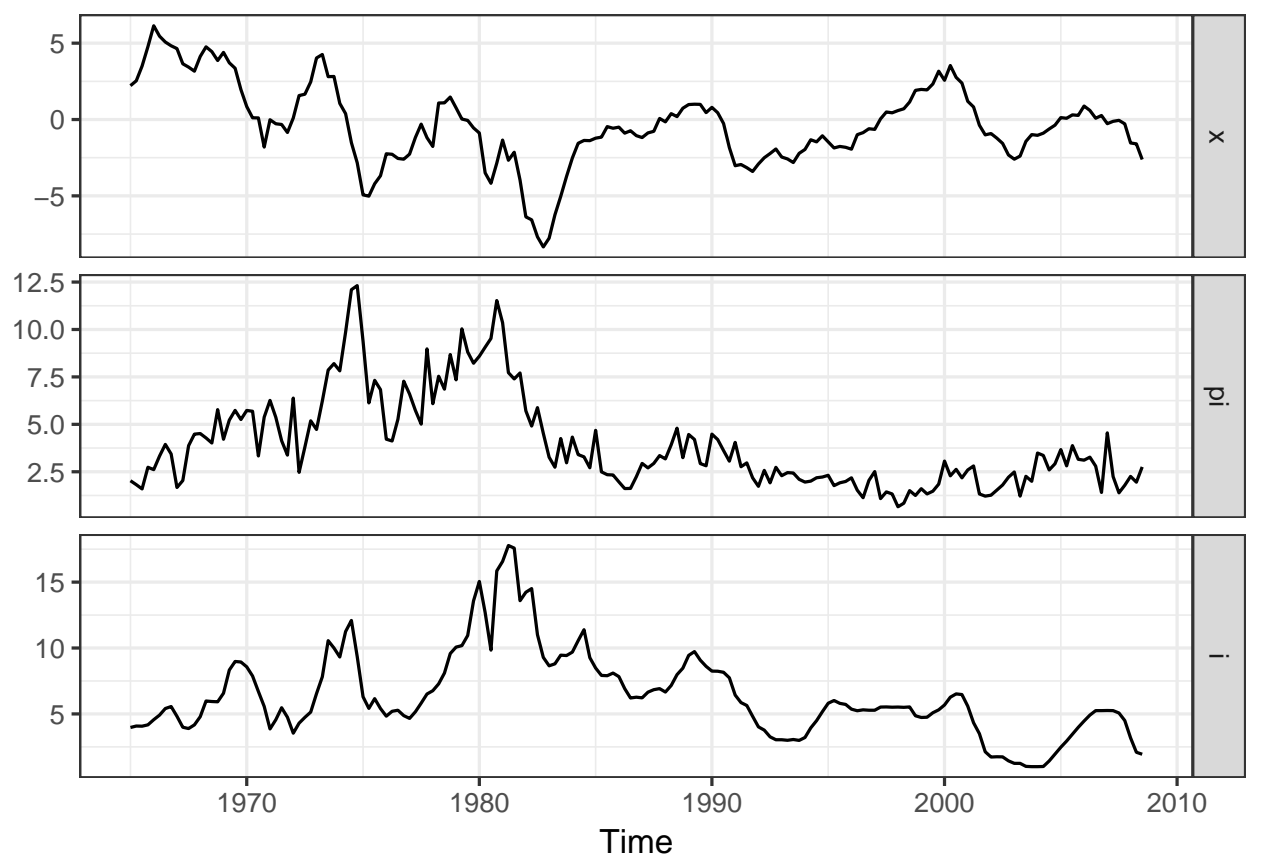

Figure 5.1 US macroeconomic data.

Identification Results

Method: Changes in Volatility

Sample size: 169

Likelihood: -564.2994

Structural Break: At Observation Number 59 during 1979 Q3

Number of GLS estimations: 21

Number of Restrictions: 0

Estimated unconditional Heteroscedasticity Matrix (Lambda):

$$
[, 1] \quad[, 2] \quad[, 3]
$$

x $\quad 0.3925906 \quad 0.000000 \quad 0.000000$

pi $0.0000000 \quad 0.1916410 .000000$

i 0.00000000 .0000001 .244348

Standard Errors of Lambda:

$$
[, 1] \quad[, 2] \quad[, 3]
$$

x $\quad 0.092658190 .00000000 \quad 0.0000000$

pi 0.000000000 .045272640 .0000000

i $0.00000000 \quad 0.00000000 \quad 0.2935572$ 


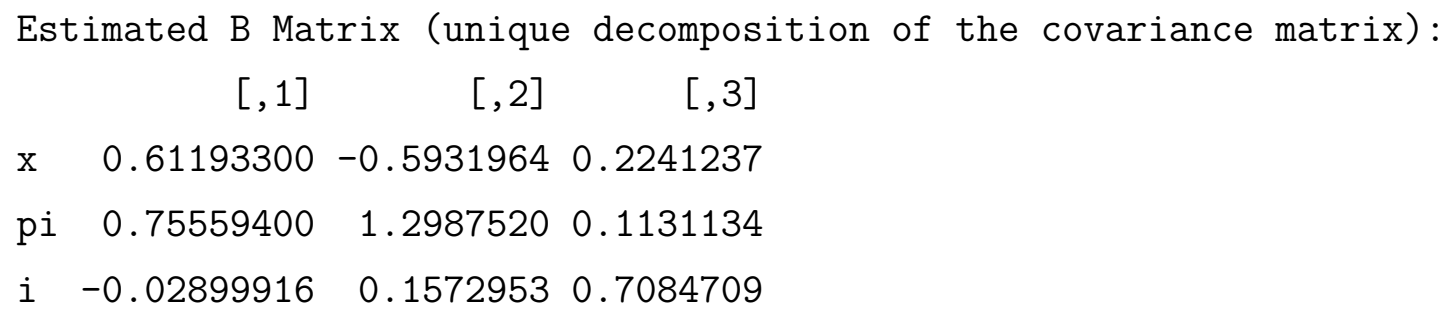

Pairwise Wald Test:

Test statistic p-value

lambda_1=lambda_2 $\quad 3.80 \quad 0.05 *$

lambda_1=lambda_3 $\quad 7.66 \quad 0.01 * *$

lambda_2=lambda_3 $\quad 12.56<2 \mathrm{e}-16 * * *$

Signif. codes: 0 '***' 0.001 '**' $0.011^{\prime} *$ ' 0.05 '.' 0.1 ' ' 1

The summary of the identified object displays the estimated decomposition of the covariance matrix $\widehat{B}$, as well as the covariance shift matrix $\widehat{\Lambda}$ and their corresponding standard errors. Moreover, the summary provides the results of pairwise Wald-type tests for distinct diagonal elements of $\widehat{\Lambda}$ which is necessary for unique identification of the structural shocks. In the present case, all three tests statistics yield a rejection of the null hypotheses of equal diagonal elements with $10 \%$ significance. The ordering of the columns of $\widehat{B}$ is arbitrary and the user has to arrange them in an economically meaningful way. For instance, Herwartz and Plödt (2016b) order the columns according to a unique sign pattern which indicates the direction of the shocks on impact. The code below orders the columns in the same way.

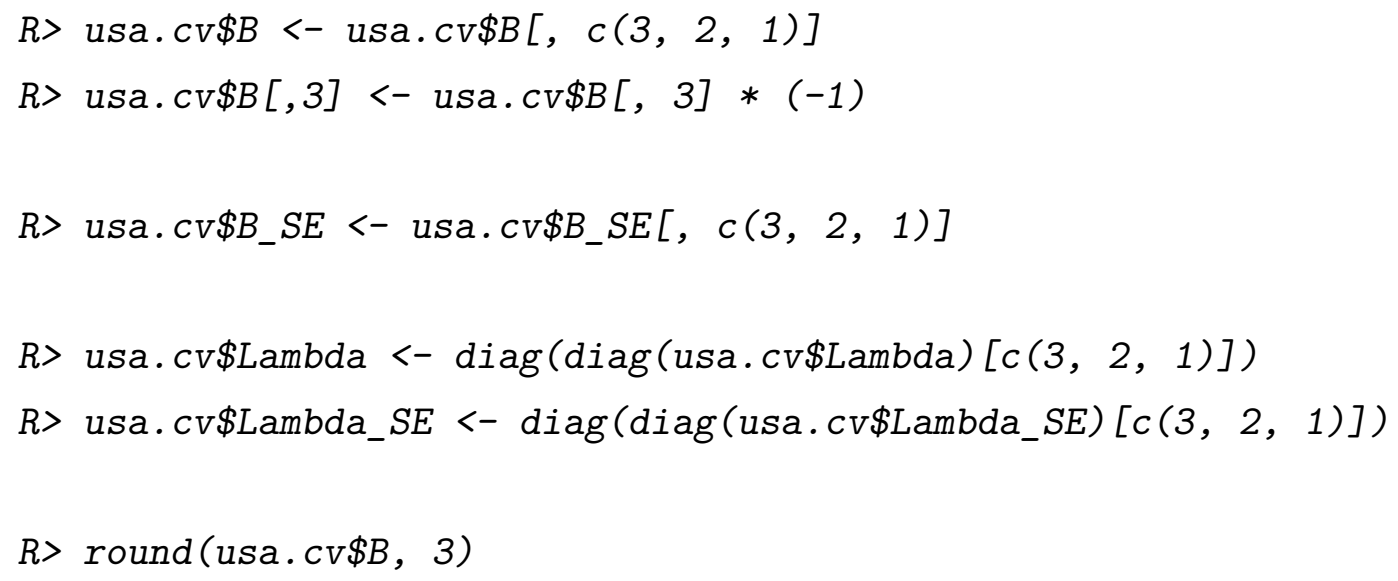




$$
\begin{array}{lrrr} 
& {[, 1]} & {[, 2]} & {[, 3]} \\
\text { x } & 0.224 & -0.593 & -0.612 \\
\text { pi } & 0.113 & 1.299 & -0.756 \\
\text { i } & 0.708 & 0.157 & 0.029 \\
& & & \\
R> & \text { round (usa.cv\$Lambda, 3) }
\end{array}
$$

$$
\begin{array}{lrrr} 
& {[, 1]} & {[, 2]} & {[, 3]} \\
\text { x } & 1.244 & 0.000 & 0.000 \\
\text { pi } & 0.000 & 0.192 & 0.000 \\
\text { i } & 0.000 & 0.000 & 0.393
\end{array}
$$

Herwartz and Plödt (2016b) interpret the impact effects in the first column of the matrix $\widehat{B}$ to characterize a demand shock. Similarly, the effects in the second (third) column indicate a supply (monetary policy) shock. The authors argue that their shock labeling according to the estmated sign patterns is in line with the relevant literature. Since the matrix $\widehat{\Lambda}$ represents the variance of structural shocks in the second regime, Herwartz and Plödt (2016b) interpret the diagonal elements of $\widehat{\Lambda}$ such that the supply and monetary policy shocks have relatively lower variances and the demand shock a higher variance in regime two (i.e., for time instances $t>T_{S B}=59$ or after the second quarter of 1979). The authors compare the results from this statistical identification scheme with a model structure implied by covariance decomposition matrix $B$ which is lower triangular by assumption (Sims, 1980). The id.cv() function enables the user to test for such restrictions by setting up a restriction matrix as described in the code below.

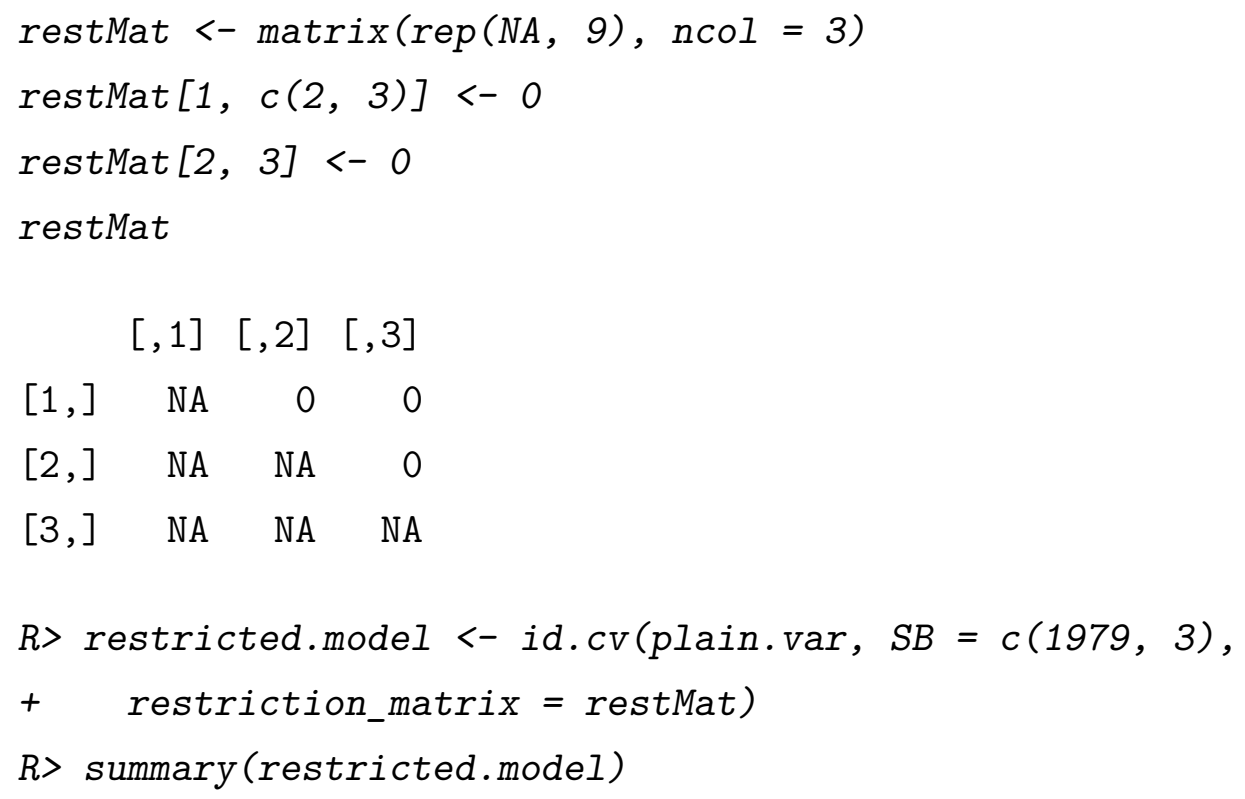

Identification Results 
Method: Changes in Volatility

Sample size: 169

Likelihood: -568.6664

Structural Break: At Observation Number 59 during 1979 Q3

Number of GLS estimations: 23

Number of Restrictions: 3

Estimated unconditional Heteroscedasticity Matrix (Lambda):

$$
[, 1] \quad[, 2] \quad[, 3]
$$

x $\quad 0.35019480 .0000000 \quad 0.0000000$

pi $0.0000000 \quad 0.23468540 .0000000$

i $0.0000000 \quad 0.0000000 \quad 0.9420116$

$$
\begin{aligned}
& \text { Standard Errors of Lambda: } \\
& {[, 1] \quad[, 2] \quad[, 3]} \\
& \text { x } 0.082667380 .00000000 \quad 0.000000 \\
& \text { pi } 0.00000000 \quad 0.056163180 .000000 \\
& \text { i } \quad 0.00000000 \quad 0.00000000 \quad 0.227189
\end{aligned}
$$

Estimated B Matrix (unique decomposition of the covariance matrix):

$$
[, 1] \quad[, 2] \quad[, 3]
$$

x $\quad 0.879884650 .0000000 \quad 0.0000000$

pi 0.081379721 .53065030 .0000000

i $\quad 0.31518384 \quad 0.2606745 \quad 0.7378484$

Standard Errors of B:

$$
[, 1] \quad[, 2] \quad[, 3]
$$

$\begin{array}{lllll}\mathrm{x} & 0.08638851 & 0.00000000 & 0.00000000\end{array}$

pi 0.103340260 .151695650 .00000000

i $\quad 0.08527442 \quad 0.08620187 \quad 0.07354585$

Pairwise Wald Test:

Test statistic p-value

$\begin{array}{lrr}\text { lambda_1=lambda_2 } & 1.34 & 0.25 \\ \text { lambda_1=lambda_3 } & 5.99 & 0.01 * * \\ \text { lambda_2=lambda_3 } & 9.13 & <2 \mathrm{e}-16 * * *\end{array}$




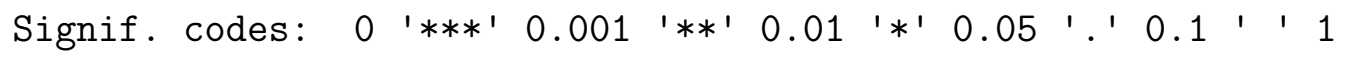

Likelihood Ratio Test:

Test statistic p-value

$$
8.7340 .033 *
$$

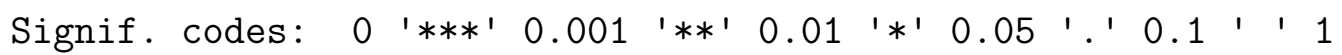

Since the structural shocks are just identified by the change in the covariance matrix, any further restriction on $B$ over identifies the model and makes the restrictions testable. The function automatically performs a likelihood ratio test in case of such over identifying restrictions. The summary depicts the estimation results from the restricted model as well as the test statistics and $p$-values. The likelihood ratio test indicates that the null hypothesis of a lower triangular structural impact matrix has to be rejected at the $5 \%$ significance level. Herwartz and Plödt (2016b) argue that identification by means of zero restrictions according to a lower triangular matrix lacks economic intuition which we can support with the obtained diagnostic. Therefore, the unrestricted model should be preferred for further analysis.

The next step is the calculation of impulse-response functions with boostrap confidence bands to investigate future effects of the economically labeled structural shocks on the variables included in the model. Moreover, the implemented bootstrap functions allow for an evaluation of the significance of unique sign patterns in $\widehat{B}$ as described in Herwartz (2018). We define a list of sign restrictions and label them as demand, supply and monetary policy shock respectively.

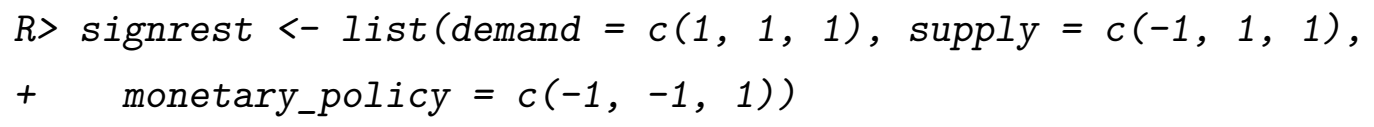

For illustration, we use the wild bootstrap implemented with a Rademacher distribution, fixed-design and 1000 bootstrap replications as in Herwartz and Plödt (2016b). To reduce computation time we parallelize the bootstrap and specify a seed to obtain reproducible results. The time horizon for the impulse-response analysis has to be determined in advance using the argument $\mathrm{n}$. ahead.

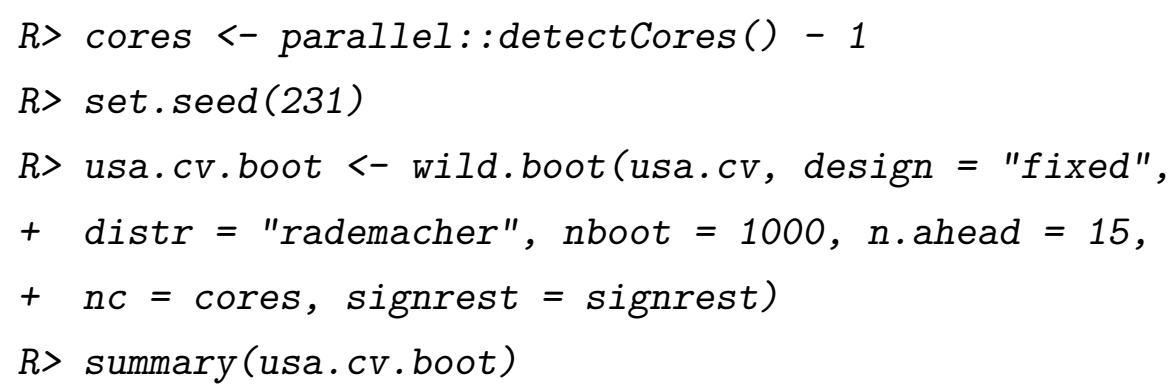


Bootstrap Results

Method: Wild bootstrap

Bootstrap iterations: 1000

Distribution used: rademacher

Design: fixed

Point estimates:

$$
[, 1] \quad[, 2] \quad[, 3]
$$

x $\quad 0.2241237-0.5931964-0.61193300$

pi $0.11311341 .2987520-0.75559400$

i $\quad 0.7084709 \quad 0.1572953 \quad 0.02899916$

Bootstrap means:

$$
[, 1] \quad[, 2] \quad[, 3]
$$

x $\quad 0.08562671-0.51047857-0.6270604$

pi $0.08586727 \quad 1.13181279-0.7800737$

$\begin{array}{llll}\text { i } & 0.69257452 & 0.02945994 & -0.1839417\end{array}$

Bootstrap standard errors:

$$
[, 1] \quad[, 2] \quad[, 3]
$$

$\begin{array}{lllll}\text { x } & 0.14112596 & 0.3093977 & 0.2501647\end{array}$

pi $0.166081740 .4580203 \quad 0.5958669$

i $\quad 0.07464771 \quad 0.23094450 .2205195$

Identified sign patterns:

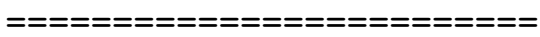

Specified sign pattern:

$\begin{array}{lrrr} & \text { demand } & \text { supply monetary_policy } \\ \mathrm{x} & 1 & -1 & -1 \\ \mathrm{pi} & 1 & 1 & -1 \\ \mathrm{i} & 1 & 1 & 1\end{array}$

Unique occurrence of single shocks according to sign pattern:

demand : $64.9 \%$

supply : $65 \%$ 
monetary_policy : $28.4 \%$

Joint occurrence of specified shocks: $12.7 \%$

$R>$ plot (usa.cv.boot, lowerq $=0.16$, upperq $=0.84$ )

The summary reveals that only $12.7 \%$ of all bootstrap estimates are in line with all economically motivated sign patterns jointly. The sign pattern of the monetary policy shock appears in only $28.4 \%$ of all bootstrap samples. Furthermore, the bootstrap means indicate that the third shock is more in line with the sign pattern of the demand shock. This result is plausible noting that the point estimate in the lower right corner is close to zero and, therefore, lacks a significantly positive effect on the interest rate. Figure 5.2 shows the impulse-response functions of normalized shocks having unit variance in the first regime. Herwartz and Plödt
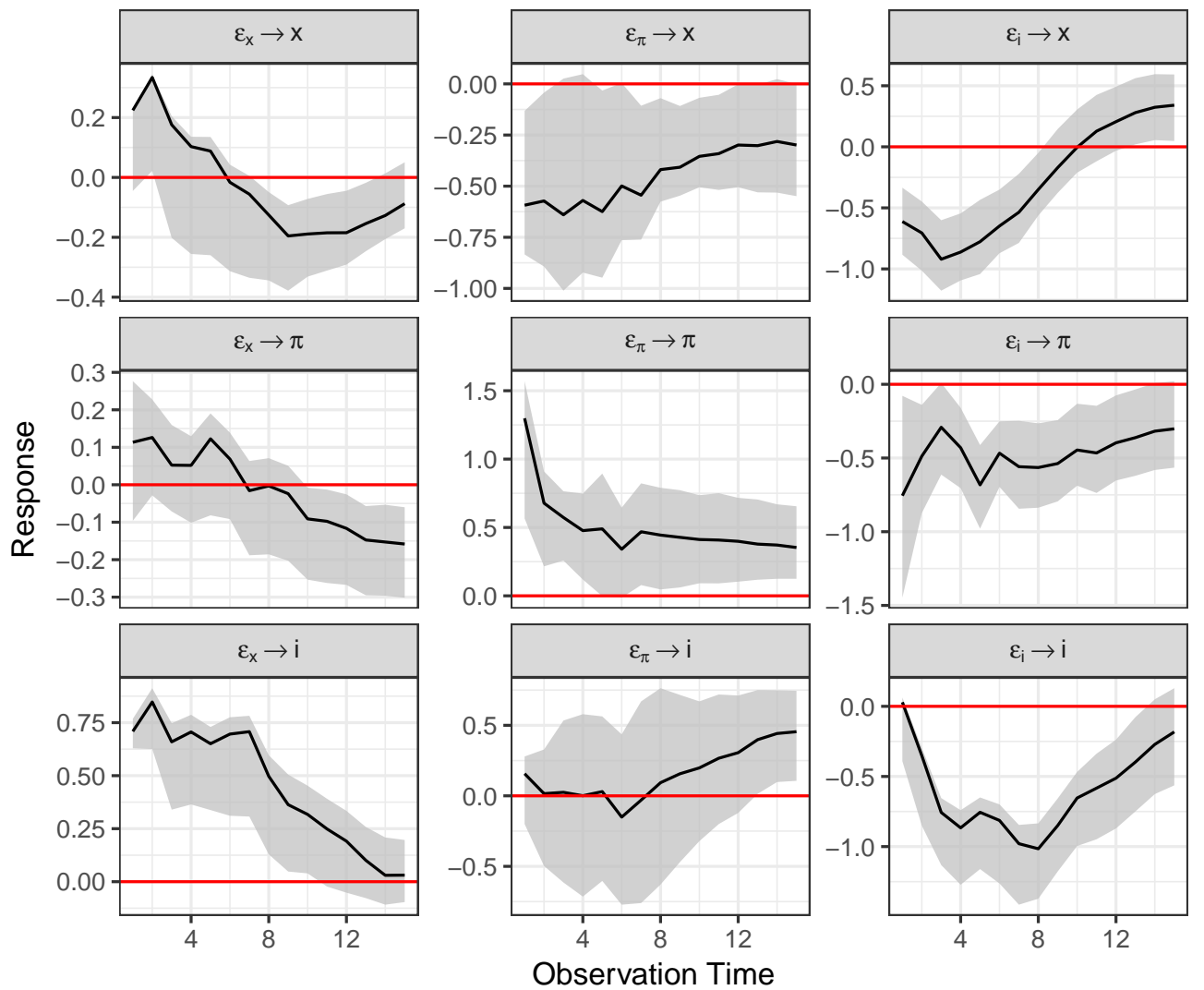

Figure 5.2 Impulse-response functions with $68 \%$ confidence bands based on 1000 bootstrap replications. Structural shocks identified through unconditional shift in the covariance structure.

(2016b) argue that the negative reaction of the interest rate to a monetary policy shock after the initial period is implausible, and puts the interpretation of this shock as a monetary policy shock into question. The results from the bootstrap support the authors' argumentation with regard to the shock labeling.

Furthermore, we can calculate the forecast error variance decomposition to investigate the 
contribution of each shock to the prediction mean squared error of the variables. The fevd() method creates an object for visual inspection of the forecast error variance decomposition by means of the plot function.

$R>$ fev.cv $<-$ fevd(usa.cv, n. ahead $=30$ )

$R>\operatorname{plot}(f e v . c v)$

Figure 5.3 depicts the forecast error variance decomposition. It is evident that the monetary policy shock accounts for more than $50 \%$ of the prediction mean squared error of the output gap, whereas the demand shock constantly accounts for only about $5 \%$ of the prediction mean squared error. Moreover, the demand shock contributes almost $100 \%$ of the forecast error variance of the interest rates on impact. Thus, the forecast error decompositions hint at a

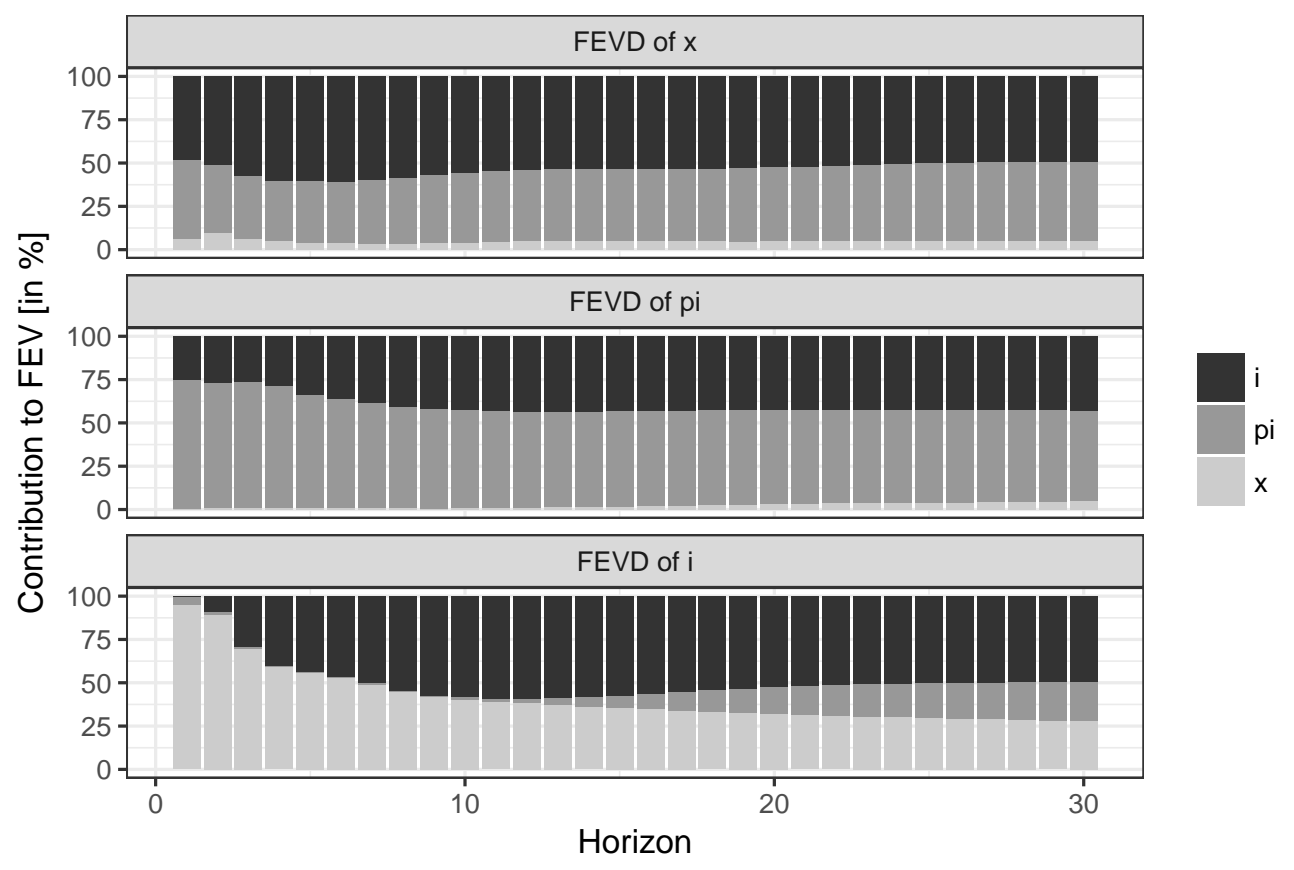

Figure 5.3 Forecast error variance decomposition for 30 periods. Structural shocks identified by means of the CV model.

shock labeling which differs from the one developed above on the basis of sign patterns of $\widehat{B}$. Furthermore, they confirm the conclusion of Herwartz and Plödt (2016b) that the empirical model fails to identify a monetary policy shock according to its theoretical effect patterns.

We re-estimate the structural form with the DC method under the assumption of independent non-Gaussian shocks. ${ }^{7}$

$R>$ usa.dc <- id.dc(plain.var, PIT = FALSE)

$R>\operatorname{summary}(\mathrm{usa} \cdot d c)$

\footnotetext{
${ }^{7}$ Component-wise kurtosis and skewness tests as implemented in the package normtest (Gavrilov and Pusev, 2015) as well as fourth-order blind identification based tests from the package ICtest (Nordhausen et al., 2018) show no indication for Gaussian components.
} 
Identification Results

Method: Distance covariances

Sample size: 169

Estimated B Matrix (unique decomposition of the covariance matrix):

$[, 1] \quad[, 2] \quad[, 3]$

x $\quad 0.541926899-0.36707854 \quad 0.1964223$

pi $0.508827712 \quad 0.92428628 \quad 0.1967426$

i $\quad 0.003560267 \quad 0.02576151 \quad 0.8194037$

The estimated structural matrix differs from the estimated matrix obtained from the CV approach. The matrix identified by means of the DC method does not allow for a labelling of the shocks that accords with a unique sign pattern. Nevertheless, it is possible to label the shocks in a meaningful way, since one could assume that the loading of the structural shocks on reduced form errors is stronger for own effects in comparison with cross variable effects. The finding that a positive monetary policy shock has a positive effect on output and inflation might seem to be at odds with intuition at first, although this mechanism can be observed rather frequently in the literature (e.g., Lütkepohl and Netsunajev, 2017a) and is usually referred to as a so-called price puzzle (Eichenbaum, 1992). Conditional on the

estimate $\widehat{B}$, we construct the historical decomposition. As an example, we decompose the output into its underlying determinants over the sample period. In the data set output is the first column and, hence, series $=1$ is the provided option.

$R>$ hd.cv.1 <- hd(usa.dc, series = 1)

$R>\operatorname{plot}(h d . c v .1)$

Figure 5.4 indicates that output fluctuations are mainly explained by demand shocks rather than supply or monetary policy shocks.

\subsection{Summary}

The $\mathrm{R}$ package svars provides a vast set of estimation techniques that build on several assumptions on the data and a variety of input arguments. In the present article we describe how the implemented identification techniques for SVAR models depend on assumptions of heteroskedasticity and independence coupled with non-Gaussianity to retrieve the structural shocks from the reduced form VAR model. Furthermore, we provide a set of auxiliary functions which complement the cornerstone identification methods, and thereby offer a complete 


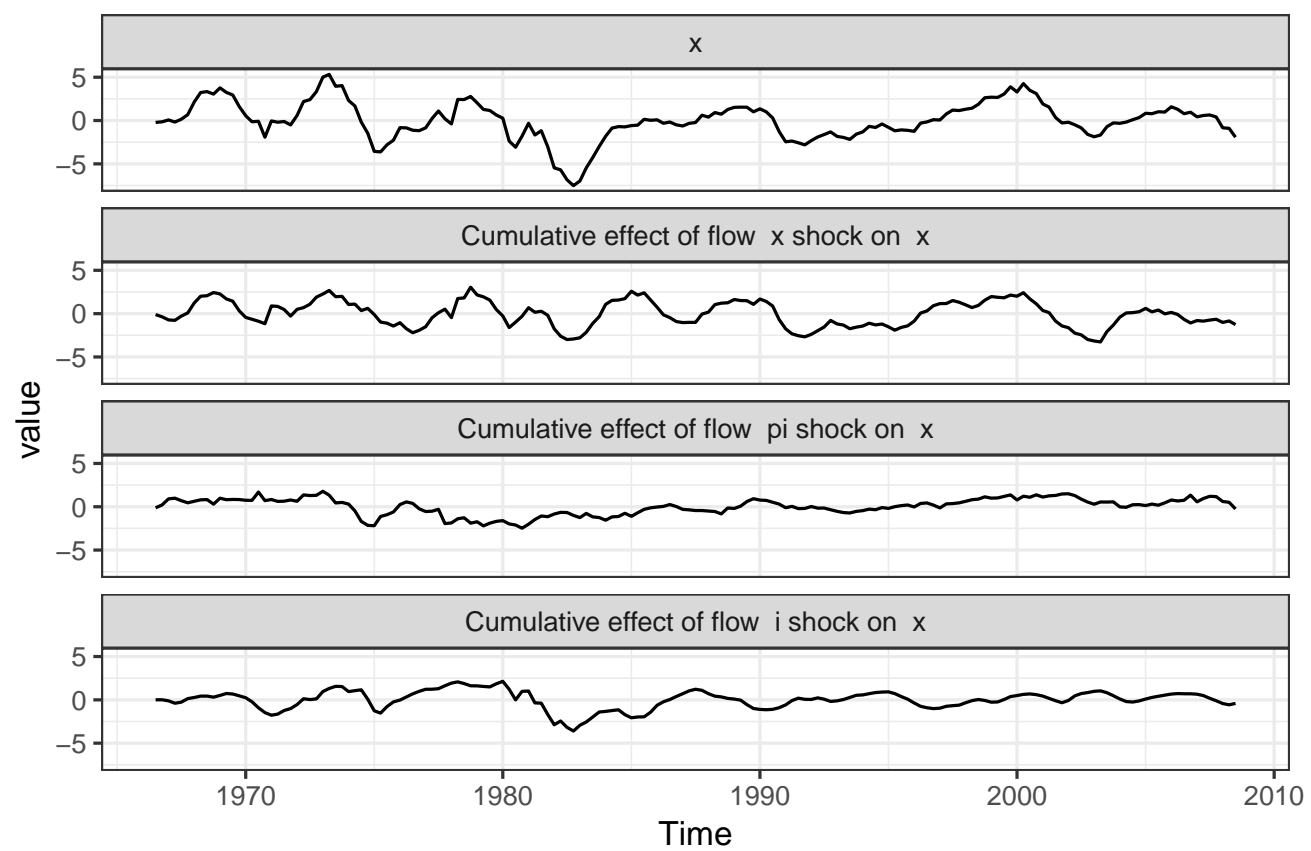

Figure 5.4 Historical decomposition of the US output gap in percent deviations from the mean. Structural shocks are identified by means of the DC algorithm.

toolbox for structural analysis in a multivariate time series context.

We give a step-by-step guideline on how to use the functions on a real dataset comparing one representative from both groups of heteroskedasticity and independence based identification. Even though the estimation results are similar, identification by means of covariance shifts might imply a misleading sign pattern which is indicated in the forecast error variance decomposition. Moreover, we illustrate how to test sign and zero restrictions by means of restricted log-likelihood estimation and bootstrap methods.

The svars package contains six alternative and recent SVAR identification techniques. Besides these, further popular data-driven identification approaches include, e.g., the heteroskedastic model with Markov switching mechanisms (Lanne et al., 2010; Herwartz and Lütkepohl, 2014) or pseudo ML estimation (Gourieroux et al., 2017). Moreover, an option to test for long run restrictions by means of likelihood based identification schemes is a possible augmentation of the package. We regard both directions as promising for future developments of svars. 


\section{Chapter Six}

\section{The threat of oil shocks to food security in Sub-Sahara Africa ${ }^{1}$}

While the causal relationship between different types of oil shocks and food prices in the US and other developed countries has been extensively studied, the inter-dynamics between global oil market turmoils and food prices in Sub-Saharan Africa (SSA) remain unclear. This gap in the literature is particularly striking as populations in developing countries are much more vulnerable to food crises than those in developed countries. In this paper we use structural vector autoregressive (SVAR) models to investigate the impacts of global oil market shocks on local corn prices in several SSA countries. We estimate the structural shocks through independent component analysis, which allows for a more agnostic identification compared with conventional methods. Our key findings are that unlike US or global corn markets, African corn markets are much less sensitive to the impacts of oil-specific demand shocks, instead, disruptions in global oil supply can lead to an increase in food prices in several markets. Countries suffering from oil-supply shocks have neither strategic or natural oil reserves to buffer import shortages, nor efficient oil distribution systems that translate into food prices through higher transport costs. We show that a large share of corn price surges in 2011 and 2012 can be attributed to oil-supply shortages caused by the Libyan revolution and the oil embargo against Iran. Conversely, the shale oil boom in the US and oil production expansion in the Middle East exerted downward pressures on corn prices in three African countries in 2014/15. Forecast scenarios reveal the potential threat to corn prices in Africa from the political tensions between the US and Iran, as well as the recent oil-price war between Saudi Arabia and Russia.

Keywords: Oil shocks, agricultural markets, SVAR, Sub-Sahara Africa, food security

\footnotetext{
${ }^{1}$ This chapter is under review at Energy Economics and co-authored by Alexander Lange (AL), who is the lead author, and Helmut Herwartz (HH). AL and HH designed the research idea. AL and Bernhard Dalheimer (BD) conceptualized the theoretical framework. AL selected and collected the variables with support from BD. AL developed the empirical strategy and implemented the econometric modelling. AL and $\mathrm{BD}$ interpreted the results. AL and BD wrote the paper. HH commented the research at all stages. All authors edited and revised the manuscript.
} 


\subsection{Introduction}

Since the early 2000s, biofuel production has transformed agricultural commodities into energy carriers by allowing their use as feedstocks for ethanol and biodiesel. This has enabled the substitution of fuel with food, adding a new level of complexity to the traditional use of crude oil derivatives as inputs for the farming, transporting and processing of agricultural products. Since then, fuel has not only been an input but also an output of agricultural production and a novel transmission channel through which crude oil prices move with food prices in industrialized countries (Abbott et al., 2011; Serra and Zilberman, 2013). However, for developing countries where technological progress is lagging behind and biofuels are not yet available, the link between crude oil and food is not well understood (Nazlioglu and Soytas, 2011). More specifically, it remains unclear whether and how local food prices are related to global oil market dynamics, or if any existing co-movement of oil and food prices is merely determined by underlying economic demand. Consequently, policies based on an understanding of global oil and food dynamics are perhaps misguided and may not be helpful in mitigating abrupt food price movements and food price crises.

At the same time, food price swings have probably the most pervasive and far-reaching impacts on livelihoods in low-income countries. At present, some 820 million people are undernourished (FAO et al., 2019) and 736 million people live in extreme poverty, the vast majority of them in non-industrialized countries (World Bank, 2020). SSA is a particularly vulnerable region, where $43 \%$ of the population still lives on less than $1.90 \mathrm{USD} /$ day (World Bank, 2020). In many regions of SSA, the undernourishment rate is higher than $25 \%$ and has even been rising since 2015 (FAO et al., 2019). Unlike in higher-income countries, where the food industry is able to cushion price peaks in agricultural commodities and food expenditures account for only a small proportion of living expenses, people in SSA are extremely vulnerable to price jumps in agricultural markets as they often spend large fractions of their income on food. Consequently, understanding the sources of price swings as well as the pertinent transmission channels in agricultural markets is essential to successful food and nutritional policies.

In this paper, we investigate the effects of global oil market shocks on local corn prices in a sample of SSA countries. We use SVAR models, building upon the oil market model of Kilian (2009) to identify three independent sources of oil market turmoils: oil-supply shocks, aggregated-demand shocks and oil-specific demand shocks. The model specification allows us to classify the African corn markets into three groups, (i) markets that are particularly threatened by global crude oil shocks, (ii) markets that are not linked at all to the global oil price dynamics, and (iii) markets where the co-movement of oil and food prices is determined by economic demand. Conditional on the respective link between global oil shocks and the domestic corn market, we propose policy strategies to stabilize local SSA food prices. 
Furthermore, we show for the first time that disruptions in global oil supply can lead to substantial surges in corn prices in Africa (e.g. during the Libyan production shortfall in 2011 and sanctions against Iran in 2012), and provide novel insights into the impending risks of food price crises in SSA resulting from future oil market shocks.

We contribute to the existing literature in several directions. Most analyses of food markets rely on reduced form vector autoregressive (VAR) or vector error correction model (VECM) specifications. Notably, few authors have overcome the lack of theoretical interpretability of reduced form VARs by means of SVAR specifications. The results of such studies show that crude oil (demand) shocks are an important source of price swings in US or global corn markets, in both the short and long term (McPhail et al., 2012; Hausman et al., 2012; Wang and McPhail, 2014). However, developing countries are characterized by different market transmissions due to imperfect competition between producers and retailers, as well as imperfect substitution between imported and domestic products (Chakravorty et al., 2019; Dillon and Barrett, 2015). Thus, the responsiveness of food markets to oil markets is likely to depend on the development status of the economy (Nazlioglu and Soytas, 2011). Furthermore, SSA is divided into net energy importers and exporters, which could add to the heterogeneity of oil shock impacts on food markets (Wang et al., 2013). Overall, the contribution of oil-supply, aggregated-demand and oil-specific demand shocks to domestic corn markets in SSA countries remains unclear and has not yet been addressed empirically. Finally, a critical discourse has recently flared up about techniques to identify oil shocks, since conventional identification approaches (e.g. recursive causation schemes (Sims, 1980) and sign and elasticity constraints (Kilian and Murphy, 2012)) crucially underestimate supply-side effects by construction (Baumeister and Hamilton, 2019a,b; Kilian, 2019; Kilian and Zhou, 2019). We provide a structural analysis based on a new and much less restrictive data-driven approach, namely independent component analysis (ICA) (Moneta et al., 2013; Lanne et al., 2017a $)^{2}$, which has already proven useful in disentangling oil market dynamics (Herwartz and Plödt, 2016c).

Our main results are threefold. First, SSA corn markets react differently to oil shocks compared with world markets. Unlike previous studies, we find that oil-supply shocks explain food prices more than oil-specific demand shocks. Second, SSA food markets are highly heterogeneous in their price responses to global oil shocks. We can clearly differentiate between food markets, that are affected by oil market turmoils and countries where food prices appear to be relatively independent from crude oil. Third, transport costs are the main channel for global oil-supply disruptions to transmit to local corn prices. Hence, regardless of the direction, neither net food producers nor net food buyers benefit from oil-supply shock induced price changes since they merely reflect changes in transport costs. Promising policies

\footnotetext{
${ }^{2}$ Under a non-Gaussian distribution, independent components can be uniquely identified (Comon, 1994). The assumption of non-Gaussianity might be reasonable for economic data (e.g. price series) in general, allowing for instance leptokurtic distributions (see e.g., Chib and Ramamurthy, 2014; Cúrdia et al., 2014).
} 
should build up strategic oil inventories to buffer fluctuations in oil supply, or promote efficient import and distribution systems, which are major bottlenecks in the fuel supply chains.

In section 6.2 , we provide an overview of how food security relates to food markets in developing countries, jointly with a condensed review of the literature concerning the crude oil-food price nexus. Section 6.3 illustrates our identification strategy and data. Subsequently, we present our findings from the baseline estimation as well as case study analysis and forecasts on recent events as well as hypothetical scenarios. We place the results in a theoretical context, derive policy implications and relate the findings to the existing literature in section 6.4, before we summarize and conclude in section 6.5. Appendix D.1 comprises further information on the oil-food price nexus. Appendix D.2 provides a detailed description of the identification strategy by means of ICA and Appendices D.3 and D.4 contain additional empirical results.

\subsection{Food insecurity in Sub-Saharan Africa and the global oil market}

The adverse effects of oil shocks on food security in SSA are not yet well understood. In this section, we briefly revisit the double-edged relationship between food security and food prices. Moreover, we provide an inventory of possible transmission channels between the oil price and food markets and assess their potential applicability to SSA markets. Finally, we review key empirical findings of the oil-food nexus literature.

\subsubsection{Food insecurity in Sub-Saharan Africa}

Globally, food security has substantially improved over the past decade. ${ }^{3}$ One widely used measure of food insecurity is the prevalence of undernourishment (PoU) indicator, which has fallen from $14.5 \%$ in 2005 to $10.8 \%$ in 2018. Despite this long-term progress, FAO et al. (2019) conclude that food insecurity has been increasing since 2015 and much of the global increase in hunger is due to rising food insecurity in SSA. At present, 22 out of the 30 most food insecure countries are located in SSA (FAOSTAT, 2020), while 56\% of people living in extreme poverty are also living in SSA (World Bank, 2020). On the one hand, extreme poverty and hunger are often immediate results of conflicts, droughts or other shocks, which primarily affect the availability of food. On the other hand, much of the long-term food insecurity is due to the lack of access to food, mostly related to the functioning of markets and the food

\footnotetext{
${ }^{3}$ The Food and Agricultural Organization of the United Nations (FAO) defines food security as "a situation that exists when all people, at all times, have physical, social and economic access to sufficient, safe and nutritious food that meets their dietary needs and food preferences for an active and healthy life". Food insecurity is the lack thereof. The definition implies four dimensions of food security: (i) availability (ii), access, (iii) utilization and (iv) stability of food consumption (FAO et al., 2019).
} 
distribution system. Needless to say, price swings may lead to sudden disruptions in access to food, including in the short term. Moreover, the stability of food consumption is crucial for ensuring the long-term supply of adequate amounts of food to individuals and it is also reliant on food markets. As food security is usually an issue in poor households who dedicate large shares of disposable income to food purchases, higher food prices are often associated with deteriorating food security. However, since the majority of the world's poor also earn their incomes from agriculture - as either smallholder farmers or farm workers - higher food prices could lead to improved rural incomes and wages (Swinnen and Squicciarini, 2012). Therefore, the net impact of food price surges on food security - such as the food price crisis of 2007/08 - depends on how many of the world's poor are net food consumers and how many are net producers.

In line with the previous considerations, empirical work on the benefits of shifting levels of food prices in SSA has found mixed results. For instance, Ivanic and Martin (2008), De Hoyos and Medvedev (2009) and Arndt et al. (2008) find that higher food prices induced dramatic increases in global and SSA undernourishment during the 2007/08 food crisis. By contrast, Headey et al. (2011) and Verpoorten et al. (2013) find that higher food prices have led to substantial improvements of food security among the global poor. Such starkly contradicting results could be due to the fact that the direction and extent of the impact of food price shocks on food security is strongly dependent on the individual context. Thus, understanding asymmetric dynamics of food price developments and their underlying determinants holds paramount importance. This implies that a joint analysis of the determinants of increases and decreases in food prices can help to explain the basis of price formation in food markets and thus reduce the associated risks.

\subsubsection{Global oil shocks and local food prices}

One of the sources of both sustained surges and declines of food prices as well as increased uncertainty and instability of food security is movements in crude oil prices, particularly after the emergence of biofuel production in the mid-2000s (Tyner and Taheripour, 2007; Baffes and Haniotis, 2010; Serra et al., 2011; Abbott et al., 2011; Busse et al., 2012; Baumeister and Kilian, 2014a; Wang et al., 2014; Du et al., 2011; Nazlioglu et al., 2013; Abdelradi and Serra, 2015; Herwartz and Saucedo, 2020). Biofuels enable the production of fuel from coarse grains and vegetable oils. Thereby crude oil and some agricultural crops become substitutes for fuel production and henceforth the co-movement of these two prices has intensified. Most importantly, the US Energy Policy Act of 2005 induced a considerable expansion of US biofuel production in 2006. ${ }^{4}$ The share of US corn harvest used for ethanol production rose from $14 \%$ to $40 \%$ and persistently changed the long-term relationship between oil and agricultural

\footnotetext{
${ }^{4}$ The Energy Policy Act made ethanol produced from corn the only gasoline additive available to US gasoline producers after May 2006.
} 


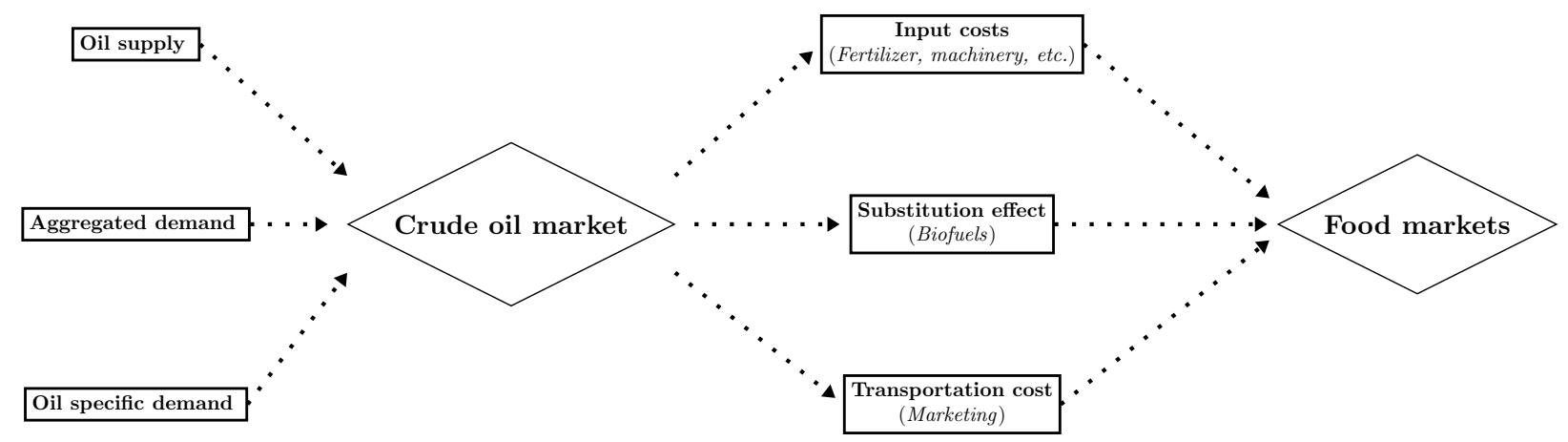

Figure 6.1 Transmission flow from oil shocks to food prices

markets (Carter et al., 2016). Since then, a large body of empirical and theoretical literature has examined the price relationships over time and strives to disentangle the direction and magnitude as well as the short- and long-term nature of causal effects.

Figure 6.1 illustrates the crude oil-food prices nexus from a theoretical perspective. The left-hand side is a stylized representation of the global crude oil market, decomposed into its three underlying source signals or shock series. Although Kilian et al. (2009) show that distinct oil shocks have fundamentally different effects on the dynamics in the oil market, most studies concerned with crude oil-food price relationships neglect the existence of different types of oil shocks. A notable exception is Wang et al. (2014), who examine the effects of underlying oil shock mechanisms on food markets using a structural model. The authors extend the model by Kilian et al. (2009) to include food prices and find that after 2006 food prices are mainly driven by oil-specific demand shocks. More specifically, if higher oil-specific demand increases the oil price, this also affects food prices. By contrast, the pass-through effect of oil-supply shocks to food prices is found to be negligible. For the period prior to 2006, the authors note that the co-movement of oil and food prices has been driven by a prolonged increase in aggregated demand, which generally raises commodity prices.

The right-hand side of Figure 6.1 details how oil shocks in turn transmit to local food prices. Based on a careful review of the relevant literature, we encounter a set of three different transmission channels between crude oil and food prices. First, both inorganic fertilizers used on the fields and fuel consumption for machinery as inputs to agricultural production are an integral part of farmers' production costs and thus influence food supply and prices (Dillon and Barrett, 2015; Serra and Zilberman, 2013; Wang et al., 2014). Although input costs constitute a traditional link between energy and food prices, they are generally considered to contribute only marginally to the extent of the co-movement between oil and food prices (Tyner and Taheripour, 2007; Serra and Zilberman, 2013; Kristoufek et al., 2012). 
Second, the substitution effect associated with the production of biofuel - spurred by blending mandates - leads to oil price changes directly affecting plant-based ethanol and biodiesel prices. The majority of authors argue that the substitution effect channels the lion's share of the co-movement between the prices (Tyner and Taheripour, 2007; Serra and Zilberman, 2013; Kristoufek et al., 2012; Abbott et al., 2011). Third, transportation costs for both farm inputs and marketable output are driven by fuel prices, which in turn are derivatives of crude oil. Transport costs have been shown to be a particularly relevant transmission channel in SSA countries, where production and marketing are largely decentralized and transport absorbs a relatively large share of production and marketing costs compared with in other parts of the world (Dillon and Barrett, 2015). ${ }^{5}$

Serra and Zilberman (2013) evaluate a large body of literature that empirically examines the relationship between crude oil and food prices. The authors conclude that there is a broad consensus in the literature that disturbances in the energy markets are passed to food markets, and increasingly so after the emergence of biofuels. One notable exception is Qiu et al. (2012), who confirm the neutrality of food prices to energy prices in the US based on results from a structural analysis. It is striking that the majority of studies that find evidence of the nonneutrality of food prices are based on world market data or observations from industrialized countries. Evidence from emerging or developing economies is scarce and (if available) tends to find neutrality of food prices to oil markets (e.g. Nazlioglu and Soytas, 2011; Fowowe, 2016). Nazlioglu and Soytas (2011) hypothesize that direct and indirect effects of oil markets on food markets might crucially depend on the stage of development of the country, which is not sufficiently addressed in the relevant literature. Consequently, any understanding of the link between food markets in developing countries and oil markets, based on global dynamics might be fundamentally flawed and lead to misguided policy recommendations.

\subsection{Empirical framework}

The analysis in this paper highlights the response of local corn prices in SSA to global oil shocks. Due to the heterogeneity of developing countries, we estimate four-dimensional VARs for each country separately. In the following, we illustrate the empirical model and identification strategy and briefly present the data.

\footnotetext{
${ }^{5}$ Besides these three main transmission channels proposed by most authors, some advocate alternative channels, which we discuss briefly in Appendix D.1.
} 


\subsubsection{Identifying oil shocks via independent components}

The econometric model in our analysis is a $(K=4)$-dimensional VAR of order $p$ of the form

$$
\begin{aligned}
y_{t} & =\nu+A_{1} y_{t-1}+\ldots+A_{p} y_{t-p}+u_{t}, \\
& =\nu+A_{1} y_{t-1}+\ldots+A_{p} y_{t-p}+\mathrm{B} \varepsilon_{t}, \\
\Leftrightarrow \quad A(L) y_{t} & =\nu+\mathrm{B} \varepsilon_{t}, \quad t=1, \ldots, T,
\end{aligned}
$$

where the vector $y_{t}=\left(\Delta q_{t}, x_{t}, p_{t}, c_{t}\right)$ contains the change in global crude oil production $\left(\Delta q_{t}\right)$, a measure of real global economic activity $\left(x_{t}\right)$, the real global price of oil $\left(p_{t}\right)$ and country-specific real corn prices $\left(c_{t}\right)$. We adopt the variable selection of Wang et al. (2014), who examine the response of US corn prices to oil shocks. Furthermore, the $A_{i}$ are $(K \times K)$ coefficient matrices and the $u_{t}$ are $K$-dimensional, serially uncorrelated residuals (Lütkepohl, 2005). The model innovations are usually characterized from two perspectives: while zero mean reduced-form residuals $u_{t}, E\left(u_{t}\right)=0$, are subject to cross-equation correlation with covariance matrix $\Sigma_{u}=\mathrm{BB}^{\prime}$, structural shocks $\varepsilon_{t}=\mathrm{B}^{-1} u_{t}$ are uncorrelated across equations with $E\left(\varepsilon_{t}\right)=0$ and $\Sigma_{\varepsilon}=I_{K}$. Estimating equation (6.1) by least squares (LS) or maximum likelihood (ML) approaches delivers reduced form errors $u_{t}$ straightforwardly. By contrast, it is more challenging to identify the structural shocks since the decomposition of the covariance matrix $\Sigma_{u}=\mathrm{BB}^{\prime}$ is not unique.

In recent decades, a large number of strategies have become available to solve the identification problem. ${ }^{6}$ In the context of the crude oil-food price nexus, oil shocks have been traditionally identified via short-run restrictions ( $\mathrm{B}$ is restricted to a lower triangular matrix (Baumeister and Kilian, 2014a; Wang et al., 2013, 2014)). Since exclusion constraints often do not match real-world dynamics, Kilian and Murphy (2012) suggest a more agnostic approach to model crude oil market dynamics and rely on a combination of sign restrictions and elasticity constraints. However, both strategies imply an (almost) zero short-run price elasticity of oil-supply and have therefore been strongly criticized. More specifically, Baumeister and Hamilton (2019a) show that the oil-supply elasticity is actually much stronger than previously assumed and oil-supply shocks have a much stronger contribution to the oil price in general. Both the modeling of oil-supply elasticity and the question of whether the approach of using recursive structures and/or elasticity constraints is still a legitimate identification strategy remain controversial (see e.g. Baumeister and Hamilton, 2019b; Kilian, 2019; Kilian and Zhou, 2019). Therefore, we use a novel and more agnostic data-driven approach based on ICA, which requires only a minimum of assumptions for identification.

Identification via independent components builds on distributional assumptions of the structural error terms (i.e. non-Gaussianity), which can be considered as external statistical

\footnotetext{
${ }^{6}$ Kilian and Lütkepohl (2017) provide a thorough overview of recent identification techniques.
} 
information. If no more than one independent component of $\varepsilon_{t}$ is Gaussian distributed, the structural matrix B can be uniquely recovered from reduced-form residuals $u_{t}$ (Comon, 1994). ${ }^{7}$ Using a simulation study, Herwartz et al. (2019) demonstrate that identification via independent components is robust to a large variety of distributional and heteroskedastic frameworks. Herwartz and Plödt (2016c) show that ICA is a useful method to identify different types of oil shocks, which are in line with the corresponding literature. For details on the exact minimization procedure, we refer to Appendix D.2 and Matteson and Tsay (2017). On the implementation side, we use the R packages steadyICA (Risk et al., 2015) and svars (Lange et al., ming) to determine $\widehat{B}$ and $\hat{\varepsilon}_{t}$ and calculate all relevant SVAR statistics, respectively.

\subsubsection{Data}

The four-dimensional VAR models comprise the following variables:

$\Delta q_{t}-$ log change in average global crude oil production $\times 100$

$x_{t}-$ global economic activity index

$p_{t}-\log$ of the real price of crude oil in US Dollars $\times 100$

$c_{t}$ - linearly detrended log of the real price of corn in domestic currency $\times 100$

First, for crude oil production we use the series from the US Energy Information Administration (EIA, 2020), which is defined as the average number of crude oil barrels produced per month. Second, we calculate the real price of oil by deflating the global market price of crude oil Brent in US Dollars from the IMF with the US consumer price index. ${ }^{8}$ Third, we use the global economic activity index - available on Kilian's website ${ }^{9}$ - which reflects dry cargo shipping rates and is particularly constructed to capture dynamics in industrial commodity markets (Kilian and Zhou, 2018). Fourth, we retrieve the real white corn price series in local currencies from the GIEWS database of the FAO. ${ }^{10}$

We choose corn price series to be suitable representatives for food markets in SSA within our oil-food markets model given their importance as both food and cash crops and the potential to produce ethanol from corn. Corn is the most important crop in Africa in terms of both production and consumption. Since 2015, annual production ranged between 75 and 85 million tons, which was more than twice the production of wheat, for instance. We consider corn prices for Chad, Ethiopia, Ghana, Kenya, Mozambique, Nigeria, Tanzania

\footnotetext{
${ }^{7}$ In the case of multiple independent Gaussian components, the system lacks full identification, although partial identification of the non-Gaussian components is possible (Maxand, 2019).

${ }^{8}$ https://data.imf.org/.

${ }^{9}$ https://sites.google.com/site/lkilian2019

${ }^{10} \mathrm{http}: / /$ www.fao.org/giews
} 
and Zambia, where the price series are available from January 2006 until June 2019, which determine the horizon for our oil-food market model, resulting in $T=162$ observations. We use retail prices unless only wholesale prices are available. All price series are collected at those food markets that are most important in the respective countries and considered to be representative for their respective domestic market situation. Some of the series contain missing values, which we linearly interpolate. ${ }^{11}$ As the world reference price for corn, we use spot prices for yellow corn No. 2 from the Chicago Board of Trade (CBOT). ${ }^{12}$ On the implementation side, we estimate the reduced-form VAR models with $p=3$ lags as suggested by the Akaike information criterion (AIC).

\subsection{Empirical findings}

Since the decomposition of the reduced-form covariance matrix $\Sigma_{u}=\mathrm{BB}^{\prime}$ is not unique under normality, at least three out of four structural shock series need to be non-Gaussian to ensure identification. We perform component-wise kurtosis and skewness tests as implemented in the R package normtest (Gavrilov and Pusev, 2014) on the four estimated shock series for each country. The results displayed in Table D.1 in Appendix D.3 indicate excess skewness and kurtosis at least in three out of four shock series for all countries, which is consistent with the findings of Lütkepohl and Netşunajev (2014) and Herwartz and Plödt (2016c), who detect that oil shocks tend to be non-Gaussian. Since there is clear evidence of non-Gaussian source signals in the data, the structural shocks are uniquely determined from a statistical perspective.

Nevertheless, a crucial modeling step in statistical identification is the labeling of shocks, since the estimated matrix $\widehat{B}$ is only unique up to column sign and column permutation. In addition, it is not guaranteed that model-implied effects of independent shocks have an economically meaningful interpretation. A common approach to link the independent components with an economic interpretation is to label the columns of $\widehat{B}$ according to a theory-based sign pattern. The entries in $\widehat{B}$ correspond to the impact effects of the shocks on the variables in the system. Kilian and Murphy (2012) powerfully argue for a clear pattern of impact directions in the oil market: A negative oil-supply shock $\left(\varepsilon_{s}<0\right.$, i.e., an unexpected shortage of crude oil on global markets) lowers oil production and economic activity and raises the price of oil. A positive aggregated-demand shock $\left(\varepsilon_{a d}>0\right.$, i.e., an unexpected increase in global economic activity, which raises the demand for all industrial commodities) has positive effects on all variables on impact. A positive oil specific demand shock $\left(\varepsilon_{o s d}>0\right.$, i.e. an

\footnotetext{
${ }^{11}$ Series for Chad, Kenya and Mozambique each contain one missing observation.

${ }^{12}$ Notably, global markets are dominated by yellow corn, whereas in SSA white corn constitutes the bulk of consumption. However, the two goods are fairly comparable as they constitute important staple foods within their respective food markets. As a robustness check, we also used the corn FOB gulf of Mexico price from the World Bank commodity price database. The results are qualitatively not different.
} 
unexpected higher demand specifically for crude oil) increases oil production and the price of oil and dampens economic activity. ${ }^{13}$ Table 6.1 displays a summary of the expected impact

Table 6.1 Theoretical impact directions of global oil shocks on the variables in the empirical model as suggested by Kilian and Murphy (2012). The signs are normalized such that all shocks have a positive impact on the oil price $p_{t}$.

\begin{tabular}{clll}
\hline \multicolumn{4}{c}{ Shocks } \\
\hline Variable & $\varepsilon_{s} \rightarrow$ & $\varepsilon_{a d} \rightarrow$ & $\varepsilon_{\text {osd }} \rightarrow$ \\
\hline$\Delta q_{t}$ & - & + & + \\
$x_{t}$ & - & + & - \\
$p_{t}$ & + & + & + \\
$c_{t}$ & $?$ & $?$ & $?$ \\
\hline
\end{tabular}

directions of the structural shocks on the variables. Even though it is unclear how shocks from the global crude oil market affect domestic corn prices in SSA, shock labeling is possible due to the unique response of the oil market series. The average impact relation matrix of the eight SSA countries reads as

$$
\overline{\widehat{B}}=\left[\begin{array}{cccc}
-0.56 & -0.15 & 0.19 & 0.03 \\
(22.36) & (4.86) & (2.97) & (0.67) \\
-5.96 & 19.57 & -1.54 & -1.97 \\
(3.93) & (33.54) & (1.05) & (1.53) \\
2.18 & 2.81 & 7.03 & 0.03 \\
(4.07) & (3.63) & (24.45) & (0.06) \\
0.70 & 0.95 & -0.28 & 8.57 \\
(1.39) & (1.40) & (0.60) & (12.04)
\end{array}\right]
$$

where the values in parentheses denote the $t$-ratios. ${ }^{14}$ With exception of element $\widehat{\widehat{B}}_{12}$ (i.e the response of oil production to an aggregated-demand shock), the sign pattern of the upper left $3 \times 3$ matrix is in line with the theoretical impact directions in Table 6.1. Moreover, the fourth column of $\overline{\widehat{B}}$ shows no significant impact effect on any of the first three variables, leading to the conclusion that the residual shock series has no explanatory content for the oil market variables on average.

In view of the results of the normality tests and the signs of the impact relation matrices, we detect three shock series that are consistent with previous oil market studies, namely oilsupply shock, aggregated-demand shock and oil-specific demand shock. This finding allows us to assess the impacts of the three independent sources of oil market turmoils on local corn markets in SSA to determine policy strategies that stabilize food prices.

\footnotetext{
${ }^{13}$ The fourth independent component contains other agriculture-specific shocks that are innovations in the corn price series, which cannot be explained by the three oil market shocks. We do not further characterize this shock, and label it as residual shock.

${ }^{14}$ The $t$-ratios are obtained as the ratio of the group means of the eight different countries and the corresponding standard errors. The vectors in the matrix $\widehat{B}$ for each country are ordered according to the sign pattern in Table 6.1.
} 


\subsubsection{Sub-Sahara African corn markets differ compared with world markets}

When discussing the relationship between oil and corn prices in SSA, a natural starting point is to clarify whether African corn markets are driven by the same dynamics as world prices. Figure 1 displays the cumulative per cent growth of SSA corn prices compared with global corn prices since 2006. Shortly after the US biofuel expansion, the global corn price increased by about 75\%. Baumeister and Kilian (2014a) and Wang et al. (2014) mainly attribute this price surge to the higher demand for corn due to a substitution effect from fossil-fuel to biofuel. However, at the same time, corn prices in SSA decreased by about $28 \%$ on average, which indicates that US policy interventions have not been transmitted to SSA markets. Another point in case is the international food price crisis of 2007/08, during which global corn prices increased by approximately 90\%, while SSA corn markets responded more ambivalently and prices only increased by about $50 \%$ on average. For instance, the corn price in Nigeria more than doubled between August 2007 and July 2008, whereas the corn price in Zambia only increased by about 20\%. Overall, it appears that some SSA countries remain relatively unaffected by global events, which may be due to poor market integration, but it also reflects that domestic food prices in SSA are particularly subject to local shocks, such as extreme weather or civil unrest.

For example, even though the corn price in Mozambique also roughly doubled from August 2007 to June 2008, it had already peaked in May 2006 following an unexpected shortfall in corn production (Figure D.1 in Appendix D.3). During this particular rally, the Mozambican corn price doubled in just three months as opposed to the seven-month surge of the 2007/08 episode. From December 2015 to January 2016, corn prices in Mozambique again increased abruptly by about $270 \%$ after drought periods. Similar patterns can also be observed in Tanzania in 2015 and 2016, when real food prices more than doubled and then rose again by more than $50 \%$ after a year of severe droughts. Over the entire period, the international food price crisis appears to be a relatively minor episode in SSA corn prices, which tend to be much more dependent on local events.

We further examine the different movements of African corn market prices compared with world market prices by replacing the corn price in the baseline model in equation 6.1 with a ratio of local prices and global prices, i.e.

$$
y_{t}=\left(\begin{array}{c}
\Delta q_{t} \\
x_{t} \\
p_{t} \\
\text { local/global }
\end{array}\right) \text {, }
$$




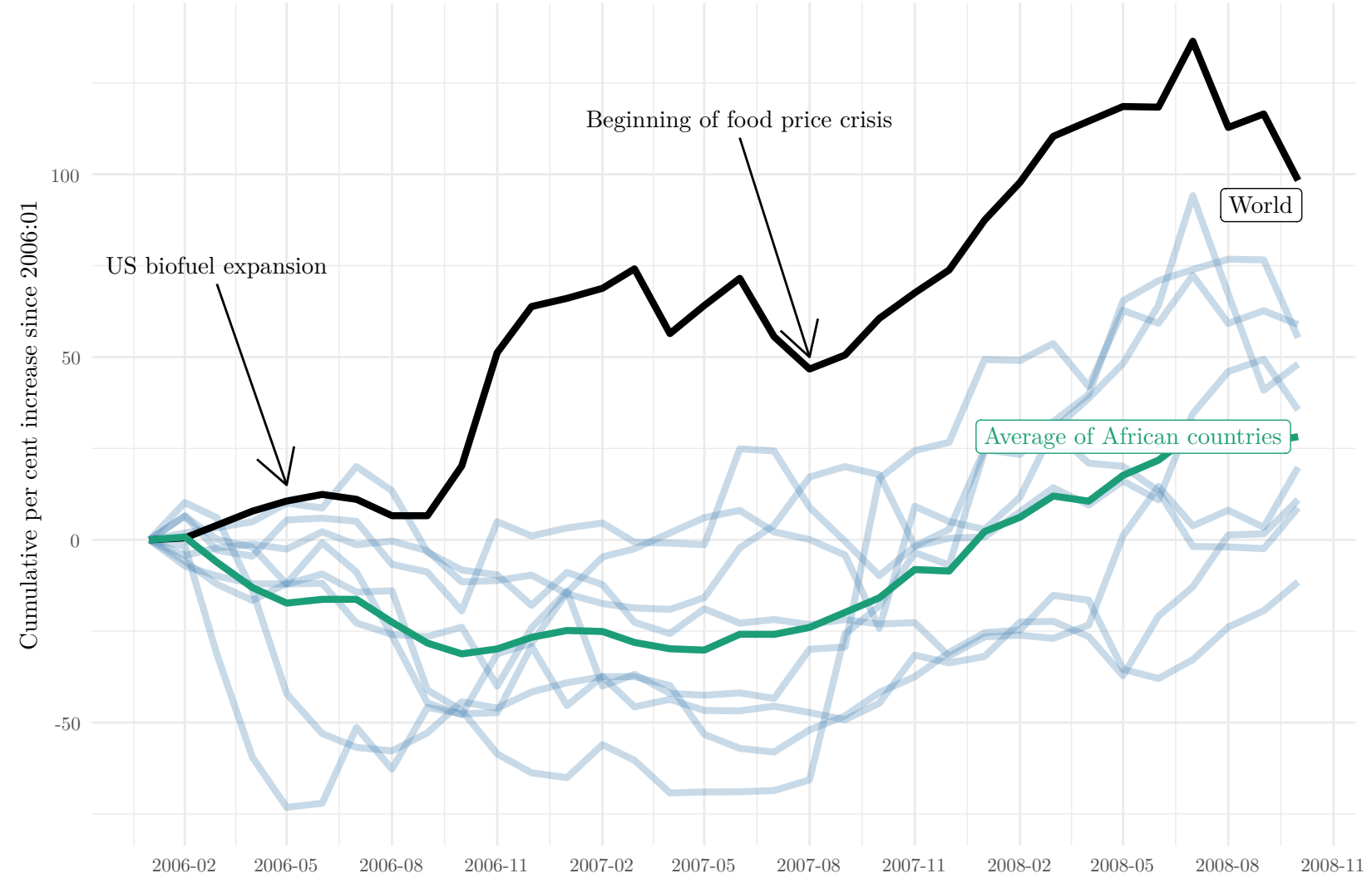

Figure 6.2 Comparison of cumulative percentage growth in real global corn prices and real African corn prices after the US biofuel mandate in May 2006 and during the international food price crisis in 2007/08. Light blue lines represent the single African countries, and the green line shows the average of SSA countries.

and calculate impulse response functions (IRFs). We construct $c_{t}^{\text {local/global }}$ as the ratio of price indices by standardizing all real corn price series to a unit value in January $2006{ }^{15}$

Table 6.2 provides an overview of statistically significant responses of the ratio $c_{t}$ local/global for at least one time point over 30 periods. The signs in the last column of Table 6.2 suggest that world prices show a stronger positive response to an unexpected higher demand for crude oil than most SSA corn prices, i.e. most SSA corn markets are less sensitive to oil-specific demand shocks. The second column confirms the findings from Figure 6.2 that African corn markets move rather ambiguously during periods of high economic demand. The first column shows that some SSA corn markets are more sensitive to global oil-supply disruptions than others such that oil-supply shocks could have fundamentally different impacts on SSA food prices compared with global prices. In sum, we note that SSA corn markets are different not only compared with world markets, but also compared with each other, i.e. we find considerable heterogeneity of SSA corn markets regarding their response to global oil shocks. Moreover, we observe that SSA corn markets are relatively less affected by global structural

\footnotetext{
${ }^{15}$ We do not discuss the issue of shock labeling again, because three out of four series remain the same and the sign pattern in Table 6.1 still applies for the model with relative prices.
} 
Table 6.2 Significant response directions to oil market shocks of African corn prices relative to global corn prices. An increase of local corn prices relative to global corn prices at the $5 \%$ (10\%) significance level is indicated by ' $++^{\prime}\left({ }^{\prime}+'\right)$. A decrease of local corn prices relative to global corn prices at the $5 \%(10 \%)$ significance level is indicated by '--' ('-'). Significance is obtained from bootstrapped IRFs.

\begin{tabular}{l|ccc} 
& Oil-supply shock & Aggregated-demand shock & Oil-specific demand shock \\
\hline Chad & 0 & 0 & 0 \\
Ethiopia & ++ & 0 & 0 \\
Ghana & 0 & - & -- \\
Kenya & ++ & 0 & -- \\
Mozambique & 0 & - & 0 \\
Nigeria & 0 & ++ & - \\
Tanzania & 0 & 0 & - \\
Zambia & 0 & - & -
\end{tabular}

changes than world corn prices.

\subsubsection{The role of oil-supply shocks in Sub-Saharan African corn markets}

One way of disentangling the many potential country-specific effects and transmission channels is to take a more disaggregated perspective and investigate the response of corn prices to each oil shock separately. This section examines the link between the global oil-supply and corn markets in SSA using IRFs and forecast error variance decompositions (FEVDs) in conjunction with three case studies. All results are obtained from the baseline model specification in equation (6.1).

\subsubsection{Do unexpected oil production shortfalls cause corn prices in Africa to surge?}

Figure 6.3 depicts the estimated IRFs of the three local corn prices, which show a significant response to an unexpected oil-supply shortage. A comparison with the point estimates of the remaining countries is provided in Figure D.2 in Appendix D.3. 

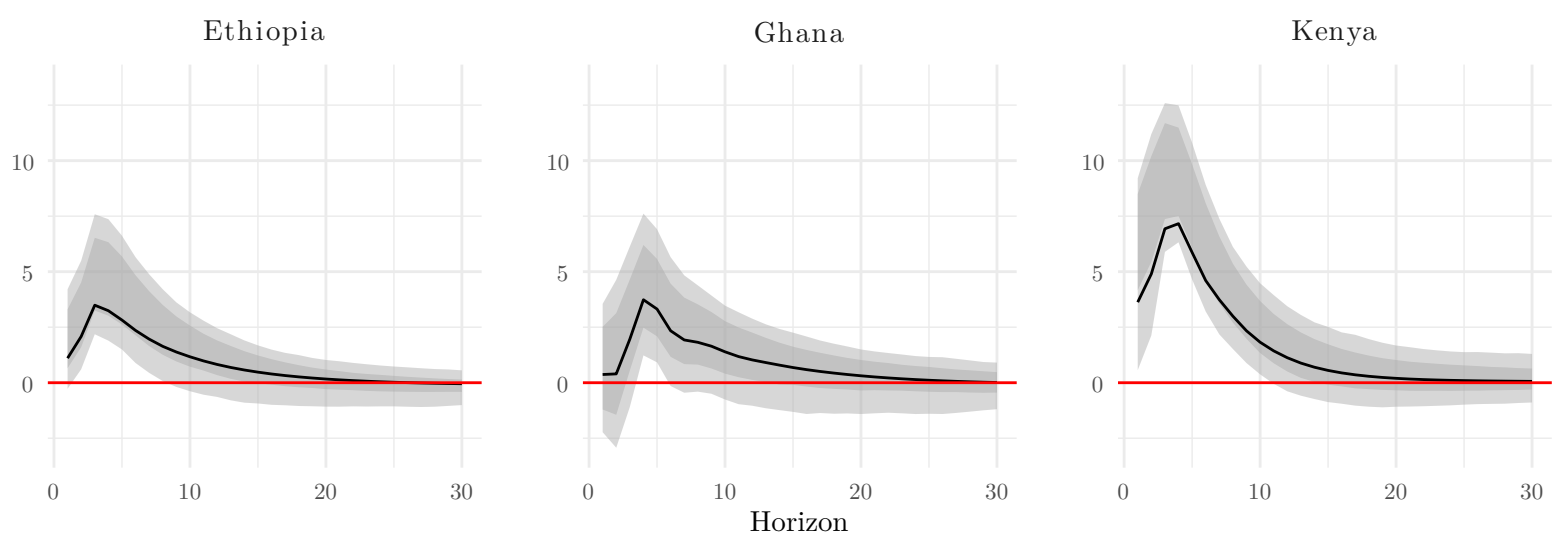

Figure 6.3 Responses of corn prices in Ethiopia, Ghana and Kenya to an oil-supply shortage joint with $68 \%$ and $90 \%$ confidence bands obtained from 2000 bootstrap iterations (Hall, 1992).

In Ethiopia, Ghana and Kenya, corn prices sharply rise and reach their maximum after about two months as a reaction to a global oil-supply shortage. The effect is rather persistent and only slowly fades out after about two years (with $68 \%$ confidence). Even with $90 \%$ confidence, we find a significant response of the corn price to an oil-supply shock in all three countries. In addition, FEVDs displayed in Table 6.3 reveal that the explanatory content of oil-supply shocks in the variation of corn prices remarkably differs between the countries. We can clearly separate corn markets affected by oil-supply disruptions (Ethiopia, Ghana, Kenya) from corn markets that are largely unaffected by oil-supply shocks (Chad, Nigeria, Tanzania, Zambia). In the first group, in particular, we find that the relative importance of oil-supply shocks increases in the long term and explains a large part of variation in the corn price. In comparison with most African corn markets, global corn markets show an opposite response with a diminishing explanatory content of oil-supply shocks.

Table 6.3 Contribution of oil-supply shocks to $h$-step ahead FEVD of local corn prices in SSA markets and world markets.

\begin{tabular}{l|cccc}
\hline & $h=1$ & $h=10$ & $h=30$ & $h=\infty$ \\
\hline Chad & 1 & 3.1 & 4.6 & 4.6 \\
Ethiopia & 1.6 & 12.9 & 13 & 13.1 \\
Ghana & 0.2 & 8.8 & 8.8 & 8.8 \\
Kenya & 20.9 & 52.3 & 47.7 & 46.5 \\
Mozambique & 0.1 & 3 & 3.2 & 3.2 \\
Nigeria & 1.1 & 1 & 1.5 & 1.7 \\
Tanzania & 0.5 & 1.6 & 1.7 & 1.7 \\
Zambia & 3.2 & 2.3 & 2.5 & 2.5 \\
\hline World & 8.7 & 6.2 & 4.9 & 4.9 \\
\hline
\end{tabular}




\subsubsection{Two case studies of oil-supply disruptions: The Libyan revolution and Iranian nuclear sanctions}

Oil-supply disruptions are often regarded to have only minor impacts on oil prices and other commodity prices. The hypothesis is grounded on the assumption that, due to a large number of oil-producing countries, bottlenecks of oil production in one region lead to an increase of oil production in other regions, and a decline of oil production caused by geopolitical events - for example, in the Middle East - accounts for only a small fraction of global oil production (e.g. Hamilton, 2009; Kilian, 2009; Kilian and Murphy, 2012). Regarding food prices, Wang et al. (2014) find that oil-supply shocks have negligible impacts on agricultural commodity prices. As this discrepancy between the recent literature and our results emerges, the impact of oil-supply shocks in SSA warrants a more nuanced level of analysis.

Baumeister and Kilian (2014a) argue that if there is a link between oil-supply shortages and corn price increases there should be some reaction of corn prices during certain historical events. For instance, the authors look at the sharp spike in the oil price in July 1990 when Saddam Hussein invaded Kuwait and find no remarkable increase of agricultural commodity prices in the US. Since the SSA price series do not cover this historical event, we consider two more recent events as case studies to investigate whether the explanatory content of oil-supply shocks in Ethiopia, Ghana and Kenya persists during these time periods. In particular, we examine the effects of the Libyan oil production shortfall in 2011 and the oil embargo against Iran in 2012. Both events are frequently considered as examples of oil price surges with a strong contribution of negative oil-supply shocks (Baumeister and Kilian, 2014b; Kilian and Lee, 2014). ${ }^{16}$

\section{The fall of the eighths largest oil producer in the world}

As a consequence of the ongoing civil unrest in Libya and its neighboring countries following the Arab spring, the Libyan revolution began in February 2011. In the following months, the oil production in Libya dropped from 1.48 million barrels per day (mdb) in January 2011 to $0.08 \mathrm{mdb}$ in May 2011. Worldwide, the oil production decreased by about $3.6 \%$ during this time period, and it took until December 2011 for global oil production to return to precrisis levels. The rather long delay in the recovery of oil supply was mainly caused by internal disputes in the organization of the petroleum exporting countries (OPEC) about the need for an oil production expansion, and hence, it took until June 2011 for Saudi Arabia to increase its oil production from $8.86 \mathrm{mbd}$ to $10 \mathrm{mbd}{ }^{17}$ In addition, the fact that the heavy and sour

\footnotetext{
${ }^{16}$ The authors describe oil price increases during these two time periods as mixtures of oil-supply shocks and oil-specific demand shocks. Nevertheless, both studies base on the oil-supply elasticity constraint by Kilian and Murphy (2012), which leads to an insufficiently small effect of oil-supply shocks by construction (Baumeister and Hamilton, 2019a). This circumstance points to the assumption that the actual share of oil-supply shocks on these price surges is indeed much higher.

${ }^{17}$ Data on the country-specific oil production comes from the US Energy Information Administration.
} 
oil from Saudi Arabia is generally considered to be of lower quality than the light and sweet oil from Libya made it difficult to find buyer countries, which caused further delays in global oil-supply. ${ }^{18}$

Figure 6.4 shows that immediately after the onset of the Libyan revolution, the corn price in Kenya almost doubled and reached the maximum during the entire sample in July 2011. In Ethiopia, the corn price increased by about $70 \%$ and the corn price in Ghana responded with some delay but increased by about 40\% until August 2011. By contrast, corn prices in the remaining African countries increased moderately by about $25 \%$ in the same time span, which is comparable with the development of the world market price during this period.

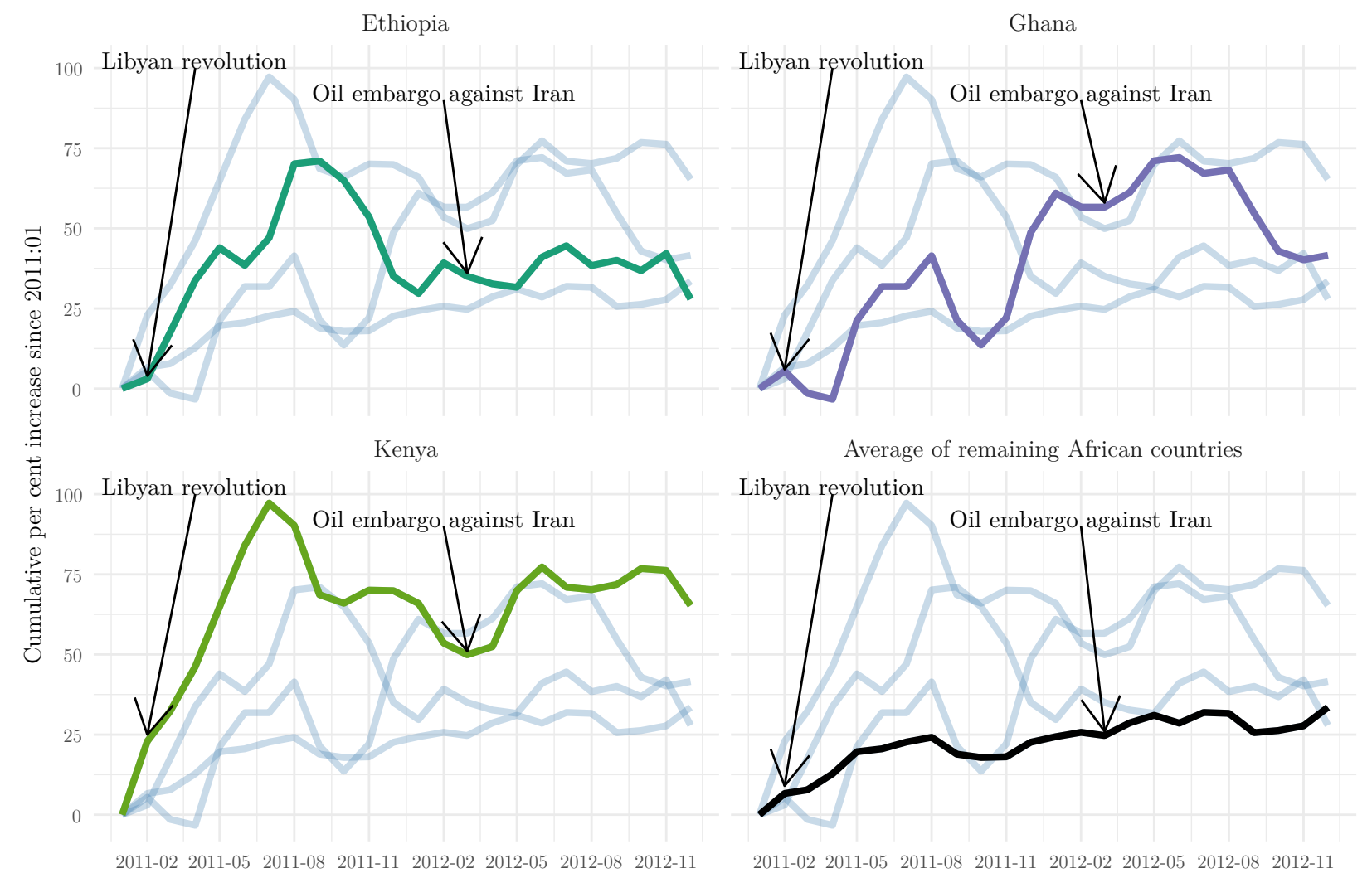

Figure 6.4 Comparison of cumulative percentage growth of real corn prices in Ethiopia, Ghana and Kenya with remaining SSA countries after the Libyan oil production shortfall in 2011 and the oil embargo against Iran in 2012.

The oil embargo against Iran

Due to its nuclear weapon program, the ongoing political tensions with Iran entered a new phase in early 2012 when the US and the EU introduced a new series of oil import sanctions.

\footnotetext{
${ }^{18}$ Light and sweet crude oils have a lower density and lower content of sulfur, which is desirable because they can be processed into gasoline fuels with much less sophisticated mechanisms. Even though, crude oils from different geographic origins are largely interchangeable, they are not perfect substitutes and oil production slumps cannot immediately be absorbed by other producers. More information on crude oil in general can be found - for instance - in World Energy Council (2016).
} 
Because most OECD countries refrained from buying Iranian oil, the production output in Iran dropped from around $4 \mathrm{mbd}$ in January/February 2012 to $3.1 \mathrm{mbd}$ in October 2012. However, global oil production recovered quickly such that the worldwide production only diminished by about $0.8 \%$ from March to June 2012, and it already exceeded the pre-embargo level by July 2012. The main reason appears to be that the other OPEC members (in particular Saudi Arabia) showed no interest in supporting the Iranian government by freezing their production ceilings. By contrast, the government in Saudi Arabia immediately signaled its willingness to close the supply gap caused by the loss of Iran's heavier type crude oil.

Figure 6.4 shows that the increase in corn prices in Ethiopia, Ghana and Kenya was much lower after the nuclear sanctions against Iran, compared with the increase after the Libyan revolution, which is in line with the circumstance that the global oil supply shortage was quickly compensated. Nevertheless, the corn price in Kenya increased by about $25 \%$ in three months and about 10\% (15\%) in Ethiopia (Ghana).

Particularly for Kenya and Ghana, we find two clear peaks of the corn prices between early 2011 and late 2012 before they started to return to the average of the other African countries. In combination with the results from the IRFs shown in Figure 6.3 and the FEVDs documented in Table 6.3, oil-supply shocks appear to have major impacts on corn price movements in three countries. However, even if the sharp increase in the corn prices shortly after two oil-supply disruptions hints towards oil-supply shocks as the main trigger, the precise role of oil supply during these events is still not convincingly clear. To further investigate the price surges displayed in Figure 6.3, we return to the structural analysis and disentangle the contribution of each shock (oil-supply shock, aggregated-demand shock and oil-specific demand shock) to the corn price surges in Ethiopia, Ghana and Kenya during the Libyan revolution and the oil embargo against Iran by means of historical decomposition.

\section{Disentangling the price surges in 2011 and 2012}

Historical decompositions have become a popular tool in the SVAR literature to disentangle alternative sources of oil price surges (e.g. Kilian and Murphy, 2012; Kilian and Lee, 2014; Herwartz and Plödt, 2016c). In particular, Kilian and Lee (2014) propose measuring the change in a series $y_{i t}$ explained by a structural shock $\varepsilon_{j}$ by comparing the difference between the contribution of $\varepsilon_{j}$ to $y_{i t}$ at time point $y_{i T_{1}}$ and time point $y_{i T_{2}}$ with the total change in the series between the respective dates. We apply this method to analyze the effects of oil shocks on corn price increases in Ethiopia, Ghana and Kenya during the Libyan revolution and Iranian nuclear sanctions.

Figure 6.5 shows that oil-supply shocks are almost exclusively responsible for the corn price increases in 2012 in all three countries, i.e., at least $70 \%$ of the corn price increase can be attributed to oil-supply shocks. Moreover, at least one other shock series exerts downward pressure on the corn price in each country, leading to the conclusion that corn prices could 


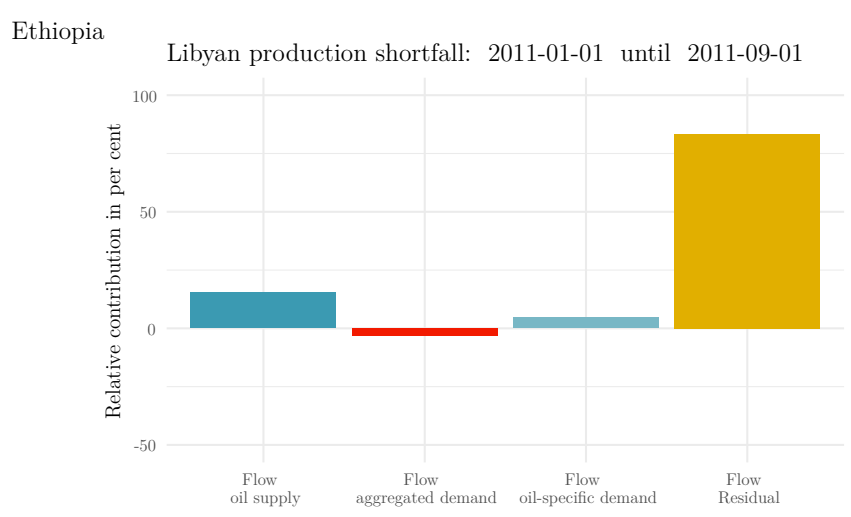

Ghana

Libyan production shortfall: 2011-01-01 until 2011-08-01

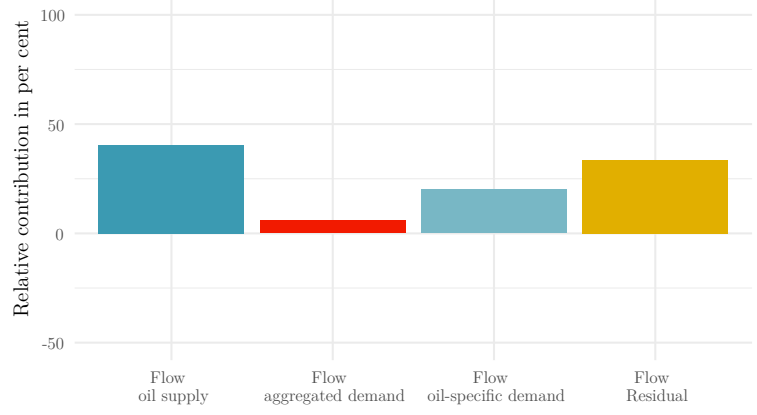

Kenya

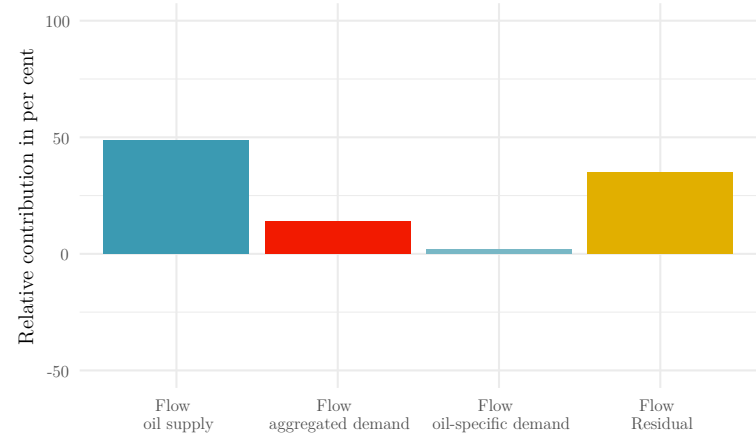

Oil embargo against Iran: 2012-03-01 until 2012-11-01

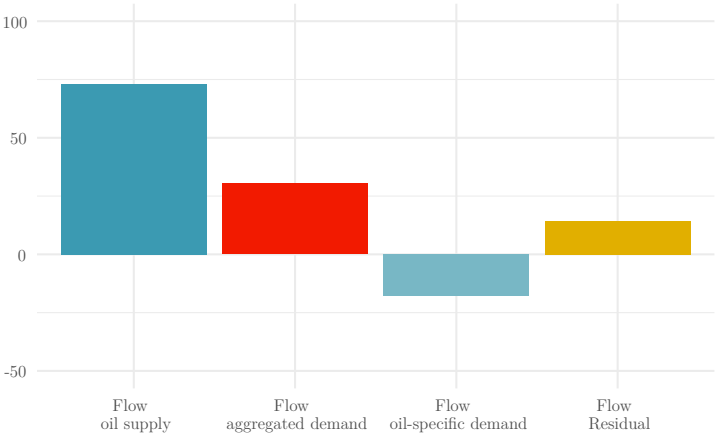

Oil embargo against Iran: 2012-03-01 until 2012-08-01

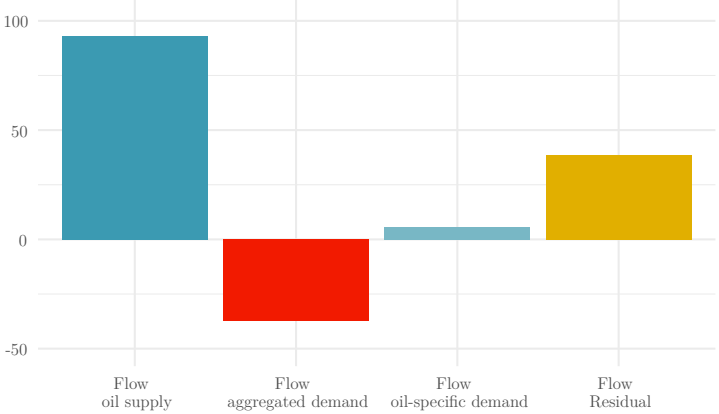

Oil embargo against Iran: 2012-03-01 until 2012-11-01

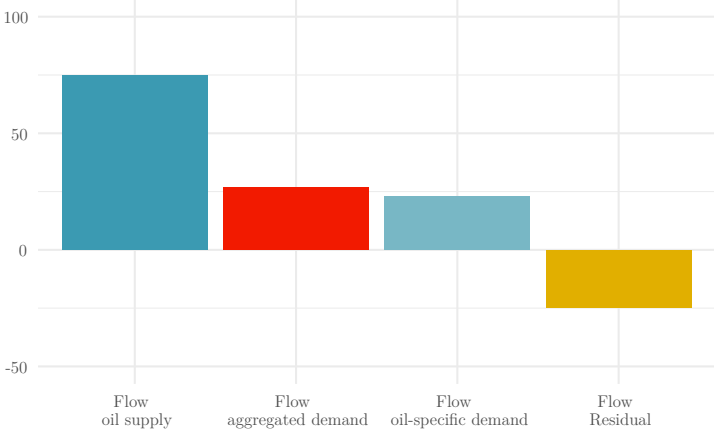

Figure 6.5 Relative contribution to cumulative change in domestic corn prices in Ethiopia, Ghana and Kenya during the Libyan production shortfall and the oil embargo against Iran by structural shocks. The contributions of the four shocks add up to $100 \%$, which represents the total corn price increase.

have been even higher in fall 2012 due to oil-supply shocks. The circumstances are slightly different during the Libyan revolution in 2011. Particularly in Ethiopia, the lion's share of the corn price surge in 2011 can be attributed to non-oil related shocks. However, in Ghana and Kenya we still find a rather high explanatory content of oil-supply shocks, i.e. half of the strongest corn price surge in Kenya is most likely due to the downfall of the Libyan oil production. Although the situation is somewhat less dramatic for Ethiopia and Ghana, the hypothesis that oil-supply shocks were important determinants of the corn price increases in 2011 and 2012 in Ethiopia, Ghana and Kenya can be confirmed. 


\subsubsection{A case study of an oil-supply boom: The expansion of oil production in the US and Middle East}

Thus far, we have investigated how negative oil-supply shocks have triggered corn price surges, although recently oil production has tended to increase in several regions, and therefore it also holds interest to examine whether positive oil-supply shocks have exerted downward pressure on corn prices.

About a decade ago, it was well established that global oil production would no longer keep pace with growing economic oil demand, due to the decline of traditional oil fields and the declining discovery of new fields (e.g. Hamilton, 2013; Benes et al., 2015). However, the invention of hydraulic fracturing (so-called 'fracking') in conjunction with horizontal drilling has made it possible to extract crude oil from rock formations characterized by low permeability, which is commonly referred to as tight oil or shale oil. The new technique is primarily used in the US and sparked the ongoing US shale oil boom in 2009 (Kilian, 2017). Even though 2009 marks the reversal of the long-standing decline in US oil production since the late 1970s, it took about three more years for US oil production to start substantially expanding. By April 2015, the total US oil supply had increased from 6 mbd in December 2011 to $9.6 \mathrm{mdb}$. As a result, the government first abolished the export ban on crude oil in 2014 and eventually lifted all remaining export restrictions by December 2015, which paved the way for a remarkable expansion of US crude oil exports. ${ }^{19}$

In addition to the US shale oil boom, several countries in the Middle East further expanded their production capacities. Predominantly, Saudi Arabia and Iraq were responsible for a sizable share of the production surge in the region. Iraq increased its oil production from $3 \mathrm{mbd}$ to $4.5 \mathrm{mbd}$ from January 2014 to January 2016. Despite the threat of terrorist activities from the Islamic State, the Iraqi government was able to upgrade the midstream infrastructure (e.g. pipelines and pumping stations) in the southern oil fields - where $90 \%$ of the country's oil is produced - and to start marketing Basra Heavy grade crude oil. ${ }^{20}$

Kilian (2017) shows that in conjunction with the US shale oil boom, the oil production expansion in the Middle East led to a $10 \$$ reduction in the price of crude oil in 2014/15. We investigate how the real price of corn in Ethiopia, Ghana and Kenya would have evolved from 2014 to 2016 if one had replaced all oil-supply shocks with zero, as if neither the shale oil boom nor the oil production expansion in the Middle East had occurred. Kilian and Lee (2014) and Kilian (2017) propose counterfactuals for the construction of such scenarios by subtracting the cumulative contribution of oil-supply shocks from the evolution of the real corn price.

\footnotetext{
${ }^{19}$ The US crude oil export ban was part of the Energy Policy and Conservation Act, which was established in 1975 in response to the 1973 oil crisis.

${ }^{20} \mathrm{~A}$ more detailed description of the oil production expansion in Iraq can be found in Asghedom (2016)
} 


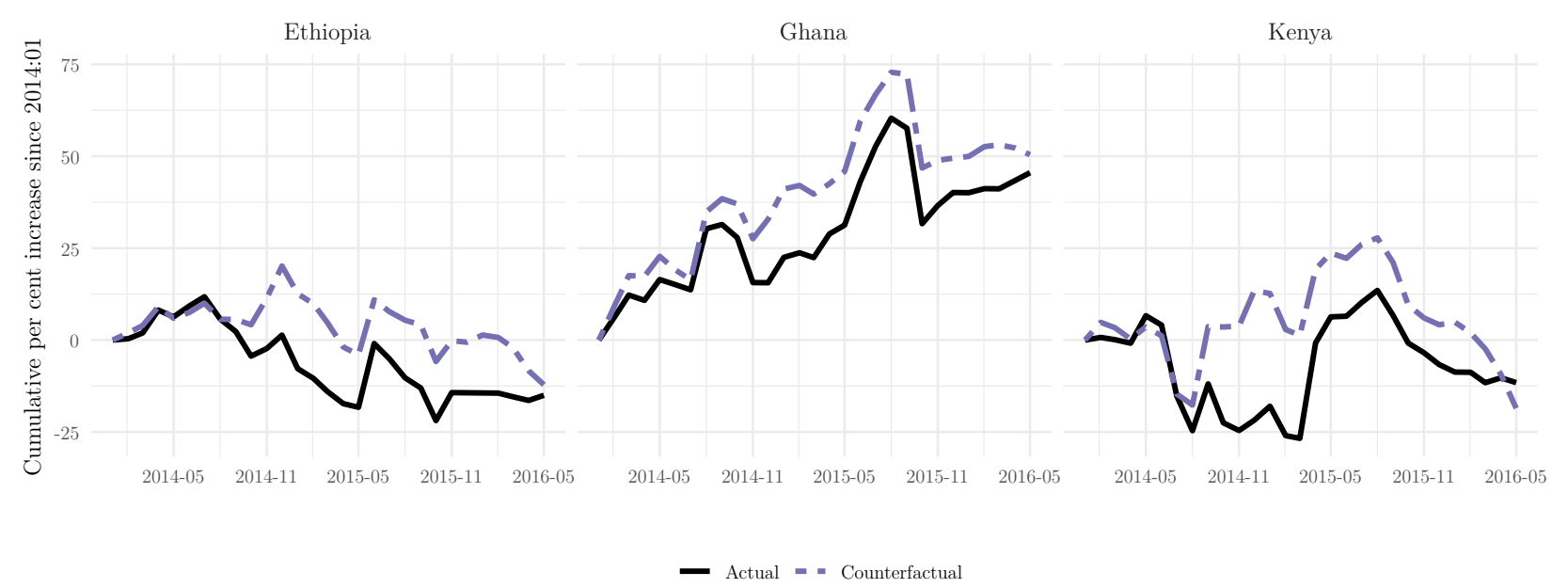

Figure 6.6 Comparison of cumulative percentage growth of real corn prices in Ethiopia, Ghana and Kenya since January 2014 with and without effects from shale oil boom and expansion of production capacity in the Middle East.

Figure 6.6 shows that on average the real price of corn in all three countries would have been about 10\% higher between early 2014 and mid-2016 without oil supply shocks. Corn prices in Ethiopia and Ghana would have been 20\% higher and in Kenya even 35\% higher without the downward pressure from increasing oil-supply in late 2014. The US shale oil boom reached its temporary peak in 2015 and US oil production declined in late 2015/early 2016 along with global oil production, whereby the negative effects from oil-supply shocks on corn prices in Africa abated in mid 2016.

\subsubsection{Why are some Sub-Saharan African corn markets responsive to oil- supply shocks and others not?}

In the previous sections, using country specific IRFs and FEVDs statistics and case study analysis we illustrated the heterogeneous responses of SSA corn prices to oil-supply shocks. Moreover, we highlighted several possible reasons that help to explain why oil-supply shocks are the most powerful instigators of domestic corn price fluctuations among all oil shocks in Ethiopia, Ghana and Kenya.

While upon first glance the importance of oil-supply shocks to SSA food markets is not intuitive in light of the existing evidence concerning global oil shocks and US food markets (Baumeister and Kilian, 2014a; Wang et al., 2014), it finds support in the literature on the crude oil-food price nexus in developing countries to some extent (Nazlioglu and Soytas, 2012). Furthermore, since food markets in developing countries and even more so in SSA countries are vertically poorly integrated (Pinstrup-Andersen, 2015), and systematically different in terms of stability patterns (Minot, 2014), it is unsurprising if they also depend on oil markets differently compared with global food markets. Dillon and Barrett (2015) show that in some cases local food prices in SSA are more subject to international oil price fluctuations than 
to global food price movements. The authors conclude that in contrast to other parts of the world, transport costs are a major determinant of local food prices in some SSA regions, particularly in Ethiopia, Kenya and Tanzania.

Our empirical results suggest that two of these countries' corn markets are most exposed to oil-supply shocks. In Ethiopia and Kenya, a large share of the arable land and farms are spread out over the countries. With markets being equally dispersed, transport comes in as an important part of the cost function of production and marketing of corn. Coupled with particularly bad road connectivity and long travel times in both countries (Dorosh et al., 2012), transport costs are likely to form a substantial share of costs along the supply chain and oil-supply disruptions are presumably transmitted to food prices through this channel (see Figure 6.1).

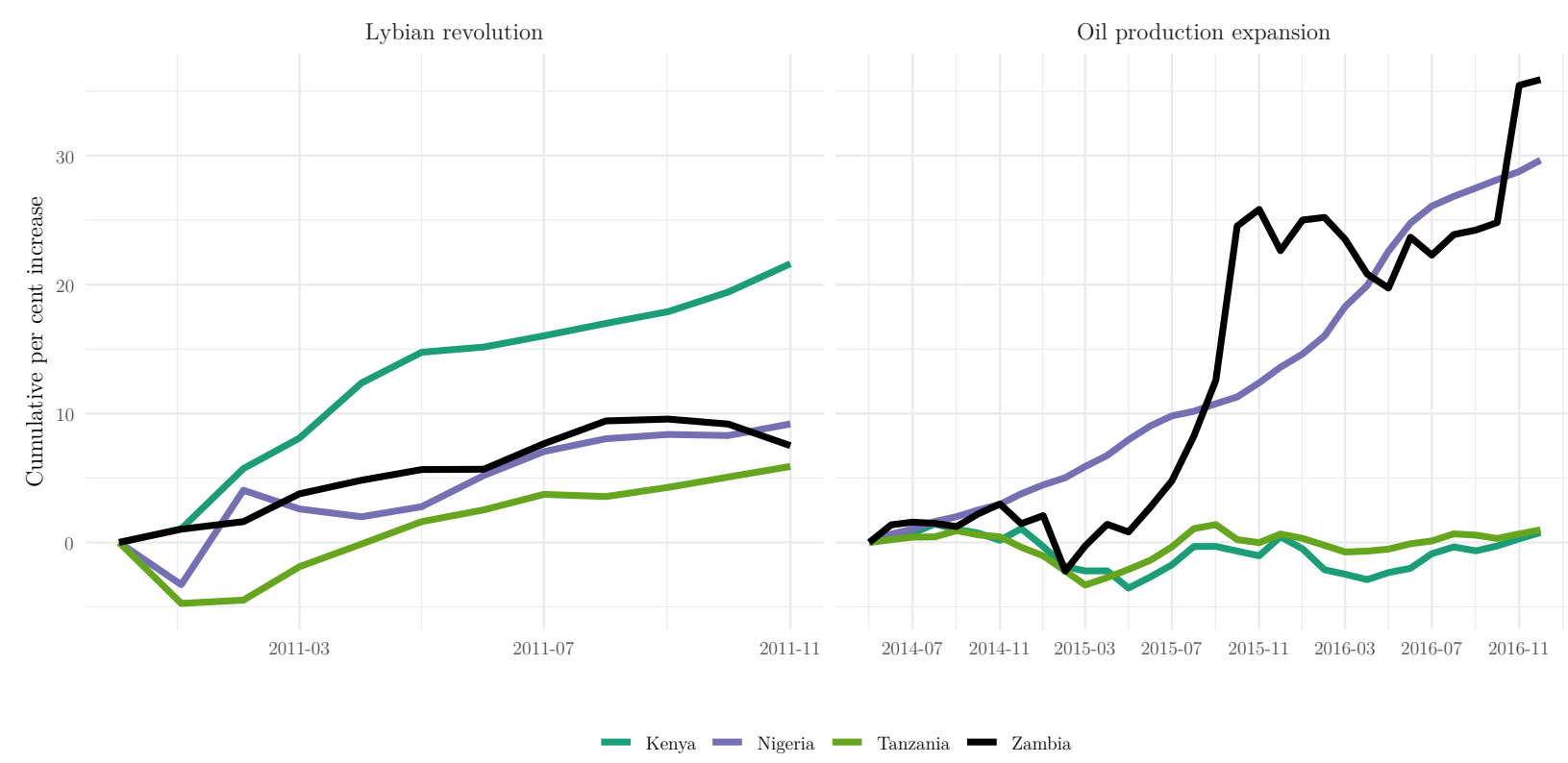

Figure 6.7 Comparison of cumulative percentage growth in transportation costs during the Libyan revolution and during the oil production expansion in several regions.

Figure 6.7 shows the development of the transportation costs in Kenya compared with countries that do not respond to unexpected oil-supply shortages. ${ }^{21}$ During the Libyan revolution in 2011, half of corn price increase in Kenya of over 90\% could be attributed to oil-supply shocks and at the same time transportation costs increased by about $20 \%(2.1 \%$ on average per month) while transportation costs in the other three countries grew with the average rate of about $0.6 \%$ per month. Conversely, during the shale oil boom in 2014 and 2015 - when oil production was expanded at global levels - transport costs dwindled in Kenya and Tanzania, while increasing faster than usual in Zambia and Nigeria (about $1 \%$

\footnotetext{
${ }^{21}$ Data for transportation costs is defined as the consumer price index in the transportation sector and can be downloaded from the national bureaus of statistics. Due to the generally poor data availability in SSA countries, we cannot provide statistics about the transportation costs in the remaining countries.
} 
on average per month). The movements of the respective series support the hypothesis that transportation costs are a major transmission channel of oil-supply shocks in SSA.

One possible reason for the extraordinary vulnerability of local transport costs to global oil-supply disruptions is the notoriously low strategic oil reserves in Kenya and Ethiopia. Both countries are net importers of crude oil and do not dispose of sufficient oil inventories to quickly buffer import shortages. The backlog has been recognized by the respective ministries, which in the past have called for the creation of national strategic reserves (Ministry of Water and Energy of Ethiopia, 2013; Ministry of Energy and Petroleum of Kenya, 2015). With the strong importance of transport costs for producers as well as a high import dependency of fossil fuels, these countries are counter-examples against the neutrality hypothesis of food markets to oil-supply shocks (Wang et al., 2014; Baumeister and Kilian, 2014b). ${ }^{22}$

The circumstances are slightly different for Ghana. Traditionally, Ghana was a major net energy importer and the Ghanaian Energy Commission (2006) warned of a possible oil and petroleum shortage due to a lack of strategic oil reserves and refinery capacities. In combination with a substantial dispersion of a large corn-producing smallholder sector and bad road quality, it is likely that transport costs are highly supply-shock-prone, similar to Kenya and Ethiopia. The situation changed in 2011 when the exploitation of off-shore oil reserves allowed Ghana to become step-wise less dependent on energy imports. Nevertheless, with an oil production between 0.1 and $0.2 \mathrm{mbd}$, Ghana still imports a considerable amount of crude oil, which explains the significant weaker overall reaction of local corn prices to global oil-supply shocks in Ghana over the entire sample. In further support of the hypothesis that susceptible transportation costs are the main transmission channel of oil-supply shocks in SSA countries, one can consider the case of Nigeria. As the largest net exporter of crude oil in our sample and boasting strategic oil reserves, corn markets in Nigeria remain unscathed from oil-supply shocks while being rather responsive to aggregated-demand shocks.

In combination with potential bottlenecks in the fuel supply chain in Ethiopia, Ghana and Kenya, we detect further country-specific characteristics that could help to explain the strong response of local corn prices in our sample. Kenya's smallholder farming is dominated by corn production. More than $70 \%$ of national corn output are produced by smallholders (DAlessandro et al., 2015) and 98\% of smallholders produce corn (Dorosh et al., 2012), i.e., direct substitutes are scarce in case of rising corn prices. Additionally, government interventions in both fuel and food markets could be obstacles to buffer oil-supply shocks. In Kenya, a heavily criticized open tender system was in place in which the winning company was put in charge of importing the entire petroleum demand for the industry (Matthews, 2014). Moreover, in Ethiopia fuel markets are subject to public tender systems in which fuel imports are granted to a limited number of companies. Additionally, Kenya operates an agency that

\footnotetext{
${ }^{22}$ More recent discoveries of oil fields in both Kenya and Ethiopia could obviously change this in the near future.
} 
strongly intervenes in grain markets by purchasing and selling substantial amounts in an effort to stabilize prices. While monopolistic or oligopolistic import structures do not necessarily imply inefficient fuel supply, they can quickly turn into narrowing bottlenecks in the supply chain in cases of collusion or poor management.

By contrast, while Tanzania exhibits similar corn as well as oil market dependencies as Kenya and Ethiopia, its corn markets are not responsive to oil-supply shocks. Unlike in Kenya and Ethiopia, Tanzanian petroleum markets are much less subject to government intervention (Dillon and Barrett, 2015). However, regarding corn, national policy is more regulative. Although domestically, the government refrained from intervening in domestic corn markets and limits its role to building up stocks, Tanzania has frequently suspended international trade to protect from international food price movements at times in which at least one of its region was declared as food insecure (Minot, 2010). Altogether, it seems that Tanzania has managed to isolate domestic corn prices from international shocks and oil shocks, through trade and domestic policy that supports the self-sufficiency of farmers (Wenban-Smith et al., 2016), as well as minimizing cross-border movements of corn.

In sum, we can deduce two main findings regarding the heterogeneous responsiveness of SSA corn markets to oil-supply shocks. First, transportation costs are an important transmission channel between oil market movements in SSA. Second, policy relating to strategic oil reserves and fuel imports as well as policy governing agricultural and energy markets shape the buffering mechanisms against oil-supply shocks via fuel prices in both food and energy markets.

\subsubsection{The role of aggregated-demand and oil-specific demand shocks in Sub-Sahara African corn prices}

According to Table 6.2, SSA corn markets are less responsive to aggregated-demand shocks as well as oil-specific demand shocks compared with world markets. The results shown in Figure 6.8 confirm the findings documented in Table 6.2. Next, we briefly analyze the role of aggregated-demand shocks and oil-specific demand shocks on SSA corn prices, in a first step using IRFs and in a second step using a case study.

\subsubsection{Does increasing commodity demand raise corn prices in Sub-Sahara Africa?}

Aggregated-demand shocks only unfold their impacts in vertically well integrated markets Aggregated-demand shocks are often considered as the driving force behind fluctuations in corn prices (e.g., Wang et al., 2014). However, the only SSA corn price that is pushed in an upward direction by higher aggregated commodity demand is the Nigerian one. All other corn prices under scrutiny show either no significant reaction or even a small negative reaction for 
a few periods. The underlying presumption about the impacts of aggregated-demand shocks on corn prices is that higher economic activity increases not only the demand for oil, but also the demand for agricultural commodities. For example, when international prices rallied in response to higher aggregated demand in 2007/08, SSA prices only moderately increased. A likely explanation for diverging responsiveness to global commodity demand is the lack of vertical integration of both energy and food markets.

The circumstances are slightly different in Nigeria, where two factors come into play. First, an increase in global economic activity increases commodity demand and therefore Nigerian oil exports. In turn, increased export demand raises national economic activity as crude oil production accounts for a large fraction of the Nigerian GDP. ${ }^{23}$ Increased national economic activity could translate into rising food demand and prices. This transmission is consistent with the finding of Wang et al. (2013), who show that for net exporters of crude oil a higher global commodity demand generates increased income. Second, since the Nigerian economy is well connected to the global economy via strong crude oil trade ties, aggregated demand also spurs demand for non-oil commodities in Nigeria, for instance, agricultural commodities.
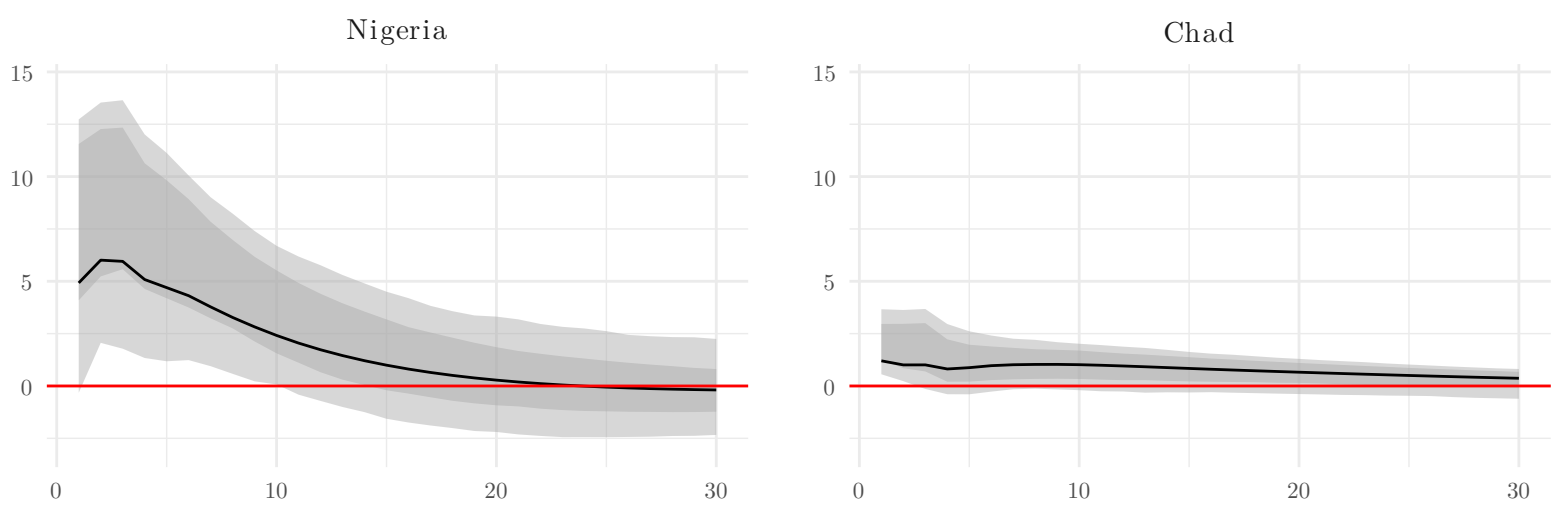

Figure 6.8 The left panel shows the response of the corn price in Nigeria to a positive aggregated-demand shock and right panel shows the response of the corn price in Chad to a positive oil-specific demand shock joint with $68 \%$ and $90 \%$ confidence bands obtained from 2,000 bootstrap iterations.

Oil-specific demand shocks are not determinants of corn price surges in SSA due to the lack of biofuel production

While we note that world corn prices increase in response to an oil-specific demand shock, we cannot find this response for SSA corn prices, with the only exception of Chad, where corn prices show a small positive reaction for the first two periods in response to an unexpected higher demand for crude oil. ${ }^{24}$ Wang et al. (2014) find that after the emergence of large-scale

\footnotetext{
${ }^{23}$ Between 8 and $38 \%$ (World Bank, 2020) in our sample period

${ }^{24}$ The case of Chad is discussed in more detail in appendix D.4.
} 
biofuel production in 2006, food prices are much more sensitive to oil-specific demand shocks, which the authors attribute to the substitutability between corn and crude oil as inputs to fuel production. However, this relationship presumes either existing capacities to produce biofuel or free trade with negligible transaction costs to swiftly convert corn into biofuel in other locations via global markets. Both presumptions are unlikely to hold in the context of SSA. First, in relative terms, SSA continues to represent less than $1 \%$ of global biofuel production. In our sample, only Kenya and Ethiopia appear with non-zero values in the respective statistical databases, although both produce substantially less than 1 mbd per day, at least up until 2015 (EIA, 2020). Thus, the integration of biofuels into national energy mixes remains in its very infancy in SSA. Second, while corn trade between SSA countries is common, corn exports of SSA countries to countries with ethanol-producing capacities do not occur (FAOSTAT, 2020). Consequently, local competition between food and fuel is negligible in these countries and local prices are not linked directly to local energy prices. Poor vertical food market integration additionally implies minimal relevance of the global substitution effect between biofuels and food crops as a transmission channel between energy and local food markets (Hatzenbuehler et al., 2017; Pinstrup-Andersen, 2015). Altogether, we conclude that oil-specific demand impacts only affects food prices when opportunities of biofuel substitution are available, which is strongly in line with the results of Dillon and Barrett (2015).

Similar to the oil-supply shock analysis in the previous sections, it makes again sense to consult case studies to better understand the role of both aggregated-demand shocks as well as oil-specific demand shocks in SSA food markets.

\subsubsection{A case study on the role of demand shocks: The international food price crisis of 2007 and 2008}

Already in 2003, the long-term decline of real food prices since the 1970s came to halt and turned around to start an upward trend. By the end of 2006, the FAO's food price index (FPI) had increased by $44 \%$ compared with its level in January 2003. Starting in 2007, international food prices began to rally and the FPI increased by $68 \%$ until it reached a peak level in June 2008. While the FPI reflects a multitude of food products, some specific commodity price spikes were even more dramatic; for instance, rice prices doubled within five months (Baffes and Haniotis, 2010). This food price explosion has not only been associated with profound changes in poverty and food insecurity (e.g. De Hoyos and Medvedev, 2009; Headey et al., 2011) but also resulted in cases of civil unrest (Bellemare, 2015).

Some international organizations and authors have warned of the threat to African food prices as well as food security from international food price surges (Wiebe et al., 2011; Wodon and Zaman, 2008, e.g.). However, as illustrated in Figure 6.2, the movements of the corn prices in Africa are extremely diverse in 2007/08, with some series doubling their values and 
some series almost moving sideways. Next, we consider only SSA corn markets where we find either at least an indication that the international dynamics in 2007/08 are transmitting to local prices, or corn markets that respond significantly to aggregated-demand or oil-specific demand shocks. Figure 6.9 depicts the actual and counterfactual paths of the corn prices in Chad, Ethiopia, Ghana and Nigeria during the international food crisis. Although all price series exhibit some remarkable price surges, demand shocks have only marginal effects.

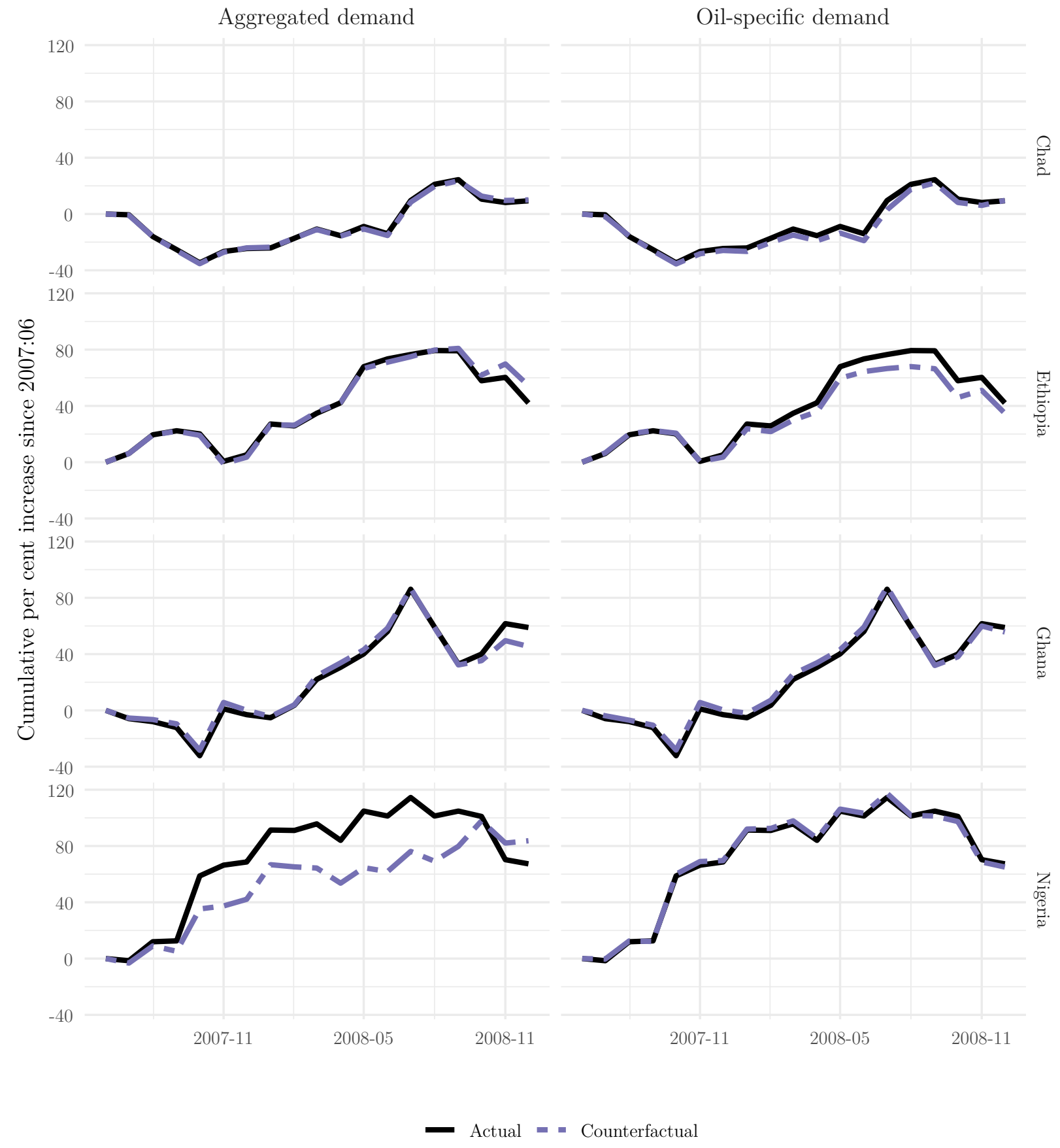

Figure 6.9 Comparison of cumulative percentage growth of real corn prices in Ethiopia, Ghana, Nigeria and Tanzania since June 2007 with and without cumulative demand shocks. 
The only exception where corn prices would have been $19 \%$ lower on average in 2007/2008 without the upward pressure of high aggregate demand is Nigeria. In May 2008, $40 \%$ of the price surge in Nigeria can be attributed to cumulative effects from aggregated-demand shocks. By contrast, there is no indication of aggregated-demand shocks as sources of the price rally in 2007/08 for any other local corn price. Overall, both demand shocks played only a minor role in all countries under consideration, both during the international food crisis and throughout the entire sample.

\subsubsection{What are the future threats to corn price stability from global oil market shocks?}

We note that the main threats to local food security from the global oil market are oil-supply shocks. In particular, corn prices in Ethiopia, Ghana and Kenya are affected by changes in oil-supply. In this section, we construct forecast scenarios to assess the sensitivity of reducedform VAR forecasts to (hypothetical) future global oil market related events based on the method of forecast scenarios described in Baumeister and Kilian (2014b).

These forecasts cannot be interpreted as the most likely future outcomes, but rather simulate the corn price movements in case of unlikely but extreme events. Since structural shocks have expectations equal to zero, all future demand and supply shocks are usually set to zero in a reduced-form VAR forecast. However, forecast scenarios are based on the idea of feeding into the model a non-zero future shock sequence. To account for interventions by policymakers and changes in the behavior of other agents based on the critique by Lucas (1976), constructed shock series for the forecast scenarios are not allowed to be extraordinarily large but have to be within the range of historical events.

\section{What if the tensions with Iran escalate?}

After Iran and the $\mathrm{P} 5+1^{25}$ countries agreed upon restricting the Iranian nuclear program in exchange for ending the sanctions against Iran in 2015, the oil production quickly reached its pre-embargo level, and Iran again took its place as the fourth largest oil producer in the world with about $4.5 \mathrm{mbd}$ of crude oil pumped out from the ground. However, in 2018 political tensions intensified again, which motivated the US administration to withdraw from the Iran deal and reimpose the sanctions whereby by early 2019 Iranian oil production almost halved to $2.7 \mathrm{mbd}$. In January 2020, the conflict between Iran and the US culminated with the killing of the Iranian general Qassem Soleimani by US battle drones.

In the first scenario, we investigate what would happen if the conflict between the Iran and the US further escalated and Iranian oil production collapsed by $60 \%$, which corresponds to a reduction of $1.7 \mathrm{mbd}$ or a global reduction of $2.1 \%$. A drop in the global oil production

\footnotetext{
${ }^{25}$ The P $5+1$ refers to the UN Security Council's five permanent members plus one non permanent member
} 
of such a magnitude is comparable with the reduction during the Libyan revolution or after the US reimposed the sanctions in 2018, and hence it is well within the variation of historical data. We simulate such an oil-supply shock for one single period and afterwards set all shocks to zero again.
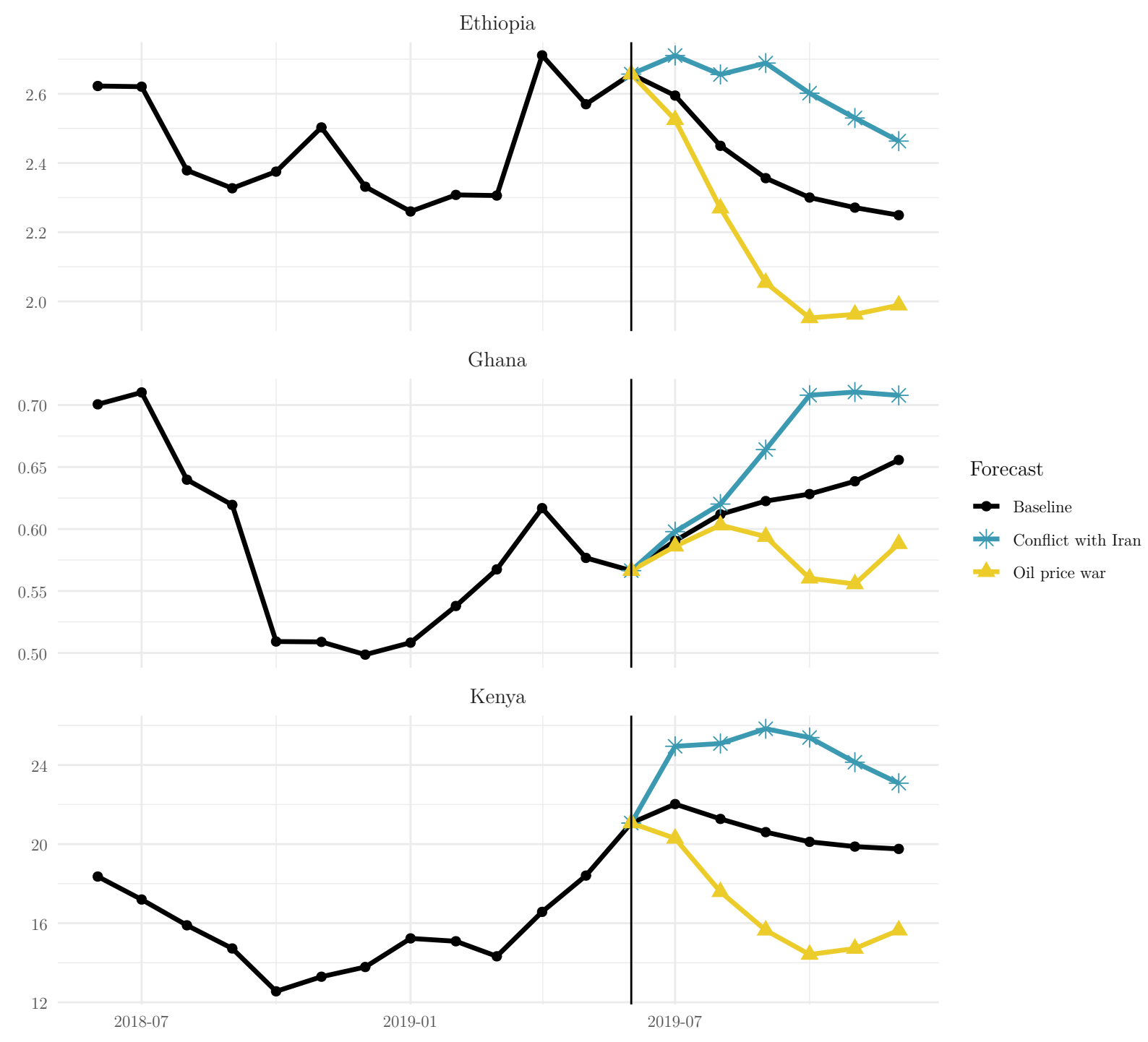

Figure 6.10 Alternative forecast scenarios for local real corn prices in domestic currencies. The vertical lines represent the beginning of the forecast periods.

Figure D.2 shows that a potential breakdown of Iranian oil production can be expected to lead to a considerably higher corn price in Ethiopia, Ghana and Kenya. The predicted real price of corn exceeds the baseline forecast by around $15 \%$ in Ethiopia and Ghana and by about $25 \%$ in Kenya after approximately five months. As already discussed in Section 6.4.2.4 the corn price increase could be much lower if local governments successfully build up strategic oil reserves to buffer oil-supply shortages.

What are the consequences of an oil price war? 
During the SARS-CoV-2 outbreak in early 2020 and the prospect of a global economic slowdown, the OPEC tried to stabilize oil prices by lowering its production ceilings. However, Saudi Arabia and OPEC+ member Russia were unable to agree on a cut in production, which prompted Saudi Arabia to raise its production ceilings to make oil production unprofitable for Russia.

In the second scenario, we simulate the consequences if Saudi Arabia and Russia unexpectedly increase their oil production. The production expansion was about $3 \mathrm{mbd}$, which is equivalent to a $3.6 \%$ increase in global oil production, much larger than the highest single oil-supply shock in our sample. Therefore, we generate one oil-supply shock that increases global oil production by $1.4 \%$ and a second one which increases global oil production by $1.2 \%$ one month later in an attempt to replicate the real-world scenario. Figure D.2 shows that corn prices in Ethiopia would be $10 \%$ lower, in Ghana about $6 \%$ lower and in Kenya about $18 \%$ lower, on average, six months after the shocks. The downward pressure on the corn price is comparable with the effects from the shale oil boom in $2014 / 15$, but although it is achieved within a much shorter time span. Since the actual increase in oil production is even stronger, the effect on the price of corn would be equally more pronounced after a sizable reduction in transport costs.

\subsection{Conclusions}

Oil prices are closely linked to food prices, particularly after the onset of large-scale biofuel production about one-and-a-half decades ago. As developed countries increasingly mandated the conversion of agricultural crops to fuel by policy, worries about adverse effects on food prices in more vulnerable regions of the world emerged in light of globally integrated markets. Consequently, a sizable body of literature examines the price relationships of crude oil and food prices and has gained a better understanding of the effects of oil markets on food prices. However, many of previous works on the crude oil-food price nexus suffer from three major shortcomings: (i) they only analyze the impacts of oils shocks on food markets in developed countries, (ii) they do not differentiate between the alternative sources of oil price fluctuation, and (iii) most of the structural analyses rely on zero restrictions or elasticity constraints, which are prone to underestimate the effects from oil-supply shocks. In a databased manner, we disentangle the causal relationships between the global crude oil market and domestic food prices according to alternative sources of oil market turmoils in eight SSA countries by means of ICA.

We provide three main novel insights into the response of SSA corn markets to global oil shocks. First, we find that fundamental changes as well as general dynamics on global corn markets influence SSA food markets very differently compared to how they impact global food markets. SSA corn markets are significantly less sensitive to oil-specific demand shocks 
and more responsive to oil-supply shocks. Overall, we attribute the non-responsiveness to oil-specific demand shocks to the absence of biofuel substitution opportunities, and fail to diagnose increased global biofuel production (including output stimulated by policy mandates) as a determinant of corn prices in SSA.

Second, SSA corn markets are not only different compared with global corn markets, but also very heterogeneous among themselves. We detect three corn markets - namely in Ethiopia, Ghana and Kenya - that are particularly sensitive to global oil-supply shocks. Some of the largest corn price surges in Ethiopia, Ghana and Kenya can be attributed to global oil-supply disruptions. For example, half of Kenya's strongest corn price increase in early 2011 is due to the unexpected shortfall of Libyan oil production. Conversely, the shale oil boom in the US combined with the production expansion in the Middle East in 2014/15 reduced corn prices by between $10 \%$ and $20 \%$ in Ethiopia, Ghana and Kenya. Moreover, we find that the price surges in SSA corn markets during the international food price crisis in 2007/08 are not linked to the crude oil market. The corn markets in the remaining SSA countries are more or less independent of global crude oil market dynamics and much more subject to unexpected local shocks.

Third, transport costs are the main channel for oil-supply shortfalls to transmit into corn price increases in SSA, while other transmission channels hold minimal importance in SSA. We conclude that SSA countries are particularly vulnerable to oil-supply shocks due to their (temporary) lack of both strategic and natural oil reserves. Further contributing factors are poor road connectivity combined with long travel distances and inefficient oil distribution systems.

Finally, we simulate the consequences of different hypothetical events on local SSA corn prices, i.e. a shutdown of Iranian oil production and the oil price war between Saudi Arabia and Russia. A shortfall in Iranian oil production can increase corn prices in SSA countries by up to $25 \%$, while SSA countries can benefit from a global oil price war that leads to corn prices that are up to $18 \%$ lower, on average. Such unusual responsiveness of SSA countries to oil-supply shocks has rather straightforward implications for the food security of both net food buyers and food sellers, since price increments or reductions are merely changes in transaction costs. However, ensuring a stable supply of energy and fuel supports a more stable food market and is a promising policy option to mitigate the adverse effects of global oil-supply shocks on food security.

We suspect that in general, food markets in developing countries - such as those in SSA - respond more heterogeneously to the global oil market than previously thought. In particular, the vulnerability of oil shocks depends on a variety of country-specific characteristics surrounding food production sectors and energy distribution systems. Given that both are often subject to government intervention, policy could be key in determining the magnitude of the threat of oil shocks on food security. 


\section{Chapter Seven}

\section{General Conclusion}

This final chapter summarises the results of the five essays and their respective policy implications. Finally, this chapter lays out some of the limitations which could be subject to future research.

The simultaneous achievement of several goals which carry economic, societal or environmental value generates a multitude of trade-offs among the three dimensions. Particularly, along agricultural value chains the pursuit of conflicting aims is eminent. For policy-makers, trade-offs are not only imperative problems to mitigate, but also are opportunities to create societal and environmental values which currently are hardly measured by conventional measures and even more rarely can be pondered adequately with competing outcomes of the economy. To formulate and successfully design targeted and optimized measures, policy is critically reliant upon case-by-case evidence and real world studies, which analyze policy effects and their potential unintended by-effects. Moreover, to deliver timely and adequate research, the toolsets of policy-analytic research must be up to date and scrutinize novel methodological innovations in detecting causal effects. To that end, the present dissertation attempts to advance the evidence-base in two distinct parts. The first part provides novel insights on the role of smallholders amidst the palm-oil boom and environmental trade-offs in Indonesia. The second part delivers a software implementation of data-driven identification techniques for multivariate time series analysis and applies said methods to detect oil shock threats to Sub-Saharan food markets.

\subsection{Summary of results}

The first essay (chapter two) asks whether technical efficiency of oil palm smallholder producers reduces or accelerates land expansion in Indonesia. Some policy-makers and policyoriented institution advocate that intensified oil palm production could lead to sparing additional ecologically valuable land from oil palm cultivation. By contrast, rebound effects might induce the opposite thereof and instead, changing economic incentives lead to additional land expansion when the demand is elastic. In a two stage approach, we first study the production 
process of smallholder producers and determine their technical efficiency using LMM that accommodate hierarchical data in a heterogeneous production technology function. In the second stage, we innovate the existing literature by predicting land expansion using technical efficiency and other covariates accounting for measurement error in an EIV model. Our main finding is that, although potential land sparing resulting from technical efficiency gains is remarkable, increasing land demand could offset net sparing by about one third.

The second essay (chapter three) analyses the environmental performance of smallholder oil palm producers regarding loss of biodiversity. While the environmental externalities of large-estate production technology has dominated the relevant literature, empirical evidence is scarce on the environmental trade-offs in smallholder production systems. We extend the hyperbolic distance functions of Cuesta et al. (2009) and develop a restricted version thereof to accommodate both fixed and variable inputs in a production function to examine the interdynamics between provision of desired and undesired outputs. Empirical evidence suggests the presence of a quadratic relationship between oil palm output and biodiversity loss and substantial environmental inefficiency. Weeding practices disproportionately lead to loss of biodiversity as they increase production and thereby significantly contribute to shortfalls in environmental performance. Moreover, we find rather high shadow prices of smallholder production amounting to $16 \%$ of annual palm oil income to conserve one species in the average biodiversity on their plantations.

The third essay (chapter four) studies the efficacy of trade policy of Indonesia, Malaysia and Thailand to manipulate international commodity prices. In light of the continuing decline of real output prices for rubber the TRC agreed upon several domestic and trade measures in an effort to counteract international price developments and support domestic production. Particularly, the set of measures consists of stimulating domestic demand, limit plantation area and temporary export quotas. We apply the seminal model by Gardner (1975) to natural and synthetic rubber markets and derive exogneous policy shocks to prices in both related markets. Empirically, we rely on an ECM and find weak exogeneity of crude oil and cointegrated synthetic and natural rubber prices. Policy attempts have partly been successful in disconnecting international rubber prices from synthetic price movements. However, increased domestic consumption of natural rubber in Indonesia might have spurred price decays in international markets.

The second focus of this dissertation turns to the identification problem in multivariate time series. Many empirical works rely on reduced form models or assumption driven identification of structural time series models. However, in the more recent past, novel data-driven identification techniques have become available in the related SVARs literature. However, at present relatively few studies overcome the constraints of assumption driven identification. In cases where it is ambiguous whether the identifying assumptions do hold, for instance the zero-elasticity restriction of oil-supply, such models allow for a more agnostic approach and 
may lead to more targeted policy measures, particularly in agricultural commodity markets.

The fourth essay (chapter four) introduces the $\mathrm{R}$ package svars which allows time series analysts to implement data-driven identification techniques. It connects to existing packages on time series analysis and enables the identification of SVARs by heteroskedasticity and independence based identification techniques, based on a user-provided reduced form model. In addition, the package delivers an array of popular model diagnostics and other analysis tools such as IRFs, HD and FEVD.

The fifth essay (chapter six) analyses the threat of global oil shocks to food security in SSA. Even though the food-oil price nexus is comparatively well understood in high-income countries and at a global level, the impacts of oil shocks on food markets in developing countries, particularly in SSA are still unclear. This is particularly striking as these regions are most affected by food price changes due to high labour force participation in agriculture as well as large proportions of income spent on food of urban consumers. We find that SSA corn markets respond fundamentally different to various oil shocks than global prices do. Moreover, within SSA countries are very heterogeneous in their food market's response to oil shocks. Particularly oil-supply shocks play a larger role in SSA than they do on global markets. As transportation costs are high in some SSA countries and fuel supply chains characterized by inefficiency and bottlenecks, oil supply shortfalls, such as during the Libyan revolution in 2011, may translate into higher food prices.

\subsection{Policy implications}

Regarding smallholder oil palm production in Indonesia, the results of this dissertation postulate several implications for domestic and international policy. First and foremost, smallholders are an important part for environmentally an socially sustainable palm oil production. Numerous works have pointed out the benefits to rural development of smallholder oil palm production (Qaim et al., 2020), and moreover, their mosaic-type spatial arrangements allow for a highly diverse landscape matrix, potentially enabling large-scale biodiversity conservation (Sayer et al., 2012).

One eminent issue of smallholder oil palm production is the relatively low productivity, particularly regarding land use. The yield gap between smallholders and large-estate production types is about 40\%, on average (Woittiez et al., 2017). The results from the production function of chapter two and, to some extend also the hyperbolic environmental efficiency function in chapter three, indicate that smallholders fall short of their potential output by a sizeable margin and could produce more at given input use, including land use. Thus, it is likely that a sizeable share of the shortfalls in yield can be attributed to technical efficiency of production. For policy this result is two-edged. On the one hand, shortfalls in yield can be substantially improved with managerial skill without needing to introduce potentially costly 
technology. I.e. smallholders are likely to be able to increase output at no additional input cost by just adjusting their management practices. On the other hand, capacity building and designing proper extension services are also a tall order and come with a number of challenges. Particularly in view of the long-standing government support smallholders have already received during the past decades - that is to some extend reflected in the model results of chapter two and three - any existing support schemes are perhaps not achieving desired outcomes and thus require thorough revision and redesign.

Turning to the environmental side, deforestation is a problem faced by all stakeholders along the value chain. While yield enhancing policy sometimes are also expected to slow down deforestation as they enable producing more on less land, chapter two finds this to be only partially true. Net land savings are smaller than expected and input demand for land of smallholder producers increases with efficiency-induced productivity boosts. Thus, if policy-makers decide to address the yield gap via management enhancing extension derives, they should be accompanied by stringent land us policy and improved formal land markets. Additionally, as other authors have shown, more formalized land titles have additionally promote intensification of production as opposed to expansion (Kubitza et al., 2018b; Gawith and Hodge, 2019).

The second environmental trade-off addressed in this dissertation is biodiversity loss in smallholder oil palm production. We find that conserving biodiversity on smallholders plantations is rather costly and amounts to $16 \%$ of average annual palm oil income to increase average biodiversity by one species. This result reflects the magnitude of economic benefits that oil palm production represents for farmers in Jambi given their current technology and management practice. However, as the production process leaves ample room to eliminate inefficiency, policy-makers could achieve both increasing output and conserving biodiversity at the same time. Specific drivers of shortfalls in environmental performance are weeding practises which have negligible impact on current production effects and disproportionally higher detrimental effects on biodiversity. Such insights could be integrated in respective outreach and extension service policy schemes to strengthen environmental sustainability in smallholder production. While shortfalls in inefficiency can be mitigated without sacrificing output and therefore should always be addressed first, if policy is interested in conserving biodiversity beyond such levels, this will require producers to curb production. PES are a promising means to compensate farmers for giving up some of their economic output and instead, provide biodiversity as a public good.

Thus regarding the smallholder trade-offs amid palm oil production we conclude that (i) improving smallholder oil palm managerial skill, (ii) introducing more formal land markets and enforcing existing land institutions, (iii) reducing management practices that disproportionally contribute to environmental degradation, and (iv) PES to compensate farmers for additional provision of biodiversity as opposed to oil palm output are all viable measures 
to improve economic, social and environmental sustainability in palm oil production. Importantly, measures (i)-(iii) should be implemented jointly to prevent area related rebound effects. Even though these insights are developed from a case study in Jambi province, where much of the lowland deforestation already took place and deforestation rates are relatively low at present, these lessons learned are likely to be valid for other regions in Indonesia where palm oil production is at an earlier stage, for instance in Kalimantan (Kubitza et al., 2018b). Moreover, as palm oil production continues to emerge as a competitive cash crop also in other parts of the world, respective policy are likely to face similar conditions with regards to (i) productivity shortfalls of smallholders, (ii) highly elastic demand, at least at farm gates, (iii) shortfalls in environmental performance and (iv) the orders of magnitude of willingness of farmers to provide environmental services in palm oil production.

Turning to the second part of this dissertation that focused on the oil shock responses of SSA food markets, one of the main insights is that SSA food markets are highly heterogeneous and very different in their response to global oil shocks compared with global markets. Thus, respective policy measures should be aware of country and region specific idiosyncrasies. Moreover, this result is likely valid for other food markets in developing countries. Particularly, oil-supply shocks are more important drivers of SSA food markets than on world markets while drivers on the demand side remain relatively ineffectual. The usual global transmission channels between crude oil and food markets, such as biofuel production have been shown to intensify the oil price-food price co-movement, we find that for our set of markets, other transmission channels are more important. Transport costs are relatively dominant factors in local cost functions of food producers and thus, food prices are highly vulnerable to changes in fuel cost. We thus conclude that strategic oil reserves and ensuring the functioning of fuel distribution systems are promising policy strategies to prevent domestic food markets from international oil-supply shocks. Being able to protect against sudden global oil supply shocks mitigates the downward pressure of food prices. Notably, transport cost related price increases come to the benefit of neither producers nor consumers and thereby threaten food security in vulnerable regions more unilaterally.

\subsection{Limitations and future research}

The findings and policy implications of this dissertation highlighted in the previous sections are of course not free from methodological and conceptual limitations. Also researchers face trade-offs in their choice of models and approaches and need to settle for assumptions which sometimes are daunting. Yet, - and needless to say - in all the cases, the compromises are considered the best option given the conceptual, methodological and data constraints. The last lines of this dissertation are dedicated to outlining some limitations of the interpretation of the results in light of such compromises. Furthermore, they ought to point out research 
which could potentially connect to this dissertation beyond these constraints.

Even though in chapters two and three we find substantial technical and environmental inefficiency, respectively, we succeed only partially in explaining their drivers. In our models, we find that obvious socioeconomic control variables such as age, education or land titles do not reveal significant effects. One particularly challenge is to interpret the transmigrant variables in our work. While we fail to associate meaningful effects on environmental or technical efficiency, which stands in some contrast to the results of other authors who find higher yields among transmigrants (Gatto et al., 2015; Euler et al., 2017), we find smallholders to be less likely to expand their plantation compared to their autochthonous counterparts when controlling for efficiency heterogeneity. This result finds support in Kubitza et al. (2018b), who suggest that transmigrant farmers are more likely to hold formal land titles and produce more intensively than expansively. Yet, the variable is more critical as it reflects the effects of government support. The result is somewhat against intuition as we would expect transmigrant farmers - which have received more government support in terms of land and production practice - to perform better than those who did not, at least regarding provision of desired outputs. One possible explanation for this result lies in agrochemical use, which has been shown to be higher in transmigrant farming as well as network effects, as the program was launched during the 1970s and expired in 2015. Thus, knowledge advantages by now could have disseminated among all farmers. The latter case, however, provides interesting avenues for research analyzing management practice dissemination among oil palm producers. Moreover, also other techniques and approaches could help shed more light on today's impact of the trasmigrasi program on economic, social and environmental outcomes as well as narrowing down further determinants of technical efficiency and shortfalls in environmental performance.

Another issue is technological and management heterogeneity between smallholders and large estates in palm oil production. Efficiency only partially explains the yield gap between the two and the remainder must be attributed to superior production technology. Better seedlings and fertilizer as well as optimized cutting techniques are thinkable differences which could lead to the inherent yield differences (Woittiez et al., 2017). However, we devote the technological differences between smallholder farmer compare technologies to close yield gaps to subsequent research.

Also the measurement of the biodiversity trade-off in chapter three, is subject to some limitations. Particularly, the biodiversity indicator $(E N S)$ describes the distance from uniformity in species distribution. While this is desirable from an ecological perspective, the indicator does not account for potential non-linearity over the entire plantation and farm. Furthermore, the indicator does not differentiate among species. Some plants are beneficial to the local ecosystem whereas others - often invasive - species are detrimental. Some species, and to that end biodiversity as a whole - are also beneficial to palm oil production. However, 
such structural effects of biodiversity on oil palm production may not be retrieved from the chosen indicator and econometric approach. Our results suggest that some farmers operate the technology at a point where increased biodiversity is associated with higher oil palm output. Such effects have recently been studied more formally in the recent work by Schaub et al. (2020). However, our model results do not allow for further conclusions and do not reveal structural biodiversity effects on production, nor do they allow to distinguish between species which are beneficial or detrimental to production. The investigation of such effects provides another avenue for future analysis.

Regarding PES designs, chapter three lays out several potential implementation strategies, costs and premiums. However, they do not include transaction costs. Surveying biodiversity as done in this study admittedly will be associated with substantial transaction costs that naturally threaten the feasibility of the outlined PES. Nevertheless, as more cost effective measurement technology such as remote sensing becomes available, surveying biodiversity outcomes as much as other environmental indicators will come at substantially lower transaction costs (Gullstrand et al., 2014).

The analyses on smallholder palm oil production and the study of rubber price policy furthermore could suffer from the omission of potential cross-effects from the other commodity, respectively. In Indonesia - and in particular the study region - both rubber and palm oil are important cash crops. Farmers' cultivation decisions - and also rural development policy actions - often are guided by developments in both sectors. This is a particular relevant aspect concerning, for instance, the work on shadow pricing biodiversity as some farmers palm oil plots are adjacent to rubber plots, sometimes also owned by the same farmer, which often harbour substantially higher levels of biodiversity. On a macro level, the third essay does not consider the effect of oil palm cultivation on rubber plantation potentials and policy effects on that. Integrative approaches which base on both sectors might bring about more comprehensive results which allow reconciling the two market developments and implications for policy and farmers.

Finally, our results regarding oil shock impacts in SSA rely on a limited number of countries as well as only once commodity under scrutiny. Since we find substantial heterogeneity of responses to oil-shocks among our sampled countries, other countries' food markets as well a different selection of commodities are likely to yield different results. To some extend this drawback is due to limited availability of data. However, as the collection and publication of rural price data series in SSA are continuously expanded with regards to time frequency, location and commodities, future research on oil shocks and food markets in SSA and other developing countries could put our results under more scrutiny while further extending the evidence base on the ambiguous effects of oil shocks. 


\section{References}

Abbott, P. C., Hurt, C., and Tyner, W. (2011). Whats driving food prices in 2011? Technical report, Farm Foundation.

Abdelradi, F. and Serra, T. (2015). Asymmetric price volatility transmission between food and energy markets: The case of Spain. Agricultural Economics, 46(4):503-513.

Adenuga, A. H., Davis, J., Hutchinson, G., Donnellan, T., and Patton, M. (2019). Environmental efficiency and pollution costs of nitrogen surplus in dairy farms: A parametric hyperbolic technology distance function approach. Environmental and Resource Economics, $74(3): 1273-1298$.

Aigner, D., Lovell, C. K., and Schmidt, P. (1977). Formulation and estimation of stochastic frontier production function models. Journal of Econometrics, 6(1):21-37.

Allen, R. (1938). Mathematical analysis for economists. Macmillan and Co., London.

Amiti, M. and Konings, J. (2007). Trade liberalization, intermediate inputs, and productivity: evidence from Indonesia. American Economic Review, 97(5):1611-1638.

Amsler, C., Prokhorov, A., and Schmidt, P. (2016). Endogeneity in stochastic frontier models. Journal of Econometrics, 190(2):280-288.

Anderson, K. (2016). Agricultural trade, policy reforms, and global food security. Springer.

Anwar, C. (2017). The role of the International Tripartite Rubber Council (TRC) in stabilizing natural rubber prices. In Proceedings of International Rubber Conference 2017, pages 1-16, Cleveland.

Ardia, D., Mullen, K. M., Peterson, B. G., and Ulrich, J. (2016). DEoptim: Differential Evolution in $R$. version 2.2-4.

Arndt, C., Benfica, R., Maximiano, N., Nucifora, A. M., and Thurlow, J. T. (2008). Higher fuel and food prices: impacts and responses for Mozambique. Agricultural Economics, 39(s1):497-511. 
Asghedom, A. (2016). Iraq is second-leading contributor to global liquids supply growth in 2015. Today in Energy - U.S. Energy Information Administration.

Auerbach, A. J. and Gorodnichenko, Y. (2012). Measuring the output responses to fiscal policy. American Economic Journal: Economic Policy, 4(2):1-27.

Azzam, A. (1998). Captive supplies, market conduct, and the open-market price. American Journal of Agricultural Economics, 80(1):76-83.

Badunenko, O., Kolomiytseva, Y., and Mozharovskyi, P. (2019). npsf: Nonparametric and Stochastic Efficiency and Productivity Analysis. R package version 0.5.2.

Baffes, J. and Haniotis, T. (2010). Placing the 2006/08 commodity price boom into perspective. World Bank Policy Research Working Paper, (5371).

Bafumi, J. and Gelman, A. (2006). Fitting multilevel models when predictors and group effects correlate. Technical report, Annual meeting of the American Political Science Association.

Balmford, A., Amano, T., Bartlett, H., Chadwick, D., Collins, A., Edwards, D., Field, R., Garnsworthy, P., Green, R., Smith, P., et al. (2018). The environmental costs and benefits of high-yield farming. Nature sustainability, 1(9):477-485.

Balmford, A., Green, R. E., and Scharlemann, J. P. (2005). Sparing land for nature: exploring the potential impact of changes in agricultural yield on the area needed for crop production. Global Change Biology, 11(10):1594-1605.

Banerjee, S., Cason, T. N., de Vries, F. P., and Hanley, N. (2017). Transaction costs, communication and spatial coordination in payment for ecosystem services schemes. Journal of Environmental Economics and Management, 83:68-89.

Barnes, A. D., Allen, K., Kreft, H., Corre, M. D., Jochum, M., Veldkamp, E., Clough, Y., Daniel, R., Darras, K., Denmead, L. H., et al. (2017). Direct and cascading impacts of tropical land-use change on multi-trophic biodiversity. Nature ecology 85 evolution, 1(10):1511-1519.

Bas, M. and Strauss-Kahn, V. (2015). Input-trade liberalization, export prices and quality upgrading. Journal of International Economics, 95(2):250-262.

Bateman, I. J., Coombes, E., Fitzherbert, E., Binner, A., Badura, T., Carbone, C., Fisher, B., Naidoo, R., and Watkinson, A. R. (2015). Conserving tropical biodiversity via market forces and spatial targeting. Proceedings of the National Academy of Sciences, 112(24):7408-7413. 
Bates, D., Mächler, M., Bolker, B., and Walker, S. (2015). Fitting linear mixed-effects models using lme4. Journal of Statistical Software, 67(1):1-48.

Baumeister, C. and Hamilton, J. D. (2019a). Structural interpretation of vector autoregressions with incomplete identification: Revisiting the role of oil supply and demand shocks. American Economic Review, 109(5):1873-1910.

Baumeister, C. and Hamilton, J. D. (2019b). Structural interpretation of vector autoregressions with incomplete identification: Setting the record straight. Technical report, UC San Diego.

Baumeister, C. and Kilian, L. (2014a). Do oil price increases cause higher food prices? Economic Policy, 29(80):691-747.

Baumeister, C. and Kilian, L. (2014b). Real-time analysis of oil price risks using forecast scenarios. IMF Economic Review, 62(1):119-145.

Bellemare, M. F. (2015). Rising food prices, food price volatility, and social unrest. American Journal of Agricultural Economics, 97(1):1-21.

Bellemare, M. F., Masaki, T., and Pepinsky, T. B. (2017). Lagged explanatory variables and the estimation of causal effect. The Journal of Politics, 79(3):949-963.

Benes, J., Chauvet, M., Kamenik, O., Kumhof, M., Laxton, D., Mursula, S., and Selody, J. (2015). The future of oil: Geology versus technology. International Journal of Forecasting, $31(1): 207-221$.

Berkhout, P. H., Muskens, J. C., and Velthuijsen, J. W. (2000). Defining the rebound effect. Energy policy, 28(6-7):425-432.

Birkenholtz, T. (2017). Assessing indias drip-irrigation boom: efficiency, climate change and groundwater policy. Water International, 42(6):663-677.

Blanchard, O. and Perotti, R. (2002). An empirical characterization of the dynamic effects of changes in government spending and taxes on output. The Quarterly Journal of Economics, $117(4): 1329-1368$.

Blanchard, O. J. and Quah, D. (1989). The dynamic effects of aggregate demand and supply disturbances. American Economic Review, 79(4):655-673.

Borlaug, N. (2007). Feeding a hungry world.

Borlaug, N. E. (2002). Feeding a world of 10 billion people: the miracle ahead. In Vitro Cellular 85 Developmental Biology-Plant, 38(2):221-228. 
Bouakez, H. and Normandin, M. (2010). Fluctuations in the foreign exchange market: How important are monetary policy shocks? Journal of International Economics, 81(1):139153.

Brandi, C., Cabani, T., Hosang, C., Schirmbeck, S., Westermann, L., and Wiese, H. (2013). Sustainability certification in the Indonesian palm oil sector: benefits and challenges for smallholders. Number 74. Studies.

Brüggemann, R., Jentsch, C., and Trenkler, C. (2016). Inference in vars with conditional heteroskedasticity of unknown form. Journal of Econometrics, 191(1):69-85.

Brümmer, B., Garrido, A., M'Barek, R., Meuwissen, M. P., and Morales-Opazo, C. (2016). Agricultural markets instability: Revisiting the recent food crises. Routledge.

Brümmer, B., Glauben, T., and Lu, W. (2006). Policy reform and productivity change in chinese agriculture: A distance function approach. Journal of Development Economics, 81(1):61-79.

Brümmer, B., Glauben, T., and Thijssen, G. (2002). Decomposition of productivity growth using distance functions: the case of dairy farms in three european countries. American Journal of Agricultural Economics, 84(3):628-644.

Brümmer, B., von Cramon-Taubadel, S., and Zorya, S. (2009). The impact of market and policy instability on price transmission between wheat and flour in Ukraine. European Review of Agricultural Economics, 36(2):203-230.

Bulte, E. H., Lipper, L., Stringer, R., and Zilberman, D. (2008). Payments for ecosystem services and poverty reduction: concepts, issues, and empirical perspectives. Environment and Development Economics, 13(3):245-254.

Busch, J., Ferretti-Gallon, K., Engelmann, J., Wright, M., Austin, K. G., Stolle, F., Turubanova, S., Potapov, P. V., Margono, B., Hansen, M. C., et al. (2015). Reductions in emissions from deforestation from Indonesias moratorium on new oil palm, timber, and logging concessions. Proceedings of the National Academy of Sciences, 112(5):1328-1333.

Busse, S., Brümmer, B., and Ihle, R. (2012). Price formation in the german biodiesel supply chain: AMarkov-switching vector error-correction modeling approach. Agricultural Economics, 43(5):545-560.

Byerlee, D. and Viswanathan, P. (2018). Plantations and economic development in the twentieth century: The end of an era? In Agricultural Development in the World Periphery, pages 89-117. Springer. 
Cacho, O. J., Milne, S., Gonzalez, R., and Tacconi, L. (2014). Benefits and costs of deforestation by smallholders: Implications for forest conservation and climate policy. Ecological Economics, 107:321-332.

Candelon, B. and Lütkepohl, H. (2001). On the reliability of chow-type tests for parameter constancy in multivariate dynamic models. Economics Letters, 73(2):155-160.

Carter, C. A., Rausser, G. C., and Smith, A. (2016). Commodity storage and the market effects of biofuel policies. American Journal of Agricultural Economics, 99(4):1027-1055.

Chakravorty, U., Hubert, M.-H., and Ural Marchand, B. (2019). Food for fuel: The effect of the US biofuel mandate on poverty in India. Quantitative Economics, 10(3):1153-1193.

Chambers, R. G., Chung, Y., and Färe, R. (1998). Profit, directional distance functions, and nerlovian efficiency. Journal of optimization theory and applications, 98(2):351-364.

Chao, A., Gotelli, N. J., Hsieh, T., Sander, E. L., Ma, K., Colwell, R. K., and Ellison, A. M. (2014). Rarefaction and extrapolation with hill numbers: a framework for sampling and estimation in species diversity studies. Ecological monographs, 84(1):45-67.

Chaplin-Kramer, R., Sharp, R. P., Mandle, L., Sim, S., Johnson, J., Butnar, I., i Canals, L. M., Eichelberger, B. A., Ramler, I., Mueller, C., et al. (2015). Spatial patterns of agricultural expansion determine impacts on biodiversity and carbon storage. Proceedings of the National Academy of Sciences, 112(24):7402-7407.

Chase, J. M., McGill, B. J., McGlinn, D. J., May, F., Blowes, S. A., Xiao, X., Knight, T. M., Purschke, O., and Gotelli, N. J. (2018). Embracing scale-dependence to achieve a deeper understanding of biodiversity and its change across communities. Ecology Letters, 21(11):17371751.

Chen, B., Kennedy, C. M., and Xu, B. (2019). Effective moratoria on land acquisitions reduce tropical deforestation: evidence from Indonesia. Environmental Research Letters, 14(4):044009.

Chevassus-Lozza, E., Gaigné, C., and Le Mener, L. (2013). Does input trade liberalization boost downstream firms' exports? Theory and firm-level evidence. Journal of International Economics, 90:391-402.

Chib, S. and Ramamurthy, S. (2014). DSGE models with Student-t errors. Econometric Reviews, 33(1-4):152-171.

Chung, Y. H., Färe, R., and Grosskopf, S. (1997). Productivity and undesirable outputs: a directional distance function approach. Journal of Environmental Management, 51(3):229240. 
Clough, Y., Krishna, V. V., Corre, M. D., Darras, K., Denmead, L. H., Meijide, A., Moser, S., Musshoff, O., Steinebach, S., Veldkamp, E., et al. (2016). Land-use choices follow profitability at the expense of ecological functions in Indonesian smallholder landscapes. Nature Communications, 7:13137.

Coggins, J. S. and Swinton, J. R. (1996). The price of pollution: a dual approach to valuing $\mathrm{SO}_{2}$ allowances. Journal of Environmental Economics and Management, 30(1):58-72.

Comon, P. (1994). Independent component analysis, a new concept? Signal Processing, $36(3): 287-314$.

Corley, R. H. V. and Tinker, P. B. (2008). The oil palm. John Wiley \& Sons.

Cuesta, R. A., Lovell, C. K., and Zofío, J. L. (2009). Environmental efficiency measurement with translog distance functions: A parametric approach. Ecological Economics, 68(89):2232-2242.

Cuesta, R. A. and Zofío, J. L. (2005). Hyperbolic efficiency and parametric distance functions: with application to Spanish savings banks. Journal of Productivity Analysis, 24(1):31-48.

Cúrdia, V., Del Negro, M., and Greenwald, D. L. (2014). Rare shocks, great recessions. Journal of Applied Econometrics, 29(7):1031-1052.

Curtis, P. G., Slay, C. M., Harris, N. L., Tyukavina, A., and Hansen, M. C. (2018). Classifying drivers of global forest loss. Science, 361(6407):1108-1111.

Dakpo, K. H., Jeanneaux, P., and Latruffe, L. (2016). Modelling pollution-generating technologies in performance benchmarking: Recent developments, limits and future prospects in the nonparametric framework. European Journal of Operational Research, 250(2):347359.

Danne, C. (2015). VARsignR: Sign Restrictions, Bayesian, Vector Autoregression Models. R package version 0.1.3.

Darras, K., Corre, M. D., Formaglio, G., Tjoa, A., Potapov, A., Brambach, F., Sibhatu, K. T., Grass, I., Tscharntke, T., Angulo Rubiano, A., et al. (2019a). Reducing fertilizer and avoiding herbicides in oil palm plantations-ecological and economic valuations. Frontiers in Forests and Global Change, 2:65.

Darras, K. F., Corre, M. D., Formaglio, G., Tjoa, A., Potapov, A., Brambach, F., Sibhatu, K. T., Grass, I., Rubiano, A. A., Buchori, D., et al. (2019b). Reducing fertilizer and avoiding herbicides in oil palm plantationsecological and economic valuations. Frontiers in Forests and Global Change, 2:65. 
De Hoyos, R. E. and Medvedev, D. (2009). Poverty effects of higher food prices: a global perspective. The World Bank.

Desquilbet, M., Dorin, B., and Couvet, D. (2017). Land sharing vs land sparing to conserve biodiversity: How agricultural markets make the difference. Environmental Modeling \&6 Assessment, 22(3):185-200.

Dickey, D. A. and Fuller, W. A. (1979). Distribution of the estimators for autoregressive time series with a unit root. Journal of the American Statistical Association, 74(366a):427-431.

Dickey, D. A., Jansen, D. W., and Thornton, D. L. (1991). A primer on cointegration with an application to money and income. In Rao, B. B., editor, Cointegration, pages 58-78. Palgrave Macmillan, London, 1st edition.

Dillon, B. M. and Barrett, C. B. (2015). Global oil prices and local food prices: Evidence from East Africa. American Journal of Agricultural Economics, 98(1):154-171.

Disdier, A.-C. and Marette, S. (2010). The combination of gravity and welfare approaches for evaluating nontariff measures. American Journal of Agricultural Economics, 92(3):713-726.

Dorosh, P., Wang, H. G., You, L., and Schmidt, E. (2012). Road connectivity, population, and crop production in Sub-Saharan Africa. Agricultural Economics, 43(1):89-103.

Du, X., Yu, C. L., and Hayes, D. J. (2011). Speculation and volatility spillover in the crude oil and agricultural commodity markets: A Bayesian analysis. Energy Economics, 33(3):497 $-503$.

DAlessandro, S. P., Caballero, J., Lichte, J., and Simpkin, S. (2015). Agricultural sector risk assessment. Technical report, Agriculture global practice technical assistance paper, World Bank Group, Washington D.C.

Eddelbuettel, D. and François, R. (2011). Rcpp: Seamless R and C++ integration. Journal of Statistical Software, 40(8):1-18.

Eddelbuettel, D. and Sanderson, C. (2014). Rcpparmadillo: Accelerating R with highperformance $\mathrm{C}++$ linear algebra. Computational Statistics and Data Analysis, 71:10541063.

Edwards, R. (2017). Tropical oil crops and rural poverty. Available at SSRN 3040400.

EIA (2020). International energy statistics. data retrieved online, https://www.eia.gov/ international/data/world.

Eichenbaum, M. (1992). Interpreting the macroeconomic time series facts: The effects of monetary policy': by christopher sims. European Economic Review, 36(5):1001-1011. 
Ellison, D., N. Futter, M., and Bishop, K. (2012). On the forest cover-water yield debate: from demand-to supply-side thinking. Global Change Biology, 18(3):806-820.

Emvalomatis, G. (2012). Productivity growth in german dairy farming using a flexible modelling approach. Journal of Agricultural Economics, 63(1):83-101.

Energy Commission (2006). Strategic national energy plan 2006 2020. Technical report, Ghana.

Engle, R. F. and Granger, C. W. (1987). Co-integration and error correction: representation, estimation, and testing. Econometrica: journal of the Econometric Society, pages 251-276.

Euler, M., Krishna, V., Schwarze, S., Siregar, H., and Qaim, M. (2017). Oil palm adoption, household welfare, and nutrition among smallholder farmers in Indonesia. World Development, 93:219 - 235.

FAO (2007). The state of food and agriculture: paying farmers for environmental services.

FAO, I., WFP, W., UNICEF, et al. (2019). The state of food security and nutrition in the world 2019: safeguarding against economic slowdowns and downturns.

FAOSTAT (2017). FAOSTAT statistical database. Data retrieved online at http://www.fao. org/faostat/en/home.

FAOSTAT (2020). FAOSTAT statistical database. Data retrieved online at http://www.fao. org/faostat/en/.

Färe, R., Grosskopf, S., and Pasurka Jr, C. A. (2007). Environmental production functions and environmental directional distance functions. Energy, 32(7):1055-1066.

Färe, R., Grosskopf, S., and Zaim, O. (2002). Hyperbolic efficiency and return to the dollar. European Journal of Operational Research, 136(3):671-679.

Federal Reserve Bank of St. Louis (2020). Economic research database. Data retrieved from https://fred.stlouisfed.org/series/FPCPITOTLZGIDN.

Feintrenie, L., Chong, W. K., and Levang, P. (2010). Why do farmers prefer oil palm? Lessons learnt from Bungo District, Indonesia. Small-scale Forestry, 9(3):379-396.

Feniuk, C., Balmford, A., and Green, R. E. (2019). Land sparing to make space for species dependent on natural habitats and high nature value farmland. Proceedings of the Royal Society B, 286(1909):20191483.

Fitzherbert, E. B., Struebig, M. J., Morel, A., Danielsen, F., Brühl, C. A., Donald, P. F., and Phalan, B. (2008). How will oil palm expansion affect biodiversity? Trends in ecology \& evolution, 23(10):538-545. 
Florens, J.-P. and Mouchart, M. (1982). A note on noncausality. Econometrica: Journal of the Econometric Society, pages 583-591.

Folberth, C., Khabarov, N., Balkovič, J., Skalský, R., Visconti, P., Ciais, P., Janssens, I. A., Peñuelas, J., and Obersteiner, M. (2020). The global cropland-sparing potential of highyield farming. Nature Sustainability, 3(4):281-289.

Foster, W. A., Snaddon, J. L., Turner, E. C., Fayle, T. M., Cockerill, T. D., Ellwood, M. F., Broad, G. R., Chung, A. Y., Eggleton, P., Khen, C. V., et al. (2011). Establishing the evidence base for maintaining biodiversity and ecosystem function in the oil palm landscapes of south east asia. Philosophical Transactions of the Royal Society B: Biological Sciences, 366(1582):3277-3291.

Fowowe, B. (2016). Do oil prices drive agricultural commodity prices? evidence from South Africa. Energy, 104:149-157.

Fuglie, K. O., Wang, S. L., Ball, V. E., et al. (2012). Productivity growth in agriculture: an international perspective. CABI.

Fuller, W. A. (2009). Measurement error models, volume 305. John Wiley \& Sons.

Garcia, V. R., Gaspart, F., Kastner, T., and Meyfroidt, P. (2020). Agricultural intensification and land use change: Assessing country-level induced intensification, land sparing and rebound effect. Environmental Research Letters.

Gardner, B. L. (1975). The farm-retail price spread in a competitive food industry. American Journal of Agricultural Economics, 57(3):399-409.

Garrett, R. D., Lambin, E. F., and Naylor, R. L. (2013). Land institutions and supply chain configurations as determinants of soybean planted area and yields in brazil. Land Use Policy, 31:385-396.

Gatto, M., Wollni, M., Asnawi, R., and Qaim, M. (2017). Oil palm boom, contract farming, and rural economic development: Village-level evidence from Indonesia. World Development, 95:127-140.

Gatto, M., Wollni, M., and Qaim, M. (2015). Oil palm boom and land-use dynamics in Indonesia: the role of policies and socioeconomic factors. Land use policy, 46:292-303.

Gavrilov, I. and Pusev, R. (2014). normtest: Tests for normality. R package version 1.1.

Gavrilov, I. and Pusev, R. (2015). normtest: Tests for the Composite Hypothesis of Normality. $\mathrm{R}$ package version 1.1 . 
Gawith, D. and Hodge, I. (2019). Focus rural land policies on ecosystem services, not agriculture. Nature Ecology \& Evolution, 3(8):1136-1139.

Gelman, A. and Hill, J. (2006). Data analysis using regression and multilevel/hierarchical models. Cambridge university press.

Genest, C., Quessy, J.-F., and Rémillard, B. (2007). Asymptotic local efficiency of cramér-von mises tests for multivariate independence. The Annals of Statistics, 35(1):166-1991.

Gilbert, C. L. (1996). International commodity agreements: an obituary notice. World Development.

Glasbergen, P. (2018). Smallholders do not eat certificates. Ecological Economics, 147:243252.

Glick, R. and Rose, A. K. (2002). Does a currency union affect trade? the time-series evidence. European Economic Review, 46(6):1125-1151.

Goncalves, S. and Kilian, L. (2004). Bootstrapping autoregressions with conditional heteroskedasticity of unknown form. Journal of Econometrics, 123(1):89-120.

Gourieroux, C., Monfort, A., and Renne, J.-P. (2017). Statistical inference for independent component analysis: Application to structural var models. Journal of Econometrics, 196(1):111-126.

Granger, C. W. (1969). Investigating causal relations by econometric models and crossspectral methods. Econometrica: Journal of the Econometric Society, pages 424-438.

Granger, C. W. J. and Newbold, P. (2014). Forecasting economic time series. Academic Press.

Grant, W. (2010). Policy instruments in the common agricultural policy. West European Politics, 33(1):22-38.

Grass, I., Kubitza, C., Krishna, V. V., Corre, M. D., Mußhoff, O., Pütz, P., Drescher, J., Rembold, K., Ariyanti, E. S., Barnes, A. D., et al. (2020). Trade-offs between multifunctionality and profit in tropical smallholder landscapes. Nature communications, 11(1):1-13.

Grosche, S.-C. (2014). What does g ranger causality prove? a critical examination of the interpretation of $\mathrm{g}$ ranger causality results on price effects of index trading in agricultural commodity markets. Journal of Agricultural Economics, 65(2):279-302.

Gullstrand, J., De Blander, R., and Waldo, S. (2014). The influence of biodiversity provision on the cost structure of swedish dairy farming. Journal of Agricultural Economics, $65(1): 87-111$. 
Gutiérrez-Vélez, V. H., DeFries, R., Pinedo-Vásquez, M., Uriarte, M., Padoch, C., Baethgen, W., Fernandes, K., and Lim, Y. (2011). High-yield oil palm expansion spares land at the expense of forests in the peruvian amazon. Environmental Research Letters, 6(4):044029.

Hafner, C. M. and Herwartz, H. (2009). Testing for linear vector autoregressive dynamics under multivariate generalized autoregressive heteroskedasticity. Statistica Neerlandica, 63(3):294-323.

Hall, P. (1992). The Bootstrap and Edgeworth Expansion. Springer-Verlag.

Hamilton, J. D. (1994). Time Series Analysis. Princeton University Press.

Hamilton, J. D. (2009). Understanding crude oil prices. The Energy Journal, 30(2):179-206.

Hamilton, J. D. (2013). Oil prices, exhaustible resources and economic growth. In Fouquet, R., editor, Handbook on Energy and Climate Change, Chapters, chapter 1, pages 29-63. Edward Elgar Publishing.

Harder, M. (2018). Natural rubber vs synthetic rubber - The price relationship and demand switchability. Halcyon Agri Corporation Limited, Singapore.

Hatzenbuehler, P. L., Abbott, P. C., and Abdoulaye, T. (2017). Price transmission in Nigerian food security crop markets. Journal of Agricultural Economics, 68(1):143-163.

Hausman, C., Auffhammer, M., and Berck, P. (2012). Farm acreage shocks and crop prices: An SVAR approach to understanding the impacts of biofuels. Environmental and Resource Economics, 53(1):117-136.

Havlík, P., Leclère, D., Valin, H., Herrero, M., Schmid, E., Soussana, J., Müller, C., and Obersteiner, M. (2015). Global climate change, food supply and livestock production systems: A bioeconomic analysis.

Headey, D. et al. (2011). Was the global food crisis really a crisis? simulations versus selfreporting. IFPRI-Research Brief, (17).

Hein, J. I. (2019). Political ecology of REDD+ in Indonesia - Agrarian conflicts and forest carbon. Routledge, New York, NY.

Hertel, T. W. (2018). Economic perspectives on land use change and leakage. Environmental Research Letters, 13(7):075012.

Herwartz, H. (2018). Hodges lehmann detection of structural shocks - an analysis of macroeconomic dynamics in the euro area. Oxford Bulletin of Economics and Statistics, 80(4):736754 . 
Herwartz, H., Lange, A., and Maxand, S. (2019). Statistical identification in SVARs - Monte Carlo experiments and a comparative assessment of the role of economic uncertainties for the US business cycle. CEGE Discussion Paper, (375).

Herwartz, H. and Lütkepohl, H. (2014). Structural vector autoregressions with markov switching: Combining conventional with statistical identification of shocks. Journal of Econometrics, 183(1):104-116.

Herwartz, H. and Plödt, M. (2016a). The macroeconomic effects of oil price shocks: Evidence from a statistical identification approach. Journal of International Money and Finance, $61(\mathrm{C}): 30-44$.

Herwartz, H. and Plödt, M. (2016b). Simulation evidence on theory-based and statistical identification under volatility breaks. Oxford Bulletin of Economics and Statistics, 78(1):94-112.

Herwartz, H. and Plödt, M. (2016c). The macroeconomic effects of oil price shocks: Evidence from a statistical identification approach. Journal of International Money and Finance, $61(\mathrm{C}): 30-44$.

Herwartz, H. and Saucedo, A. (2020). Foodoil volatility spillovers and the impact of distinct biofuel policies on price uncertainties on feedstock markets. Agricultural Economics.

Hill, M. O. (1973). Diversity and evenness: a unifying notation and its consequences. Ecology, $54(2): 427-432$.

Hoang, V.-N. and Coelli, T. (2011). Measurement of agricultural total factor productivity growth incorporating environmental factors: a nutrients balance approach. Journal of Environmental Economics and Management, 62(3):462-474.

Hodges, J. and Lehmann, E. (2006). Hodges-Lehmann Estimators. Encyclopedia of Statistical Sciences.

Hofert, M., Kojadinovic, I., Maechler, M., and Yan, J. (2017). copula: Multivariate Dependence with Copulas. $\mathrm{R}$ package version 0.999-18.

Holloway, G. J. (1991). The farm-retail price spread in an imperfectly competitive food industry. American Journal of Agricultural Economics, 73(4):979-989.

Hooper, D. U., Adair, E. C., Cardinale, B. J., Byrnes, J. E., Hungate, B. A., Matulich, K. L., Gonzalez, A., Duffy, J. E., Gamfeldt, L., and OConnor, M. I. (2012). A global synthesis reveals biodiversity loss as a major driver of ecosystem change. Nature, 486(7401):105-108. 
Horowitz, I. (1963). An econometric analysis of supply and demand in the synthetic rubber industry. International Economic Review, 4(3):325-345.

Hosseini, S. and Shahbazi, H. (2010). A model of Iran's farm-retail marketing margin for beef. Journal of Agricultural Science and Technology, 12(3):255-264.

Hsieh, T., Ma, K., and Chao, A. (2016). inext: an r package for rarefaction and extrapolation of species diversity (Hill numbers). Methods in Ecology and Evolution, 7(12):1451-1456.

Huang, S. Y. and Sexton, R. J. (1996). Measuring returns to an innovation in an imperfectly competitive market: application to mechanical harvesting of processing tomatoes in Taiwan. American Journal of Agricultural Economics.

Huang, W., Bruemmer, B., and Huntsinger, L. (2016). Incorporating measures of grassland productivity into efficiency estimates for livestock grazing on the qinghai-tibetan plateau in china. Ecological Economics, 122:1-11.

IFPRI (2019). The palm oil dilemma: Policy tensions among higher productivity, rising demand, and deforestation. Technical report, IFPRI policy brief, June 2019.

Ihle, R., Brümmer, B., and Thompson, S. R. (2012). Structural change in European calf markets: decoupling and the blue tongue disease. European Review of Agricultural Economics, 39:157-179.

Indonesian Ministry of Agriculture (2016). Tree crop estate statistics of Indonesia 2015-2017 oil palm. Technical report, Directorate General of Estates, Jakarta.

International Rubber Consortium Limited (2001). Joint Ministerial Declaration.

International Tripartite Rubber Council (2014). Press release: Ministerial Committee meeting 2014 .

International Tripartite Rubber Council (2015). Press release: Ministerial Committee meeting 2015 .

International Tripartite Rubber Council (2016). Press release: by the International Tripartite Rubber Council ministers on the implementation of the Agreed Export Tonnage Scheme.

IPBES (2019). Assessment of socio-economic functions of tropical lowland transformation systems in Indonesia-sampling framework and methodological approach. Technical report, IPBES secretariat, Bonn, Germany.

IPCC, W. (2000). Special report on emissions scenarios. Intergovernmental panel on climate change special reports on climate change. Cambridge University Press, Cambridge, 570. 
IUCN (2015). The iucn red list of threatened species. International Union for Conservation of Nature and Natural Resources. Online at: http://www. iucnredlist. org/(accessed 11 May 2020).

Ivanic, M. and Martin, W. (2008). Implications of higher global food prices for poverty in low-income countries. Agricultural Economics, 39(s1):405-416.

Jack, B. K. et al. (2017). Environmental economics in developing countries: An introduction to the special issue. Journal of Environmental Economics and Management, 86(C):1-7.

Jack, B. K., Kousky, C., and Sims, K. R. (2008). Designing payments for ecosystem services: Lessons from previous experience with incentive-based mechanisms. Proceedings of the National Academy of Sciences, 105(28):9465-9470.

Jelsma, I., Schoneveld, G., Zoomers, A., and Van Westen, A. (2017). Unpacking Indonesias independent oil palm smallholders: An actor-disaggregated approach to identifying environmental and social performance challenges. Land Use Policy, 69:281-297.

Jevons, W. S. (1879). The theory of political economy. Macmillan and Company.

Johansen, S. (1991). Estimation and hypothesis testing of cointegration vectors in Gaussian vector autoregressive models. Econometrica, 59(6):1551-1580.

Jones, R. W. (2000). Globalization and the theory of input trade. MIT Press, Cambridge.

Jost, L. (2006). Entropy and diversity. Oikos, 113(2):363-375.

Jost, L. (2007). Partitioning diversity into independent alpha and beta components. Ecology, 88(10):2427-2439.

Khandelwal, A. K., Schott, P. K., and Wei, S.-J. (2013). Trade liberalization and embedded institutional reform: evidence from Chinese exporters. American Economic Review, 103(6):2169-2195.

Kilian, L. (1998). Small-sample confidence intervals for impulse response functions. The Review of Economics and Statistics, 80(2):218-230.

Kilian, L. (2009). Not all oil price shocks are alike: Disentangling demand and supply shocks in the crude oil market. American Economic Review, 99(3):1053-69.

Kilian, L. (2017). The impact of the fracking boom on Arab oil producers. The Energy Journal, Volume 38(6):137-160.

Kilian, L. (2019). Facts and fiction in oil market modeling. Working Papers 1907, Federal Reserve Bank of Dallas. 
Kilian, L. and Lee, T. K. (2014). Journal of international money quantifying the speculative component in the real price of oil: The role of global oil inventories. Journal of International Money and Finance, 42(C):71-87.

Kilian, L. and Lütkepohl, H. (2017). Structural vector autoregressive analysis. Cambridge University Press.

Kilian, L. and Lütkepohl, H. (2017). Structural Vector Autoregressive Analysis. Cambridge University Press.

Kilian, L. and Murphy, D. P. (2012). Why agnostic sign restrictions are not enough: Understanding the dynamics of oil market VAR models. Journal of the European Economic Association, 10(5):1166-1188.

Kilian, L., Rebucci, A., and Spatafora, N. (2009). Oil shocks and external balances. Journal of international Economics, 77(2):181-194.

Kilian, L. and Zhou, X. (2018). Journal of international money and finance modeling fluctuations in the global demand for commodities. Journal of International Money and Finance, $88(\mathrm{C}): 54-78$.

Kilian, L. and Zhou, X. (2019). Oil supply shock redux? Technical report, Federal Reserve Bank of Dallas.

Kinnucan, H. W. and Tadjion, O. (2014). Theoretical restrictions on farm-retail price transmission elasticities: a note. Agribusiness, 30(3):278-289.

Kinnucan, H. W. and Zhang, D. (2015). Notes on farm-retail price transmission and marketing margin behavior. Agricultural Economics, 46(6):729-737.

Klasen, S., Meyer, K. M., Dislich, C., Euler, M., Faust, H., Gatto, M., Hettig, E., Melati, D. N., Jaya, I. N. S., Otten, F., et al. (2016). Economic and ecological trade-offs of agricultural specialization at different spatial scales. Ecological Economics, 122:111-120.

Koh, L. P. and Wilcove, D. S. (2008). Is oil palm agriculture really destroying tropical biodiversity? Conservation Letters, 1(2):60-64.

Kopp, T. and Brümmer, B. (2017). Traders' market power along Indonesian rubber value chains. China Agricultural Economic Review, 9(2):169-187.

Kopp, T. and Sexton, R. J. (2019). Farmers, Traders, and Processors: Estimating the Welfare Loss from Double Marginalization for the Indonesian Rubber Sector. Proceedings of the 2019 Agricultural and Applied Economics Association Annual Meeting, pages 1-38. 
Krishna, V., Euler, M., Siregar, H., and Qaim, M. (2017a). Differential livelihood impacts of oil palm expansion in Indonesia. Agricultural Economics, 48(5):639-653.

Krishna, V. V., Kubitza, C., Pascual, U., and Qaim, M. (2017b). Land markets, property rights, and deforestation: insights from Indonesia. World Development, 99:335-349.

Krishna, V. V., Pascual, U., and Qaim, M. (2014). Do emerging land markets promote forestland appropriation? evidence from Indonesia. Technical report, EFForTS Discussion Paper Series.

Kristoufek, L., Janda, K., and Zilberman, D. (2012). Correlations between biofuels and related commodities before and during the food crisis: A taxonomy perspective. Energy Economics, 34(5):1380-1391.

Kubitza, C., Krishna, V. V., Alamsyah, Z., and Qaim, M. (2018a). The economics behind an ecological crisis: livelihood effects of oil palm expansion in Sumatra, Indonesia. Human ecology, 46(1):107-116.

Kubitza, C., Krishna, V. V., Urban, K., Alamsyah, Z., and Qaim, M. (2018b). Land property rights, agricultural intensification, and deforestation in Indonesia. Ecological Economics, $147: 312-321$.

Kutlu, L., Tran, K. C., and Tsionas, M. G. (2019). A time-varying true individual effects model with endogenous regressors. Journal of Econometrics.

Kwiatkowski, D., Phillips, P. C. B., Schmidt, P., and Shin, Y. (1992). Testing the null hypothesis of stationarity against the alternative of a unit root: how sure are we that economic time series have a unit root? Journal of Econometrics, 54(1-3):159-178.

Lahiri, S. N. (2003). Resampling Methods for Dependent Data. New York: Springer-Verlag.

Lange, A., Dalheimer, B., Herwartz, H., and Maxand, S. (forthcoming). svars: An R package for data-driven identification in multivariate time series analysis. Journal of Statistical Software.

Lanne, M. and Lütkepohl, H. (2008). Identifying monetary policy shocks via changes in volatility. Journal of Money, Credit and Banking, 40(9):1131-1149.

Lanne, M., Lütkepohl, H., and Maciejowska, K. (2010). Structural vector autoregressions with markov switching. Journal of Economic Dynamics and Control, 34(2):121-131.

Lanne, M., Meitz, M., and Saikkonen, P. (2017a). Identification and estimation of nonGaussian structural vector autoregressions. Journal of Econometrics, 196(2):288-304. 
Lanne, M., Meitz, M., and Saikkonen, P. (2017b). Identification and estimation of nongaussian structural vector autoregressions. Journal of Econometrics, 196(2):121-131.

Lanne, M. and Saikkonen, P. (2007). A multivariate generalized orthogonal factor GARCH model. Journal of Business \&6 Economic Statistics, 25(1):61-75.

Lanz, B., Dietz, S., and Swanson, T. (2018). The expansion of modern agriculture and global biodiversity decline: An integrated assessment. Ecological Economics, 144:260-277.

Linkie, M., Martyr, D. J., Holden, J., Yanuar, A., Hartana, A. T., Sugardjito, J., and LeaderWilliams, N. (2003). Habitat destruction and poaching threaten the Sumatran tiger in kerinci seblat national park, Sumatra. Oryx, 37(1):41-48.

Liu, R. Y. (1988). Bootstrap procedures under some non-i.i.d. models. The Annals of Statistics, 16(4):1696-1708.

Lloyd, T. (2017). Forty years of price transmission research in the food industry: Insights, challenges and prospects. Journal of Agricultural Economics, 68(1):3-21.

Lockwood, J. (2018). eivtools: Measurement Error Modeling Tools. R package version 0.1-8.

Lucas, R. E. (1976). Econometric policy evaluation: A critique. Carnegie-Rochester Conference Series on Public Policy, 1:19 - 46.

Lütkepohl, H. (2005). New Introduction to Multiple Time Series Analysis. Springer-Verlag, Berlin [u.a.].

Lütkepohl, H. (2005). New introduction to multiple time series analysis. Springer-Verlag, Berlin.

Lütkepohl, H. (2011). Vector autoregressive models. EUI Working Paper ECO 2011/30, European University Institute, Florence.

Lütkepohl, H. and Kraetzig, M. (2004). Applied Time Series Econometrics. Cambridge University Press.

Lütkepohl, H. and Milunovich, G. (2016). Testing for identification in svar-garch models. Journal of Economic Dynamics and Control, 73(C):241-258.

Lütkepohl, H. and Netşunajev, A. (2014). Disentangling demand and supply shocks in the crude oil market : How to check sign restrictions in structural VARs. Journal of Applied Econometrics, 29(3):479-496.

Lütkepohl, H. and Netsunajev, A. (2017a). Structural vector autoregressions with heteroskedasticity: A review of different volatility models. Econometrics and Statistics, 1(C):2 $-18$. 
Lütkepohl, H. and Netsunajev, A. (2017b). Structural vector autoregressions with smooth transition in variances. Journal of Economic Dynamics and Control, 84(C):43 - 57.

Lütkepohl, H. and Schlaak, T. (2018). Choosing between different time-varying volatility models for structural vector autoregressive analysis. Oxford Bulletin of Economics and Statistics, 80(4):715-735.

Lütkepohl, H. and Schlaak, T. (2019). Bootstrapping impulse responses of structural vector autoregressive models identified through garch. Journal of Economic Dynamics and Control, 101:41 - 61.

Lütkepohl, H. and Velinov, A. (2016). Structural vector autoregressions: Checking identifying long-run restrictions via heteroskedasticity. Journal of Economic Surveys, 30(2):377-392.

Maddala, G. S. (1977). Econometrics. McGraw-Hill, New York.

Maertens, M., Zeller, M., and Birner, R. (2006). Sustainable agricultural intensification in forest frontier areas. Agricultural Economics, 34(2):197-206.

Magurran, A. E. and Henderson, P. A. (2003). Explaining the excess of rare species in natural species abundance distributions. Nature, 422(6933):714716.

Malaysian Rubber Board (2012). Press release: implementation of the agreed export tonnage scheme (AETS) in Malaysia.

Mamardashvili, P., Emvalomatis, G., and Jan, P. (2016). Environmental performance and shadow value of polluting on swiss dairy farms. Journal of Agricultural and Resource Economics, 41(1835-2016-149562):225-246.

Mammen, E. (1993). Bootstrap and wild bootstrap for high dimensional linear models. The Annals of Statistics, 21(1):255-285.

Marchand, S. (2012). The relationship between technical efficiency in agriculture and deforestation in the brazilian amazon. Ecological Economics, 77:166-175.

Matteson, D. S. and Tsay, R. S. (2017). Independent component analysis via distance covariance. Journal of the American Statistical Association, 112(518):623-637.

Matthews, W. G. (2014). Opportunities and challenges for petroleum and LPG markets in Sub-Saharan Africa. Energy Policy, 64(C):78 - 86.

Maxand, S. (2019). Identification of independent structural shocks in the presence of multiple gaussian components. Econometrics and Statistics. (to appear). 
McCarthy, J. F., Gillespie, P., and Zen, Z. (2012). Swimming upstream: Local Indonesian production networks in globalized palm oil production. World Development, 40(3):555 569.

McMillan, M. S. and Rodrik, D. (2011). Globalization, structural change and productivity growth. Technical report, National Bureau of Economic Research.

McPhail, L. L., Du, X., and Muhammad, A. (2012). Disentangling corn price volatility: The role of global demand, speculation, and energy. Journal of Agricultural and Applied Economics, 44(3):401-410.

Meeusen, W. and van Den Broeck, J. (1977). Efficiency estimation from cobb-douglas production functions with composed error. International economic review, pages 435-444.

Mehta, Y. and Brümmer, B. (2020). Efficiency aggregation in stochastic frontier analysis with hierarchical data. ZfS Working papers, (23).

Mertens, K. and Ravn, M. O. (2010). Measuring the impact of fiscal policy in the face of anticipation: a structural var approach. The Economic Journal, 120(544):393-413.

Meyer, J. and von Cramon-Taubadel, S. (2004). Asymmetric price transmission: a survey. Journal of agricultural economics, 55(3):581-611.

Milunovich, G. and Yang, M. (2013). On identifying structural VAR models via ARCH effects. Journal of Time Series Econometrics, 5(2):117-131.

Ministry of Agriculture Indonesia (2008). ITRC and IRCO. Agreement to overcome the decrease of natural rubber prices.

Ministry of Energy and Petroleum of Kenya (2015). National energy and petroleum policy. Technical report, Nairobi.

Ministry of Industry and Trade Indonesia (2002). The assignment of the indonesian rubber producers association (gapkindo) as the national tripartite rubber corporation (ntrc). Decree NO. 58/MPP/Kep/I/2002, http://storage.jak-stik.ac.id/ProdukHukum/ DalamNegri/58.pdf [accessed 05 January 2018].

Ministry of Industry and Trade Indonesia (2016). Press release: rubber exporters committed to reducing exports.

Ministry of Water and Energy of Ethiopia (2013). Ethiopian national energy policy (2nd draft). Technical report, Addis Ababa. 
Minot, N. (2010). Staple food prices in tanzania. Technical report, Prepared for the Comesa policy seminar on Variation in staple food prices: Causes, consequence, and policy options, Maputo, Mozambique.

Minot, N. (2014). Food price volatility in Sub-Saharan Africa: Has it really increased? Food Policy, 45:45-56.

Mitra, S. and Josling, T. (2009). Agricultural export restrictions: welfare implications and trade disciplines. International Food and Agricultural Trade Policy Council, IPC Position Paper Series, Washington D.C.

Miyamoto, M. (2006). Forest conversion to rubber around Sumatran villages in Indonesia: Comparing the impacts of road construction, transmigration projects and population. Forest Policy and Economics, 9(1):1-12.

Moneta, A., Chlaß, N., Entner, D., and Hoyer, P. (2011). Causal search in structural vector autoregressive models. In NIPS Mini-Symposium on Causality in Time Series, pages 95114.

Moneta, A., Entner, D., Hoyer, P. O., and Coad, A. (2013). Causal inference by independent component analysis: Theory and applications. Oxford Bulletin of Economics and Statistics, $75(5): 705-730$.

Mundlak, Y. (1978). On the pooling of time series and cross section data. Econometrica: journal of the Econometric Society, pages 69-85.

Myers, R. J., Sexton, R. J., and Tomek, W. G. (2010). A century of research on agricultural markets. American Journal of Agricultural Economics, 92(2):376-403.

Nazlioglu, S., Erdem, C., and Soytas, U. (2013). Volatility spillover between oil and agricultural commodity markets. Energy Economics, 36(5):658-665.

Nazlioglu, S. and Soytas, U. (2011). World oil prices and agricultural commodity prices: Evidence from an emerging market. Energy Economics, 33(3):488-496.

Nazlioglu, S. and Soytas, U. (2012). Oil price, agricultural commodity prices, and the dollar: A panel cointegration and causality analysis. Energy Economics, 34(4):1098-1104.

Nelson, D. B. (1995). Vector attenuation bias in the classical errors-in-variables model. Economics Letters, 49(4):345-349.

Newbold, T., Hudson, L. N., Hill, S. L., Contu, S., Lysenko, I., Senior, R. A., Börger, L., Bennett, D. J., Choimes, A., Collen, B., et al. (2015). Global effects of land use on local terrestrial biodiversity. Nature, 520(7545):45-50. 
Nordhausen, K., Oja, H., Tyler, D. E., and Virta, J. (2018). ICtest: Estimating and Testing the Number of Interesting Components in Linear Dimension Reduction. R package version $0.3-1$.

Normadin, M. and Phaneuf, L. (2004). Monetary policy shocks: Testing identification conditions under time-varying conditional volatility. Journal of Monetary Economics, 51(6):1217-1243.

O’Donnell, C. J. (2018). Productivity and Efficiency Analysis. Springer.

OECD-FAO (2011). OECD-FAO agricultural outlook 2011-2020. Organisation for Economic Co-operation and Development.

Olivero, M. P. et al. (2019). Fiscal policy and credit spreads: Evidence from a svar. Economics Bulletin, 39(2):1393-1403.

Olper, A., Curzi, D., and Raimondi, V. (2017). Imported Intermediate Inputs and Firms' Productivity Growth: Evidence from the Food Industry. Journal of Agricultural Economics, 68(1):280-300.

Parmeter, C. F., Kumbhakar, S. C., et al. (2014). Efficiency analysis: a primer on recent advances. Foundations and Trends® in Econometrics, 7(3-4):191-385.

Pavcnik, N. (2002). Trade liberalization, exit, and productivity improvements: evidence from Chilean plants. The Review of Economic Studies, 69(1):245-276.

Pfaff, B. (2008). Var, svar and svec models: Implementation within R package vars. Journal of Statistical Software, 27(4).

Phalan, B., Green, R., and Balmford, A. (2014). Closing yield gaps: perils and possibilities for biodiversity conservation. Philosophical Transactions of the Royal Society B: Biological Sciences, 369(1639):20120285.

Pinstrup-Andersen, P. (2015). Food price policy in an era of market instability: a political economy analysis. Oxford University Press, USA.

Potapov, A. M., Dupérré, N., Jochum, M., Dreczko, K., Klarner, B., Barnes, A. D., Krashevska, V., Rembold, K., Kreft, H., Brose, U., et al. (2019). Functional losses in ground spider communities due to habitat-structure degradation under tropical land-use change. Ecology, page e02957.

Qaim, M., Sibhatu, K. T., Siregar, H., and Grass, I. (2020). Environmental, economic, and social consequences of the oil palm boom. Annual Review of Resource Economics. 
Qiu, C., Colson, G., Escalante, C., and Wetzstein, M. (2012). Considering macroeconomic indicators in the food before fuel nexus. Energy Economics, 34(6):2021-2028.

Rasmussen, L. V., Coolsaet, B., Martin, A., Mertz, O., Pascual, U., Corbera, E., Dawson, N., Fisher, J. A., Franks, P., and Ryan, C. M. (2018). Social-ecological outcomes of agricultural intensification. Nature Sustainability, 1(6):275-282.

R Core Team (2017). R: A Language and Environment for Statistical Computing. R Foundation for Statistical Computing, Vienna, Austria.

Reed, W. R. (2015). On the practice of lagging variables to avoid simultaneity. Oxford Bulletin of Economics and Statistics, 77(6):897-905.

Reinhard, S., Lovell, C. K., and Thijssen, G. (1999). Econometric estimation of technical and environmental efficiency: an application to dutch dairy farms. American Journal of Agricultural Economics, 81(1):44-60.

Rembold, K., Mangopo, H., Tjitrosoedirdjo, S. S., and Kreft, H. (2017). Plant diversity, forest dependency, and alien plant invasions in tropical agricultural landscapes. Biological Conservation, 213:234-242.

Rifin, A. (2010). The effect of export tax on indonesia's crude palm oil (cpo) export competitiveness. ASEAN Economic Bulletin, pages 173-184.

Rigobon, R. (2003). Identification through heteroskedasticty. Review of Economics and Statistics, 28(1):777-792.

Rigobon, R. and Sack, B. (2004). The impact of monetary policy on asset prices. Journal of Monetary Economics, 51(8):1553-1575.

Risk, B. B., James, N. A., and Matteson, D. S. (2015). steadyICA: ICA and tests of independence via multivariate distance covariance. $\mathrm{R}$ package version 1.0.

Rist, L., Feintrenie, L., and Levang, P. (2010a). The livelihood impacts of oil palm: smallholders in Indonesia. Biodiversity and conservation, 19(4):1009-1024.

Rist, L., Feintrenie, L., and Levang, P. (2010b). The livelihood impacts of oil palm: smallholders in Indonesia. Biodiversity and Conservation, 19(4):1009-1024.

Robbins, P., Chhatre, A., and Karanth, K. (2015). Political ecology of commodity agroforests and tropical biodiversity. Conservation Letters, 8(2):77-85.

Rodrik, D. (2007). World too complex for one-size-fits-all models. Post-Autistic Economics Review, 44:73-74. 
Salzman, J., Bennett, G., Carroll, N., Goldstein, A., and Jenkins, M. (2018). The global status and trends of payments for ecosystem services. Nature Sustainability, 1(3):136-144.

Sattler, C. and Matzdorf, B. (2013). Pes in a nutshell: From definitions and origins to pes in practiceapproaches, design process and innovative aspects. Ecosystem services, 6:2-11.

Savilaakso, S., Garcia, C., Garcia-Ulloa, J., Ghazoul, J., Groom, M., Guariguata, M. R., Laumonier, Y., Nasi, R., Petrokofsky, G., Snaddon, J., et al. (2014). Systematic review of effects on biodiversity from oil palm production. Environmental Evidence, 3(1):4.

Sayer, J., Ghazoul, J., Nelson, P., and Boedhihartono, A. K. (2012). Oil palm expansion transforms tropical landscapes and livelihoods. Global Food Security, 1(2):114-119.

Schaub, S., Buchmann, N., Lüscher, A., and Finger, R. (2020). Economic benefits from plant species diversity in intensively managed grasslands. Ecological Economics, 168:106488.

Schleifer, P. and Sun, Y. (2020). Reviewing the impact of sustainability certification on food security in developing countries. Global Food Security, 24:100337.

Schmidt, P. and Sickles, R. C. (1984). Production frontiers and panel data. Journal of Business \& Economic Statistics, 2(4):367-374.

Schomers, S. and Matzdorf, B. (2013). Payments for ecosystem services: A review and comparison of developing and industrialized countries. Ecosystem services, 6:16-30.

Schwarze, S., Euler, M., Gatto, M., Hein, J., Hettig, E., Holtkamp, A. M., Izhar, L., Kunz, Y., Lay, J., Merten, J., et al. (2015). Rubber vs. oil palm: an analysis of factors influencing smallholders' crop choice in jambi, indonesia. Technical report, University of Goettingen, Collaborative Research Centre 990" EFForTS .

Sentana, E. and Fiorentini, G. (2001). Identification, estimation and testing of conditionally heteroskedastic factor models. Journal of Econometrics, 102(2):143-164.

Serra, T. and Zilberman, D. (2013). Biofuel-related price transmission literature: A review. Energy Economics, 37(C):141-151.

Serra, T., Zilberman, D., Gil, J. M., and Goodwin, B. K. (2011). Nonlinearities in the U.S. corn-ethanol-oil-gasoline price system. Agricultural Economics, 42(1):35-45.

Shephard, R. W. (1970). Theory of cost and production functions. Princeton University Press.

Sibhatu, K. T. (2019). Oil palm boom and farm household diets in the tropics. Frontiers in Sustainable Food Systems, 3:75. 
Sims, C. A. (1972). Money, income, and causality. The American economic review, 62(4):540552.

Sims, C. A. (1980). Macroeconomics and reality. Econometrica, 48(1):1-48.

Sims, C. A., Goldfeld, S. M., and Sachs, J. D. (1982). Policy analysis with econometric models. Brookings papers on economic activity, 1982(1):107-164.

Sims, K. R. and Alix-Garcia, J. M. (2017). Parks versus pes: Evaluating direct and incentivebased land conservation in mexico. Journal of Environmental Economics and Management, $86: 8-28$.

Skevas, I. (2019). A hierarchical stochastic frontier model for efficiency measurement under technology heterogeneity. Journal of Quantitative Economics, 17(3):513-524.

Skevas, I., Zhu, X., Shestalova, V., and Emvalomatis, G. (2018). The impact of agrienvironmental policies and production intensification on the environmental performance of dutch dairy farms. Journal of Agricultural and Resource Economics, 43(1835-20183859):423-440.

Sodhi, N. S., Koh, L. P., Brook, B. W., and Ng, P. K. (2004). Southeast asian biodiversity: an impending disaster. Trends in Ecology E Evolution, 19(12):654 - 660.

Soliman, T., Lim, F. K. S., Lee, J. S. H., and Carrasco, L. R. (2016). Closing oil palm yield gaps among Indonesian smallholders through industry schemes, pruning, weeding and improved seeds. Royal Society Open Science, 3(8):160292.

Song, J., Guo, Y., Wu, P., and Sun, S. (2018). The agricultural water rebound effect in china. Ecological Economics, 146:497-506.

Stefanski, L. A. and Boos, D. D. (2002). The calculus of m-estimation. The American Statistician, 56(1):29-38.

Stephens, E. C., Mabaya, E., Cramon-Taubadel, S. v., and Barrett, C. B. (2012). Spatial price adjustment with and without trade. Oxford Bulletin of Economics and Statistics, $74(3): 453-469$.

Stigler, M. (2010). Threshold Cointegration: Overview and Implementation in R. R package version $0.7-2$.

Stock, J. and Watson, M. (2003). Has the business cycle changed and why? NBER Macroeconomics Annual 2002, 17:159-230. 
Suwarno, A., van Noordwijk, M., Weikard, H.-P., and Suyamto, D. (2018). Indonesias forest conversion moratorium assessed with an agent-based model of land-use change and ecosystem services (luces). Mitigation and adaptation strategies for global change, 23(2):211-229.

Swinnen, J. and Squicciarini, P. (2012). Mixed messages on prices and food security. Science, 335(6067):405-406.

Swinnen, J. F. (2010). The political economy of agricultural and food policies: recent contributions, new insights, and areas for further research. Applied Economic Perspectives and Policy, 32(1):33-58.

Székely, G. J., Rizzo, M. L., and Bakirov, N. K. (2007a). Measuring and testing dependence by correlation of distances. The Annals of Statistics, 35(6):2769-2794.

Székely, G. J., Rizzo, M. L., and Bakirov, N. K. (2007b). Measuring and testing dependence by correlation of distances. Annals of Statistics, 35(6):2769-2794.

TEEB (2012). The economics of ecosystems and biodiversity: ecological and economic foundations. Routledge, London and Washington.

Teuscher, M., Vorlaufer, M., Wollni, M., Brose, U., Mulyani, Y., and Clough, Y. (2015). Trade-offs between bird diversity and abundance, yields and revenue in smallholder oil palm plantations in Sumatra, Indonesia. Biological Conservation, 186:306-318.

Thai Rubber Association (2016). Press Release: Assessment of Thailand's Rubber Industry 2016.

Thompson, S. R., Herrmann, R., and Gohout, W. (2000). Agricultural market liberalization and instability of domestic agricultural markets: the case of the CAP. American Journal of Agricultural Economics, 82(3):718-726.

Thurman, W. N., Fisher, M. E., et al. (1988). Chickens, eggs, and causality, or which came first. American journal of agricultural economics, 70(2):237-238.

Topalova, P. and Khandelwal, A. (2011). Trade liberalization and firm productivity: the case of India. Review of Economics and Statistics, 93(3):995-1009.

Tothmihaly, A., Ingram, V., and von Cramon-Taubadel, S. (2019). How can the environmental efficiency of Indonesian cocoa farms be increased? Ecological Economics, 158:134-145.

Tran, K. C. and Tsionas, E. G. (2015). Endogeneity in stochastic frontier models: Copula approach without external instruments. Economics Letters, 133:85-88.

Tsay, R. S. (2015). MTS: All-Purpose Toolkit for Analyzing Multivariate Time Series (MTS) and Estimating Multivariate Volatility Models. R package version 0.33. 
Tsionas, E. G. (2002). Stochastic frontier models with random coefficients. Journal of Applied Econometrics, 17(2):127-147.

Tyner, W. E. (2010). The integration of energy and agricultural markets. Agricultural Economics, 41(s1):193-201.

Tyner, W. E. and Taheripour, F. (2007). Renewable energy policy alternatives for the future. American Journal of Agricultural Economics, 89(5):1303-1310.

Uhlig, H. (2005). What are the effects of monetary policy on output? results from an agnostic identification procedure. Journal of Monetary Economics, 52(2):381-419.

UNCTAD/WTO, I. T. C. (2017). Trade map: trade statistics for international business development. Data retrieved from https://www.trademap.org/Index.aspx.

United Nations (2015). Transforming our world: The 2030 agenda for sustainable development. General Assembley 70 session.

Verico, K. (2013). Economic cooperation in natural rubber: the impacts on natural rubber's world supply and Indonesia's economy. Asian Journal of Agriculture and Development, $10(2): 75-93$.

Verpoorten, M., Arora, A., Stoop, N., and Swinnen, J. (2013). Self-reported food insecurity in africa during the food price crisis. Food Policy, 39(C):51-63.

Vijay, V., Pimm, S. L., Jenkins, C. N., and Smith, S. J. (2016). The impacts of oil palm on recent deforestation and biodiversity loss. PLOS ONE, 11(7):1-19.

Villamor, G. B. and van Noordwijk, M. (2011). Social role-play games vs individual perceptions of conservation and pes agreements for maintaining rubber agroforests in Jambi (Sumatra), Indonesia. Ecology and Society, 16(3).

Villoria, N. B., Byerlee, D., and Stevenson, J. (2014). The effects of agricultural technological progress on deforestation: what do we really know? Applied Economic Perspectives and Policy, 36(2):211-237.

Waltner-Toews, D. and Lang, T. (2000). A new conceptual base for food and agricultural policy: the emerging model of links between agriculture, food, health, environment and society. Global Change and Human Health, 1(2):116-130.

Wang, S. L. and McPhail, L. (2014). Impacts of energy shocks on US agricultural productivity growth and commodity pricesa structural VAR analysis. Energy Economics, 46(C):435444. 
Wang, Y., Wu, C., and Yang, L. (2013). Oil price shocks and stock market activities: Evidence from oil-importing and oil-exporting countries. Journal of Comparative Economics, 41(4):1220-1239.

Wang, Y., Wu, C., and Yang, L. (2014). Oil price shocks and agricultural commodity prices. Energy Economics, 44(C):22-35.

Wenban-Smith, H., Fasse, A., and Grote, U. (2016). Food security in Tanzania: The challenge of rapid urbanisation. Food security, 8(5):973-984.

Wickham, H. (2009). ggplot2: Elegant Graphics for Data Analysis. Springer-Verlag New York.

Wiebe, K., Dawe, D., Stamoulis, K., et al. (2011). Food prices and economic crises: Causes and consequences for food security in developing countries. The food and financial crises in Sub-Saharan Africa: Origins, impacts and policy implications, pages 48-60.

Wodon, Q. and Zaman, H. (2008). Rising food prices in sub-Saharan Africa: Poverty impact and policy responses. The World Bank.

Woittiez, L. S., van Wijk, M. T., Slingerland, M., van Noordwijk, M., and Giller, K. E. (2017). Yield gaps in oil palm: A quantitative review of contributing factors. European Journal of Agronomy, 83:57-77.

World Bank (2020). World development indicators database. Data retrieved from https: //databank.worldbank.org/source/world-development-indicators.

World Energy Council (2016). World energy resources. World Energy Council Report.

Wunder, S., Engel, S., and Pagiola, S. (2008). Taking stock: A comparative analysis of payments for environmental services programs in developed and developing countries. Ecological Economics, 65(4):834-852.

$\mathrm{Xu}, \mathrm{X} .(2000)$. International trade and environmental regulation: time series evidence and cross section test. Environmental and Resource Economics, 17(3):233-257.

Yeah, K. L., Yanagida, J. F., and Yamauchi, H. (1994). Evaluation of external market effects and government intervention in Malaysia's agricultural sector: a computable general equilibrium framework. Agricultural Economics, 11(2-3):237-256.

Yu, J. and Bouamra-Mechemache, Z. (2016). Production standards, competition and vertical relationship. European Review of Agricultural Economics, 43(1):79-111. 
Zeileis, A., Leisch, F., Hornik, K., and Kleiber, C. (2002). strucchange: An R package for testing for structural change in linear regression models. Journal of Statistical Software, $7(2): 1-38$.

Zhang, C. and Qu, X. (2015). The effect of global oil price shocks on China's agricultural commodities. Energy Economics, 51(C):354-364. 
APPENDICES 


\section{Appendix A}

\section{Appendix of Chapter Two}

\section{A.1 Random intercept model}

Table A.1 Random intercept model estimation results

\begin{tabular}{|c|c|}
\hline & LMM \\
\hline \multicolumn{2}{|l|}{ Technology } \\
\hline$\beta_{0}($ Intercept $)$ & $0.16(0.56)$ \\
\hline$\beta_{1}($ Size $)$ & $0.90(0.09)^{* * *}$ \\
\hline$\beta_{2}$ (Labour) & $0.09(0.05)$ \\
\hline$\beta_{3}$ (Agrochemicals) & $0.16(0.05)^{* * *}$ \\
\hline$\beta_{4}$ (Tree age) & $0.21(0.10)^{* *}$ \\
\hline$\beta_{5}$ (Tree density) & $0.21(0.10)^{* *}$ \\
\hline$\beta_{13}$ & $-0.02(0.04)$ \\
\hline$\beta_{12}$ & $0.04(0.08)$ \\
\hline$\beta_{14}$ & $0.37(0.12)^{* * *}$ \\
\hline$\beta_{15}$ & $-0.12(0.19)$ \\
\hline$\beta_{23}$ & $-0.02(0.03)$ \\
\hline$\beta_{24}$ & $-0.24(0.09)^{* * *}$ \\
\hline$\beta_{25}$ & $0.13(0.19)$ \\
\hline$\beta_{34}$ & $-0.01(0.04)$ \\
\hline$\beta_{35}$ & $-0.03(0.10)$ \\
\hline$\beta_{45}$ & $0.31(0.24)$ \\
\hline$\beta_{11}$ & $0.12(0.12)$ \\
\hline$\beta_{33}$ & $0.05(0.02)^{* *}$ \\
\hline$\beta_{22}$ & $-0.09(0.05)^{*}$ \\
\hline$\beta_{44}$ & $-0.95(0.21)^{* * *}$ \\
\hline$\beta_{55}$ & $-0.89(0.47)^{*}$ \\
\hline$\rho$ & $-0.09(0.14)$ \\
\hline InputDummy & $-0.29(0.12)^{* *}$ \\
\hline \multicolumn{2}{|l|}{ Group predictors } \\
\hline$\gamma_{1}$ (Age) & $0.01(0.02)$ \\
\hline
\end{tabular}




\begin{tabular}{lc}
\hline & LMM ctd. \\
\hline$\gamma_{11}$ I $\left(\right.$ Age $\left.^{2}\right)$ & $-0.00(0.00)$ \\
$\gamma_{2}$ Education & $0.01(0.01)$ \\
$\gamma_{3}$ HHSize & $-0.08(0.03)^{* * *}$ \\
$\gamma_{4}$ Transmigrant & $0.05(0.13)$ \\
$\gamma_{5}$ trans & $-0.03(0.12)$ \\
$\gamma_{6}$ Land title & $-0.01(0.17)$ \\
\hline AIC & 774.75 \\
BIC & 896.32 \\
Log Likelihood & -355.38 \\
Num. obs. & 330 \\
Num. groups: hid & 211 \\
Var: hid $($ Intercept $)$ & 0.12 \\
Var: Residual & 0.27 \\
\hline${ }^{* * *} p<0.01,{ }^{* *} p<0.05,{ }^{*} p<0.1$ &
\end{tabular}

Table A.1 Statistical models

\section{A.2 Derivation of land efficiency measure}

Reinhard et al. (1999) consider a detrimental output and derive the respective environmental efficiency from a translog production function. In their model, the undesired output enters the equation as an input and the measure aims at capturing the distance of actual input (undesired output) level and the potential minimum input (undesired output). In other words, the ratio between the minimum input (detrimental output) and the actually produced amount of input (detrimental output) in their model. Thus this represents an input oriented efficiency measure which is tailored towards one input only while not considering other production factors. What follows is an application of the environmental efficiency measure of Reinhard et al. (1999) to derive land efficiency of the oil palm smallholders. We start from the translog production specification as in Equation 2.6. At zero inefficiency the land efficient producer uses $x_{i c t} *$ land and his production function is

$$
y_{i c t}=\beta_{0}+\beta 1 x_{i c t}+\sum_{j} \beta_{j=2}^{5} x_{i c t j}+\frac{1}{2} \sum_{j=2} \sum_{k}^{5} \beta_{j k} x_{i c t j} x_{i c t k}+\sum_{j} \beta_{1 j} x_{i c t j} x_{i c t}^{*}+0.5 \beta_{11} x_{i c t}^{* 2}+v_{i c t} .
$$

We can now isolate the logarithmized land efficiency measure $L E_{i c t}=x_{1 i c t}^{*}-x_{1 i c t}$ by setting equations 2.6 and Equation A.1 equal resulting in 


$$
\frac{1}{2} \beta_{11}\left[x_{1 i c t}^{2}-x_{1 i c t}^{2}\right]+\sum_{j=2}^{5} \beta_{1 j} x_{i c t}\left[x_{1 i c t}-x_{1 i c t}\right]+\beta_{1}\left[x_{1 i c t}-x_{1 i c t}\right]+u_{c}=0 .
$$

A further simplification thereof is

$$
\frac{1}{2} \beta_{11}\left[x_{1 i c t}-x_{1 i c t}\right]^{2}+\left[\beta_{1}+\sum_{j=2}^{5} \beta_{1 j} x_{i c t}+\beta_{11} x_{1 i c t}\right] \times x_{1 i c t}^{*}-x_{1 i c t}+u_{c}=0
$$

which we solve for $L E_{i c t}=x_{1 i c t}^{*}-x_{1 i c t}$ yielding the land efficiency measure

$L E_{i c t}=\frac{\left[-\left(\beta_{1}+\sum_{j}^{4} \beta_{1 j} x_{i c t j}+\beta_{11} x_{1 i c t}\right) \pm\left\{\left(\beta_{1}+\sum_{j}^{4} \beta_{1 j} x_{i c t j}+\beta_{11} x_{1 i c t}\right)^{2}-2 \beta_{11} u_{i c t}\right\}^{.5}\right]}{\beta_{11}}$. 


\section{Appendix B}

\section{Appendix of Chapter Three}

\section{B.1 Biodiversity indicators}

Figure B.1 Density of sample plots with different levels of plant species diversity assessed by diversity indices of order $(q=0)(S R),(q=1)(E N S)$, and $(q=$ 2) (Simpson diversity). $\mathrm{SR}$ is more sensitive to differences between samples but potentially unreliable as diversity measure when undersampling is expected

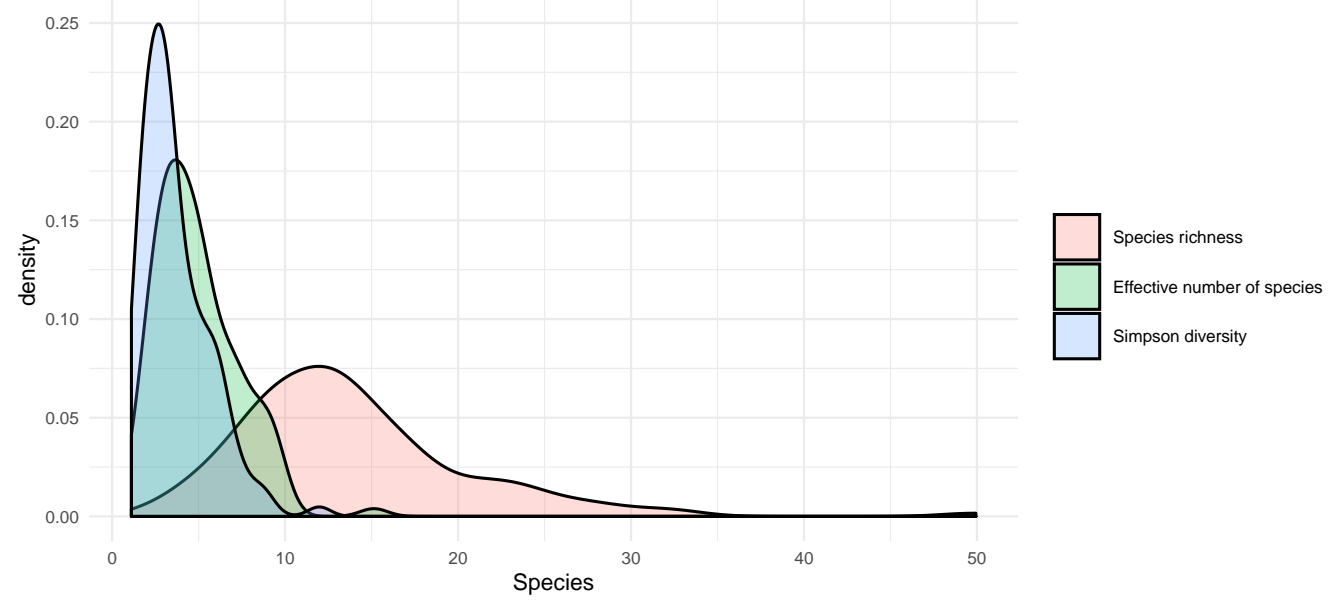

\section{B.2 Hyperbolic and enhanced hyperbolic specifications and estimation results}

Empirical specification of the hyperbolic distance function: 


$$
\begin{array}{r}
-\ln y_{i}=\alpha_{0}+\sum_{k=1}^{4} \alpha_{k} \ln \left(x_{k i}\right)+\beta_{1} \ln \left(b_{i}^{*}\right)+\sum_{k=1}^{4} \beta_{1 k} \ln \left(b_{i}^{*}\right) \ln \left(x_{i}\right) \\
+\frac{1}{2} \sum_{k=1}^{4} \sum_{l=1}^{4} \alpha_{k l} \ln \left(x_{k i}\right) \ln \left(x_{l i}\right)+ \\
+\frac{1}{2} \beta_{11} \ln \left(b_{i}^{*}\right)^{2}+\rho_{0} t_{i}+u_{i}+v_{i} .
\end{array}
$$

Empirical specification of the enhanced hyperbolic distance function:

$$
\begin{array}{r}
-\ln y_{i}=\alpha_{0}+\sum_{k=1}^{4} \alpha_{k} \ln \left(x_{k i}^{*}\right)+\beta_{1} \ln \left(b_{i}^{*}\right)+\sum_{k=1}^{4} \beta_{1 k} \ln \left(b_{i}^{*}\right) \ln \left(x_{i}^{*}\right) \\
+\frac{1}{2} \sum_{k=1}^{4} \sum_{l=1}^{4} \alpha_{k l} \ln \left(x_{k i}^{*}\right) \ln \left(x_{l i}^{*}\right)+ \\
+\frac{1}{2} \beta_{11} \ln \left(b_{i}^{*}\right)^{2}+\rho_{0} t_{i}+u_{i}+v_{i} .
\end{array}
$$

\begin{tabular}{|c|c|c|}
\hline & $D_{H}(x, y, b)$ & $D_{E}(x, y, b)$ \\
\hline \multicolumn{3}{|l|}{ Technology } \\
\hline$\alpha_{0}($ Intercept $)$ & $-0.49(0.09)^{* * *}$ & $-0.35(0.04)^{* * *}$ \\
\hline$\alpha_{1}(\mathrm{Size})$ & $-0.43(0.08)^{* * *}$ & $-0.26(0.03)^{* * *}$ \\
\hline$\alpha_{2}$ (Labor) & $-0.06(0.06)$ & $-0.10(0.03)^{* * *}$ \\
\hline$\alpha_{3}$ (Agrochemicals) & $-0.04(0.02)$ & $-0.00(0.01)$ \\
\hline$\alpha_{4}$ (Age of palms) & $-0.33(0.09)^{* * *}$ & $-0.25(0.03)^{* * *}$ \\
\hline$\beta_{1}$ (Biodiversity loss) & $-0.45(0.04)^{* * *}$ & $-0.12(0.04)^{* *}$ \\
\hline$\beta_{12}$ & $-0.07(0.07)$ & $0.03(0.05)$ \\
\hline$\beta_{13}$ & $-0.05(0.05)$ & $0.02(0.06)$ \\
\hline$\beta_{14}$ & $-0.02(0.02)$ & $0.01(0.01)$ \\
\hline$\beta_{15}$ & $-0.03(0.07)$ & $-0.02(0.05)$ \\
\hline$\alpha_{12}$ & $0.04(0.09)$ & $-0.05(0.05)$ \\
\hline$\alpha_{13}$ & $0.01(0.02)$ & $0.00(0.01)$ \\
\hline$\alpha_{14}$ & $-0.17(0.12)$ & $-0.05(0.04)$ \\
\hline$\alpha_{23}$ & $0.01(0.01)$ & $-0.01(0.01)$ \\
\hline$\alpha_{24}$ & $0.18(0.08)^{* *}$ & $0.10(0.03)^{* * *}$ \\
\hline$\alpha_{34}$ & $0.03(0.02)^{*}$ & $0.00(0.01)$ \\
\hline$\alpha_{11}$ & $-0.15(0.13)$ & $0.02(0.04)$ \\
\hline$\alpha_{22}$ & $-0.00(0.03)$ & $-0.03(0.02)$ \\
\hline$\alpha_{33}$ & $-0.00(0.01)$ & $0.00(0.00)$ \\
\hline
\end{tabular}

Table B.1 Hyperbolic and enhanced hyperbolic distance functions 


\begin{tabular}{lcc}
\hline & $D_{H}(x, y, b)$ & $D_{E}(x, y, b)$ \\
\hline$\alpha_{44}$ & $-0.20(0.20)$ & $-0.04(0.06)$ \\
$\beta_{11}$ & $0.15(0.07)^{* *}$ & $-0.03(0.08)$ \\
$\rho_{0}$ & $0.08(0.04)^{* *}$ & $0.07(0.02)^{* * *}$ \\
$\sigma_{v}$ & & \\
$\omega_{0}$ & $-3.76(0.40)^{* * *}$ & $-4.29(0.15)^{* * *}$ \\
Inefficiency & & \\
$\tau_{0}$ & $0.95(2.42)$ & $-1.54(7.51)$ \\
$\tau_{1}$ (Age) & $-0.28(0.13)^{* *}$ & $-0.71(0.41)^{*}$ \\
$\tau_{2}$ (Age $\left.{ }^{2}\right)$ & $0.00(0.00)^{* *}$ & $0.01(0.00)^{*}$ \\
$\tau_{3}$ (Education) & $-0.05(0.44)$ & $1.71(2.18)$ \\
$\tau_{4}$ (Education $\left.{ }^{2}\right)$ & $0.03(0.08)$ & $-0.33(0.40)$ \\
$\tau_{5}$ (HH size) & $0.30(0.16)^{*}$ & $0.44(0.38)$ \\
$\tau_{6}$ (Transmigrant) & $1.01(0.49)^{* *}$ & $2.41(1.34)^{*}$ \\
$\tau_{7}$ (Chemical weeding) & $0.64(0.50)$ & $4.99(3.22)$ \\
$\tau_{8}$ (Manual weeding) & $1.09(0.41)^{* * *}$ & $3.66(1.50)^{* *}$ \\
$\tau_{10}$ (Land title) & $0.89(0.59)$ & $1.68(1.42)$ \\
\hline Mean TE & 0.78 & 0.96 \\
Observations $_{2}$ (E) & 123 & 123 \\
\hline
\end{tabular}

${ }^{* * *} p<0.01,{ }^{* *} p<0.05,{ }^{*} p<0.1$ 
Table B.2 Marginal effects of determinants of inefficiency (from hyperbolic and enhanced hyperbolic distance functions)

\begin{tabular}{|c|c|c|c|c|c|c|c|c|}
\hline & \multicolumn{4}{|c|}{$D_{H}(x, y, b)$} & \multicolumn{4}{|c|}{$D_{E}(x, y, b)$} \\
\hline & Mean & St. Dev. & Min & Max & Mean & St. Dev. & Min & $\operatorname{Max}$ \\
\hline Age & -0.039 & 0.016 & -0.093 & -0.011 & -0.018 & 0.029 & -0.172 & 0.000 \\
\hline Education & -0.006 & 0.003 & -0.015 & -0.002 & 0.043 & 0.070 & 0.000 & 0.414 \\
\hline Household size & 0.042 & 0.018 & 0.012 & 0.101 & 0.011 & 0.018 & 0.000 & 0.107 \\
\hline Transmigrant & 0.141 & 0.060 & 0.041 & 0.336 & 0.060 & 0.099 & 0.000 & 0.583 \\
\hline Chemical weeding & 0.090 & 0.038 & 0.026 & 0.215 & 0.125 & 0.204 & 0.001 & 1.205 \\
\hline Manual weeding & 0.152 & 0.065 & 0.044 & 0.362 & 0.092 & 0.150 & 0.001 & 0.883 \\
\hline Land title & 0.125 & 0.053 & 0.036 & 0.298 & 0.042 & 0.069 & 0.000 & 0.406 \\
\hline
\end{tabular}

Table B.3 Shadow pirces in '000 IDR (Derived from hyperbolic and enhanced hyperbolic distance functions

\begin{tabular}{rrrrrrrrr}
\hline & \multicolumn{3}{c}{$D_{H}(x, y, b)$} & & \multicolumn{3}{c}{$D_{E}(x, y, b)$} \\
\cline { 2 - 3 } \cline { 7 - 8 } & Mean & Median & St. Dev. & & Mean & Median & St. Dev. \\
\hline 2018 & 6,381 & 4,187 & 17,659 & & 1,120 & 11,357 & 107,277 \\
2015 & 6,381 & 4,187 & 17,659 & & 1,106 & 11,212 & 105,914 \\
2012 & 5,551 & 3,642 & 15,363 & & 975 & 9,880 & 93,330 \\
\hline
\end{tabular}

\section{B.3 Hyperbolic, enhanced hyperbolic and restricted hy- perbolic with SR loss as undesired output}

Table B.4 Hyperbolic, restricted and enhanced hyperbolic distance functions with inverse of $S R$ as an undesirable output

\begin{tabular}{lccc}
\hline & $D_{H}(x, y, b)$ & $D_{R}(x, y, b)$ & $D_{E}(x, y, b)$ \\
\hline Technology & & & \\
$\alpha_{0}$ (Intercept) & $-0.49(0.09)^{* * *}$ & $-0.48(0.08)^{* * *}$ & $-0.35(0.04)^{* * *}$ \\
$\alpha_{1}$ (Size) & $-0.43(0.08)^{* * *}$ & $-0.37(0.08)^{* * *}$ & $-0.26(0.03)^{* * *}$ \\
$\alpha_{2}$ (Labor) & $-0.06(0.06)$ & $-0.06(0.06)$ & $-0.10(0.03)^{* * *}$ \\
$\alpha_{3}$ (Agrochemicals) & $-0.04(0.02)$ & $-0.06(0.02)^{* * *}$ & $-0.00(0.01)$ \\
$\alpha_{4}$ (Age of palms) & $-0.33(0.09)^{* * *}$ & $-0.26(0.08)^{* * *}$ & $-0.25(0.03)^{* * *}$ \\
$\beta_{1}$ (Biodiversity loss) & $-0.45(0.04)^{* * *}$ & $-0.42(0.04)^{* * *}$ & $-0.12(0.04)^{* *}$ \\
$\beta_{12}$ & $-0.07(0.07)$ & $-0.08(0.06)$ & $0.03(0.05)$ \\
$\beta_{13}$ & $-0.05(0.05)$ & $-0.06(0.05)$ & $0.02(0.06)$ \\
$\beta_{14}$ & $-0.02(0.02)$ & $-0.01(0.01)$ & $0.01(0.01)$ \\
$\beta_{15}$ & $-0.03(0.07)$ & $-0.06(0.07)$ & $-0.02(0.05)$ \\
$\alpha_{12}$ & $0.04(0.09)$ & $0.03(0.08)$ & $-0.05(0.05)$ \\
\hline
\end{tabular}




\begin{tabular}{|c|c|c|c|}
\hline & $D_{H}(x, y, b)$ & $D_{R}(x, y, b)$ & $D_{E}(x, y, b)$ \\
\hline$\alpha_{13}$ & $0.01(0.02)$ & $0.01(0.02)$ & $0.00(0.01)$ \\
\hline$\alpha_{14}$ & $-0.17(0.12)$ & $-0.14(0.11)$ & $-0.05(0.04)$ \\
\hline$\alpha_{23}$ & $0.01(0.01)$ & $0.01(0.01)$ & $-0.01(0.01)$ \\
\hline$\alpha_{24}$ & $0.18(0.08)^{* *}$ & $0.16(0.08)^{*}$ & $0.10(0.03)^{* * *}$ \\
\hline$\alpha_{34}$ & $0.03(0.02)^{*}$ & $0.04(0.01)^{* * *}$ & $0.00(0.01)$ \\
\hline$\alpha_{11}$ & $-0.15(0.13)$ & $-0.12(0.11)$ & $0.02(0.04)$ \\
\hline$\alpha_{22}$ & $-0.00(0.03)$ & $-0.00(0.03)$ & $-0.03(0.02)$ \\
\hline$\alpha_{33}$ & $-0.00(0.01)$ & $-0.01(0.00)^{* *}$ & $0.00(0.00)$ \\
\hline$\alpha_{44}$ & $-0.20(0.20)$ & $-0.19(0.19)$ & $-0.04(0.06)$ \\
\hline$\beta_{11}$ & $0.15(0.07)^{* *}$ & $0.18(0.08)^{* *}$ & $-0.03(0.08)$ \\
\hline$\rho_{0}$ & $0.08(0.04)^{* *}$ & $0.06(0.04)$ & $0.07(0.02)^{* * *}$ \\
\hline \multicolumn{4}{|l|}{$\sigma_{v}$} \\
\hline$\omega_{0}$ & $-3.76(0.40)^{* * *}$ & $-3.94(0.38)^{* * *}$ & $-4.29(0.15)^{* * *}$ \\
\hline \multicolumn{4}{|l|}{ Inefficiency } \\
\hline$\tau_{0}$ & $0.95(2.42)$ & $1.24(2.36)$ & $-1.54(7.51)$ \\
\hline$\tau_{1}$ (Age) & $-0.28(0.13)^{* *}$ & $-0.29(0.12)^{* *}$ & $-0.71(0.41)^{*}$ \\
\hline$\tau_{2}\left(\operatorname{Age}^{2}\right)$ & $0.00(0.00)^{* *}$ & $0.00(0.00)^{* *}$ & $0.01(0.00)^{*}$ \\
\hline$\tau_{3}$ (Education) & $-0.05(0.44)$ & $-0.03(0.43)$ & $1.71(2.18)$ \\
\hline$\tau_{4}\left(\right.$ Education $\left.^{2}\right)$ & $0.03(0.08)$ & $0.03(0.08)$ & $-0.33(0.40)$ \\
\hline$\tau_{5}(\mathrm{HH}$ size $)$ & $0.30(0.16)^{*}$ & $0.31(0.15)^{* *}$ & $0.44(0.38)$ \\
\hline$\tau_{6}$ (Transmigrant) & $1.01(0.49)^{* *}$ & $1.17(0.48)^{* *}$ & $2.41(1.34)^{*}$ \\
\hline$\tau_{7}$ (Chemical weeding) & $0.64(0.50)$ & $0.50(0.46)$ & $4.99(3.22)$ \\
\hline$\tau_{8}$ (Manual weeding) & $1.09(0.41)^{* * *}$ & $1.09(0.39)^{* * *}$ & $3.66(1.50)^{* *}$ \\
\hline$\tau_{10}($ Land title $)$ & $0.89(0.59)$ & $0.98(0.55)^{*}$ & $1.68(1.42)$ \\
\hline Mean TE & 0.78 & 0.78 & 0.96 \\
\hline Observations & 123.00 & 123.00 & 123.00 \\
\hline
\end{tabular}

${ }^{* * *} p<0.01,{ }^{* *} p<0.05,{ }^{*} p<0.1$ 


\section{Appendix C}

\section{Appendix of Chapter Four}

\section{C.1 Derivation of relation between agricultural and industrial input price changes}

First we insert equations (4.1) and (4.3) into the equilibrium condition on the agricultural input market, equation (4.7), which yields

$$
h(a, U)(1+t)=p_{Q} f_{a},
$$

where $f_{a}$ is the partial derivative of $Q(a, b)$ with respect to $a$. We now differentiate equation (C.1) with respect to $W:^{1}$

$$
h_{a} \frac{\partial a}{\partial U}(1+t)=p_{Q} f_{a a} \frac{\partial a}{\partial U}+p_{Q} f_{a b} \frac{\partial b}{\partial U}+f_{a} \frac{\partial p_{Q}}{\partial U}
$$

The next step is to derive the equivalent of equation (12) in Gardner (1975, p. 400), appended by the policy. To do so, the differentiations in equation (C.2) are replaced by elasticities, then input shares are included, and $f_{a a}$ and $f_{a b}$ are replaced. ${ }^{2}$

$$
0=-\left(\frac{S_{b}}{\sigma}+\frac{1}{\varepsilon_{a}}\right)\left(\frac{1}{1+t}\right) E_{a W}+\frac{S_{b}}{\sigma} E_{b W}+E_{p_{Q} W}-\varepsilon_{a, U}
$$

The $E$ refer to "elasticities which take into account equilibrating adjustments in all three markets simultaneously" (Gardner, 1975, p. 400). Regarding notation, the first variable in the subscript indicates the variable that reacts to a shock stemming from the second one. From (C.3) we derive the equivalent to equation (A.8) in Gardner (1975, p. 409), analogous to the appendix in Gardner:

$$
E_{p_{a}^{W}, U}=\frac{\varepsilon_{U} \varepsilon_{a}\left(\varepsilon_{b}+S_{a} \sigma-S_{b} \eta_{Q}\right)}{(1+t) D}
$$

Equation (C.4) describes the elasticity of the agricultural output price with respect to a shift and tilting in the agricultural supply. $\varepsilon_{U}$ is the elasticity describing the reaction of $p_{a}$

\footnotetext{
${ }^{1}$ For the derivation of equation (C.2) see Gardner (1975, p. 400, equation (9)).

${ }^{2}$ For the derivation of equation (C.3), see Gardner (1975, p. 408, equation (A.8)). The difference to the cited equation is that Gardner differentiates with respect to $N$ (shift in output demand) while this application does so with respect to $W$ (shift in agricultural supply) as described in Gardner (1975, p. 402).
} 
to $U .{ }^{3} \varepsilon_{U}$ captures the effect of the policy induced reduction of the agricultural output resulting from a reduction of production capacity. The industrial output's reaction to a supply shift in the agricultural output, $E_{p_{b}}^{W}$, is equivalent to equation A.17 in Gardner (1975, p. 409):

$$
E_{b, U}=\frac{\varepsilon_{a} \varepsilon_{b} S_{a}\left(\eta_{Q}+\sigma\right)}{D}
$$

With $E_{b, U}=\varepsilon_{b} E_{p_{b}, U}$ we can derive the expression for $E_{p_{b}, U}:^{4}$

$$
E_{p_{b}, U}=\frac{\varepsilon_{a} S_{a}\left(\eta_{Q}+\sigma\right)}{D}
$$

The relation between agricultural and industrial input price changes, the cross price elasticity $\varepsilon_{a, b}$ between $a$ and $b$ is generated by dividing equation (C.4) by equation (C.6):

$$
\varepsilon_{a, b}=\frac{E_{p_{a}^{W}, U}}{E_{p_{b}, U}}=\frac{\varepsilon_{U}}{(1+t)} \frac{\left(\varepsilon_{b}+S_{a} \sigma-S_{b} \eta_{Q}\right)}{S_{a}\left(\eta_{Q}+\sigma\right)}
$$

which is text equation (4.8).

\footnotetext{
${ }^{3}$ Note the difference to $E_{a, U}$, which stands for the total elasticities, while $\varepsilon_{U}$ accounts for the partial elasticity.

${ }^{4}$ The equivalent calculation for good $a$ is provided in Gardner (1975, p. 408).
} 


\section{C.2 Simulation of elasticities based on varying values for sigma}

Figure C.1 Simulation elasticity based on different values for $\sigma$. The red line indicates the value $(\sigma=10)$ that was used for the calculation in equation (4.10).

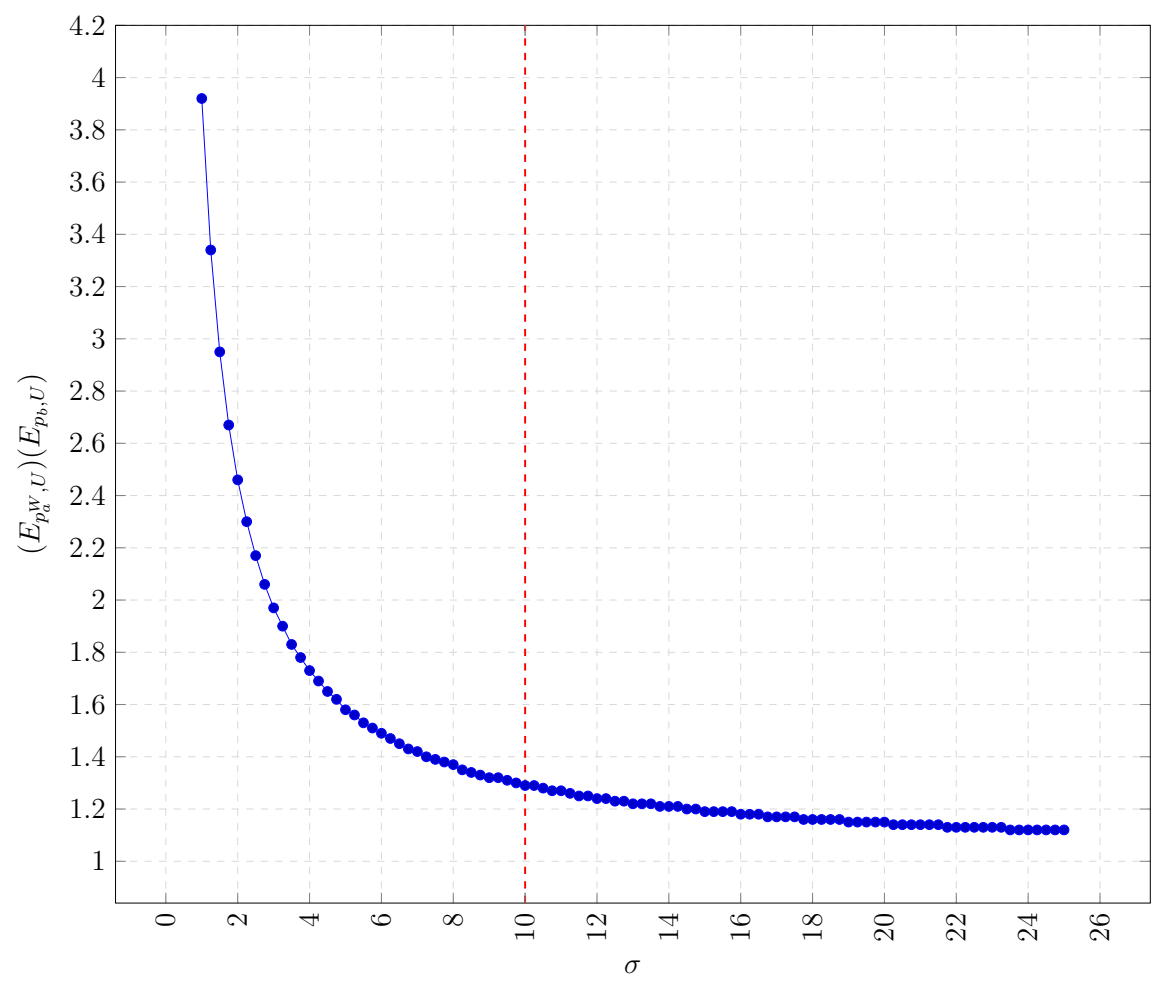

- Values of $\left(E_{p_{a}^{W}, U}\right)\left(E_{p_{b}, U}\right)$ 


\section{C.3 Robustness checks of $S M S$ measure}

Table C.1 Long run regression models

\begin{tabular}{lccccc}
\hline & Model 1 & Model 2 & Model 3 & Model 4 & Model 5 \\
\hline (Intercept) & -3.47 & -3.52 & -3.53 & -3.19 & -3.35 \\
& $(0.07)$ & $(0.06)$ & $(0.06)$ & $(0.06)$ & $(0.07)$ \\
$p^{S R}$ & 1.05 & 1.14 & 1.07 & 0.97 & 1.01 \\
& $(0.01)$ & $(0.01)$ & $(0.01)$ & $(0.01)$ & $(0.01)$ \\
$p^{C O}$ & 0.17 & 0.04 & 0.15 & 0.28 & 0.22 \\
& $(0.01)$ & $(0.01)$ & $(0.01)$ & $(0.01)$ & $(0.01)$ \\
$S M S_{\text {ex }}$ & -0.01 & -0.17 & & & \\
& $(0.01)$ & $(0.01)$ & & & \\
$S M S_{T O}$ & & -0.20 & -0.07 & -0.18 & \\
& & $(0.01)$ & $(0.01)$ & $(0.01)$ & \\
$S M S_{h a}$ & & & & -0.31 & -0.09 \\
& & & & $(0.01)$ & $(0.01)$ \\
\hline$R^{2}$ & 0.93 & 0.95 & 0.94 & 0.95 & 0.93 \\
Adj. $R^{2}$ & 0.93 & 0.95 & 0.94 & 0.95 & 0.93 \\
Num. obs. & 1484 & 1484 & 1484 & 1484 & 1484 \\
RMSE & 0.12 & 0.10 & 0.12 & 0.10 & 0.12 \\
\hline
\end{tabular}

Standard errors in parentheses. 


\section{C.3.1 Results of short run regression}

Table C.2 ECM based on LR model 4

\begin{tabular}{lrr}
\hline & \multicolumn{1}{c}{$\Delta p_{t}^{N R}$} & \multicolumn{1}{c}{$\Delta p_{t}^{S R}$} \\
\hline$\Delta p_{t}^{C O}$ & $0.09(0.02)$ & $0.16(0.04)$ \\
$A E T S_{t}$ & $0.00(0.01)$ & $0.02(0.01)$ \\
$E C T_{t-1}$ & $0.01(0.00)$ & $0.01(0.01)$ \\
$\Delta p_{t-1}^{N R}$ & $0.17(0.03)$ & $-0.04(0.06)$ \\
$\Delta p_{t-1}^{S R}$ & $-0.01(0.01)$ & $-0.08(0.03)$ \\
$\Delta p_{t-1}^{C O}$ & $0.02(0.02)$ & $-0.04(0.04)$ \\
$\Delta p_{t-2}^{N R}$ & $0.11(0.03)$ & $-0.00(0.06)$ \\
$\Delta p_{t-2}^{S R}$ & $0.00(0.01)$ & $0.01(0.03)$ \\
$\Delta p_{t-2}^{C O}$ & $0.03(0.02)$ & $0.05(0.04)$ \\
$\Delta p_{t-3}^{N R}$ & $0.15(0.03)$ & $0.07(0.06)$ \\
$\Delta p_{t-3}^{S R}$ & $0.01(0.01)$ & $-0.05(0.03)$ \\
$\Delta p_{t-3}^{C O}$ & $0.05(0.02)$ & $0.02(0.04)$ \\
$\Delta p_{t-4}^{N R}$ & $0.07(0.03)$ & $0.05(0.06)$ \\
$\Delta p_{t-4}^{S R}$ & $0.00(0.01)$ & $0.02(0.03)$ \\
$\Delta p_{t-4}^{C O}$ & $0.04(0.02)$ & $-0.10(0.04)$ \\
$\Delta p_{t-5}^{N R}$ & $-0.02(0.03)$ & $-0.01(0.06)$ \\
$\Delta p_{t-5}^{S R}$ & $-0.01(0.01)$ & $0.06(0.03)$ \\
$\Delta p_{t-5}^{C O}$ & $0.01(0.02)$ & $0.01(0.04)$ \\
$\Delta p_{t-6}^{N R}$ & $-0.01(0.03)$ & $0.07(0.06)$ \\
$\Delta p_{t-6}^{S R}$ & $0.01(0.01)$ & $-0.00(0.03)$ \\
$\Delta p_{t-6}^{C O}$ & $0.02(0.02)$ & $0.04(0.04)$ \\
$\Delta p_{t-7}^{N R}$ & $-0.07(0.03)$ & $-0.01(0.06)$ \\
$\Delta p_{t-7}^{S R}$ & $0.01(0.01)$ & $-0.05(0.03)$ \\
$\Delta p_{t-7}^{C O}$ & $0.04(0.02)$ & $-0.06(0.04)$ \\
$\Delta p_{t-8}^{N R}$ & $0.06(0.03)$ & $0.01(0.06)$ \\
$\Delta p_{t-8}^{S R}$ & $0.01(0.01)$ & $0.02(0.03)$ \\
$\Delta p_{t-8}^{C O}$ & $-0.02(0.02)$ & $0.02(0.04)$ \\
$\Delta p_{t-9}^{N R}$ & $-0.03(0.03)$ & $0.02(0.06)$ \\
$\Delta p_{t-9}^{S R}$ & $0.01(0.01)$ & $0.02(0.03)$ \\
$\Delta p_{t-9}^{C O}$ & $-0.04(0.02)$ & $0.07(0.04)$ \\
$\Delta p_{t-10}^{N R}$ & $0.08(0.03)$ & $-0.11(0.06)$ \\
$\Delta p_{t-10}^{S R}$ & $0.01(0.01)$ & $-0.01(0.03)$ \\
$\Delta p_{t-10}^{C O}$ & $0.02(0.02)$ & $-0.01(0.04)$ \\
\hline $\mathrm{Num.} \mathrm{obs.}$ & 1473 & 1473 \\
\hline & &
\end{tabular}


Table C.3 Importers and exporters of rubber and tires

\begin{tabular}{lcccccc} 
Country & $\begin{array}{c}\text { Tire } \\
\text { Exports }\end{array}$ & $\begin{array}{c}\text { Synth. Rubber } \\
\text { Exports }\end{array}$ & $\begin{array}{c}\text { Nat. Rubber } \\
\text { Exports }\end{array}$ & $\begin{array}{c}\text { Tire } \\
\text { Imports }\end{array}$ & $\begin{array}{c}\text { Synth. Rubber } \\
\text { Imports }\end{array}$ & $\begin{array}{c}\text { Nat. Rubber } \\
\text { Imports }\end{array}$ \\
\hline China & $18.7 \%$ & $9.5 \%$ & $0.1 \%$ & $1.0 \%$ & $13.6 \%$ & $23.2 \%$ \\
European Union & $7.3 \%$ & $13.1 \%$ & $0.2 \%$ & $9.5 \%$ & $8.1 \%$ & $13.3 \%$ \\
Japan & $6.3 \%$ & $7.9 \%$ & $0.0 \%$ & $1.5 \%$ & $1.9 \%$ & $8.6 \%$ \\
United States & $6.3 \%$ & $7.2 \%$ & $0.5 \%$ & $18.5 \%$ & $9.3 \%$ & $14.4 \%$ \\
Thailand & $6.1 \%$ & $3.2 \%$ & $23.1 \%$ & $0.6 \%$ & $4.1 \%$ & $0.0 \%$ \\
Korea & $4.3 \%$ & $15.2 \%$ & $0.0 \%$ & $1.0 \%$ & $2.1 \%$ & $5.1 \%$ \\
India & $2.2 \%$ & $0.9 \%$ & $0.1 \%$ & $0.5 \%$ & $3.3 \%$ & $7.2 \%$ \\
Indonesia & $0.2 \%$ & $0.7 \%$ & $40.3 \%$ & $0.8 \%$ & $3.4 \%$ & $0.1 \%$ \\
Vietnam & $1.2 \%$ & $0.0 \%$ & $7.4 \%$ & $0.4 \%$ & $2.6 \%$ & $2.2 \%$ \\
Malaysia & $0.4 \%$ & $0.2 \%$ & $9.2 \%$ & $0.8 \%$ & $1.3 \%$ & $3.1 \%$ \\
\hline C3 & $32.4 \%$ & $38.5 \%$ & $72.6 \%$ & $32.1 \%$ & $28.3 \%$ & $46.2 \%$ \\
\hline
\end{tabular}

Source: Own production, based on data from TradeMap (2020) and Market Access Database (2020) for data on extra-EU trade.

The following data enter the table: HS400122 (technically specified rubber, i.e., natural rubber), HS400211 + HS400219 (styrene butadine rubber, i.e., synthetic rubber), HS4011 (new tires made of rubber, including all kinds of tires, including cars, motorcycles, bicycles, aircrafts, buses, lorries, heavy machinery).

All numbers are for 2018 and indicate shares of export and import values, respectively. Table includes the four largest countries in each category. 


\section{Appendix D}

\section{Appendix of Chapter Six}

\section{D.1 Alternative transmission channels from crude oil to food markets}

Some authors argue that exchange rates are another transmission channel for oil market turmoils transmitted to food markets. For instance Abbott et al. (2011), Nazlioglu et al. (2013) and Wang et al. (2014), consider potential wealth effects to allow the oil price and oil shocks, respectively, to lead to currency appreciation or depreciation. Others consider exchange rates more as exogenous determinants of food markets rather than as part of possible transmission channels of oil shocks to food markets (e.g. Dillon and Barrett, 2015; Tyner, 2010; Wang and McPhail, 2014; Chakravorty et al., 2019; Zhang and Qu, 2015). Besides the theoretical exogeneity of exchange rates within the oil-food nexus, reasons for omission simply stem from empirical infeasibility. While it is rather straightforward to take exchange rate effects into account by including an appropriate indicator in respective multivariate time series models, in case of small sample sizes adding further dimensions to structural models might result in a lack of degrees of freedom, since the number of parameters increases quadratically with the number of dimensions. Additionally, increased trader activity on derivative markets could also constitute a pathway for oil price movements to transmit to food prices (Du et al., 2011; Wang et al., 2014). Nonetheless, this presumption still lacks sound theoretical foundations as well as empirical evidence. Therefore, we refrain from accounting for further dynamics in our analysis.

\section{D.2 Identification by means of independent components}

Matteson and Tsay (2017) suggest an approach based on the so-called distance covariance of Székely et al. (2007b) - denoted $\mathcal{U}_{T}$ - for the implementation of ICA. More specifically, for a $K$-dimensional vector of structural shocks $\varepsilon_{t}$ at time $t=1, \ldots, T$ the distance covariance $\mathcal{V}^{2}$ detects dependence between two subsets of the components. Between the $k$ th component $\varepsilon_{t, k}, k \in\{1, \ldots, K\}$ and all subsequent ones $\varepsilon_{t, k^{+}}$with $k^{+}=k+1, \ldots, K$, dependence is measured by $\mathcal{V}^{2}\left(\varepsilon_{t, k}, \varepsilon_{t, k^{+}}\right)$which is the distance between the characteristic 
functions $\varphi_{\varepsilon_{t, k}, \varepsilon_{t, k}}$ and $\varphi_{\varepsilon_{t, k}} \varphi_{\varepsilon_{t, k}+}$, the joint characteristic function and the one under independence, respectively. To measure mutual dependence - i.e. dependence of all possible combinations between the variables $\varepsilon_{t, 1}, \ldots, \varepsilon_{t, K}$ - the dependence criterion reads as

$$
\mathcal{U}_{T}\left(\varepsilon_{t, 1}, \ldots, \varepsilon_{t, K}\right)=T \cdot \sum_{k=1}^{K-1} \mathcal{V}^{2}\left(\varepsilon_{t, k}, \varepsilon_{t, k^{+}}\right)
$$

In the sense of Hodges-Lehman (HL) estimation, the distance covariance $\mathcal{U}_{T}\left(\hat{\varepsilon}_{t, 1}, \ldots, \hat{\varepsilon}_{t, K}\right)$ is then minimized to identify $\hat{\varepsilon}_{t}=\mathrm{B}^{-1} \hat{u}_{t}$ with least dependent components, which consequently determines the estimated matrix $\widehat{B}$. Conditional on a particular nuisance free test statistic, the HL estimator of a parameter of interest is the specific parameter value obtaining the largest $p$-value when subjected to testing. Principles of HL estimation motivate detecting least dependent structural shocks by minimizing non-parametric dependence criteria. 


\section{D.3 Further empirical results and data}

Table D.1 Test results on kurtosis and skewness of the estimated structural shocks. Values in parentheses denote $p$-values.

\begin{tabular}{|c|c|c|c|c|c|}
\hline & & $\hat{\varepsilon}_{1}$ & $\hat{\varepsilon}_{2}$ & $\hat{\varepsilon}_{3}$ & $\hat{\varepsilon}_{4}$ \\
\hline \multirow[t]{2}{*}{ Chad } & Kurtosis: & $\begin{array}{l}3.07 \\
(0.85)\end{array}$ & $\begin{array}{l}4.60 \\
(0.00)\end{array}$ & $\begin{array}{l}3.41 \\
(0.26)\end{array}$ & $\begin{array}{l}4.21 \\
(0.01)\end{array}$ \\
\hline & Skewness: & $\begin{array}{l}0.17 \\
(0.38)\end{array}$ & $\begin{array}{c}-0.50 \\
(0.01)\end{array}$ & $\begin{array}{c}-0.47 \\
(0.02)\end{array}$ & $\begin{array}{l}0.33 \\
(0.08)\end{array}$ \\
\hline \multirow[t]{2}{*}{ Ethiopia } & Kurtosis: & $\begin{array}{l}2.98 \\
(0.96)\end{array}$ & $\begin{array}{l}4.58 \\
(0.00)\end{array}$ & $\begin{array}{l}3.50 \\
(0.15)\end{array}$ & $\begin{array}{l}8.01 \\
(0.00)\end{array}$ \\
\hline & Skewness: & $\begin{array}{l}0.23 \\
(0.23)\end{array}$ & $\begin{array}{c}-0.40 \\
(0.04)\end{array}$ & $\begin{array}{c}-0.46 \\
(0.02)\end{array}$ & $\begin{array}{c}-0.72 \\
(0.00)\end{array}$ \\
\hline \multirow[t]{2}{*}{ Ghana } & Kurtosis: & $\begin{array}{l}2.60 \\
(0.26)\end{array}$ & $\begin{array}{l}3.68 \\
(0.05)\end{array}$ & $\begin{array}{l}3.89 \\
(0.02)\end{array}$ & $\begin{array}{l}5.23 \\
(0.00)\end{array}$ \\
\hline & Skewness: & $\begin{array}{l}0.27 \\
(0.16)\end{array}$ & $\begin{array}{c}-0.30 \\
(0.11)\end{array}$ & $\begin{array}{c}-0.45 \\
(0.02)\end{array}$ & $\begin{array}{c}-0.31 \\
(0.10)\end{array}$ \\
\hline \multirow[t]{2}{*}{ Kenya } & Kurtosis: & $\begin{array}{l}2.82 \\
(0.62)\end{array}$ & $\begin{array}{l}3.52 \\
(0.13)\end{array}$ & $\begin{array}{l}4.30 \\
(0.00)\end{array}$ & $\begin{array}{l}3.76 \\
(0.04)\end{array}$ \\
\hline & Skewness: & $\begin{array}{l}0.21 \\
(0.26)\end{array}$ & $\begin{array}{c}-0.13 \\
(0.49)\end{array}$ & $\begin{array}{c}-0.71 \\
(0.00)\end{array}$ & $\begin{array}{c}-0.09 \\
(0.62)\end{array}$ \\
\hline \multirow[t]{2}{*}{ Mozambique } & Kurtosis: & $\begin{array}{l}3.74 \\
(0.04)\end{array}$ & $\begin{array}{l}4.73 \\
(0.00)\end{array}$ & $\begin{array}{l}3.40 \\
(0.24)\end{array}$ & $\begin{array}{l}8.36 \\
(0.00)\end{array}$ \\
\hline & Skewness: & $\begin{array}{l}0.19 \\
(0.32)\end{array}$ & $\begin{array}{c}-0.66 \\
(0.00)\end{array}$ & $\begin{array}{c}-0.52 \\
(0.01)\end{array}$ & $\begin{array}{l}1.10 \\
(0.00)\end{array}$ \\
\hline \multirow[t]{2}{*}{ Nigeria } & Kurtosis: & $\begin{array}{l}2.98 \\
(0.96)\end{array}$ & $\begin{array}{l}4.52 \\
(0.00\end{array}$ & $\begin{array}{l}3.56 \\
(0.12)\end{array}$ & $\begin{array}{l}4.03 \\
(0.01)\end{array}$ \\
\hline & Skewness: & $\begin{array}{l}0.17 \\
(0.34)\end{array}$ & $\begin{array}{c}-0.40 \\
(0.04)\end{array}$ & $\begin{array}{c}-0.41 \\
(0.03)\end{array}$ & $\begin{array}{c}-0.17 \\
(0.38)\end{array}$ \\
\hline \multirow[t]{2}{*}{ Tanzania } & Kurtosis: & $\begin{array}{l}2.57 \\
(0.22)\end{array}$ & $\begin{array}{l}3.68 \\
(0.05)\end{array}$ & $\begin{array}{l}3.29 \\
(0.43)\end{array}$ & $\begin{array}{l}4.77 \\
(0.00)\end{array}$ \\
\hline & Skewness: & $\begin{array}{l}0.26 \\
(0.26)\end{array}$ & $\begin{array}{c}-0.14 \\
(0.45)\end{array}$ & $\begin{array}{c}-0.47 \\
(0.02)\end{array}$ & $\begin{array}{l}0.41 \\
(0.03)\end{array}$ \\
\hline \multirow[t]{2}{*}{ Zambia } & Kurtosis: & $\begin{array}{l}3.04 \\
(0.91)\end{array}$ & $\begin{array}{l}4.20 \\
(0.01)\end{array}$ & $\begin{array}{l}3.54 \\
(0.1)\end{array}$ & $\begin{array}{l}3.14 \\
(0.70)\end{array}$ \\
\hline & Skewness: & $\begin{array}{l}0.21 \\
(0.27)\end{array}$ & $\begin{array}{c}-0.48 \\
(0.01)\end{array}$ & $\begin{array}{c}-0.49 \\
(0.02)\end{array}$ & $\begin{array}{c}-0.48 \\
(0.01)\end{array}$ \\
\hline
\end{tabular}


Figure D.1 Real corn price series in domestic currency. World prices are given in US Dollars. 


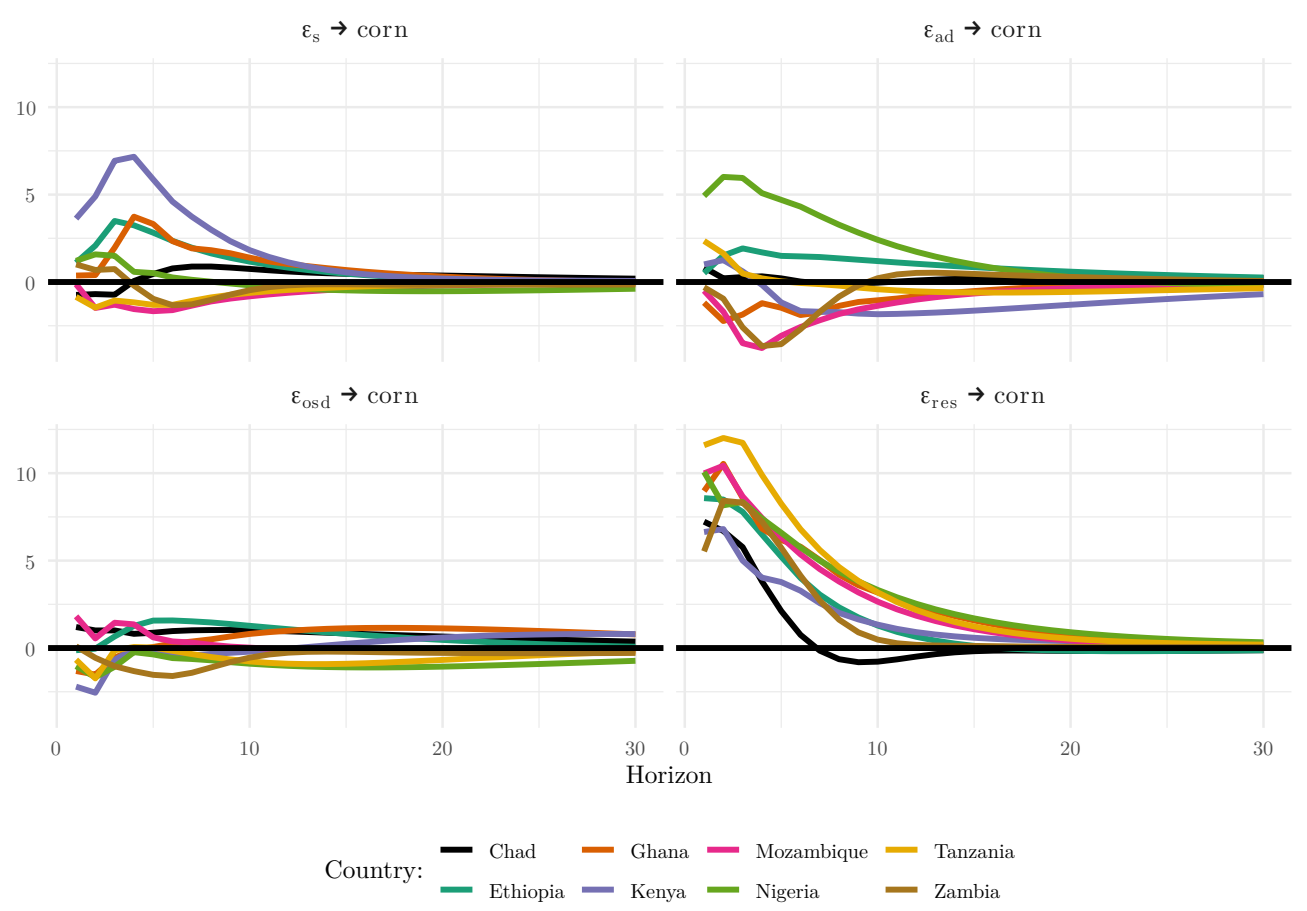

Figure D.2 Point estimates of corn price reactions in Africa to different types of oil shocks and a non-oil related shock to corn price.

\section{D.4 Country case: Chad}

Chad is the only country in our sample whose market is responsive to oil-specific demand shocks. Even though biofuel production capacities are also not available in Chad, its corn markets are surprisingly similar to global corn markets. One possible reason for this circumstance is compared with to all other countries in our sample, in Chad corn constitutes an unusually minor share of caloric intake in diets. Calorie supply per day and person stands at $130 \mathrm{kcal}$ in 2017 which is less than half of that in Nigeria, one-third of that in Ethiopia, and one sixth of that in Kenya for instance (FAOSTAT, 2020). With low consumption rates, much more abundantly available substitutes such as sorghum, millet and wheat can easily compensate the country-specific impacts of oil shocks such that (in the absence of impeding policies and trade barriers) local corn price dynamics in Chad reflect those of global prices. 


\section{Appendix E}

\section{Declarations}

1. I, hereby, declare that this Ph.D. dissertation has no not been presented to any other examining body either in its present or a similar form. Furthermore, I also affirm that I have not applied for a Ph.D. at any other higher school of education.

Göttingen, June 2, 2020,

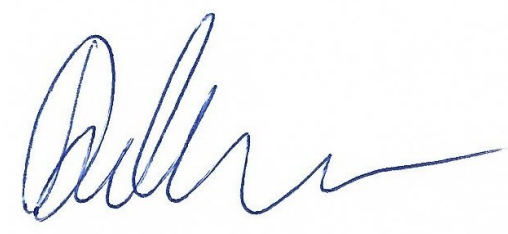

Bernhard Dalheimer

2. I, hereby, solemnly declare that this dissertation was undertaken independently and without any unauthorised aid.

Göttingen, June 2, 2020,

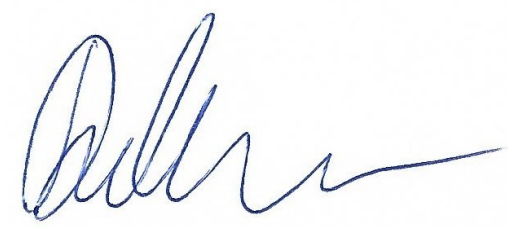

Bernhard Dalheimer 